Matthew Gardner und Hanna Walsdorf (Hg.)

$$
\text { Musik - Politik - Identität }
$$

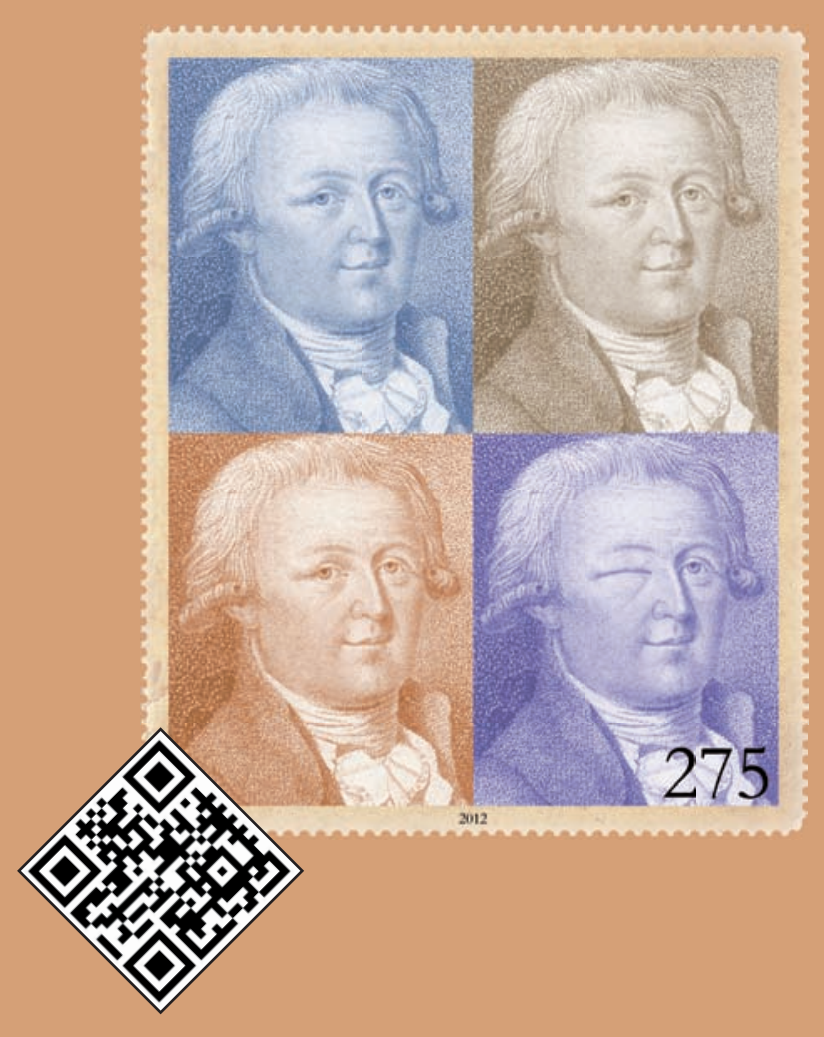

Universitätsverlag Göttingen 

Matthew Gardner und Hanna Walsdorf (Hg.) Musik - Politik - Identität

Dieses Werk ist lizenziert unter einer Creative Commons Namensnennung - Weitergabe unter gleichen Bedingungen 4.0 International Lizenz.

@() ( ๑) 
erschienen als Band 3 der Freien Referate

des 15. Internationalen Kongresses der Gesellschaft für Musikforschung im Universitätsverlag Göttingen 2016 
Matthew Gardner und

Hanna Walsdorf (Hg.)

Musik - Politik - Identität

15. Internationaler Kongress der Gesellschaft für Musikforschung Freie Referate

Band 3

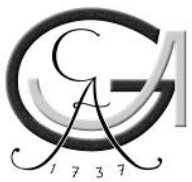

Universitätsverlag Göttingen 2016 


\section{Bibliographische Information der Deutschen Nationalbibliothek}

Die Deutsche Nationalbibliothek verzeichnet diese Publikation in der Deutschen Nationalbibliographie; detaillierte bibliographische Daten sind im Internet über $<$ http://dnb.dnb.de $>$ abrufbar.

Gemeinsames Bund-Länder-Programm für bessere Studienbedingungen und mehr Qualität in der Lehre.

Dieses Vorhaben wird aus Mitteln des Bundesministeriums für Bildung und Forschung unter dem Förderkennzeichen 01PL11061 gefördert. Die Verantwortung für den Inhalt dieser Veröffentlichung liegt bei den Autoren.

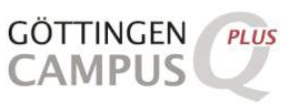

I. Niedersächsisches Ministerium für Wissenschaft und Kultur

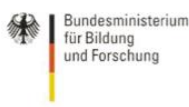

Dieses Buch ist auch als freie Onlineversion über die Homepage des Verlags sowie über den Göttinger Universitätskatalog (GUK) bei der Niedersächsischen Staats- und Universitätsbibliothek Göttingen (http://www.sub.uni-goettingen.de) erreichbar. Es gelten die Lizenzbestimmungen der Onlineversion.

Satz und Layout: Matthew Gardner, Andreas Waczkat und Hanna Walsdorf Umschlaggestaltung: Jutta Pabst

Titelabbildung: Gīsan Mári

C 2016 Universitätsverlag Göttingen

http://univerlag.uni-goettingen.de

ISBN: 978-3-86395-258-7 


\section{Inhalt}

Hanna Walsdorf und Matthew Gardner

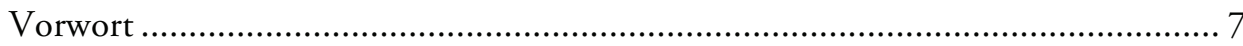

\section{Musikalische Identität und politische Realität}

Hanna Walsdorf

Deutsche Nationalmusik? Ein diskursgeschichtlicher Annäherungsversuch 11

Mauro Fosco Bertola

„Die Musik ist mediterran“: Orient, Latinität und Musikgeschichte, oder:

Wie Nietzsche 1937 Italiens koloniale Macht legitimieren sollte

Yvonne Wasserloos

„Nordische Musik“ als Faktor der Propaganda der Nordischen Gesellschaft und der DNSAP in Dänemark um 1940.

Simon Nußbruch

„Was ließen jene, die vor uns schon waren...?“

Musik in der Bündischen Jugend nach 1945 67

Gilbert Stöck

Methoden musikalischer Opposition in Portugal während der Salazar-Diktatur bei Jorge Peixinho und José Afonso 


\title{
Paul Christiansen
}

'The Stakes Are Too High For You to Stay Home': Divergent Uses of

Music in TV Political Ads in the 1964 U.S. Presidential Election

\section{II (Musikalische) Konstruktionen von eigener und fremder Identität}

\author{
Matthew Gardner \\ 'Das Land ohne Musik'? National Musical Identity \\ in Victorian and Edwardian England
}

\section{Rebekka Sandmeier}

Reflections of European Culture in the Grey Collection

(National Library of South Africa)

Mario Dunkel

Jazz and the Emergence of the African-Roots Theory

Dorothea Suh

Achim Freyers Mr. Rabbit and the Dragon King:

Eine Interpretation des koreanischen P'ansori Sugungga

Ludwig Pesch

Unity in Diversity, Antiquity in Contemporary Practice?

South Indian Music Reconsidered 


\section{Vorwort}

Musik ist (fast) immer politisch. Komponist*innen wie Musiker*innen verhalten sich mit ihrem schöpferischen und performativen Tun immer auf die eine oder andere Art zum politischen Rahmen, innerhalb dessen sie sich befinden. So ist die Musikpraxis einer Zeit immer auch Spiegel und Kristallisationspunkt gesellschaftlicher Paradigmen, lassen sich (nationale) Identitätsdiskurse auch im Sprechen und Schreiben über Musik ausmachen.

Der vorliegende Sammelband vereint Beiträge aus der Sektion „Freie Referate“ in deutscher und englischer Sprache, die beim Musikforschungskongress „Musik | Musiken. Strukturen und Prozesse" im September 2012 in Göttingen präsentiert wurden und sich - in der Gesamtschau - mit einer großen Bandbreite von historischen und gegenwärtigen Diskursen beschäftigen, die um das Verhältnis von Politik und musikalischem Schaffen kreisen. Die von den internationalen Autorinnen und Autoren betrachteten Dynamiken und Wirkungszusammenhänge von theoretischabstrakter und politisch-konkreter Identitätsbildung sind dabei in zwei thematische Bereiche aufgeteilt:

Im ersten Teil sind Beiträge zusammengefasst, die sich mit „Musikalischer Identität und politischer Realität" befassen und dabei ideologische Zuschreibungsprozesse im Musikdiskurs thematisieren: Ihrem jeweiligen Untersuchungsgegenstand gemäß chronologisch gereiht, werden hier Diskursgeschichten aus Deutschland (Hanna Walsdorf und Simon Nußbruch), Italien (Mauro Fosco Bertola) und Dänemark (Yvonne Wasserloos), aus Portugal (Gilbert Stöck) und den USA (Paul Christiansen) nachgezeichnet, die das Spannungsverhältnis zwischen Wunsch und Wirklichkeit verdeutlichen und kontextuell verorten. 
Der zweite Teil des Bandes umfasst Betrachtungen über „(Musikalische) Konstruktionen von eigener und fremder Identität" aus verschiedensten nationalen $\mathrm{Zu}$ sammenhängen, und auch hier ist die Anordnung der Beiträge inhaltlichchronologischen Gesichtspunkten geschuldet: Bei der Frage nach musikalischer Identität erweisen sich Staatsgrenzen und nationale Bezüge häufig als flexibel verhandelbar oder gar als gänzlich irrelevant, wie hier mit Blick auf England (Matthew Gardner), Südafrika (Rebekka Sandmeier) und Afro-Amerika (Mario Dunkel), auf Südkorea/Deutschland (Dorothea Suh) und Südindien (Ludwig Pesch) exemplarisch nachvollzogen ist.

Unser herzlichster Dank richtet sich an Dr. Christine Hoppe, Prof. Dr. Birgit Abels, Prof. Dr. Morag Josephine Grant und Prof. Dr. Andreas Waczkat vom Organisationsteam des Göttinger Kongresses für das uns entgegengebrachte Vertrauen bei der Redaktion dieses Teilbandes.

Hanna Walsdorf und Matthew Gardner Leipzig und Frankfurt/Main, im April 2015 
I Musikalische Identität und politische Realität 



\title{
Deutsche Nationalmusik? Ein diskursgeschichtlicher Annäherungsversuch
}

\author{
Hanna Walsdorf (Leipzig)
}

In der alten ${ }^{1}$ wie der neuen $\mathrm{MGG}^{2}$ folgt auf das Lemma „Nationalhymne“ direkt „Nationalsozialismus“. Ein Eintrag zu „Nationalmusik“ fehlt, obwohl sich zahlreiche Musikethnologen und -historiker zwischen etwa 1890 und 1960 auf die Suche nach nationalen Eigenheiten in der Musik gemacht und mit ihren einschlägigen Publikationen ein Diskursfeld von beträchtlichem Umfang hinterlassen haben, das von der späteren Musikwissenschaft zu Recht kritisch beäugt, historisch geordnet und revidiert wurde. Die Diskussion um Sein oder Nichtsein einer deutschen Nationalmusik, anfangs ernsthaftes Anliegen, nun eher ein Fall für diskursgeschichtliche Betrachtungen, lässt sich vielmehr jeweils unter D wie Deutschland nachschlagen. Es ist heute freilich ein anderes Deutschland als das imperiale von 1871, das totalitäre von 1933 oder das geteilte von 1949, in dem die Frage nach der deutschen Nation und ihrer Musik immer wieder aufgeworfen wurde und wird. Diese hat sich bereits seit etwa 1500 wiederholt - zuletzt seit 1990 - neu gestellt. ${ }^{3}$ Dementsprechend wan-

\footnotetext{
${ }^{1}$ Friedrich Blume (Hg.), Die Musik in Geschichte und Gegenwart. Allgemeine Enzyklopädie der Musik, 17 Bde. (München: Deutscher Taschenbuchverlag, 1989); hier: Bd. 9.

${ }^{2}$ Ludwig Finscher (Hg.), Die Musik in Geschichte und Gegenwart. Allgemeine Enzyklopädie der Musik, 26 Bde. (Kassel und Stuttgart: Bärenreiter, 1994-2008); hier: Sachteil, Bd. 7 (1997).

${ }^{3}$ Vgl. hierzu Wolfgang Hardtwig, „Vom Elitenbewußtsein zur Massenbewegung - Frühformen des Nationalismus in Deutschland 1500-1840“, in Nationalismus und Bürgerkultur in Deutschland 1500-
} 
delt(e) sich auch das Bedürfnis nach dem Auffinden einer deutschen Nationalmusik stetig. ${ }^{4}$ Was galt den Deutschen jeweils als identitätsstiftende nationale Musik? Womit füllen, wie begrenzen die Deutschen eigentlich den Terminus „Nationalmusik“ - und bei wem liegt die Entscheidungs- und Definitionsmacht darüber?

Die rückwirkende, häufig eng mit einer zweifelhaften Genie-Ästhetik verzahnte Erforschung des ,Deutschen' in der Musik hat es vielfach versäumt, neben den ,hochkulturellen' Musikerzeugnissen vergangener Jahrhunderte auch musikalische Äußerungen aus dem Volk zu berücksichtigen. Die für Prozesse der Gemeinschaftsbildung so wichtige Tanzmusik etwa spielte für die musikhistorische Forschung lange Zeit keine oder allenfalls eine stark untergeordnete Rolle, oder sie wurde gleich ganz in das Gebiet der musikalischen Volkskunde abgeschoben - mit der Konsequenz, dass zwei Musikwissenschaften zwei Musikgeschichten schrieben, die die musikalische Identität der Deutschen nach sehr unterschiedlichen Kriterien bemaßen und dingfest zu machen suchten. Der Begriff der Nationalmusik kam so zu stark kontrastierenden Definitionen seines Inhalts und Umfangs, wie im Folgenden aufgezeigt werden soll.

\section{Nationen und die Suche nach ihrer musikalischen Charakteristik vor 1800}

Der Begriff der Nation gehört unzweifelhaft zu den besonders elastischen Termini (nicht nur) der europäischen Kulturgeschichtsschreibung. So folgte das Verständnis davon, was eine Nation denn eigentlich sei, mitunter sehr unterschiedlichen Kriterien. ${ }^{5}$ Der Historiker Hagen Schulze etwa definiert ,Nationen' zunächst sehr allgemein - im Anschluss an den französischen Religionswissenschaftler Ernest Renan (1823-1892) und unübersehbar auch mit Benedict Andersons ${ }^{6}$ Konzept im Hinterkopf -als

1914, hg. von Wolfgang Hardtwig (Göttingen: 1994), 34-55. Siehe auch Wolfgang Bergem, Identitätsformationen in Deutschland. Forschung Politik (Wiesbaden: VS Verlag für Sozialwissenschaften, 2005).

${ }^{4}$ Das von der Politikwissenschaft ausgerufene postnationale Zeitalter hinterlässt auch in der Musikwissenschaft bereits Spuren, siehe etwa Ignacio Corona, Postnational Musical Identities: Cultural Production, Distribution, and Consumption in a Globalized Scenario (Lanham, MD [u.a.]: Lexington Books, 2007).

${ }^{5}$ Siehe hierzu exemplarisch Manfred Beller, Eingebildete Nationalcharaktere: Vorträge und Aufsätze zur literarischen Imagologie, hg. von Elena Agazzi (Göttingen: V\&R unipress, 2006).

${ }^{6}$ Benedict Anderson, Imagined Communities: Reflections on the Origin and Spread of Nationalism (London: Verso, 1983). 
geistige Wesen, Gemeinschaften, die existieren, solange sie in den Köpfen und Herzen der Menschen sind, und die erlöschen, wenn sie nicht mehr gedacht und gewollt werden; Nationen beruhen auf Nationalbewusstsein. Nationen erkennen sich in einer gemeinsamen Geschichte, in gemeinsamem Ruhm und gemeinsamen Opfern wieder - man muß hinzufügen, daß diese gemeinsame Geschichte in aller Regel von begrenzter Realität ist, in aller Regel mehr erträumt und konstruiert als wirklich.?

Was aber war dann eine Nation in jenen Zeiten, als das Wort natio gerade erst aus dem Lateinischen in die europäischen Volkssprachen übernommen worden war, als es noch lange keinen Nationalismus gab und schon gar keine Staaten im heutigen Sinne? Schulze stellt in seiner historischen Darstellung über Staat und Nation in der europäischen Geschichte ( $\left.{ }^{2} 1995\right)$ klar, dass die ,Nationen“ „vom Hohen Mittelalter bis gegen das Ende des 18. Jahrhunderts“ nicht von der "Gesamtheit des Volks“ gebildet wurden, sondern aus der „herrschenden, politisch repräsentierten Schicht; nicht mit ,Volksnationen' haben wir hier zu tun, sondern mit ,Adelsnationen ““8 - oder auch ,Universitätsnationen'? Die Grenzen dieser Nationen verlaufen freilich zu einem Gutteil anders als die heute vertrauten Staatsgrenzen - die Bestimmung von Nationen in der pränationalistischen Zeit war stark von regionalen Machtkonstellationen, Bräuchen und Dialektgrenzen abhängig. Mit der Beobachtung der eigenen und fremden, positiven und negativen Eigenschaften formten sich nationale Identitäten aus, die in unzähligen literarischen Charakterisierungen benannt und manifestiert wurden. Entgegen der heutigen Begriffsverwendung wurde mit dem Wort, Charakter ' bis ins 19. Jahrhundert hinein jedoch nicht etwa die „inneren Wesenszüge einer Person " bezeichnet, sondern äußere Merkmale und Zeichen. ${ }^{10}$

Die Herausbildung nationaler Besonderheiten und Unterscheidungsmerkmale wurde nicht zuletzt durch Kriege zwischen den Adelsnationen befördert, waren es doch „von Beginn an [...] die Abgrenzung gegen den Nachbarn, die Feindschaft und der Kampf, wodurch die europäischen Nationen zu sich selbst fanden“. Dies war allerdings ein sich über mehrere Jahrhunderte erstreckender Prozess, der

\footnotetext{
${ }^{7}$ Hagen Schulze, Staat und Nation in der europäischen Geschichte (2. Aufl., München: Beck, 1995), $110 f$.

${ }^{8}$ Ebd., $117 f$.

${ }^{9}$ Ebd., $118 f$.

${ }^{10} \mathrm{Vgl}$. Gerda Baumbach, Schauspieler. Historische Anthropologie des Akteurs. Bd. 1 (Leipzig: Leipziger Univ.-Verl., 2012), 194. Die Kenntnis der ursprünglichen Wortbedeutung wurde jedoch seit dem ausgehenden 17. Jahrhundert ,auf Stand und Rang einer Person (...) und in zunehmendem Maße seit der 1. Hälfte des 18. Jahrhunderts auf die Gesamtheit ihrer Wesenszüge, auf ihre Eigenart bezogen. Der Charakter ist also im wesentlichen das dem Menschen ,Eingeritzte, Eingeprägte’ an psychischen und geistigen Eigenarten." Siehe „Charakter“, in Etymologisches Wörterbuch des Deutschen, hg. von Wolfgang Pfeifer (München: Dt. Taschenbuch-Verl., 1995), 191.
} 
noch für lange Zeit Sache des Adels und weniger bürgerlicher Patrizier und Intellektueller war, der in Zeiten relativer politischer Ruhe stagnierte, um in unruhigen Perioden wieder aufzuleben, und der eigentlich erst um die Wende vom 18. zum 19. Jahrhundert begann, die Massen dauerhaft zu ergreifen und zur materiellen Gewalt zu werden. ${ }^{11}$

Dennoch lässt sich das Auf- und Erfinden von Nationalcharakteren noch deutlich weiter als in diese (letztgenannte) Zeit zurückverfolgen, waren doch die frühen europäischen Nationen Teil einer international vielschichtig vernetzten höfischen Kultur und als solche immer wieder Thema in deren politischen und theatralen, musikalischen und tänzerischen Repräsentationen:

The culture of the baroque court was shaped by the assumption that political power and social hierarchy could not be taken for granted but had to be expressed over and over again, with ceremonies and symbols, architectural monuments and festive display. Theatricality, therefore, was the essential characteristic of the courtier's world. [...] Life at court was filled with receptions and parades, banquets and balls, an endless variety of fêtes and galas that amused the courtly entourage and displayed the ruler's wealth and power. [...] / The theatre was [...] a specialized and intense expression of court life. Dramatic performances offered unlimited opportunities for the conspicuous assumption of the ruler's money and the direct exercise of his authority. ${ }^{12}$

Am Beispiel der Nationenballette, die vom Ende des 16. bis weit ins 18. Jahrhundert hinein bei Hofe getanzt wurden, lässt sich dies sehr gut nachvollziehen (Abb. 1): Hier hatten Nationen, Völker, Provinzen und Städte einen festen Platz im Rolleninventar und dienten einerseits der performativen Darstellung und Bestätigung von Identitätszuschreibungen, andererseits zur Vermittlung politischer Gegebenheiten, Ent-

\footnotetext{
${ }^{11}$ Vgl. Baumbach, Schauspieler. Historische Anthropologie des Akteurs, 126. Siehe auch James J. Sheehan, German History 1770-1866. 1989, Reprint. Oxford history of modern Europe (Oxford [u.a.]: Clarendon, 1991), 371: „Much of the confusion [in the scholarly literature on nationalism] arises from the pervasive belief that nations and nationalism are natural phenomena, the one based on objective realities, the other on people's growing awareness of these realities' existence and importance. That this belief has no historical basis should be particularly apparent in the German case, where geography, language, culture, and politics combine to confound attempts to find a natural, objectively defined nation. Nations are inventions, the products of particular historical circumstances and movements; they are not the causes and objects of national self-consciousness, but rather its products and projections. Typically, nations get defined in the course of social, cultural, or political struggles in which one side uses its identification with 'national values' or the ,national cause' as a weapon against its enemies at home and abroad."

${ }^{12}$ Sheehan, German History 1770-1866, 150.
} 
wicklungen und Absichten. ${ }^{13}$ Für das höfische Theater wurden die Nationen zunächst äußerlich durch die Kostümgestaltung stereotypisiert, um eine Wiedererkennbarkeit zu sichern: „Les diverses Nations ont leurs habits particuliers qui les distinguent ", ${ }^{14}$ schrieb der Jesuit Claude-François Ménestrier 1682 in seiner Abhandlung Des Ballets anciens et modernes, und er wusste hinzuzufügen, dass sie auch von ihrem musikalischen Charakter her zu unterscheiden seien:

Il y a des airs allemands, italiens, espagnols, français etc. Les Provinces mêmes ont la plupart des danses particulières. Ce n'est pas une des moindres beautés des ballets que cette diversité, quand on représente les peuples et les nations les plus barbares qui dansent à la manière de leur pays. ${ }^{15}$

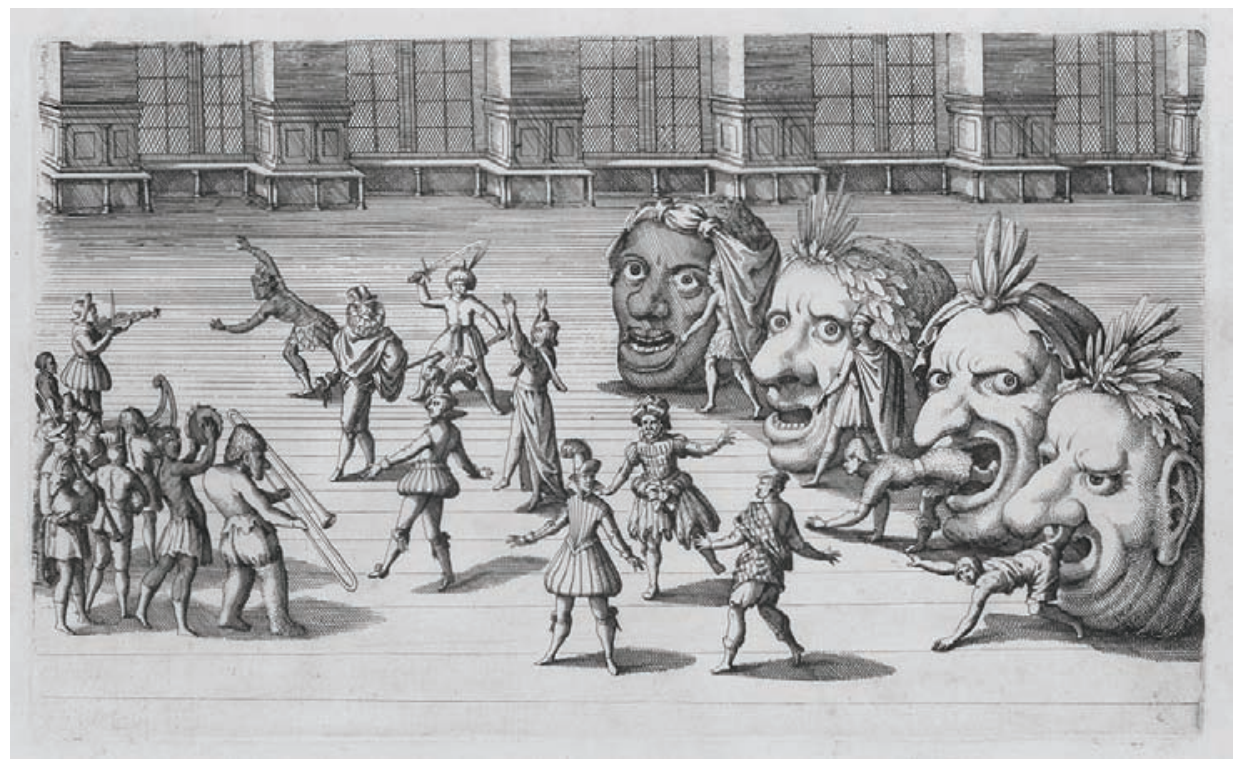

Abbildung 1: Vier übergrosse gebildete Menschenköpfe sog. „4 grosse Weltköpf“ die Nationen mit ihren Landtrachten und gebräuchlichen Spihlleuten hervorbringend [Kopf-Ballett], Stuttgart 1616. SLUB / Deutsche Fotothek, Inv.-Nr.: Hist.Suev. 44,2. Foto: Ramona Ahlers-Bergner

\footnotetext{
${ }^{13}$ Vgl. Gerrit Berenike Heiter, „Getanzte Vielfalt der Nationen: Ihre Darstellung und Funktion im französischen Hofballett (Ende 16. Jahrhundert bis Mitte 17. Jahrhundert)“, in „All'ungaresca - al español“: Die Vielfalt der europäischen Tanzkultur 1420-1820, hg. von Uwe W. Schlottermüller (Freiburg i.Br.: fa-gisis, 2012), 59-71.

${ }^{14}$ Claude-François Ménestrier, Des ballets anciens et modernes selon les règles du théâtre (Paris: Guignard, 1682), 143.

${ }^{15}$ Ebd., 205.
} 
Ménestriers Wissen um diese Dinge kam nicht von ungefähr, hatte er doch jahrzehntelange Erfahrung in der Organisation großer höfischer Festlichkeiten und epochale Traktate über Musik und Tanz verfasst. ${ }^{16}$ Sein Zeugnis von der musikalischen Präsenz verschiedener Nationen am französischen Hof verweist auf eine musikalischtänzerische Praxis, die schon seit dem 16. Jahrhundert Tanzsätze unterschiedlicher Herkunft zu Tanzfolgen verband. Die Entwicklung der Suite - zum Tanzen oder in der späteren Entwicklung als kaum mehr tanzbare Instrumentalmusik - ist in eben diesem Lichte zu sehen. Die im Nachhinein standardisierte Abfolge von ,deutscher (oder eher: alemannischer?) Allemande und französischer Courante, von (vermeintlich) spanischer Sarabande und englischer Gigue sind als (erweiterbares) Gerüst für eine Folge von Tänzen oder stilisierten Tanzsätzen, die die lange währende Tradition fortführt, auf einen langsamen und gravitätischen Vortanz einen schnelleren Nachoder Springtanz folgen zu lassen.

Es ist wohl kein Zufall, dass sich die Danse allemande mit ihrem prozessionalen Charakter als Eröffnungstanz auch in der französischen und englischen Suitentradition etablieren konnte - dies aber wohl weniger, weil sie „deutsch“ war, sondern eher aufgrund ihrer choreographischen Anlage. Die Tatsache, dass sie deutschen Ursprungs war, ist in zahlreichen Beschreibungen nicht-deutscher Autoren seit dem 16. Jahrhundert immer wieder hervorgehoben - und führte dazu, dass man seit Anfang des 17. Jahrhunderts auch in Deutschland von Allemande sprach, wo bisher von „deutschem Tantz" die Rede gewesen war. ${ }^{17}$ Von der Idee einer Nationalmusik aber war man im 17. Jahrhundert (und bis weit ins 18. hinein) noch weit entfernt - ohne Volksnation zwar Ballets des Nations, aber keine Nationalmusik?

\section{Nationalmusik als Musik des Volkes: Die Sicht der frühen Musikethnologie}

Nicht minder problematisch als der Begriff der Nation ist der der Nationalmusik, der anfänglich das bezeichnete, was heute gemeinhin als Volksmusik kategorisiert ist. Als beispielsweise der deutsche Musikwissenschaftler Carl Engel (1818-1882) im Jahr 1866 seine Introduction to the Study of National Music ${ }^{18}$ publizierte, zielte er da-

\footnotetext{
${ }^{16}$ Claude-François Ménestrier, Des Représentations en musique anciennes et modernes (Paris: René Guignard, 1681) sowie Ders., Des Ballets anciens et modernes selon les règles du théâtre, a.a.O.

${ }^{17}$ Vgl. Karl Heinz Taubert, Höfische Tänze. Ihre Geschichte und Choreographie (Mainz: Schott, 1968), 87-96; siehe auch Richard Hudson, The Allemande, the Balletto and the Tanz (Cambridge [u.a.]: Cambridge University Press, 1986); Ernst Mohr, Die Allemande: Eine Untersuchung ihrer Entwicklung von den Anfängen bis zu Bach und Händel. 2 Bde. (Zürich: Hug, 1932).

${ }^{18}$ Carl Engel, An Introduction to the Study of National Music: Combining Researches into Popular Songs, Traditions and Customs (London: Longmans, Green, Reader \& Dyer, 1866).
} 
mit keineswegs auf eine national eingegrenzte Betrachtung tonkünstlerischer Werke in Geschichte und Gegenwart, sondern wagte sich als einer der ersten auf das Gebiet der seriösen Volksmusikforschung vor. 1878/79 präsentierte er eine kommentierte Bibliographie der bis dato verfügbaren Literature of National Music, ${ }^{19}$ die - auf neun Ausgaben verteilt - in der Musical Times and Singing-Class Circular erschien. Im ersten Teil versuchte er zur Einführung und Legitimation seiner Literatursammlung eine Definition von ,Nationalmusik':

Still, whoever has obtained some insight into the rich treasures of popular songs and tunes, which have been hitherto but little explored, will probably be convinced that the study of National Music is sure to become gradually appreciated by the earnest promoters of the art. / As regards the term National Music, it must be remembered that, taken in its widest sense, it designates any music which, being composed in the peculiar taste of the nation to which it appertains, appeals more powerfully than other music to the feelings of that nation, and is consequently preeminently cultivated in a certain country. In this sense Haydn, Mozart, and Beethoven may be regarded as representatives of German National Music; Rossini, Bellini, and Donizetti of Italian National Music; Auber, Boieldieu, and Hérold of French National Music. However, distinguished composers have developed their style in great measure by studying the works of previous masters of different countries. The peculiar characteristics of the music of the nation are therefore more strongly exhibited in the popular songs and dance-tunes traditionally preserved by the country-people and the lower classes of society, which form the great majority of the nation. These musical conceptions, generally simple and unpretending in construction, often retain their popularity for a long period, since the views and sentiments of the uneducated or simple-minded man are less subjected to external influences than are those of the educated or ambitious man. Thus may perhaps be explained the fact that we find among the rural population in some countries tunes still sung which are known to be above a century old. True, they have been somewhat altered in the course of time. It is surprising that their alteration is not very great, considering that they have been preserved traditionally from mouth to mouth, at least only so by the country-people who own them. ${ }^{20}$

Das Verständnis von Nationalmusik, so wird mit diesem Zitat exemplarisch deutlich, war schon zu Engels Zeit in zwei Diskursstränge geteilt: Auf der einen Seite

\footnotetext{
${ }^{19}$ Carl Engel, „The Literature of National Music“, The Musical Times and Singing-Class Circular 19, Nr. 425 (1878), 374-77; Nr. 426 (1878), 432-35; Nr. 427 (1878), 484-87; Nr. 428 (1878), 53135; Nr. 429 (1878), 587-89; Nr. 430 (1878), 654-57; The Musical Times and Singing-Class Circular 20, Nr. 433 (1879), 133-36; Nr. 431 (1879), 11-14; Nr. 432 (1879), 69-72.

${ }^{20}$ Carl Engel, ,The Literature of National Music“, The Musical Times and Singing Class-Circular 19, Nr. 425 (1878), 374-77; 374.
} 
stand die Tendenz, nationale Musikgeschichte entlang besonders berühmter Komponisten von Kunstmusik zu erzählen; auf der anderen Seite wurde die Ansicht vertreten, dass es doch wesentlich plausibler sei, anstelle dieser wenigen herausragenden Individuen vielmehr das gemeine Volk als Trägerschicht einer über Jahrhunderte mündlich tradierten nationalen Kultur wahrzunehmen und zu würdigen. Beide Lager lieferten über Jahrzehnte rhetorisch engagierte Debattenbeiträge - und vor allem die volkskundlich fokussierenden unter ihnen wurden nicht müde, mit größtem Nachdruck immer wieder zu betonen, dass auch und gerade die Tanzmusik eines Volkes als dessen eigentliche, Nationalmusik' zu gelten habe, von der letztlich ja auch die Instrumentalgattungen der Kunstmusik abstammten:

\begin{abstract}
And yet it may be doubted if we owe more to the music of science than to the songs of the people. Rhythm is the very essence of the art, and it is to the folk-music that we are indebted for rhythm and all that results from it. Without this element we could never have arrived at our modern form so obviously founded on balance and proportion. Without it our scale system might never have been attained, for it is not difficult to see how the introduction of cadences must have influenced tonality. ${ }^{21}$
\end{abstract}

Nun sind die oben zitierten Behauptungen Trotters (1854-1934) sicherlich nicht in allen Einzelheiten wissenschaftlich haltbar. Bemerkenswert aber ist die Beobachtung, dass er seine Forschungen - wie auch viele weitere englischsprachige und/oder international wirkende Musikwissenschaftler seiner Zeit - ganz im Herder'schen Geist nicht auf eines, nämlich sein eigenes Herkunftsland ausrichtet, sondern stets um eine vergleichende Perspektive bemüht ist. Nationalmusik erforschen und beschreiben heißt hier nicht, sich auf einen nationalen Kontext festzulegen, um dessen herausragende Stellung gegenüber anderen zu beweisen. Nationalmusik zu untersuchen bedeutet hier schlicht und ergreifend, sich in Abgrenzung zu Kirchen- und Kunstmusik mit der Musik der Völker verschiedener Länder zu befassen, wurde doch in den Nationalmelodien die „Stimme der Menschheit“ vermutet, und das „durch alle Charakterunterschiede hindurch“. ${ }^{22}$ Der musikalische Charakter eines Volkes - sein Tem-

\footnotetext{
${ }^{21}$ Thomas Henry Yorke Trotter, „Rhythm in National Music“. Proceedings of the Musical Association 31st Sess. (1904/05), 17-41; 17. - Der Zusammenhang zwischen choreographischen Voraussetzungen und satztechnischen Konsequenzen in der Tanz- und auch Kunstmusik wird in der Tanzmusikforschung seit jeher ernst genommen, siehe etwa Otterbach, Friedemann, Die Geschichte der europäischen Tanzmusik: Einführung, 3. Aufl. Taschenbücher zur Musikwissenschaft (Wilhelmshaven: Noetzel, Heinrichshofen-Bücher, 1991); zuletzt Rentsch, Ivana, Die Höflichkeit musikalischer Form: Tänzerische und anthropologische Grundlagen der frühen Instrumentalmusik (Kassel: Bärenreiter, 2012).

${ }^{22}$ Vgl. Adolf Nowak, „Vom ,Trieb nach Vaterländischem': Die Idee des Nationalen in der Musikästhetik des 18. und 19. Jahrhunderts“, in Deutsche Meister - böse Geister? Nationale Selbstfindung in der
} 
perament - äußere sich dabei jedoch nicht in der schriftlichen Fixierung von mündlich überlieferten Melodien, sondern ausschließlich in der musikalischen Performanz, wie ganze 150 Jahre nach Herder der ungarische Komponist und Musikethnologe Béla Bartók in der Musical Times schrieb:

To get the right idea of national temperament we never looked for melodies written down or printed because, in general, we considered them to be dead material. To enter the true vibrating life of popular music by means of these tunes is an impossibility. Whosoever desires to enjoy the charms of genuine popular music must get into immediate contact with the peasants. And it is of equal importance to get acquainted with the surroundings from whence these tunes have sprung. It is necessary to see the peasant's mimicry, to be present at his dances, wedding festivities, Christmas celebrations, funeral ceremonies, because every occasion brings forth its special melodies which most advantageously reflect the national temperament. ${ }^{23}$

Das Temperament einer Nation sei einzig und allein der ländlichen Bevölkerung abzulauschen, finde sich folglich also nicht in der sogenannten Kunstmusik. Wenn diese in irgendeiner Form ,national' klingen solle, so die Implikation der Bartók'schen Aussage, müsse sie die Musik des Volkes, d.h. deren Rhythmen und Melodien integrieren. Dieses Prinzip ist freilich nicht nur für die ungarische Musik gültig, sondern lässt sich auf (fast) jeden nationalen Kontext im Europa (nicht nur) seiner Zeit übertragen - Allemande, Deutscher Tanz, Ländler und Walzer sind im Umfeld deutschen Musikschaffens hierfür das beste Beispiel.

\section{Nationalmusik als Musik für das Volk: Identitätskonstruktionen im Zeichen des Nationalismus}

Im ausgehenden 19. und beginnenden 20. Jahrhundert dagegen war die „Denkfigur des ,Deutschen“ in der Musik“24 bald weniger von Ideen der Völkerverständigung als von diskursiven Abgrenzungsstrategien getrieben, lagen die Interessenschwerpunkte bei der Betrachtung nationaler Besonderheiten in der Suche nach Substantiellem begründet - was freilich in eine Sackgasse führte. Probebohrungen in den riesigen Be-

\footnotetext{
Musik, hg. von Hermann Danuser und Herfried Münkler (Schliengen: Edition Argus, 2001), 151-65; $154 \mathrm{f}$.

${ }^{23}$ Béla Bartók, „The National Temperament in Music“, The Musical Times 69, Nr. 1030 (1928), 1079 .

${ }^{24}$ Bernd Sponheuer, „Über das ,Deutsche in der Musik: Versuch einer idealtypischen Rekonstruktion", in Deutsche Meister - böse Geister? Nationale Selbstfindung in der Musik, hg. von Hermann Danuser und Herfried Münkler, 123-50, 148.
} 
stand an einschlägiger Forschungs- und Populärliteratur führen recht schnell zu dem (erwartbaren) Befund, dass die Idee einer ,deutschen Musik' und deren Etikettierung als ,Nationalmusik' ein Konzept vor allem des 19. Jahrhunderts ist, das die politischen Realitäten und staatlichen Verfasstheiten vergangener Jahrhunderte großzügig zugunsten einer behaupteten, angeblich seit der Antike bestehenden Kulturnation einebnet. Den einsamen Gipfel dieser Geschichtskonstruktionen bildet unzweifelhaft der vielzitierte Ausspruch des für seinen Antisemitismus und Pangermanismus berüchtigten englischen Schriftstellers Houston Stewart Chamberlain, der in seinen Grundlagen des 19. Jahrhunderts (1899) allen Ernstes behauptete, die Musik sei von den Alten Griechen direkt an die Germanen weitergereicht worden. ${ }^{25}$

Exemplarisch für das national/istische Bewusstsein in der deutschen Musikforschung stehen große Editionsprojekte wie die Denkmäler Deutscher Tonkunst (65 Bände erschienen zwischen 1892 und 1931), Das Erbe deutscher Musik (seit 1935 erschienen über 120 Bände in der Hauptreihe, 16 in einer Sonderreihe sowie 16 Landschaftsdenkmale). Einschlägige Monographien zur "deutschen Musikgeschichte“ stammen beispielsweise von Hermann von der Pfordten ${ }^{26}$ und Arnold Schering (1917), ${ }^{27}$ Rudolf Malsch (1928), ${ }^{28}$ Ernst Bücken (1935), ${ }^{29}$ Joseph Müller-Blattau (1938), ${ }^{30}$ Otto Schumann ${ }^{31}$ und Adolf Seifert (1940), ${ }^{32}$ Ludwig Schiedermair $(1954)^{33}$ und Hans Mersmann (1958)..$^{34}$ Nicht nur Überlegenheitspostulate spielten hier eine Rolle, sondern auch die Selektion und Kanonisierung vor allem kunstmusi-

${ }^{25}$ „Der Germane - in allen Zweigen dieser [indoeuropäischen] Völkergruppe - ist der musikalischste Mensch auf Erden; Musik ist seine spezifisch eigene Kunst, diejenige, in welcher er unter allen Menschen der unvergleichliche Meister ist." Houston Stewart Chamberlain, Die Grundlagen des 19. Jahrhunderts (München ${ }^{22} 1937$ [OA 1899]), 1143f., zitiert nach Sponheuer, „Über das ,Deutsche' in der Musik“, 163.

${ }^{26}$ Hermann von der Pfordten, Deutsche Musik: auf geschichtlicher und nationaler Grundlage dargestellt (Leipzig: Quelle \& Meyer, 1917).

${ }^{27}$ Arnold Schering, Deutsche Musikgeschichte im Umriß (Leipzig: Siegel, 1917).

${ }^{28}$ Rudolf Malsch, Geschichte der deutschen Musik, ihrer Formen, ihres Stils und ihrer Stellung im deutschen Geistes- und Kulturleben (Berlin: Vieweg, 1926).

29 Ernst Bücken, Deutsche Musikkunde (Potsdam: Akademische Verlags-Gesellschaft Athenaion, 1935).

${ }^{30}$ Joseph Müller-Blattau, Geschichte der deutschen Musik (Berlin: Vieweg, 1938).

${ }^{31}$ Otto Schumann, Geschichte der deutschen Musik (Leipzig: Bibliographisches Institut, 1940).

${ }^{32}$ Adolf Seifert, Von Art und Wesen deutscher Musik. 2 Bde. (Reichenberg: Ullmann; Berlin: Vieweg, 1940).

${ }^{33}$ Ludwig Schiedermair, Deutsche Musik im europäischen Raum: Geschichtliche Grundlinien (Münster [u.a.]: Böhlau, 1954).

${ }^{34}$ Hans Mersmann, Deutsche Musik des XX. Jahrhunderts im Spiegel des Weltgeschehens. Kontrapunkte (Rodenkirchen/Rhein: Tonger, 1958). 
kalischer Hinterlassenschaften, die erstere schwarz auf weiß untermauen sollten. Der sich bis mindestens in die 1940er Jahre immer mehr zuspitzende Nationalismus im Musikdiskurs erdichtete und kolportierte diese historische Entwicklungslinie, die von der vorchristlichen, indogermanischen Antike über ein Mittelalter und eine Neuzeit mit vielen verschiedenen musikalischen Schauplätzen (und nicht minder divers gesetzten Epochengrenzen) bis in die Gegenwart der betreffenden Autoren reichte. Bei der Konstruktion dieses nationalistisch motivierten Geschichtsbildes wurde nach dem jeweiligen historischen Selbstverständnis freilich kaum gefragt. Musikkultur als Alltagskultur mit verschiedenen sozialen Orten zu betrachten, die immer auch Tanz inkludierte, lag weit außerhalb des Wahrnehmungsspektrums fast aller Autoren: ${ }^{35}$ Tanz oder Tanzmusik kommt in den allermeisten Kunstmusikgeschichten dieser Prägung nicht oder nur in Nebensätzen vor; allenfalls wird - ausgerechnet - dem Wiener Walzer ein eigenes kurzes Kapitel zugedacht.

Die zahlreichen Arbeiten von Hans Joachim Moser (1889-1967), der es als stramm nationalistisch denkender Musikhistoriker bis zum Leiter (1938-40) und Generalsekretär (1940-45) der Reichsstelle für Musikbearbeitungen im Reichsministerium für Volksaufklärung und Propaganda brachte, zeigen besonders eindrücklich, wie lange die unverhohlen nationalistische Musikgeschichtsschreibung salonfähig war. ${ }^{36}$ Der deutschen Nation als einer, die in ihren musikalischen oder , tonkünstlerischen' Erzeugnissen allen anderen überlegen sei, wurde bis mindestens in die 1950er Jahre hinein mit schäumendem Eifer gehuldigt. Walter Wiora sprach sogar in der (alten) MGG noch von „Grundschichten der deutschen Musik“, zu deren „Durchforschung [...] W. H. Riehl, R. v. Liliencron, H. J. Moser, J. Müller-Blattau u.a. beigetragen "hätten: ${ }^{37}$

Die deutsche Musik ist, wie alle Hochkultur, gesellschaftlich, seelisch und zeitlich geschichtet. Ihre „Grundschichten“ sind: a) im Aufbau der Gesellschaft die „Volksmusik“ als Eigengut breiter Volksmassen unter schmäleren Oberschichten der Tonkunst, Bildung, Macht und Kirche; b) im seelischen Aufbau auch der Oberschichten die allgemein menschliche und die heimatlich deutsche Substanz; c) in der geschichtlichen Dimension

\footnotetext{
${ }^{35}$ Diesen Diskursstrang überließ man der nicht minder nationalisierten Volkstanzforschung, die exakt die gleiche historische Entwicklungslinie zog und die zeitgenössische Volkstanzpraxis in direkter Nachkommenschaft germanischer Tanzformen sah.

${ }^{36}$ Hans Joachim Moser, Geschichte der deutschen Musik. 2 Bde. (Stuttgart [u.a.]: J. G. Cotta’sche Buchhandlung Nachfolger, 1920-1924); Kleine deutsche Musikgeschichte (Stuttgart: Cotta, 1949); Das musikalische Denkmälerwesen in Deutschland. Musikwissenschaftliche Arbeiten (Kassel [u.a.]: Bärenreiter, 1952); Die Musik der deutschen Stämme (Wien [u.a.], 1957).

${ }^{37}$ Vgl. Walter Wiora, Bruno Stäblein, Hans Albrecht, Friedrich Blume, Rudolf Gerber, Ernst Laaff und Georg Feder, „Deutschland“, in Die Musik in Geschichte und Gegenwart. Allgemeine Enzyklopädie der Musik, Bd. 3 (München: Dt. Taschenbuch-Verl., 1989 [OA 1954]), 261.
} 
die Musik der Frühzeit, deren „Archetypen“ in seelisch tiefer Musik der späteren Zeiten fortwirken, z.B. in der Zauberflöte oder bei Bruckner. ${ }^{38}$

Unübersehbar sind hier die besonders abstrusen, in der ersten Jahrhunderthälfte gereiften Ideen zur deutschen Musikgeschichte unüberprüft (weil nicht überprüfbar) und unreflektiert übernommen. Erst in der zweiten Jahrhunderthälfte sollte sich nach und nach ein kritischerer Umgang mit der deutschen Musikgeschichte und mit dem historischen musikwissenschaftlichen Diskurs über sie durchsetzen ${ }^{39}$ - für die Neue MGG ist der Eintrag „Deutschland“ von Rudolf Stephan, Ludwig Finscher, Andreas Jaschinski und Klaus Mehner neu verfasst und auf den neuesten Diskursstand (1995) gebracht. ${ }^{40}$ Die national(sozial)istischen Argumentationslinien, die noch den Vorgängerartikel durchzogen, sind hier einer recht ausgewogenen Geschichte der Musik in deutschen Landen gewichen.

\section{„Nationalmusik“ als Problem der Musikwissenschaft}

Obwohl sich die meisten Autoren zwischen 1890 und 1950 sicher zu sein scheinen, dass es eine ,deutsche Musik' gebe und dass diese von höherer Qualität sei als jede andere, ergab sich ein definitorisches Problem aus der argumentativ doch elementaren Frage, was denn ,deutsche Musik' eigentlich bedeute: dass sie in Deutschland (bzw. im deutschsprachigen Raum) entstanden ist, dass ihre Urheber Deutsche sein müssen, oder beides? Was, wenn eine als ursprünglich deutsch geltende Gattung, ein Stil oder eine Melodie von einem Komponisten anderer Nationalität verwendet und interpretiert wird - handelt es sich im Ergebnis auch dann noch um eine irgendwie deutsche Musik? Die diskursiven Unzulänglichkeiten bei der Frage, was das Deut-

\footnotetext{
${ }^{38}$ Wiora u.a., „Deutschland“.

${ }^{39}$ Vgl. etwa Celia Applegate, „What Is German Music? Reflections on the Role of Art in the Creation of the Nation“, German Studies Review 15 (1992): 21-32; Dies., „How German Is It? Nationalism and the Idea of Serious Music in the Early Nineteenth Century", 19th-Century Music 21, Nr. 3 (1998): 274-96; Hermann Danuser (Hg.), Deutsche Meister - böse Geister? Nationale Selbstfindung in der Musik (Schliengen: Edition Argus, 2001); Celia Applegate und Pamela Potter (Hg.), Music and German national identity (Chicago, Ill. [u.a.]: University of Chicago Press, 2002); Ute Lemm, „Musikwissenschaft in Westdeutschland nach 1945: Analysen und Interpretationen diskursiver Konstellationen." Diss., Universität Bonn, 2005. http://hss.ulb.uni-bonn.de/2005/0616/0616.htm. In zahlreichen, hier nicht aufgelisteten Publikationen wurde zudem die Rolle von Musikern und Musikwissenschaftlern im ,Dritten Reich' aufgearbeitet.

${ }^{40}$ Vgl. Ludwig Finscher, Andreas Jaschinski, Klaus Mehner und Rudolf Stephan, „Deutschland“, in Die Musik in Geschichte und Gegenwart. Allgemeine Enzyklopädie der Musik, 2., neu-bearbeitete Ausgabe, hg. von Ludwig Finscher, Sachteil, Bd. 2 (Kassel und Stuttgart: Bärenreiter, 1995), 1173-97.
} 
sche in der Musik sei und wer denn darüber zu entscheiden habe - die Komponisten selbst, das Publikum oder gar die Musikwissenschaft? - hat Celia Applegate 1998 wie folgt zusammengefasst:

[...] so what might be called the German problem, the problem of whether one can or indeed ought to place music by Germans in a national context, remains unresolved. I And perhaps this is how it should be. Perhaps the national problem in music is simply an artifact of the awkwardness of writing general surveys, a process that necessarily involves even the most circumspect author in unsustainable generalizations and inelegant aggregations. The bulk of musicological work can concentrate, after all, on individual composers, works, genres, and even eras, thus avoiding altogether a heretofore unproductive confrontation with the contingencies of place and nationality. Unfortunately, the national problem in music, particularly as it does or does not apply to German music, is like pulling a weed only to find that its roots are intertwined with everything you wish to keep in your garden. [...] And so from style, the features of which might be catalogued and compared, we move quickly to the far less manageable, in fact nearly openended, set of empirical data posed by musical contexts and musical valuations. And precisely at this point of opening out onto society, politics, and culture (in the wide and messy sense), musicology must confront the inadequacy of its own artificially limited definitions of the words nation and nationalism, definitions that have long shut out such complicated problems as what is the German nation and what has been the cultural force of German nationalism over the centuries. ${ }^{41}$

Kern des, deutschen Problems' im wissenschaftlichen Diskurs scheint es also zu sein, dass der Begriff der Nation, auf dessen Inhalt und Umfang man sich schon in der Politik- und Sozialwissenschaft ebenso wenig hat einigen können wie in Staatsphilosophie und Völkerrecht, ${ }^{42}$ in der Musikwissenschaft erst recht zu einem metaphorischen, beliebig verwendbaren Terminus geworden ist. Im Anschluss an Carl Dahlhaus versteht Bernd Sponheuer das ,Deutsche' in der Musik folgerichtig nicht als Substanz-, sondern als Funktionsbegriff, wonach das ,Deutsche“ „keine empirisch nachweisbare Eigenschaft tatsächlicher Art" ist, die sich ,etwa durch stilkritische Beschreibung induktiv eruieren ließe“. Schließlich seien ,alle Versuche in dieser Richtung, etwa melodisch-rhythmische Phänomene als ,deutsch` zu reklamieren“, gescheitert (und das nicht nur in der Diskussion um die Kunstmusik, sondern auch im volkskundlich orientierten Diskursstrang). Der Begriff des, Deutschen' in der Musik müsse vielmehr in seiner historischen Funktionalität und Bedingtheit gesehen wer-

\footnotetext{
${ }^{41}$ Applegate, „How German Is It?“, 276.

${ }^{42}$ Siehe hierzu Christian Bala, „Nation“, in: Handwörterbuch des politischen Systems der Bundesrepublik Deutschland, hg. von Uwe Andersen und Wichard Woyke. 6. Aufl., 448-54 (Opladen: Leske+Budrich, 2009).
} 
den, denn letztlich sei er ebenso wie der Begriff der Nation ein Wertbegriff im Weber'schen Sinne, d.h. „eine idealisierte Form der Selbstbeschreibung, die von den gesellschaftlich führenden Schichten anerkannt und durch Bildungsprozesse vermittelt" werde. ${ }^{43}$ "Selbst Produkt einer historischen Entwicklung", stellt Sponheuer fest, „hat er durch die Produktion von identitätsverheißenden Wunschbildern des Vergangenen und des Zukünftigen maßgeblich auf den Gang der deutschen Musikgeschichte eingewirkt. “44 Aus ähnlichen Überlegungen heraus hatte Celia Applegate daher bereits 1992 für eine Absage an den Nationalbegriff zugunsten desjenigen der Identität plädiert:

There are a number of reasons, conceptual and methodological, for the comparative neglect of the national context of music. First is the problem of national character itself. 'Histories' of national character, musical or otherwise, would appear to be undertakings of doubtful empirical value. To assert the existence - and influence - of a national character is to avoid the harder work of explaining certain behaviors and outcomes in terms of complex historical circumstances or, to put it more bluntly, of doing actual historical research. The pursuit of a national character is in any case out of fashion. National character implies an objective reality in which few historians of the nation any longer believe. We are much more comfortable with the notion of identity, with its implications of a felt reality and a collectively constructed subjectivity. To concede the existence of a national character is uncritically to take on the perspective of our historical subjects, the nationalists themselves. / But being unable to invoke the influence of a German 'national character' leaves a large gap in the study of music. ${ }^{45}$

Applegate bemerkt zu Recht, dass die Suche nach einem Nationalcharakter in der deutschen Musik aus Mangel an Beweisen eingestellt wurde. Es ist jedoch mehr als fraglich, ob die mangelnde Substantialität eines deutschen Nationalcharakters in der Kunstmusik tatsächlich ein Hindernis für die Studierbarkeit der Musikgeschichte darstellt. Die Geschichte welcher bzw. wessen Musik hier gemeint ist, lässt sich nur mutmaßen. Sicherlich ist angesichts der ideologischen Vorbelastung des Nationaldiskurses ein Ausweichen auf den Begriff der Identität verlockend. Einfacher wird es damit aber wohl nicht, sind Identitäten doch bekanntlich einer mindestens ebenso dynamischen Entwicklung unterworfen wie Nationen es sind - ein abstraktes Konzept mit einem anderen abstrakten Konzept zu ersetzen, wenn man doch eigentlich nach Konkretem sucht, scheint hier wenig gewinnbringend.

\footnotetext{
${ }^{43}$ Sponheuer, „Über das ,Deutsche‘ in der Musik“, 127.

${ }^{44}$ Ebd., $127 f$.

${ }^{45}$ Applegate, „What Is German Music?“, 24.
} 


\section{Fazit}

Eine deutsche Nationalmusik ist nicht zu fassen. Als die Rede von „national mu-

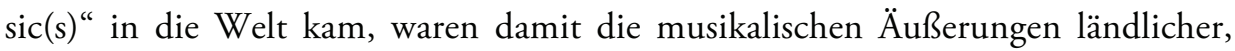
nicht privilegierter Bevölkerungsschichten bezeichnet - später abgelöst durch den Terminus Volksmusik. Die Bedeutung von „Nationalmusik“ verschob sich im Verbund mit einem rassistisch aufgeladenen Nationalismus hin zu einer Bestimmung des Deutschen (vorwiegend) in der Kunstmusik. Die Abgrenzung und Abwertung von anderen Nationen stand hier klar im Vordergrund, doch waren die einschlägigen Theorien, die eine quasi naturgegebene und historisch bis in die griechische Antike zurückreichende Überlegenheit deutscher Musikkultur belegen sollten, notwendigerweise haltlos und hanebüchen. Die Musikwissenschaft hat erst im letzten Drittel des 20. Jahrhunderts mit einer kritischen Durchsicht und Revision ideologisch verirrter Positionen begonnen.

Unbestreitbar ist der Begriff der Nation durch den Nationalismus in seinen historischen Extremen nachhaltig belastet; dennoch greift eine Forderung wie die Celia Applegates, deshalb die Idee eines 'nationalen Charakters' als Forschungsansatz abzulehnen, wiederum historisch zu kurz. Denn erstens ist dieses Konzept ja bekanntlich wesentlich älter als der geschmähte Nationalismus, der - so das berühmte Diktum Benedict Andersons - die Nationen erst hervorgebracht habe. Diese Sichtweise wird der historischen Entwicklung der europäischen Nationen in ihrer vornationalistischen Gestalt und Bedeutung für die Musik- und Tanzgeschichte nicht gerecht (und wäre nicht einmal dann tragfähig, wenn die deutsche Musikgeschichte tatsächlich mit Bach angefangen hätte). Zweitens ist das Hineindenken in das Selbstverständnis derer, die die Musikhistoriographie aus immer neuen Perspektiven beleuchtet haben, für unser heutiges (Fremd-)Verständnis vergangener wie gegenwärtiger Musikauffassungen unabdingbar. Abstrakte Begriffe, wie „Nationalmusik“ einer ist, lassen sich eben nicht fassen - weder im schriftlich noch im klanglich Konkreten.

\section{Literatur}

Anderson, Benedict. Imagined Communities: Reflections on the Origin and Spread of Nationalism. London: Verso, 1983.

Applegate, Celia. „What Is German Music? Reflections on the Role of Art in the Creation of the Nation". German Studies Review 15 (1992): 21-32.

— „How German Is It? Nationalism and the Idea of Serious Music in the Early Nineteenth Century“. 19th-Century Music 21, Nr. 3 (1998): 274-96.

Applegate, Celia und Pamela Potter (Hg.). Music and German national identity. Chicago, Ill. [u.a.]: University of Chicago Press, 2002. 
Bala, Christian. „Nation“, in Handwörterbuch des politischen Systems der Bundesrepublik Deutschland, hg. von Uwe Andersen und Wichard Woyke. 6. Aufl. Opladen: Leske+Budrich, 2009, 448-54.

Bartók, Béla. „The National Temperament in Music“. The Musical Times 69, Nr. 1030 (1928): 1079.

Baumbach, Gerda. Schauspieler. Historische Anthropologie des Akteurs. Bd. 1, Leipzig: Leipziger Univ.-Verl., 2012.

Beller, Manfred. Eingebildete Nationalcharaktere: Vorträge und Aufsätze zur literarischen Imagologie, hg. von Elena Agazzi. V\&R unipress, 2006.

Bergem, Wolfgang. Identitätsformationen in Deutschland. Forschung Politik. Wiesbaden: VS Verlag für Sozialwissenschaften, 2005.

Bücken, Ernst. Deutsche Musikkunde. Potsdam: Akademische Verlags-Gesellschaft Athenaion, 1935.

Chamberlain, Houston Stewart. Die Grundlagen des 19. Jahrhunderts. München ${ }^{22} 1937$ (OA 1899).

Corona, Ignacio. Postnational Musical Identities: Cultural Production, Distribution, and Consumption in a Globalized Scenario, Lanham, MD [u.a.]: Lexington Books, 2007.

Danuser, Hermann (Hg.). Deutsche Meister - böse Geister? Nationale Selbstfindung in der Musik. Schliengen: Edition Argus, 2001.

Engel, Carl. An Introduction to the Study of National Music: Combining Researches into Popular Songs, Traditions and Customs. London: Longmans, Green, Reader \& Dyer, 1866.

Engel, Carl. „The Literature of National Music“. The Musical Times and Singing Class Circular 19, Nr. 425 (1878): 374-77; Nr. 426 (1878): 432-35; Nr. 427 (1878): 484-87; Nr. 428 (1878),: 531-35; Nr. 429 (1878): 587-89; Nr. 430 (1878): 654-57; The Musical Times and Singing Class Circular 20, Nr. 433 (1879): 133-36; Nr. 431 (1879): 11-4; Nr. 432 (1879): 69-72.

Finscher, Ludwig, Andreas Jaschinski, Klaus Mehner und Rudolf Stephan. „Deutschland“. In Die Musik in Geschichte und Gegenwart. Allgemeine Enzyklopädie der Musik, 2., neu-bearbeitete Ausgabe, hg. von Ludwig Finscher, Sachteil, Bd. 2, 1173-97. Kassel und Stuttgart: Bärenreiter, 1995.

Hardtwig, Wolfgang. Nationalismus und Bürgerkultur in Deutschland 1500-1914, Göttingen 1994. 
Heiter, Gerrit Berenike. „Getanzte Vielfalt der Nationen: Ihre Darstellung und Funktion im französischen Hofballett (Ende 16. Jahrhundert bis Mitte 17. Jahrhundert)“. In „All'ungaresca - al español“: Die Vielfalt der europäischen Tanzkultur 1420-1820, hg. von Uwe W. Schlottermüller, 59-71. Freiburg i.Br.: fa-gisis, 2012.

Hudson, Richard. The Allemande, the Balletto and the Tanz. Cambridge [u.a.]: Cambridge University Press, 1986.

Lemm, Ute. „Musikwissenschaft in Westdeutschland nach 1945: Analysen und Interpretationen diskursiver Konstellationen“. Diss., Universität Bonn, 2005.

Malsch, Rudolf. Geschichte der deutschen Musik, ihrer Formen, ihres Stils und ihrer Stellung im deutschen Geistes- und Kulturleben. Berlin: Vieweg, 1926.

Ménestrier, Claude-François. Des ballets anciens et modernes selon les règles du théâtre. Paris: Guignard, 1682.

- Des Représentations en musique anciennes et modernes, Paris: René Guignard, 1681.

Mersmann, Hans. Deutsche Musik des XX. Jahrbunderts im Spiegel des Weltgeschehens. Kontrapunkte. Rodenkirchen/Rhein: Tonger, 1958.

Mohr, Ernst. Die Allemande: Eine Untersuchung ihrer Entwicklung von den Anfängen bis zu Bach und Händel. 2 Bde. Zürich: Hug, 1932.

Moser, Hans Joachim. Geschichte der deutschen Musik. 2 Bde. Stuttgart [u.a.]: J. G. Cotta'sche Buchhandlung Nachfolger, 1920-4.

— Kleine deutsche Musikgeschichte. Stuttgart: Cotta, 1949.

— Das musikalische Denkmälerwesen in Deutschland. Musikwissenschaftliche Arbeiten. Kassel [u.a.]: Bärenreiter, 1952.

—Die Musik der deutschen Stämme. Wien [u.a.], 1957.

Müller-Blattau, Joseph. Geschichte der deutschen Musik. Berlin: Vieweg, 1938.

Nowak, Adolf. „Vom ,Trieb nach Vaterländischem': Die Idee des Nationalen in der Musikästhetik des 18. und 19. Jahrhunderts". In Deutsche Meister - böse Geister? Nationale Selbstfindung in der Musik, hg. von Hermann Danuser und Herfried Münkler, 151-65. Schliengen: Edition Argus, 2001.

Otterbach, Friedemann. Die Geschichte der europäischen Tanzmusik: Einführung, 3. Aufl. Taschenbücher zur Musikwissenschaft. Wilhelmshaven: Noetzel, Heinrichshofen-Bücher, 1991. 
Pfeifer, Wolfgang (Hg.). Etymologisches Wörterbuch des Deutschen, München: Dt. Taschenbuch-Verl., 1995.

Pfordten, Hermann von der. Deutsche Musik: auf geschichtlicher und nationaler Grundlage dargestellt. Leipzig: Quelle \& Meyer, 1917.

Rentsch, Ivana. Die Höflichkeit musikalischer Form: Tänzerische und anthropologische Grundlagen der frühen Instrumentalmusik. Kassel: Bärenreiter, 2012.

Schering, Arnold. Deutsche Musikgeschichte im Umriß. Leipzig: Siegel, 1917.

Schiedermair, Ludwig. Deutsche Musik im europäischen Raum: Geschichtliche Grundlinien. Münster [u.a.]: Böhlau, 1954.

Schulze, Hagen. Staat und Nation in der europäischen Geschichte, 2. Aufl., München: Beck, 1995.

Schumann, Otto. Geschichte der deutschen Musik. Leipzig: Bibliographisches Institut, 1940.

Seifert, Adolf. Von Art und Wesen deutscher Musik. 2 Bde. Reichenberg: Ullmann; Berlin: Vieweg, 1940.

Sheehan, James J. German History 1770-1866. 1989, Reprint. Oxford History of Modern Europe. Oxford [u.a.]: Clarendon, 1991.

Sponheuer, Bernd. „Über das „Deutsche' in der Musik: Versuch einer idealtypischen Rekonstruktion“. In Deutsche Meister - böse Geister? Nationale Selbstfindung in der Musik, hg. von Hermann Danuser und Herfried Münkler, 12350. Schliengen: Edition Argus, 2001.

Taubert, Karl Heinz. Höfische Tänze. Ihre Geschichte und Choreographie, Mainz: Schott, 1968.

Trotter, Thomas Henry Yorke. „Rhythm in National Music“. Proceedings of the Musical Association 31st Sess. (1904/ 05): 17-41.

Wiora, Walter, Bruno Stäblein, Hans Albrecht, Friedrich Blume, Rudolf Gerber, Ernst Laaff, Georg Feder. „Deutschland“. In Die Musik in Geschichte und Gegenwart. Allgemeine Enzyklopädie der Musik, Bd. 3, 261-373. München: Dt. Taschenbuch-Verl., 1989 (OA 1954). 


\title{
„Die Musik ist mediterran“: Orient, Latinität und Musikgeschichte, oder: Wie Nietzsche 1937 Italiens koloniale Macht legitimieren sollte
}

\author{
Mauro Fosco Bertola (Heidelberg)
}

„Vergiss Dein Griechenland, es ist gewesen.

Das Alte schwand, das Neue begann."

August von Kotzebue, Die Ruinen von Athen

\section{„Und es gibt nichts Neues unter der Sonne“: Was einen gewissen Gustavo Pesenti mit Beethoven nicht verbindet}

Am 9. Februar 1812 wurde das neue Theater der ungarischen Donaustadt Pest mit dem Festspiel Die Ruinen von Athen feierlich eingeweiht. Den Text hatte August von Kotzebue (1761-1819) verfasst, die Musik stammte aus der Feder von Ludwig van Beethoven, und der Theaterbau war vom Kaiser von Österreich, Franz Joseph Karl (1768-1835), finanziert worden. In einer politisch bewegten Zeit, die unter dem Zeichen napoleonischer Bündnispolitik und der Auflösung des Heiligen Römischen Reiches Deutscher Nation stand, feierte sich die k.u.k.-Monarchie mit Die Ruinen von Athen selbst, um sich ihrer selbst und ihrer Bedeutung in der Welt zu vergewissern. Mit der Wahl des Aufführungsortes brachte sie zugleich ihr Bestreben zum 
Ausdruck, sich die Treue Ungarns zu sichern, dessen Bevölkerung der Herrschaft des Wiener Hofes nicht immer unkritisch gegenüberstand. Dafür brachte das Festspiel ein Narrativ auf die Bühne, das eine historische Linearität suggerierte: Nach jahrhundertelangem Schlaf erwacht die Göttin Athena 1812 wieder zum Leben. Erschrocken über die Ruinen, zu denen ihre Stadt unter der türkischen Herrschaft verkommen ist, entscheidet sich die Göttin, Griechenland zu verlassen und sich nach Pest zur Einweihung des neuen Theaters zu begeben.

Die Botschaft des Stückes war für die Zuschauer wohl unverkennbar: Die altgriechische Kultur blühe unter dem politischen Gebilde des österreichischen Kaisertums wieder auf, das sich dadurch als legitimer (Allein-)Vertreter der gesamten westlichen Kultur ausgab. Rein politisch betrachtet, stellte die k.u.k.-Monarchie mit Die Ruinen von Athen das Königtum Ungarn vor eine forced choice zwischen Ein- und Ausschließung in den bzw. aus dem Westen, zwischen Zivilisation und Barbarei.

Ein Jahr nach Mussolinis Gründung des Impero veröffentlichte der italienische Ethnomusikologe und Armeegeneral Gustavo Pesenti (1878-1960) im Jahre 1937 ein Buch, das den programmatischen Titel Die Musik ist mediterran trug. ${ }^{1}$ Mit dem Instrumentarium seiner Disziplin zeichnete Pesenti darin eine musikhistorische Entwicklungslinie, die von den alten Gesängen des Nahen Ostens und Nordafrikas bis zu der sogenannten Generazione dell'80 führte: Die Musik, die in der Antike in den ehemaligen kaiserlich-römischen Provinzen rund um das Mittelmeer entstanden sei, habe nun nach tausendjähriger Entwicklung in der Musikproduktion des neuen faschistischen Roms ihre Vervollkommnung erfahren.

\footnotetext{
${ }^{1}$ Gustavo Pesenti, La musica è mediterranea (Milano: L'Eroica, 1937). Über die durchaus kuriose Figur von Gustavo Pesenti, Militär, Gouverneur der italienischen Kolonie in Somalia, Ethnomusikologe, Komponist (1915 erschienen beim Genuesischen Verleger Fratelli Serra beispielsweise seine Dieci Canti für Singstimme und Klavier auf Texte von Heinrich Heine, Sándor Petőfi u.a.), Musikkritiker und Verfasser zahlreicher geopolitischer und musikhistorischer Veröffentlichungen, gibt es kaum Sekundärliteratur. Über seine vor allem in den 1910er bis 30er Jahren rege Tätigkeit als Ethnomusikologe siehe Francesco Giannattasio: „Parole (...nostre) e musica (...degli altri): i canti sacri e profani dei ,Somàli“ secondo Gustavo Pesenti (1929)“, in Pensieri per un maestro. Studi in onore di Pierluigi Petrobelli, hg. von Stefano La Via und Roger Parker (Torino: EDT, 2002), 387-405. Nach dem Zweiten Weltkrieg gab Pesenti beim Verleger Bertello in Borgo S. Dalmazzo eine Reihe von Monografien heraus, in denen er seine kolonialen und rechtsradikalen geopolitischen Ansichten, wenn auch mit verändertem Vokabular, weiterhin vertrat (z.B. La svastica infranta. Note e considerazioni sul defunto 3. Reich, 1945 und Euraffrica, 1953). Ebenfalls in jenen Jahren und beim selben Verleger veröffentlichte Pesenti auch einige musikhistorische Studien, u.a. über Chopin (Federico Chopin nel centenario della morte, 1949), Schumann (Amore e follia nell'arte di Roberto Schumann, 1950), Debussy (Debussy musicista aristocratico, 1950) und die italienische Musik zwischen dem 16. und 18. Jahrhundert (Tre secoli d'oro della musica italiana : il '500, il '600, il '700, 1951).
} 
Diese beiden Beispiele scheinen die biblische Weisheit „nichts Neues unter der Sonne " zum wiederholten Male zu bestätigen. ${ }^{2}$ Obwohl sich beide historischen Narrative in ihrer genuin politischen Funktion mutatis mutandis auf frappierende Weise ähneln und in einer Reihe von ähnlichen Fällen stehen, die von Herodots Ägypten bis zum berüchtigten Athen Heideggers reicht, soll das Augenmerk hier nun aber nicht etwa auf die Gemeinsamkeiten gerichtet werden, sondern es soll das hermeneutische Spiel der feinen Unterschiede betrieben werden, wenn auch nicht im Sinne Bourdieus. ${ }^{3}$ Die Unterschiede, die erkannt und gedeutet werden sollen, spielen sich hier nicht in der Synchronie eines sozialen Raumes, sondern in der Diachronie eines historischen Geschehens ab. Im Folgenden soll damit versucht werden, Pesentis Verwendung des alten Narrativs vom Ursprung der westlichen Zivilisation in einem geografischen und kulturellen Anderen in der Spezifität seines eigenen, damaligen Kontexts zu lesen. Oder, anders gesagt, Pesentis Gebrauch dieses historiographischen Konstrukts soll in den Kontext einer Zäsur im westlichen Denken gestellt werden, die sich im Übergang vom 19. zum 20. Jahrhundert vollzog und welche nicht so sehr das Narrativ an sich, sondern vor allem seinen realpolitischen Nutzwert als Mittel für die Legitimation einer Überlegenheit des Eigenen gegenüber dem Fremden radikal in Frage stellte. Diese Zäsur hing eng mit dem Namen Friedrich Nietzsche (18441900) zusammen, auf dessen anthropologische und kulturgeschichtliche Thesen Pesenti seine gesamte Argumentation explizit gründete, deren herrschaftskritisches Potential er jedoch unterminierte.

Mit der Betrachtung des ideen- und motivgeschichtlichen Hintergrundes von Pesentis Buch wird also ein Moment der italienischen Nietzsche-Rezeption beleuchtet, die - genau wie zu jener Zeit in Deutschland, wenn auch mit anderen Schwerpunkten - Nietzsche zwar als den Denker anerkannte, der die intellektuellen Koordinaten für das neue Jahrhundert entworfen hatte, dessen Thesen jedoch in ihr Gegenteil verkehrte. Damit soll ein Teilaspekt jenes verwickelten, aber durchaus engen Verhältnisses erhellt werden, das den italienischen Musikdiskurs mit der deutschen Kultur - vom Ende des 19. Jahrhunderts bis zu den Darmstädter Ferienkursen der 1950er und 60er Jahre - verband. Und dafür, sollen wir zuerst mit Hegel (17701831) anfangen.

\footnotetext{
${ }^{2}$ Prediger 1,9 .

${ }^{3}$ Pierre Bourdieu, Die feinen Unterschiede. Kritik der gesellschaftlichen Urteilskraft (Frankfurt am Main: Suhrkamp, 1982). Der französische Originaltitel des 1979 erschienenen Werkes lautet La distinction. Critique sociale du jugement.
} 


\section{Hegel - oder doch nicht? \\ Koloniale Imagination und Genderrollen}

Im Vorwort zu den Berliner Vorlesungen über die Philosophie der Geschichte aus den 1820er Jahren verdeutlicht Hegel seinen Zuhörern einen grundlegenden Aspekt seines Ansatzes anhand einer Metapher: Der Gang der Weltgeschichte gleiche dem "Tagewerk" eines Blinden, der zum ersten Mal den Sonnenaufgang erblickt. ${ }^{4}$ Nach anfänglichem Staunen erkennt der geheilte Blinde die ihn umgebenden Gegenstände, die damit ins Innere seines Geistes eindringen. Danach „geht der Mensch dann aus tatlosem Beschauen zur Tätigkeit heraus und hat am Abend ein Gebäude erbaut, das er aus seiner inneren Sonne bildete". 5 Damit hat der Blinde für Hegel einen dialektischen Prozess vollendet: Von einer passiven Rezeptivität gelangt er durch eine Externalisierung ins Objekt (das Errichten eines Gebäudes) zu einem reflexiven, bewussten Umgang mit der anfänglichen Erfahrung (das Gebäude ist nun seine Sonne, die objektive Verkörperung seines anfänglichen Staunens). „Halten wir dies Bild fest“, schließt Hegel den Abschnitt ab, „so liegt schon darin der Gang der Weltgeschichte, das große Tagewerk des Geistes". ${ }^{6}$ Anhand dieser Metapher liefert Hegel nicht allein ein synthetisches Beispiel für seine dialektische Logik und verweist auf jenes vollkommene Selbstbewusstsein des Geistes, das den Endpunkt sowohl seines gesamten Systems als auch der Weltgeschichte darstellt. Das Beispiel des Tagewerks des Blinden verdeutlicht zusätzlich, wie die Geschichte der Welt räumlich als ein Gang von Osten nach Westen aufgefasst werden soll: „Die Weltgeschichte geht von Osten nach Westen, denn Europa ist schlechthin das Ende der Weltgeschichte, Asien der Anfang. "“

Mehr als hundert Jahre später stellt genau dieses historische Narrativ den apodiktischen Ausgangspunkt von Pesentis musikgeschichtlicher Argumentation in La musica è mediterranea dar. Im Vorwort schreibt er: „So wie das Licht aus dem Orient in unsere Welt kam, so kamen auch die Religion, das Denken und die Tonkunst von dort. “8 Natürlich steht man hier vor einem allgemeinen Topos westlicher Selbstauffassung, und man könnte Pesenti genauso gut mit anderen älteren oder jüngeren Texten vergleichen. Anhand der Gegenüberstellung mit der besagten Hegelschen

\footnotetext{
${ }^{4}$ Georg Wilhelm Friedrich Hegel, Vorlesungen über die Philosophie der Geschichte (Frankfurt am Main: Suhrkamp, 1970), 133f. Diese Vorlesungsreihe hat Hegel mehrere Male in den 1820er Jahren an der Humboldt-Universität zu Berlin gehalten; sie wurde 1837 von Eduard Gans und Hegels Sohn Karl posthum erstveröffentlicht.

${ }^{5}$ Hegel, Vorlesungen, 134.

${ }^{6}$ Ebd.

${ }^{7}$ Ebd.

8 „Come dall'Oriente venne al mondo nostro la luce, così venne la religione, il pensiero e anche l'arte dei suoni." Pesenti, La musica, 12.
} 
Passage wird es jedoch möglich, einen wichtigen Strang in Pesentis Argumentation sichtbar zu machen. Dafür soll hier auf die Fußnote eingegangen werden, welche Pesenti seiner oben zitierten Sentenz hinzugefügt hat: „Strenggenommen“, bemerkt der Ethnomusikologe, „waren alle schöpferischen Kräfte des Denkens nicht lateinischen Ursprungs: Das Denken war griechisch; die Religionen semitisch; lateinisch war und ist die konstruktive Kunst; Rom war die größte konstruktive Macht, die jemals die Welt beseelt hat, genauso wie Griechenland der Ursprung des westlichen Wissens war."9

Hier wird deutlich, dass Pesenti mit Hegel nicht allein ein topisches Ost-WestNarrativ über die geschichtliche Entwicklung der Zivilisation teilt: Pesenti und Hegel stimmen auch in der Art und Weise überein, wie die beiden geographischen und kulturellen Pole, auf die sich dieses Narrativ gründet, inhaltlich zu verstehen sind. Knotenpunkt der gesamten Hegelschen Argumentation ist eine (nicht hinterfragte) Charakterisierung des Westens als ein geografisch-geistiger Ort, der sich durch einen reflexiven Umgang mit der Welt auszeichnet. Die Welt wird hier zum Objekt innerer Anschauung gemacht: Sie wird zum Mittel für die Konstruktion und Entfaltung des Selbst. Das Andere ist stattdessen passiv: Das Staunen, wodurch es sich konstituiert, ist reine Empfänglichkeit, die an sich steril bleibt. Pesenti, dessen Schrift nicht die Komplexität Hegels teilt, greift diesen Topos auf und stellt einen „konstruktiven“ Okzident - hier mit dem imperialen Rom statt wie bei Hegel mit dem Preußentum identifiziert - einem „passiven“ Orient gegenüber. Damit jedoch enden die Gemeinsamkeiten zwischen Hegel und Pesenti bereits.

Entscheidend ist es nun, nicht so sehr die von Hegels Preußen zu Pesentis Rom wandernde Verortung der sancta sanctorum des Westens weiter zu hinterfragen. Wichtig ist es stattdessen, dass Pesenti die Entwicklungslinie der Kultur von Osten nach Westen grundsätzlich - also strukturell - anders als Hegel versteht. Die beiden Pole von Passivität und Aktivität, von Osten und Westen gehen bei Pesenti nicht im wohlgeordneten dialektischen Gang bis zum westlichen gran finale - dem vollständigen Selbstbewusstsein des Geistes - ineinander über. Der Hegelschen Auffassung eines linearen Werdens von Osten nach Westen setzt Pesenti eine noch einmal differenzierte Sicht des Westens entgegen: Für Pesenti gibt es einen „dekadenten“ und einen „lateinischen“ Westen. Die Spaltung zwischen Orient und Okzident wird von ihm gewissermaßen innerhalb desselben Okzidents noch einmal reproduziert.

Pesentis Auffassung der Weltgeschichte lautet ungefähr so: Nach einem (de rigueur obskuren) mythischen Anfang in uralten Zivilisationen des „orientalischen“ Mediterranen (vertreten etwa durch die Sumerer, Babylonier und Ägypter) habe die westliche (Musik-)Kultur ihre idealtypische Gestalt im alten Griechenland und im

\footnotetext{
${ }^{9}$ „A rigor di logica le forze creatrici del pensiero non furono latine: greco il pensiero; semitiche le religioni; latina fu ed è l'arte costruttiva; Roma fu la più grande potenza costruttrice che abbia mai animato il mondo, così come la Grecia fu la matrice del sapere occidentale." Pesenti, La musica, 12.
} 
Mauro Fosco Bertola

imperialen Rom gefunden. Hier also sei die Latinität zu verorten; jene latinità, welche die geistige "vagina et fucina gentium “ des Mittelmeerraumes politisch und kulturell zu vereinen gewusst habe. ${ }^{10}$ Nach dem Zusammenbruch des römischen Kaiserreichs von den Arabern gepflegt und weitertradiert, sei die wahre kulturelle Identität des Westens, d.h. die Latinität, durch das maurische Spanien und die Kreuzzüge zum italienischen Rinascimento und damit in die Modernität gelangt. ${ }^{11}$ An diesem Punkt der Erzählung angekommen, verwandelt sich Pesentis chauvinistische Kurzgeschichte des Westens in eine Diagnose der kulturellen Lage der Gegenwart. Und genau hier entpuppt sich der Versuch einer dialektischen Synthese definitiv als unbrauchbar für Pesentis gesamthistorische Vision: Der Ethnomusikologe liest die Gegenwart nicht als Aufhebung des Vergangenen, sondern als erlösende Rückkehr des Gewesenen.

Ohne Not springt Pesenti von der Renaissance zum „Mondo Nuovo“ des Faschismus und bemerkt: „Die neue Welt lässt [die Kultur] der letzten Jahrhunderte hinter sich und schließt sich stattdessen der Kultur der klassischen, griechischrömischen (und daher heidnischen) Antike sowie der Renaissance an “. ${ }^{12}$ Die neue Welt blicke damit wieder auf ihren Ursprung, auf jene griechisch-römische Kultur, jene Latinität, aus der sich die Grundlage für die geistige Zuordnung der kulturellen Vielfalt des „orientalischen“ Mittelmeerraumes herauskristallisiert habe. Wir stehen hier nicht mehr vor einem geschichtlichen Werdegang, sondern vor einer radikalen Rückkehr der und zur latinità der Antike; einer Rückkehr, die sich als befreiender Ausweg aus einer Sackgasse des Westens gestaltet bzw. aus einem Aufhebungsprozess, der in einer gewissen Weise Amok gelaufen ist. Pesentis Latinität, auf deren Züge im nächsten Abschnitt eingegangen wird, ist ein Vergangenes, das nicht vergeht, eine historische Substanz, die in sich geschlossen nur das Negative des Vergessens, nicht jedoch das transformative Spiel des aufhebenden Werdens kennt. Wie die Freudschen Triebe, aber hier im positiven Sinne gewendet, kennt diese Substanz nur das Wiederkehren.

Die Legitimierung einer kolonialen Rolle des Westens, impliziert in Hegels dialektischer Strukturierung der Polarität zwischen Orient und Okzident, nimmt bei Pesenti mithin eine problematische Wendung. Der Topos von orientalischer Passivität und westlicher Aktivität lässt sich im Rahmen der Hegelschen Dialektik auf eine im eng bourgeoisen Sinne - „gendergerechte“ Gesamtvision harmonischen Zusammenlebens zurückführen: Der passiv-weibliche Orient wird durch das männliche Prinzip einer westlichen Aktivität entfaltet und zu sich selbst geführt. Dies sichert ein (imaginäres) Zufriedenstellen beider Pole, selbst wenn es in der Form eines

\footnotetext{
${ }^{10}$ Pesenti, La musica, 15.

${ }^{11}$ Ebd., $15-17$.

12 „Il nuovo mondo tende ad allontanarsi dai secoli a noi più vicini e a riallacciarsi all'antichità classica, greca e latina (quindi pagana) e, con essa, alla Rinascenza." Ebd., 18.
} 
Kiplingschen White Man's Burden geschieht. ${ }^{13}$ Bei Pesenti stehen wir stattdessen im Unterschied zu Hegel - vor einer problematischen ménage à trois zwischen Orient, Latinität und dekadentem Westen bzw. vor einem in sich gespaltenen männlichen Prinzip, vor einem Westen, der seine Funktion nicht mehr zu erfüllen weiß und „erlöst" werden soll. Selbstverständlich ist für Pesenti die Frage nach einem solchen Erlöser politisch schnell beantwortet: Der Faschismus sei diejenige Kraft, welche diesen Akt zu vollziehen vermöge. Dennoch trägt diese Lösung etwas Paradoxes in sich: Erlöst wird der Westen de rigore nicht vom weiblich-mediterranen Orient, sondern von sich selbst, d.h. von dem wahren Selbst seiner inhärenten (und nun faschistisch artikulierten) Latinität. Eine Art parsifalesque „Erlösung des Erlösers“, die genau wie ihr Wagnersches Modell nicht wenige Ungereimtheiten in sich birgt. Pesentis musikgeschichtliches Narrativ steckt damit noch tief in jener Krise, welche sich die kulturelle Reflexion um die Jahrhundertwende zum Thema gemacht hatte und die sich im Topos einer zwischen Männervernichtung und erlösender Selbstaufopferung schwankenden Weiblichkeit ausgedrückt hatte, die jegliche Aufhebung der Dichotomie zwischen den zwei Geschlechtspolen untergrub. Es ist also kein Zufall, dass Pesenti die intellektuellen Koordinaten, mit denen er sein Latinitätskonzept entwirft, von demjenigen Autor nimmt, der aus dieser Krise die umfassendste Diagnose und zugleich den radikalsten Ausweg geliefert hatte: Friedrich Nietzsche.

\section{Latinität, oder: Von einem Wagnerschen Problem}

Nach der durchaus hörbaren Hinrichtung Till Eulenspiegels am Ende von Richard Strauss' gleichnamiger Sinfonischer Dichtung von 1894/95 erklingt bekanntlich das lustige Thema seines Protagonisten in all seinem stürmischen Lebensdrang noch ein letztes Mal. Mit diesem überraschenden Ende befreite sich Strauss ein Jahr nach der Premiere seiner ersten Oper Guntram von jenem Wagnerschen, weltverneinenden Pessimismus, welcher seinen ersten Opernversuch noch geprägt hatte. Nicht nur lebt Till Eulenspiegel mit höchster Zufriedenheit ein Leben, das ganz und gar auf das Diesseits ausgerichtet ist, sondern es wird auch - der abschließenden Hinrichtung zum Trotz - ein völlig positives Fazit gezogen. Pesentis Latinitätskonzept gleicht in gewisser Weise Till Eulenspiegels weltbejahendem Gestus, selbst wenn dies mit viel weniger Humor vollzogen wird: Dahinter steht genau wie bei Strauss das Denken Nietzsches. Mit folgenden Worten definiert Pesenti diese Latinität:

\footnotetext{
${ }^{13}$ Rudyard Kiplings Gedicht The White Man's Burden. The United States and the Philippine Islands erschien erstmals in McClure's Magazine 12 (Februar 1899). Das Gedicht ist nun in Rudyard Kipling, The Complete Verse (London: Kyle Cathie, 2006), 257 abgedruckt.
} 
Das Konzept eines Lebens, das nicht der Askese und den unnötigen Einschränkungen unterworfen ist [...], ist ein strahlendes [solare], kosmisches, sicherlich paganes und mediterranes Konzept; ein gesundes Konzept, weil natürlich und daher menschlich; ein Konzept, nach dem die heutige Welt, welche von den tellurischen, nach dem Blutbad [des Ersten Weltkrieges, d. V.] freigesetzten Kräften verjüngt wurde, die Arme durstig ausstreckt. Der Geist und die Vernunft sind von selbst imperialistisch und pagan. ${ }^{14}$

Paganismus und Imperialismus, erstere als eine Art Rückkehr zur Naturreligion, letzterer als koloniale Macht Italiens über das gesamte Mittelmeergebiet zu verstehen, sind damit die Merkmale von Pesentis Latinität und zugleich die Antwort auf eine Krise des Westens, die für ihn in den Schützengräben des Ersten Weltkrieges sowohl ihre verhängnisvolle Überspitzung als auch ihre befreiende Überwindung erfahren hatte. Pesentis Latinität steht damit eindeutig in einer italienischen NietzscheRezeption, die zwischen den 1890er und den 1910er Jahren ihr bis zum Ende des Zweiten Weltkriegs geltendes Profil gefunden hatte. ${ }^{15}$

Von einem mehrteiligen Artikel von Pasquale Villari (1827-1917) aus dem Jahr 1891 eingeleitet, in dem der bedeutende Renaissance-Historiker und Politiker Nietzsches Vom Nutzen und Nachteil der Historie für das Leben (die bereits 1873 erschienene zweite der Unzeitgemäßen Betrachtungen) rezensierte, war Nietzsches Philosophie in Italien vor allem durch das Wirken von Gabriele D’Annunzio (18631938) geprägt worden. ${ }^{16} \mathrm{Zu}$ einer Zeit, als die Werke des deutschen Philosophen noch nicht ins Italienische übersetzt waren, führte D’Annunzio, der sie auf Französisch las, nicht nur Nietzsches Denken in Italien ein, sondern legte auch die Grundlage für eine durchaus selektive Aneignung seiner Philosophie. Einige Kernkonzepte wurden stark hervorgehoben, der philosophische Rahmen, in dem sie zu verorten waren, blieb jedoch unbeachtet und mit ihm die weitreichenden, über das einzelne

\footnotetext{
${ }^{14}$ Das komplette Zitat lautet: „Il concetto della vita non soggiogata agli ascetismi e alle inutili restrizioni [...], è un concetto, direi, solare, cosmico, certamente pagano e mediterraneo; concetto sano, perché naturale e quindi umano, a cui il mondo di oggi, ringiovanito dalle forze telluriche, in fermento dopo tanto lavacro di sangue, tende avidamente le braccia. Lo spirito e l'intelligenza sono istintivamente e naturalmente imperialisti e pagani. [...] La guerra portò a delle reazioni nella sostanza e nelle forme della vita: (c'è anche qui una trasmutazione, se non anche una inversione dei valori, annunciata dal grande precursore: Federico Nietzsche). La vita realistica, sgombra da principi assoluti, da pregiudizi, da formule, da artificiali legami, è appena al cominciamento." Pesenti, La musica, $17 \mathrm{f}$.

${ }^{15}$ Für die italienische Nietzsche-Rezeption bis zum Zweiten Weltkrieg siehe Domenico M. Fazio, Il caso Nietzsche. La cultura italiana di fronte a Nietzsche, 1872-1940 (Settimo Milanese: Marzotti, 1988).

${ }^{16}$ Siehe Pasquale Villari, „La storia come scienza?“ Nuova Antologia (1891), Bd. 31, H. 3, 409-36, Bd. 32, H. 8, 609-36 und Bd. 34, H. 14, 209-25.
} 
Konzept hinausgehenden Implikationen von Nietzsches Denken. ${ }^{17}$ Insbesondere in den Romanen Il trionfo della morte von 1894 und dem ein Jahr später erschienenen La vergine delle rocce schuf D'Annunzio einen Nietzsche, der Zarathustra direkt gleicht und eine radikale anthropologische Revolution ankündigt. Nietzsches Denken wurde auf das anthropologische Modell eines Übermenschen reduziert, der von der im Christentum verkörperten Sklavenmoral befreit und allein von einem triebähnlichen Willen zur Macht geleitet sei.

Als der Sozialist und spätere Antifaschist Claudio Treves (1869-1933) im November 1908 einen Konferenzvortrag über Nietzsche am Teatro Comunale in Forlì hielt, betitelte er seine Rede nicht zufällig mit Die Philosophie der Macht (La filosofia della forza.${ }^{18}$ Damit folgte Treves einer italienischen Nietzsche-Rezeption im Zeichen des Übermenschen, die mittlerweile quer durch das gesamte politische Spektrum ging. Ebenfalls nicht zufällig gilt Treves 'Veranstaltung für einen seiner damaligen Parteigenossen (und späteren unerbittlichen Gegners) als Beginn von dessen Auseinandersetzung mit Nietzsche: Benito Mussolini. In den auf die Konferenz folgenden Wochen veröffentlichte der zukünftige Duce del fascismo in der republikanischen Zeitschrift Il pensiero Romagnolo einen langen, dreiteiligen Artikel über Treves Konferenz und hob dabei unter anderem den „mediterranen Charakter" von Nietzsches Philosophie hervor. ${ }^{19}$ In seinem Artikel nahm Mussolini einen weiteren Topos der italienischen Nietzsche-Rezeption auf, welcher ebenfalls auf D'Annunzio zurückgeführt werden muss. ${ }^{20}$ Nietzsches oft anzutreffende Verweise auf den Menschen der Renaissance und der griechisch-römischen Antike - als zwischen Vorstufe und Vorbild schwankende Verkörperungen des Übermenschen - boten ihm den Anlass, Italien als privilegierten Empfängnisort von Nietzsches Botschaft zu preisen. ${ }^{21}$

\footnotetext{
${ }^{17}$ Für eine erste Einführung in D’Annunzios Nietzsche-Rezeption und seine spätere Verbindung zum Faschismus siehe Mario Sznajder, „Nietzsche, Mussolini, and the Italian Fascism“, in Nietzsche, Godfather of Fascism? On the Uses and Abuses of a Philosophy, hg. von Jacob Golomb und Robert S. Wistrich (Princeton u.a.: Princeton University Press, 2002), 235-62.

${ }^{18}$ Sznajder, „Nietzsche, Mussolini, and the Italian Fascism“, $247 \mathrm{f}$.

${ }^{19}$ Der Artikel erschien in drei Teilen am 29.11., 6. und 13.12.1908. Der vollständige Text ist in Benito Mussolini, „La filosofia della forza. (Postille alla conferenza dell’on. Treves)“, in Opera Omnia di Benito Mussolini, Bd. 1, hg. von Edoardo e Duilio Susmel (Florenz: La Fenice, 1951), 174-84 abgedruckt.

${ }^{20}$ Mussolini, La filosofia, 174.

${ }^{21}$ Paradigmatisch ist in diesem Sinne D'Annunzios Nachruf für Nietzsche Per la morte di un distruttore. F. N. XXV Agosto MCM. Im Gedicht wird Italien als zugleich Grabstatt des Leichnams Nietzsches und erwähltes Land für die Entfaltung dessen Denkens explizit gepriesen, siehe Gabriele D’Annunzio, Versi d'amore e di gloria (Milano: Mondadori, 1980), Bd. 2, 465-82, insbesondere 481. Über Nietzsches Bild des italienischen Renaissancemenschen und seine Verbindung zu Jacob Burckhardts Auffassung der Renaissance siehe Luca Farulli, „Nietzsche e l'uomo italiano della Rinascenza“, in Nietzsche
} 
Dass Pesenti in seinen musikgeschichtlichen Betrachtungen das stark nationalisierte Thema von Renaissance und Antike aufgriff, sollte daher ebenso wenig verwundern wie sein explizites Eingehen auf Nietzsches Behauptung, eine Mediterranisierung der Musik sei notwendig. ${ }^{22}$ „Mediterranität“ heißt jedoch bei Pesenti mit politisch geschickter metonymischer Verschiebung „Latinität“: Wodurch zeichnet sie sich musikalisch aus?

Pesentis Ausgangspunkt ist eine radikale Gegenüberstellung von orientalischer und westlicher Musikalität, die sich grob auf die Gegenpole Melodie vs. Harmonie, Repetition vs. Entwicklung sowie Vokal vs. Instrumental reduzieren lässt. ${ }^{23}$ Seine Dichotomie ist ebenso grob wie banal: Sie gibt genau jene sich gegenseitig ausschließenden musikalischen Eigenschaften wieder, die sich im Laufe des 19. Jahrhunderts in der Gegenüberstellung von einer „deutschen“ und einer „italienischen“ Musik verfestigt hatten. ${ }^{24}$ Pesenti gibt eben dieser Dichotomie jedoch eine durchaus interessante Wendung, denn in seiner Fassung steht nun Italien als Teil des Westens auf der ehemaligen deutschen Seite: Pesenti verwendet ein unmissverständliches „Wir“, als von Harmonie, Entwicklung und Orchesterklang die Rede ist. Dies ist alle Mal kuri-

und Italien. Ein Weg vom Logos zum Mythos?, hg. vom Italienischen Kulturinstitut Stuttgart (Tübingen: Stauffenburg, 1990), 41-57.

22 „Il faut méditerraniser la musique: ich habe Gründe zu dieser Formel (Jenseits von Gut und Böse, S. 220). Die Rückkehr zur Natur, Gesundheit, Heiterkeit, Jugend, Tugend! Und doch war ich Einer der corruptesten Wagnerianer...“, Friedrich Nietzsche, Der Fall Wagner (München: DTB, 2011), 16.

${ }^{23}$ „Mentre noi concepiamo - ,grosso modo“ - la musica verticalmente; gli orientali la concepiscono orizzontalmente. I suoni, distinti in superficie, divengono, sotto il dominio del ritmo, melodia; discendenti in profondità, armonia. Gli orientali invece, questo discendere del suono in profondità quasi lo disconoscono, mentre possiedono, fortissimo, ossessionante quasi, il senso del ritmo (iqã). Essi si arrestano alla enunciazione musicale, ripetendola; noi invece sentiamo che nella musica, come nell'architettura, esiste indubbiamente una costruzione nello spazio, ,costruzione che è dentro dei suoni e delle cose', costruzione che vuol essere sviluppo di almeno un'idea. Se per l'orientale la voce è tutto e l'istrumento è poco o niente, per noi spesso l'istrumento divenne pari alla voce e l'orchestra vive di vita propria, indipendentemente dalla voce." Pesenti, La musica, $13 \mathrm{f}$.

${ }^{24}$ Dieser Vergleichstopos wurde in Italien das gesamte 19. Jahrhundert hindurch (und darüber hinaus) in inhaltlich kaum veränderter Form weitertradiert. Ein paradigmatisches Beispiel dafür bietet der Vergleich zwischen einem „frühen“ Text wie Mazzinis 1836 erschiener Filosofia della musica und einem am Ende des 19. Jahrhunderts veröffentlichten Artikel des italienischen Musikwissenschaftlers Luigi Torchi, vgl. Giuseppe Mazzini, La filosofia della musica (Roma-Milano: Bocca, 1954), 148f. und Luigi Torchi, „La musica istrumentale in Italia nei secoli XVI, XVII e XVIII“, Rivista musicale italiana 4 (1897), 589, Fußnote 1. Siehe außerdem Luca Aversano, „Identitäten im Spiegel. Das wechselseitige Bild von Deutschland und Italien im frühen 19. Jahrhundert", in Migration und Identität. Wanderbewegungen und Kulturkontakte in der Musikgeschichte, hg. von Sabine Ehrmann-Herfort und Silke Leopold (Kassel [u.a.]: Bärenreiter, 2013), 182-93. 
os. Tatsächlich hatte er bereits zuvor die behauptete Bipolarität mit der Bemerkung relativiert, dass sie nur vordergründig gelte, weil eigentlich „nicht ein trennender Ozean, sondern ein verbindendes und vereinendes Mittelmeer" zwischen Okzident und Orient bestehe. ${ }^{25}$

Hier wird Pesentis Ziel sichtbar, denn hinter seiner Argumentation steht unzweifelhaft sein Konzept der Latinität als verbindendes Element: Auch in ihrer innermusikalischen Artikulation ist die Latinität im Sinne Pesentis eine Mediation bzw. Aufhebung der Gegenüberstellung von Orient und Okzident. Und auch in diesem Fall soll sie nicht als eine Art Vorstufe zur postkolonialen Reflexion der 1990er Jahre verstanden werden: Pesentis musikalische Latinität ist nicht ein third space à la Homi Bhabha, ein ewig unbestimmtes und unbestimmbares in-between zwischen zwei Polen einer Dichotomie. Sie markiert nicht jenen immer offenen „dritten Raum“, aus dem die Hegelsche Dialektik von Herr und Knecht ihre radikale Deplatzierung erfährt. ${ }^{26}$ Sie ist nicht das konzeptuelle Mittel eines Außerkraftsetzens der diskursiven Koordinaten kolonialer Machtverhältnisse. Stattdessen ist sie gerade der Signifikant für einen solchen kolonialen Diskurs. Anstatt ein immer Neues zu ermöglichen, das jeglichen bestehenden Diskurs zusammen mit dessen Machtstrukturen in Frage stellt, ist die Latinität auch musikalisch ein ewig Waltendes. Daher strukturiert sich Pesentis Latinität auch im Fall der Musik um die Figur einer Rückkehr des Identischen. Mit folgenden Worten definiert er die Musik der 1880er-Generation, welche seiner Meinung nach die Latinität in der Gegenwart musikalisch vertritt:

[Die Musik von Casella, Malipiero, Pizzetti, d. V.] strebt nach einer Rückkehr zur klassischen Tradition, zu Claudio Monteverdi, zu Pergolesi, zu Scarlatti, zu Vivaldi, zum göttlichen Lächeln des Großen aus Pesaro; [allen Komponistenpersönlichkeiten, die] im Geist

\footnotetext{
25 „Di primo acchito, fra Oriente e Occidente sembra esservi sempre stato (ed esservi ancora) un oceano separatore, anzichè un Mediterraneo collegatore e unificatore." Pesenti, La musica, 13.

${ }^{26}$ Mit folgenden Worten definiert Bhabha diesen „dritten Raum“: „The intervention of the Third Space of enunciation, which makes the structure of meaning and reference an ambivalent process, destroys this mirror of representation in which cultural knowledge is customarily revealed as integrated, open, expanding code. Such an intervention quite properly challenges our sense of the historical identity of culture as homogenizing, unifying force, authenticated by originary Past, kept alive in the national tradition of the People“, vgl. Homi K. Bhabha, The location of culture (London: Routledge, 2004), 54. Diesbezüglich siehe auch Jonathan Rutherford, „The Third Space. Interview with Homi Bhabha", in Identity: Community, Culture, Difference, hg. von Jonathan Rutherford (London: Lawrence and Wishart, 1990), 207-21.
} 
und in den [musikalischen] Formen das Nationale, das Italienische in besonderem Maße [vertraten]. ${ }^{27}$

Was Pesenti in der Musik dieser Komponisten hört, ist nicht das Neue, das sich hinter der vordergründigen Rückkehr der alten Formen ankündigt. Er erkennt nicht das Spezifische (und daher radikal Neue) eines musikhistorischen Moments, in dem alle zur Verfügung stehenden musikalischen Mittel ihre Fähigkeit verloren zu haben schienen, die moderne Welterfahrung zu artikulieren und zugleich immer noch „alles was man eben hat" darstellten, um sich musikalisch ausdrücken zu können. ${ }^{28}$ Der gespenstisch-unheimliche Charakter einer leeren, inhaltlich gebrochenen Rückkehr älterer Musikformen, der in den besten Werken der 1880er-Generation erklingt (und sei es auch in der depotenzierten Form eines melancholisch-elegischen Rückschauens), und welcher sie musikgeschichtlich neu macht, bleibt von Pesenti ungehört. Mögen die Formen und die Darbietungsarten sich auch unterscheiden, substanziell ändert sich für Pesenti in der Musikgeschichte nichts: Die Latinität erklingt bei Casella wie bei Rossini oder Palestrina an sich unverändert weiter. Rechts und links dieser Latinität liegen seiner Meinung nach ein musikalischer Orient und Okzident, die ebenfalls hypostasiert werden: Der eine ist das Reich der „kindlichen“ Musik, der musikalischen „Naivität“, der andere aber jenes der Dekadenz, deren Versinnbildlichungsfigur, wie zu erwarten, Richard Wagner ist. ${ }^{29}$ Dass die Latinität politisch über den Orient und kulturell über den Okzident zu herrschen habe, leitet sich unweigerlich aus solchen Prämissen ab. Pesenti sieht die Musikgeschichte als eine Art ewiges Spiel der rein akzidentellen Veränderungen in einer ewig zu wiederholenden forced choice zwischen Dekadenz und Repetition des Identischen.

\section{„Mais où sont les yeux pour le voir?“ Mit Nietzsche binter Nietzsche}

Hinter jenem entscheidenden Wendepunkt im westlichen Denken, den Jacques Derrida 1967 mit der gleichzeitigen Veröffentlichung der Aufsatzsammlung Die Schrift und die Differenz und von Grammatologie eingeleitet hatte und der später un-

\footnotetext{
27 „Esso vuole ritornare alla tradizione classica, a Claudio Monteverdi, a Pergolesi, a Scarlatti, a Vivaldi, al divino riso del grande Pesarese, così nazionali, così italiani, nello spirito e nelle forme." Pesenti, $L a$ musica, 168.

${ }^{28}$ Die scharfsinnigste Formulierung dieser Unmöglichkeit des Ausdrucks stellt bekanntlich Hofmannsthals sogenannter Chandos-Brief dar, siehe Hugo von Hofmannsthal, „Ein Brief“, in Sämtliche Werke, hg. von Ellen Ritter (Frankfurt am Main: Fischer, 1991), Bd. 31 (Erfundene Gespräche und Briefe), 45-55.

${ }^{29}$ Pesenti, La musica, 19.
} 
ter dem Namen Poststrukturalismus bekannt wurde, stand vor allem die Reflexion von und über zwei Philosophen: Martin Heidegger und Friedrich Nietzsche. Als Teil dieser Neuformulierung der Denkkoordinaten des Westens ist auch einer der frühen Aufsätze von Jean-Luc Nancy $\left({ }^{*} 1940\right)$ zu verstehen: 1968 erschienen, entwarf Nancy in Nietzsche. Mais où sont les yeux pour le voir? eine Deutung der Philosophie Nietzsches, die im engen Dialog mit Heideggers Pariser Nietzsche-Vorlesungen der späteren 1930er Jahre die Thesen Heideggers zugleich vertiefte und ins Gegenteil verkehrte. $^{30}$

Während Nietzsche - nach Heideggers Auffassung - in seiner radikalen Kritik jeglicher metaphysischer Ordnung der Metaphysik am Ende doch nicht zu entgehen wusste (wenn auch in Form von deren Negativbild), spricht Nancy ein viel positiveres Urteil über Nietzsche. Er sieht in ihm nicht nur den begnadeten „genealogischen“ Denker, der jegliche metaphysische Ordnung zu dekonstruieren wusste, sondern auch denjenigen, der diese Position eines kontinuierlichen Zweifels zudem reflexiv auf seine eigenen Thesen anwendete, die schließlich immer offen, immer nur kontextuell zu lesen sind. In seinem Denken wird nicht, wie Heidegger behauptet hatte, mittels der Kritik eine „falsche" Ordnung demaskiert und die dahinter liegende „wahre" Struktur der Welt offengelegt. Für Nancy ist Nietzsche stattdessen, wie er schreibt, der „Anti-Logos des Suspektes“: Seine Überwindung des metaphysischen, Substanzen voraussetzenden Denkens des Westens besteht im Offenlegen des fiktionalen Charakters jeglicher Denkposition. Die alte Dichotomie zwischen "Wahrheit“ und „Schein" ist bei ihm überwunden, denn, wie Nietzsche am Ende der berühmten Passage „Wie die ,wahre Welt" endlich zur Fabel wurde“ aus Götzen-Dämmerung schreibt: „Die wahre Welt haben wir abgeschafft: welche Welt blieb übrig? die scheinbare vielleicht?... Aber nein! mit der wahren Welt haben wir auch die scheinbare abgeschafft! ${ }^{\text {(31 }}$

Hinter den vielen Vereinfachungen und Grobheiten von Pesentis (und insgesamt von der damaligen italienischen) Nietzsche-Rezeption steht gerade das Missverständnis jenes grundlegenden Zuges von Nietzsches Denken, den Nancy in seinem Artikel deutlich hervorgehoben hat. Pesenti übernimmt Nietzsches Kritik des Christentums als Sklavenmoral und mit ihr die Vision eines Übermenschen, der, von allen Werten befreit, seinen bei Pesenti ins Schlagwort des Imperialismus umgewandelten Willen zur Macht ungezügelt lebt. Pesenti hypostasiert diese Konzepte jedoch: Er

\footnotetext{
${ }^{30}$ Jean-Luc Nancy, „Nietzsche. Mais où sont les yeux pour le voir?“ Esprit (März 1968), 482-503. Über Nancys Denken und insbesondere diesen frühen Aufsatz siehe Ian James, The fragmentary demand. An introduction to the philosophy of Jean-Luc Nancy (Stanford, CA: Stanford University Press, 2006), 15-21. Die in den späten 1930er und in den 1940er Jahren von Heidegger gehaltenen Vorlesungen über Nietzsche wurden zum ersten Mal 1961 veröffentlicht (und erst 1972 ins Französische übersetzt), siehe Martin Heidegger, Nietzsche I und II (Stuttgart: Klett-Cotta, 2008).

${ }^{31}$ Friedrich Nietzsche, Götzen-Dämmerung (München: DTB, 2011), 81.
} 
versteht ihre rein kritische Funktion gegenüber der Wissensordnung nicht, in der Nietzsche lebte und welche er mitsamt ihrer metaphysischen Fiktionen anhand dieser Konstrukte unterminieren wollte.

Wie Peter Sloterdijk jüngst noch einmal hervorgehoben hat, sind Nietzsches anthropologische Visionen - seien sie rückwärts auf die Figur eines Antiken- oder Renaissancemenschen oder vorwärts auf jene eines Übermenschen gerichtet - immer nur als „Allochronien“ zu verstehen: Sie haben einen rein kritischen, immer offen dekonstruierenden Charakter gegenüber der kulturspezifischen Epoche, in der sie artikuliert werden. ${ }^{32}$ Dessen ungeachtet gibt Pesenti diesen Konzepten eine konkrete Substanz: Er verortet sie historisch im imperialen Rom, im Italien der Renaissance und schließlich im neuen Rom des Faschismus. Sie sind also nicht mehr „Allo-“, sondern „Panthachronien“: Sie stellen unter dem Schlagwort der Latinität die einzige wahre Substanz der Geschichte dar; eine Geschichte, die entweder die „lateinische“ Aktualisierung dieser Konzepte oder das Schwanken zwischen einem Noch-Nicht des Orients und der Dekadenz des Nordens annimmt.

Die Reduktion der musikalischen Mittel, mit der Gustav Mahler im vierten Satz seiner dritten Sinfonie jene „Tiefe der Welt“ zum Klingen brachte, die Nietzsche im vorletzten Abschnitt von Also sprach Zarathustra in poetischer Form angesprochen hatte, ist bis heute atemberaubend. In der Parallele zu dem, was Nietzsche an dieser Stelle für das Sein und den Menschen auszudrücken versuchte, wollte Mahler jene hinter dem Klang stehende Tiefendimension des Musikalischen suggerieren, welche die regelrechte Existenzbedingung des Klanges bildet und aus der die Musik in ihren historisch vielfältigen Erscheinungen immer neu hervorquillt. Weit davon entfernt, diese das Neue hervorbringende Tiefenzeit der (Musik-) Geschichte zu sein, liefert Pesentis Latinität viel mehr den Beweis für die Flachheit einer historischen Auffassung, die das genuin Neue nicht kennt. Es ist gerade diese Flachheit, die in der Geschichte allein das Sich-selbst-Bestätigende sieht, die der Ethnomusikologe schließlich mit seinem politischen Gönner Mussolini teilte.

\section{Literatur}

Aversano, Luca. „Identitäten im Spiegel. Das wechselseitige Bild von Deutschland und Italien im frühen 19. Jahrhundert". In Migration und Identität. Wanderbewegungen und Kulturkontakte in der Musikgeschichte, hg. von Sabine Ehrmann-Herfort und Silke Leopold, 182-93. Kassel [u.a.]: Bärenreiter, 2013.

Bhabha, Homi K. The location of culture. London: Routledge, 2004, 1. Aufl. 1997.

\footnotetext{
32 Peter Sloterdijk, Du mußt dein Leben ändern (Frankfurt am Main: Suhrkamp, 2012), 52-68.
} 
Bourdieu, Pierre. Die feinen Unterschiede. Kritik der gesellschaftlichen Urteilskraft, Frankfurt am Main: Suhrkamp, 1982.

D’Annunzio, Gabriele. Versi d'amore e di Gloria, 2 Bde., Milano: Mondadori, 1980.

Farulli, Luca. „Nietzsche e l'uomo italiano della Rinascenza“. In Nietzsche und Italien. Ein Weg vom Logos zum Mythos? Akten des deutsch-italienischen Nietzsche-Kolloquiums, Tübingen, 27.-28. November 1987, hg. vom Italienischen Kulturinstitut Stuttgart, 41-57. Tübingen: Stauffenburg, 1990.

Fazio, Domenico M. Il caso Nietzsche. La cultura italiana di fronte a Nietzsche, 1872-1940. Settimo Milanese: Marzotti, 1988.

Giannattasio, Francesco. „Parole (...nostre) e musica (...degli altri): i canti sacri e profani dei ,Somàli ‘ secondo Gustavo Pesenti (1929)“. In Pensieri per un maestro. Studi in onore di Pierluigi Petrobelli, hg. von Stefano La Via und Roger Parker, 387-405. Torino: EDT, 2002.

Hegel, Georg Wilhelm Friedrich. Vorlesungen über die Philosophie der Geschichte. Frankfurt am Main: Suhrkamp, 1970.

Heidegger, Martin. Nietzsche I und II. Stuttgart: Klett-Cotta, 2008.

Hofmannsthal, Hugo von. „Ein Brief“. In Sämtliche Werke, Bd. 31 (Erfundene Gespräche und Briefe), hg. von Ellen Ritter, 45-55. Frankfurt am Main: Fischer, 1991.

James, Ian. The fragmentary demand. An introduction to the philosophy of Jean-Luc Nancy. Stanford, CA: Stanford University Press, 2006.

Kipling, Rudyard. The complete verse, London: Kyle Cathie, 2006.

Mazzini, Giuseppe. La filosofia della musica. Roma-Milano: Bocca, 1954, 1. Aufl. 1836.

Mussolini, Benito. „La filosofia della forza. (Postille alla conferenza dell'on. Treves)“. In Opera Omnia di Benito Mussolini, Bd. 1, hg. von Edoardo e Duilio Susmel, 174-84. Florenz: La Fenice, 1951.

Nancy, Jean-Luc. „Nietzsche. Mais où sont les yeux pour le voir?“ Esprit (März 1968): 482-503.

Nietzsche, Friedrich. Der Fall Wagner, München: DTB, 2011 (= Kritische Studienausgabe, hg. von Giorgio Colli und Mazzino Montinari, Bd. 6).

Nietzsche, Friedrich. Götzen-Dämmerung, München: DTB, 2011 (= Kritische Studienausgabe, hg. von Giorgio Colli und Mazzino Montinari, Bd. 6). 
Pesenti, Gustavo. La musica è mediterranea. Milano: L'Eroica, 1937.

Rutherford, Jonathan. „The Third Space. Interview with Homi Bhabha“. In Identity: Community, Culture, Difference, hg. von Jonathan Rutherford, 207-21. London: Lawrence and Wishart, 1990.

Sloterdijk, Peter. Du mußt dein Leben ändern. Frankfurt am Main: Suhrkamp, 2012, 1. Aufl. 2009.

Sznajder, Mario. „Nietzsche, Mussolini, and the Italian Fascism“. In Nietzsche, Godfather of Fascism? On the Uses and Abuses of a Philosophy, hg. von Jacob Golomb und Robert S. Wistrich, 235-62. Princeton, Oxford: Princeton University Press, 2002.

Torchi, Luigi. „La musica istrumentale in Italia nei secoli XVI, XVII e XVIII“, Rivista musicale italiana 4 (1897): 581-630.

Villari, Pasquale. „La storia come scienza?“, Nuova Antologia (1891), Bd. 31, H. 3, 409-36; Bd. 32, H. 8, 609-36 und Bd. 34, H. 14, 209-25. 


\section{„Nordische Musik“ als Faktor der Propaganda der Nordischen Gesellschaft und der DNSAP in Dänemark um 1940}

Yvonne Wasserloos (Düsseldorf)

Der Zweite Weltkrieg stellte für das Deutsche Reich in erster Linie einen Eroberungskrieg zur Gewinnung von Territorium und Macht dar. Propaganda und Kulturpolitik gehörten zu den wesentlichen Mitteln, um im Ausland ,Sympathie für die NS-Ideologie zu erwecken sowie mit Ausbruch des Zweiten Weltkriegs die deutsche Fremdherrschaft in den besetzen Gebieten Europas zu legitimieren. ${ }^{1}$ Wie in der NSPropaganda im Reich selbst, spielte die Musik auch in der Außen- bzw. Besatzungspolitik eine entscheidende Rolle, um eine ästhetische Faszination für eine politische Ideologie zu erschaffen.

Im Rahmen des kulturellen ,Missionierungszugs' sind unterschiedliche Vorgehensweisen zu konstatieren. Bei der Okkupation im Osten, vorrangig in Polen und der Sowjetunion, herrschten Gewalt, Zerstörung und Unterdrückung vor, da die slawischen Völker - den nationalsozialistischen Rassekategorien gemäß - als „Untermenschen “ deklariert worden waren. Nach dem Verständnis der Nationalsozialisten musste dort eine „Germanisierung“ bei gleichzeitiger Vernichtung der einheimischen Kultur stattfinden. In West- und Nordeuropa hingegen wurde eher eine „angepasste“ Kulturpolitik betrieben. Insbesondere im Norden erkannten die Deut-

\footnotetext{
${ }^{1}$ Vgl. Karl Christian Lammers, „Kultur- und Kunstpolitik in Dänemark“, in Kultur - Propaganda Öffentlichkeit. Intentionen deutscher Besatzungspolitik und Reaktionen auf die Okkupation, hg. von Wolfgang Benz, Gerhard Otto und Annabella Weismann (Berlin: Metropol-Verlag, 1998), 105.
} 
schen die „Blutsverwandtschaft“ mit der „Nordischen Rasse“ als gegeben an, so dass hier mit mehr ,Respekt 'vor der nationalen Kultur verfahren wurde. Es war in erster Linie Dänemark, das als „Musterprotektorat“ aufgebaut und nach der Besatzung weiterhin politisch souverän agieren sollte. Einen der Hintergründe für diese Entscheidung lieferte die Einordnung der dänischen Kultur als eine der deutschen Kultur zumindest verwandte, weshalb in erster Linie kulturpolitische Initiativen und Kanalisierungsmaßnahmen inszeniert wurden, um die dänische Bevölkerung deutschfreundlich zu stimmen. ${ }^{2}$

Als ein gemeinsam identitätsstiftendes Moment zwischen Deutschen und Dänen sind das „Nordische“ und der „Nordische Gedanke“ herauszustellen, als dessen stärkster grenzübergreifender Katalysatoren hier die Lübecker Nordische Gesellschaft näher beleuchtet werden soll. Der „Nordische Gedanke“ ist sowohl im musikalischen Schrifttum der Nordischen Gesellschaft als auch im musikästhetischen Profil eines parteilichen Organs - der DNSAP (Danmarks National-Socialistiske Arbejder-Parti) - und damit dem dänischen Pendant der NSDAP zu beobachten. $\mathrm{Zu}$ vergleichen sind die Aussagen und Mittel der Nordischen Gesellschaft und der DNSAP, mithilfe derer es gelingen sollte, die Dänen trotz der vorrangig negativen Einstellung gegen „das Deutsche“ für den Nationalsozialismus zu gewinnen. Anhand des DNSAP-Liedes, „Solhvervs-Sang“ („Sonnenwend-Lied“) ${ }^{3}$ soll dieser Prozess konkretisiert werden. Es gilt zu hinterfragen, wie das kulturtheoretische Konstrukt des „Nordischen“ von deutscher wie dänischer Seite definiert und propagiert bzw. welchen Anklang diese Art von versuchter Identitätsstiftung bei der dänischen Bevölkerung fand.

\section{Die Kulturpolitik der deutschen Nationalsozialisten im besetzten Dänemark: Dänische Identität und Deutschenhass}

Der deutsche Einfluss in Dänemark ist seit jeher als stark einzuschätzen. Durch Kulturtransferprozesse oder auch politische Konstellationen in der dänischen Regierung waren die Deutschen oder prinzipiell „das Deutsche“ stets präsent gewesen. Gegen diese Übermacht regte sich in Dänemark bereits im Ausgang des 18. Jahrhunderts Widerstand. Die Kriege um die Herzogtümer Schleswig und Holstein 1848 und 1864 förderten nationales Bewusstsein und Pathos. Eine ausgeprägte Feindschaft und Ablehnung alles Preußischen und Deutschen entwickelte sich nach der Kriegsniederlage gegen Preußen 1864, die mit der Gebietsabtretung der Herzogtümer Schleswig und Holstein einherging und Dänemark zu einem Kleinstaat degradierte.

\footnotetext{
${ }^{2}$ Vgl. Lammers, „Kultur- und Kunstpolitik in Dänemark“, $120 \mathrm{f}$.

${ }^{3}$ Alle Übersetzungen vom Dänischen ins Deutsche stammen, wenn nicht anders angegeben, von der Verfasserin.
} 
So prägte sich u.a. über politische Zäsuren bei der der dänischen Bevölkerung im Verlauf des 19. Jahrhundert eine Identität aus, die sich beispielsweise über eine dänische ,Nationalmusik' klingend artikulierte. ${ }^{4}$

Es wurde eine stark nationale und antideutsche Haltung durch die lange Tradition des Singens in Dänemark seit Mitte des 19. Jahrhunderts in zahlreichen Gesängen durch die Generationen weitergetragen. Besungen wurde diese Haltung in Liedern wie „Dengang jeg drog af sted“ („Damals, als ich auszog“, 1848) von Peter Faber (1810-1877) oder „Brat af slaget rammet“ („Jäh vom Schlage getroffen“, 1864) von Frederik Paludan-Müller (1809-1876). ${ }^{5}$ Als zentrale und weit verbreitete Sammlung diente das „Folkehøjskole Sangbog“(„Volkshochschul-Liederbuch“), das bis in die Gegenwart zum Inventar jeder dänischen öffentlichen Einrichtung und jedes Privathaushalts gehört. Infolge war der Deutschenhass in Dänemark tief verankert. Das Wort „Preuße“ oder „Tysker“ („Deutscher“) hielt sich bis in die 1920er Jahre als Schimpfwort. ${ }^{6}$

So konnte sich auch der Nationalsozialismus kaum durchsetzen, da er, abgesehen von aller Abgründigkeit seiner Ideologie, in erster Linie ein deutsches ,Produkt war. Aufgrund dessen hatte das „Dritte Reich“ in Dänemark bereits in den 1930er Jahren eine umfangreiche Kulturpropaganda betrieben, indem dänische Vereine und Delegationen zum Besuch nach Deutschland eingeladen wurden, um für ein Klima des Austauschs zu sorgen. Gleichzeitig wurden zusätzliche kulturelle Aktionsmöglichkeiten geschaffen: Konzerte aller Art, u.a. mit Militärorchestern, Kunst- und Kulturausstellungen, Vorträge, Bibliotheken, Informationsbüros und wissenschaftliche Institute. Zahlreiche Bücher und Zeitschriften wurden in Dänemark produziert oder aus Deutschland importiert.

Mit der Besetzung Dänemarks am 9. April 1940 trat die Kulturpropaganda der deutschen Nationalsozialisten in eine neue Phase ein. Die dänischen Medien, die Presse und der staatliche Rundfunk, wurden unter Androhung zensorischer Maßnahmen dazu gedrängt, das Deutschlandbild besonders idealisierend und verklärend darzustellen. Der Gegenwind von Seiten der Dänen war jedoch enorm, so dass von einem „Kulturkampf ${ }^{\star 8}$ gesprochen werden kann. Der Hintergrund ist jener, dass

\footnotetext{
${ }^{4}$ Vgl. Yvonne Wasserloos, Kulturgezeiten. Niels W. Gade und C.F.E. Horneman in Leipzig und Kopenhagen (Hildesheim, Zürich u. New York: Olms, 2004).

${ }_{5}^{5}$ Abgedruckt in Folkehøjskolens Sangbog, hg. von Heinrich Nutzhorn, Ejnar Skovrup und Foreningen for Højskoler og Landbrugsskoler, 14. Aufl.. Odense: Foreningens Forlag, 1959, Nr. 428 und Nr. 441.

${ }^{6}$ Vgl. Aage Trommer, „Das Bild der Deutschen in der illegalen Presse Dänemarks“, in Kultur-Propaganda - Öffentlichkeit, 123-34; $124 \mathrm{f}$.

${ }^{7}$ Vgl. John T. Lauridsen, De danske nazister 1930-45. En forskningsoversigt ([Kopenhagen:] Kongelige Bibliotek, 1995), 63.

${ }^{8}$ Lammers, „Kultur“, 116.
} 
sowohl Identität als auch nationale Eigenständigkeit der dänischen Nation eng mit dem „dänischen Wesen“ verbunden sind. Darauf besannen sich die meisten Dänen während der Krise in der Besatzungszeit zurück. Die Nation galt es nicht nur zu proklamieren, sondern auch zu bewahren. ${ }^{9}$ Die Besatzungszeit in Dänemark 1940 bis 1945 wurde für die dänische Bevölkerung zu einer Phase, in der die Frage der nationalen Identität überlebenswichtig wurde, befand sich ihr Land doch im krisenhaften Zustand infolge der eingeschränkten politischen Souveränität.

In Gedichten und Liedern dieser Zeit wurden nationale Themen in mannigfaltiger Weise ausgedrückt. Die Identifikation mit der dänischen Geschichte, mit Land und Volk wurde damit außerordentlich stark belebt und verbreitet. ${ }^{10}$ Das Singen gewann somit während der Besatzungszeit besondere Bedeutung zum Transport der kollektiven Idee von einem gemeinsamen Schicksal. Eine wichtige Funktion übernahm der Alsang („Gemeinschaftsgesang“), der sich zu einer nationalen Manifestation entwickelte. Bereits in den ersten Kriegsjahren wuchs er zu einem Sammelpunkt für die Gemütslage der Nation heran. Der einzige Programmpunkt der AlsangTreffen bestand aus dem Absingen dänischer Nationallieder, vorwiegend aus dem „Højskolesangbog“. Voraussetzung für diese Alsang-Veranstaltungen war, dass keine aggressiven oder provozierenden Lieder gesungen wurden. Eines der größten AlsangTreffen fand am 1. September 1940 statt. Rund 740.000 Menschen versammelten sich zeitgleich in ganz Dänemark und sangen das populäre Nationallied „Moders Navn er en himmelsk Lyd“ („Der Name der Mutter ist ein himmlischer Klang“) von N.S.F. Grundtvig (1783-1876) in der Vertonung von Henrik Rung (1807-1871).

Der Brutalität der Besatzung wurde mit Gleichmut und nationalem Stolz in Form des Alsang als singendem, kulturellem Protestes begegnet. ${ }^{11}$ Solche Gedichte oder Liedtexte hoben zur Stärkung des dänischen Selbstbewusstseins positive Eigenschaften und Charakterzüge hervor, die als typisch dänisch galten. Vermittelt wurde dies symbolisch über die Schilderung leuchtender, sonniger Landschaften sowie die Idealisierung mythischer Nationalfiguren, beispielsweise Holger Danske, und Legenden als Repräsentanten dänischer Identität. ${ }^{12}$ Während die Rückversicherung dänischer Identität hier zur Strategie der Abgrenzung in der anti-nationalsozialistisch eingestellten Bevölkerung heranwuchs, sollte das Begriffsfeld des als allgemeiner zu verortenden „Nordischen“ für deutsche wie dänische Propagandisten eine inkludierende Funktion übernehmen.

\footnotetext{
${ }^{9}$ Vgl. Thorkild Borup Jensen, „Besættelsenstidens digte og sange som udtryk for national oplevelse og bevisthed", in Dansk Identitetshistorie, hg. von Ole Feldbæk, Bd. 4, 9-391 (Kopenhagen: C.A. Reitzel, 1992), 9-14.

${ }^{10}$ Vgl. Jensen, „Besættelsenstidens digte“, 9-11.

11 „Månedens fokus: Den Danske Sangskat. Edition Wilhelm Hansen“, aufgerufen am 4. November 2013. http://www.ewh.dk/sites/wh150/fokus/fokus04.htm.

${ }^{12}$ Vgl. Jensen, „Besættelsenstidens digte“, $12 \mathrm{f}$.
} 


\section{Das „Nordische“ als Propagandamotor}

Der „Nordische Gedanke“ war Teil der NS-Rasseideologie. Hans F. K. Günther (1891-1968) definierte ihn 1927 in seiner Schrift „Der Nordische Gedanke unter den Deutschen“ als den "Gedanken von der Vorbildlichkeit des gesunden nordischen Menschen für die Auslese im Deutschen Volk. "13 Sprachlich gesehen wird in diesem Sinne „nordisch“ nicht als geographische Bestimmung, sondern als biologisches Qualitätsmerkmal verstanden. Die geographische Verortung Skandinaviens oder Nordeuropas wurde stattdessen mit dem Wort „nordländisch“ bezeichnet. Nachfolgend bezog sich die von den NS-Behörden ausgegeben Definition des Begriffs „,nordische Völker“ auf die skandinavischen Länder Dänemark, Norwegen und Schweden sowie auf die Niederlande und die flämischen Volksgruppen. Hier wurden eine "gemeinsame germanische Abstammung" und eine "Artverwandtschaft" unterstellt, so dass diese Völker den Deutschen besonders nahe stünden. ${ }^{14}$

Bereits in den 1930er Jahren wurde der "Nordische Gedanke" als verbindendes Element zwischen den Völkern von der Nordischen Gesellschaft propagiert, die stark in die Bemühungen zu Verbesserung der deutsch-dänischen Beziehungen involviert war. Die Nordische Gesellschaft hatte sich 1921 in Lübeck zunächst als Verein ohne jegliche politische Ambitionen gegründet und sich der Pflege der wirtschaftlichen und kulturellen Beziehungen zwischen Lübeck und den Ostsee-Anrainerstaaten verschrieben. Nach der raschen Gleichschaltung nach 1933 wurde sie zu einer unter der Führung der NSDAP stehenden, zentralen Stelle zur Verbreitung des „Nordischen Gedankens" umfunktioniert. ${ }^{15}$

Bis 1940 konzentrierten sich die zwischenstaatlichen Aktivitäten der Nordischen Gesellschaft auf kulturelle Veranstaltungen, die vorwiegend im Deutschen Reich und zu einem geringeren Teil in Skandinavien stattfanden. Die Bürger im Reich sollten für den „Nordischen Gedanken“ und nachfolgend für die nordischen Länder, ihre Einwohner und deren Kultur begeistert werden. Andersherum war ebenso die dänische bzw. in einem ausgedehnteren Maße die skandinavische Bevölkerung von Deutschland zu überzeugen. So fanden zahlreiche Zusammenkünfte statt, in erster Linie Vortragsabende mit deutschen oder nordeuropäischen Redner. In den Hochzeiten im Winter 1936/37 sind durchschnittlich zwei bis drei Veranstaltungen pro Tag nachweisbar. ${ }^{16}$ Das zentrale Medium der Gesellschaft war die Zeitschrift „Der

\footnotetext{
${ }^{13}$ Hans F. K. Günther, Der Nordische Gedanke unter den Deutschen (2. umgearb. Aufl. München: J. F. Lehmann, 1927), 30.

${ }^{14}$ Vgl. Birgitta Almgren, Jan Hecker-Stampehl, Ernst Piper, „Alfred Rosenberg und die Nordische Gesellschaft", Nordeuropa-Forum 2 (2008), 43.

${ }^{15}$ Vgl. Hans-Jürgen Lutzhöft, Der Nordische Gedanke in Deutschland 1920-1940 (Stuttgart: Klett, 1971), 55.

${ }^{16}$ Dies ergab eine Durchsicht der Jahrgänge 12 (1935) bis 21 (1944) von Der Norden.
} 
Norden", die 1935 bis 1944 monatlich erschien und der Pflege der wirtschaftlichen und kulturellen Beziehungen mit Nordeuropa dienen sollte. Auch die Propagierung einer mit "nordischen Musik“ definierten Kunstästhetik fand in dieser Zeitschrift statt.

\section{„Nordische Musik“"}

Wie sich „Nordische Musik“ konkret definierte, war selbst aus Richard Eichenauers ,Standardwerk ' „Rasse und Musik ${ }^{\text {“17 }}$ nicht einheitlich logisch herauslesen. Will man die „Nordische Musik“ dennoch auf einige Merkmale festlegen, so seien hier einige Zuschreibungen genannt, die im Musikschrifttum des „Dritten Reiches“ häufiger anzutreffen sind und die sich explizit auf deutsche „nordische“ (im obengenannten Sinne) Komponisten beziehen. Festgestellt wurde, dass „Nordische Musik“ eine tiefgehende Wirkung entfalte, die auf eine unsentimentale Prägnanz und Herbheit mit gleichzeitiger Monumentalität zurückzuführen sei. Das Werk Johann Sebastian Bachs und Ludwig van Beethovens wurde als Prototyp dieser Musik gekennzeichnet. In Bezug auf die „Nordische Musik“ Nordeuropas wurden andere Kriterien zugrunde gelegt. Der Zusammenhang von Komponist und „natürlicher" Umgebung wurde besonders hervorgehoben. Hingewiesen wurde auf die im geographischen Norden allgegenwärtige Präsenz der Natur. Die mit ihr eng verknüpfte Volksmusik oder volkstümliche Musik wurde als hervorstechendstes Charakteristikum der „Nordischen Musik" apostrophiert. ${ }^{18}$

Insbesondere Wilhelm Heinitz (1883-1963), der Haus- und Hof-Musikwissenschaftler der Nordischen Gesellschaft, von dem die meisten Beiträge in „Der Norden“ stammen, trug mit seinem Aufsatz „Musik des Nordens“von 1938 zur Unterscheidung dessen bei, was zuvor als „nordisch“ und „nordländisch“ als trennendes ästhetisches und geographisches Kriterium benannt wurde. ${ }^{19}$ Heinitz forderte die nordeuropäischen Komponisten auf, ein Bekenntnis zur Volkstümlichkeit auch in der Kunstmusik abzulegen, indem die „Größe der schlichten musikalischen Linie [...] einem ehrlichen Volkslied das gleiche Recht gibt wie einer womöglich unehrlichen Sinfonie. " ${ }^{20}$

In den Jahrgängen ab 1940, also mit Beginn der Besatzung in Dänemark und Norwegen finden sich in „Der Norden“ kaum noch Aussagen zum „Nordischen Gedanken“, so dass auch die Propagierung einer „Nordischen Musik“ zumindest von

\footnotetext{
${ }^{17}$ Richards Eichenauer, Musik und Rasse (München: J.F. Lehmann, 1932).

${ }^{18}$ Vgl. Ruth-Maria Gleissner, Der unpolitische Komponist als Politikum. Die Rezeption von Jean Sibelius im NS-Staat (Frankfurt/M.: Peter Lang, 2002), 115.

${ }^{19}$ Wilhelm Heinitz, „,Musik des Nordens‘ oder ,Nordische Musik'?“ Der Norden 15 (1938), 271-78.

${ }^{20}$ Ebd., 276.
} 
Seiten der deutschen Musikforschung unterblieb. Gleichwohl wurde die Propagierung einer rassegleichen Musik nicht ausgesetzt, sondern auf die gegenüberliegende, dänische Seite verschoben. 1943 erschien der Aufsatz „Dänische Musik und Europa“ ${ }^{21}$ des Kopenhagener Musikforschers Tage Wind [Lebensdaten nicht ermittelbar], ${ }^{22}$ der zuvor im Juli 1943 in dänischer Sprache in der Parteizeitung der DNSAP „Fædrelandet“ („Vaterland“) erschienen war. Auch Wind konzentrierte sich ebenso auf das folkloristische Element einer „Nordischen Musik“ des Nordens und unternahm eine Spezifizierung, indem er das dänische Volkslied mit seinem charakteristischen „Ton“ als dänische „Großtat auf dem Gebiet des einstimmigen Liedes“ hervorhob. ${ }^{23}$ Die Definition des "dänischen Tones“ ummantelte er ebenso wie die deutsche NS-Musikpropaganda mit Bildern von Natur und damit assoziierter „Natürlichkeit“. Er betonte, der „dänische Ton“ sei „schwer zu definieren, aber unverkennbar für jeden..., der ihn nur einmal erfaßt hat. Er gleicht keinem andern, er klingt zusammen mit der lichten Buchenpracht unseres Landes und dem sturmgepeitschten, schattenschweren Meer, aber auch mit den sicheren Kennzeichen der nordgermanischen Rasse... “24 Exakt dieser Ansatz, Musik und Natur als „nordisches“ Qualitätsmerkmal zusammenzubringen, ist bei der DNSAP auf dänischer, parteilicher Ebene der Musik-Propaganda zu konstatieren.

\section{Die DNSAP}

Die DNSAP als Imitationspartei der NSDAP wurde am 16. November 1930 infolge der Weltwirtschaftskrise und der Wahlerfolge der NSDAP bei den deutschen Reichstagswahlen von Cay Lembcke (1885-1965) $)^{25}$ gegründet. Von 1933 bis 1944 führte sie der Arzt Fritz Clausen (1893-1947) ${ }^{26}$ an. Die DNSAP bekannte sich zu

\footnotetext{
${ }^{21}$ Erstmals erschienen unter dem Titel „Danks Musik og Europa“, Fedrelandet, 27. Juni 1943. In der deutschen Übersetzung: „Dänische Musik und Europa“, Der Norden 20 (1943): 265-69.

${ }^{22}$ Tage Wind, dänischer Musikwissenschaftler, enge Zusammenarbeit mit sowie Vortragstätigkeit bei dänischen Militärmusikeinheiten.

${ }^{23}$ Wind, „Dänische Musik“, 265.

${ }^{24}$ Ebd., 267.

${ }^{25}$ Cay Lembcke, Rittmeister, Gründer des Dänischen Pfadfinderbundes 1910, Gründung der DNSAP am 16. November 1930, „Führer“ der Partei bis zur Übergabe an Clausen am 26. Juli 1933. Lembcke formulierte bei der Gründung der Partei als deren oberstes Ziel den Ausschluss von Frauen aus dem politischen Leben sowie die ,Bereinigung ' Kopenhagens von der ,jüdischen“ Presse.

${ }^{26}$ Frits Clausen stammte aus einer dänischen Familie in der Grenzregion in Nordschleswig und zog auf der Seite des deutschen Heers in den Ersten Weltkrieg. Seit 1924 praktizierte er als Arzt in Bovrup in der Nähe von Aabenraa. 1931 trat er in die DNSAP ein. Durch eine Intrige Clausens wurde Cay
} 
einer gleichartigen antisemitischen Einstellungen und rassistisch geprägter Ideologie wie die deutsche Partei. Dazu übernahm sie ebenso die NS-Symbolik, u.a. das Hakenkreuz, den Hitler-Gruß sowie das „Horst-Wessel“-Lied in einer dänischen Neutextierung. Wie der deutsche Nationalsozialismus sich auf Mythen, Tradition und Geschichte zurückzog, um Paradigmen für die Gegenwart zu schaffen, so nutzte die DNSAP ebenso historische Attitüden zur Selbst-Legitimation (s. Abb. 1).

In den ersten Jahren rekrutierten sich die Anhänger und Mitglieder der DNSAP hauptsächlich aus der von der Krise betroffenen Landwirtschaft, während der Okkupation später aus den Arbeitslosen in den größeren Städten, insbesondere Kopenhagen. In der breiten dänischen Bevölkerung entfachte die Partei jedoch wenig Durchschlagskraft, da sie von vornherein als deutscher ,Import' abgelehnt wurde. Bei den dänischen Reichstagswahlen 1935 erhielt sie 16.000 Stimmen (1\% der Wähler), 193931.000 Stimmen (1,8\% der Wähler) und war mit drei Sitzen im dänischen Parlament („Folketinget“) vertreten. Zu diesem Zeitpunkt hatten sich ihr 5.000 Mitglieder angeschlossen. 1.000 waren in die dänische SA eingetreten. Während der Besatzungszeit erreichte die Partei-Mitgliederzahl 1943 mit ca. 21.000 Personen ihren Höchststand, was vergleichsweise wenig war. ${ }^{27}$ Aus den Parlamentswahlen am 23. März 1943 ging die DNSAP geschwächt hervor. Zwar erreichte sie 43.000 Stimmen und damit 4.000 mehr als zuvor, jedoch war gleichzeitig die Wahlbeteiligung von 79 Prozent auf 90 Prozent gestiegen. ${ }^{28}$ Clausen wurde danach als, Führer' abgesetzt und an die Ostfront geschickt. Die Besetzung Dänemarks am 9. April 1940 wurde von der DNSAP unterstützt. Im Gegensatz zur Besatzungspolitik der Deutschen in Norwegen und auch in den Niederlanden sollte die DNSAP zunächst nicht unmittelbar, sondern nach Kriegsende an der Regierung beteiligt werden. Dennoch erhielt die Partei von deutscher Seite politische Unterstützung durch die Finanzierung der täglich erscheinenden Parteizeitung „Fædrelandet“. ${ }^{29}$ Musik war ein gewichtiger Faktor in der Arbeit der Partei, denn wie auch das deutsche „Vorbild“ unternahm die DNSAP den Versuch, die Bevölkerung durch Faszination für die nationalsozialistische Ideologie zu ,begeistern'. Dabei musste doppelte Überzeugungsarbeit geleistet werden. Wie beschrieben war die dänische Bevölkerung nach dem letzten, verlore-

Lembcke als Parteiführer abgesetzt und durch Clausen ersetzt. Er verschärfte daraufhin die Anlehnung der Partei an das Vorbild der NSDAP. 1944 meldete er sich als Arzt zur Waffen-SS.

${ }^{27}$ Zahlen nach „Danmarks Nationalsocialistiske Arbejderparti“, aufgerufen am 4. November 2013. http://danmarkshistorien.dk/leksikon-og-kilder/vis/materiale/danmarks-nationalsocialistiskearbejderparti-dnsap sowie Hans Kirchhoff, „Die dänische Staatkollaboration“, in Okkupation und Kollaboration (1938-1945). Beiträge zu Konzepten und Praxis der Kollaboration in der deutschen Okkupationspolitik, hg. von Werner Röhr (Berlin u. Heidelberg: Hüthig, 1994), 101-18; 104.

${ }^{28}$ Vgl. Steen Bo Frandsen, Dänemark - der kleine Nachbar im Norden. Aspekte der deutsch-dänischen Beziehungen im 19. und 20. Jahrhundert. Darmstadt: Wissenschaftliche Buchgesellschaft, 1994, 182.

${ }^{29}$ Vgl. Lammers, „Kultur“, 116. 
nen Krieg 1864 gegen Preußen besonders deutschfeindlich eingestellt. Dies potenzierte sich im Hinblick auf die Deutschen als Besatzungsmacht.

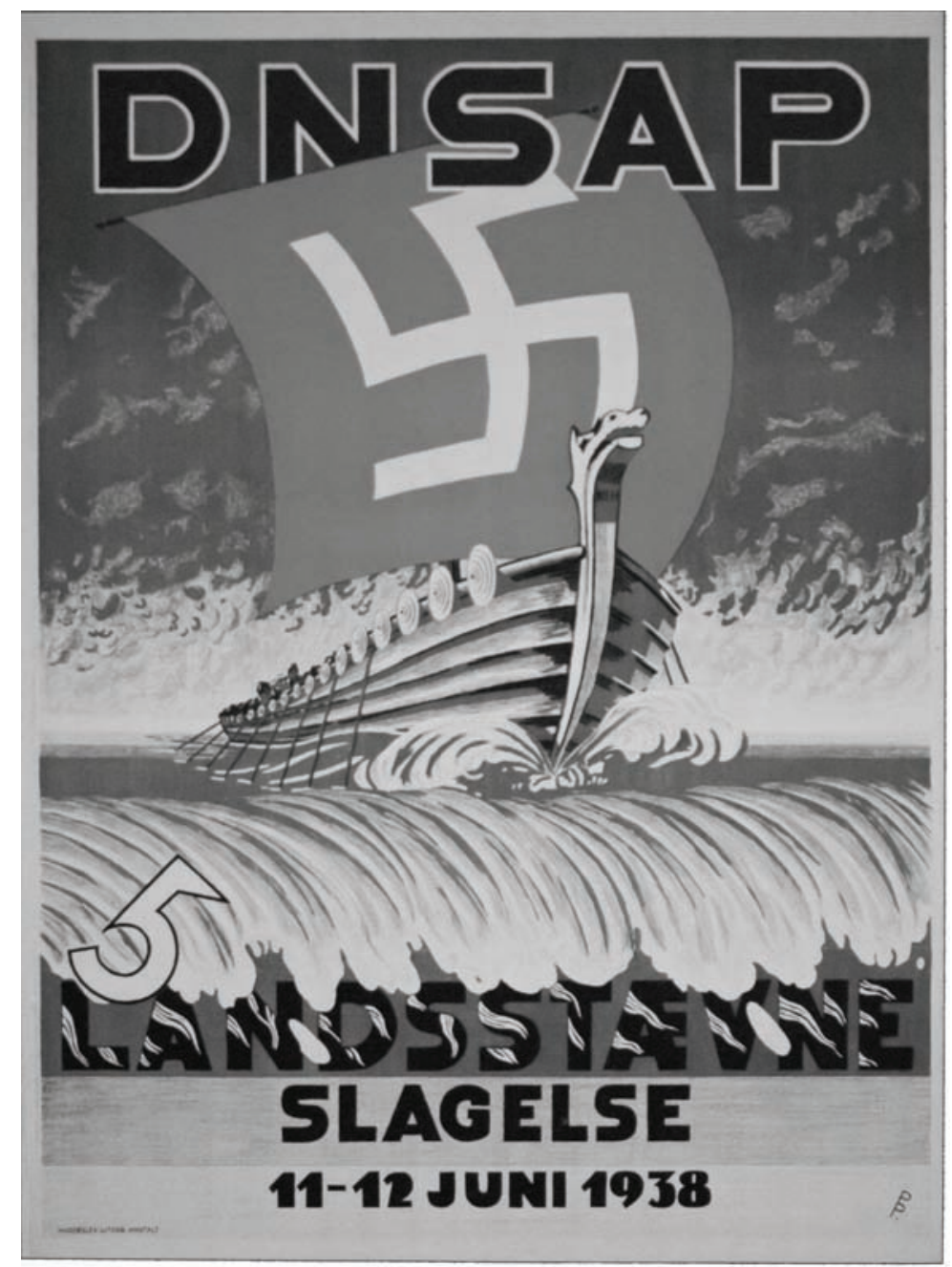

Abbildung 1: Plakat der DNSAP zum 5. Landestreffen der Partei in Slagelse, 1938; Wikimedia Commons

Der Besatzungszustand seit 1940 war für die dänischen Nationalsozialisten ein Zeichen für den Verfall des Landes. Nach ihrer Einschätzung konnte dieser Zustand lediglich bekämpft werden, indem die Dänen einen maßgeblichen Platz in Hitlers „neuem Europa“ einnähmen und aktiv an der neuen „Weltordnung“ und ihrer Realisierung teilhätten. Mit dieser Haltung und der fortdauernden Kritik an der vermeintlich „schwachen“ Regierung wurde die Tatsache verschleiert, dass die Beset- 
zung einseitig durch die Deutschen erfolgt war, die den Nicht-Angriffspakt mit Dänemark gebrochen hatten. Das „Dritte Reich“ sollte nicht als Aggressor verstanden werden; diese Vorgabe hatte in der Propaganda der dänischen Nationalsozialisten höchste Priorität. ${ }^{30}$ Stattdessen setzte die DNSAP auf den Appell an den Nationalstolz der Dänen. Das dies die Befreiung von den deutschen Besatzern bedeuten könnte, wurde nicht thematisiert. Stattdessen erschien in „Fædrelandet“ am Tag der deutschen Okkupation am 9. April 1940 ein Artikel von N. Larsen [Person nicht eindeutig identifizierbar]. Er unterstrich, dass es stets „Brauch der Dänen“ gewesen sei „zu singen“ („Det er de Danskes Sæd at synge“). Der dänische Volksgeist komme zwar in Volks- und Vaterlandsliedern zum Ausdruck, gleichwohl gäben aber erst die Lieder der Nationalsozialisten den Dänen die Zuversicht über die herrliche Wiederauferstehung des Landes: „... wie jede andere völkische Erweckung in den Sinn des Volkes gesungen wird, so soll auch der der dänische Nationalsozialismus hinein gesungen werden, damit er tief eingedrückt in jedes Landsmannes Bewusstsein stehen möge [...] Selbst der trägste Däne muss mitgerissen werden und erkennen, dass der Nationalsozialismus Leben und Stärke bedeutet für ein ratloses und wurzelloses Volk.“"31

\section{Musikpropaganda und Lieder der DNSAP}

Inhaltlich sollte die Musik- und Kulturpropaganda der DNSAP die Wiedererweckung der Nation fördern. In diesem Punkt lehnte sich die DNSAP deutlich an die NSDAP an. Im Parteiprogramm vom September 1933 wurde als oberster Punkt die wirtschaftliche und moralische Wiederrichtung des dänischen Volkes auf der Grundlage nordischer Kultur und Rasse genannt. Unter dem Symbol des Hakenkreuzes werde die Zusammenarbeit mit dem nordisch-germanischen Volk gesucht, mit dem die Dänen durch das „Band des Blutes verbunden“ seien (,...til hvilke vi er knyttet med Blodets Baand"), hieß es dort. ${ }^{32}$ In Gedichten und Liedern wurde die Vorstellung vom Geltungsdrang der dänischen Nation verkündet und verbreitet. Zugrunde lag die Notwendigkeit einer rassenreinen, disziplinierten und handlungsfähigen „Volksgemeinschaft“, die mit Begeisterung und Respekt nach der eigenen

\footnotetext{
${ }^{30} \mathrm{Vgl}$. Jensen, „Besættelsenstidens digte“, 322.

${ }^{31}$ Artikel von N. Larsen in Fadrelandet, 9. April 1940. „... som enhver anden folkelig Vækkelse er sunget in i Folkets Sind, saaledes skal ogsaa den danske National-Socialisme synges ind, saa den staar dybt prentet i hver eneste Landsmænds Bevisthed [...]. Selv den mest lunkne Dansker maa rives med og erkende, at Nationalsocialismen er Liv og Styrke til et raad- og rodløst Folk."

32 "Frits Clausen: Danmarks Nationalsocialistiske Arbejderpartis Partiprogram, September 1933. Danmarks Historien“, aufgerufen am 4. November 2013. http://danmarkshistorien.dk/leksikon-ogkilder/vis/ materiale/danmarks-nationalsocialistiske-arbejderpartis-partiprogram-1933.
} 
Kulturtradition und nationalen Voraussetzungen leben würde. Besonders durch Lieder sollten die Dänen lernen, ihr „Land und ihre Kultur zu lieben“ (, at elske deres Land og Kultur") und sich darüber bewusst werden, dass sie eine „Erbe zu heben hätten“ („en Arv at løfte“), wie es häufig in den Proklamationen der Partei hieß. ${ }^{33}$

Es war sicherlich dem Parteiführer Frits Clausen geschuldet, dass Musik in der DNSAP einen außergewöhnlich hohen Stellenwert besaß. In seinen Memoiren hielt Clausen eine Begebenheit aus den 1920er Jahren in Bovrup fest. Laut derer sei es ihm gelungen, relativ einfach einen vormals deutsch-gesinnten deutschen Beamten durch Musik für eine ausgesprochen dänische Einstellung zu gewinnen. ${ }^{34}$ Darf diese so eindeutige Durchschlagskraft auch bezweifelt werden, so ist dennoch zu konstatieren, dass der Laien-Violinist Clausen sich zumindest der Wirkungen von Musik durchaus bewusst war.

Dem deutschen Vorbild entsprechend unternahm die DNSAP den Versuch, die Bevölkerung durch Musik zu manipulieren. Auch sollten die eigenen Mitglieder nach dem Willen der Parteidoktrin geformt werden. Um diese Stärke dem eigenen Volk vor Augen zu führen, griffen die dänischen Nationalsozialisten in ihren Liedern auf die Vergangenheit zurück. Darin sollten die Dänen ihre Kulturtradition erkennen und ihre Bedeutung schätzen lernen. Aus Tradition wiederum sollte die Kraft und Stärke für eine glorreiche Zukunft erwachsen. ${ }^{35}$

Seit 1933 erschienen Liedersammlungen, wie etwa das "Sangbog for NationalSocialister („Liederbuch für Nationalsozialisten“, 1933) oder „Den brune Sangbog“ („Das braune Liederbuch“, 1934 und 1937). Enthalten sind darin überwiegend populäre dänische Volks- und Nationallieder des 19. Jahrhunderts, die entweder neu textiert oder in einem anderen, nationalsozialistischen Kontext gebraucht und interpretiert wurden. Dieses Muster wurde während der Besatzungszeit fortgesetzt, wie sich in den beiden wichtigsten Liederbüchern von 1942, dem „Frikorps Danmarks Sangbog“ („Liederbuch des dänischen Freikorps“) und dem „NSU ${ }^{36}$ Sangbog“ („Liederbuch der NSU“), erkennen lässt. Angereichert wurden diese Sammlungen mit Liedern, die auch im Vorrat des Alsang zu finden sind sowie traditionsreiche Hymnen von besonderer nationalistischer Begeisterung und starkem martialischen und visionären Charakter. Eine Besonderheit, die in der deutschen NS-Partei nicht existierte, stellte der hauseigene Musikverlag der dänischen Partei dar: „DNSAP's Musikforlag“. Die Produktion des Verlags hielt sich vermutlich jedoch in Grenzen.

\footnotetext{
${ }^{33}$ Zit. nach Jensen, „Besættelsenstidens digte“, 321.

34 "Føreren har ordet!" Frits Clausen om sig selv og DNSAP, hg. v. John T. Lauridsen (Kopenhagen: Museum Tusculanums Forlag, 2003), 161.

${ }^{35} \mathrm{Vgl}$. Jensen, „Besættelsenstidens digte“, 323.

${ }^{36}$ Nationalsocialistisk Ungdom, („Nationalsozialistische Jugend“), 1932 gegründetes, dänisches Pendant zur deutschen Hitler-Jugend.
} 
Nachweisbar sind lediglich drei Ausgaben, wovon zwei 1942 erschienen und eine undatiert ist. ${ }^{37}$

Eine neue Phase in der Musikpropaganda der Partei läutete das Schaffen des Komponisten Karl A. Vøttrup [Lebensdaten nicht ermittelbar] ein. In Ergänzung zu den bereits erwähnten Liederbüchern entstanden durch Vøttrup geschaffene Neukompositionen. Damit stützte die Partei sich nicht nur mehr auf die traditionellen Lieder und deren Neutextierung, sondern nutzte kontextungebundene Musik. Dies deutet darauf hin, dass die Durchschlagkraft der Liederbücher vermutlich schwach war und neue Wege zur Überzeugung der Bevölkerung begangen werden sollten. Der anscheinend geringe Produktionsgrad mit nur drei nachweisbaren Ausgaben im parteieigenen Verlag lässt jedoch ebenso vermuten, dass auch sie entweder wenig Resonanz fanden und/oder dass sie finanziell schlichtweg zu kostspielig waren. Dennoch lassen sich aufschlussreiche Rückschlüsse auf die Art der Propaganda durch Musik ziehen, weshalb die Ausgabe „Dansker-Sange“ („Lieder der Dänen“) und das darin enthaltene „Solhvervs-Sang“ („Sonnenwend-Lied“) von Laurits Skov $\left({ }^{*} 1900\right)$ und Vøttrup eingehender betrachtet werden soll.

\section{Laurits Skov}

Der im Jahr 1900 geborene Laurits Skov galt als Gelegenheitsdichter und ,Hauspoet der DNSAP, der im ersten Jahr der Besatzung täglich Gedichte in „Fædrelandet“ publizierte. Der Inhalt seiner Verse war meist aufmunternden und ermahnenden Charakters, versehen mit Kommentaren zur aktuellen Situation. Häufig benutzte er in seinen Gedichten einen kommandohaften Ton und bezog Bilder und Symbole aus dem Soldatenleben mit ein. Diese Art von Sprachgebrauch sollte der Mobilisierung der Dänen und der Erweckung nationaler Tatkraft dienen. ${ }^{38}$ Das mystische, heroische und visionäre Dänemarkbild, das Skov evozierte, entsprach der bevorzugten Version der DSNAP. Um die Verbundenheit Dänemarks mit dem Norden als Wurzel und Grundlage für eine glorreiche Zukunft zu unterstreichen, benutzte der Dichter häufig altnordisch klingende Verse mit ihrem typischen stark akzentuierten Rhythmus. Dies entsprach der Vorstellung der dänischen Nationalsozialisten von der nordischen Urkraft als deren wahre Erben sie sich betrachteten.

\footnotetext{
${ }^{37}$ Lange Schmidt, Fr., Nu er gryet paa vej over vang [für Gesang und Klavier]. Kopenhagen und Bovrup: DNSAP's Musikforlag (undatiert); Skov, Laurits/Vøttrup, Karl A., Dansker-Sange [für Gesang und Klavier]. Kopenhagen und Bovrup: DNSAP's Musikforlag 1942; Skov, Laurits/Vøttrup, Karl A., Minde-Runer. Recitativ og Kor. Den danske Dåds Døde til Minde [für vierstimmigen Männerchor und vier Luren. [Enthält eine deutsche Übersetzung aus dem Dänischen von Louis von Kohl]. Kopenhagen und Bovrup: DNSAP's Musikforlag, 1942.

${ }^{38} \mathrm{Vgl}$. Jensen, „Besættelsenstidens digte“, 326.
} 
Auch die Rassenlehre sowie die „Blut- und Boden-Ideologie“ des deutschen Nationalsozialismus ist bei Skov wiederzufinden. Beispielsweise schilderte er in „Korstog i Norden“39 („Kreuzzug im Norden“, 1941) zunächst den Kampf zwischen den „Kimbern und Germanen“, d.h. mit „Blondhaarigkeit“ und Größe assoziierten Volksstämmen. Diese fänden sich dann in den Dänen und Deutschen wieder, die vereint für „Blut und Boden“ („for Blodet og for Jorden“) zum Wohl der Zukunft dieser Geschlechter und für das „Recht der Rasse auf den Norden“ („for Racens Ret til Norden“) kämpften. Skovs Gedicht kann als Versuch einer Rechtfertigung von Hitlers Russland-Feldzug, des Beitritts Dänemarks zum Antikomintern-Pakt und der Gründung des Frikorps Danmark („Freikorps Dänemark“) interpretiert werden. Besonders dieses Freikorps betrachtete die DNSAP als dänischen Beitrag zur Unterstützung der aggressiven Eroberungspolitik Hitlers. In „Korstog i Norden“ herrscht daher durchgängig das Lob an den stolzen Eroberungswillen und das Expansionsstreben vor, was mit den ,wahren' deutsch-dänischen Eigenschaften gleichgesetzt wird.

\section{Karl A. Vøttrup}

Über den Komponisten Karl A. Vøttrup ist kaum etwas bekannt. Zu konstatieren ist lediglich, dass er im Rahmen der Aktivitäten für die DNSAP häufig mit Laurits Skov zusammenarbeitete. Darüber hinaus unterstützte Vøttrup seit 1942 die verwundeten Soldaten in einem Kopenhagener Feldlazarett. Er war nicht der einzige Künstler, der sich damit im Krieg engagierte. Zahlreiche weitere dänische Kulturschaffende wie die Opernsängerin Ellen Laub, der Opernsänger Alfred Møller, der Museumsinspektor Poul Schwenesen, die Balletttänzerin Eva Munck und der Dichter Carl V. Jensen [Lebensdaten aller genannten Personen nicht ermittelbar] folgten seinem Beispiel. In der illegalen Presse der dänischen Freiheitsbewegung wurde vor Vøttrup gewarnt und sein Verhalten als Verrat an den dänischen Interessen angeprangert. ${ }^{40}$

Seine Kompositionen sind überwiegend schlicht gehalten und entsprechen dem Charakter der Lieder, die auch in den Gesangbüchern der dänischen Volkshochschulbewegung enthalten sind. Der durchweg syllabische und homophone Satz kommt der Textverständlichkeit zugute, die im Vordergrund der Propagandalieder zu stehen hatte.

\footnotetext{
${ }^{39}$ Skov, Laurits, „Korstog i Norden“, Jul i Norden 1941 (Jahrbuch der DNSAP).

${ }^{40}$ Verlautbarung des DNSAP-Pressedienstes vom 24. November 1942 über den Einsatz von Künstlern im Krieg, abgedruckt in „Kunstnere, som vi bør undgaa“, De frie Danske 1942, Nr. 2, 2.
} 


\section{Solhvervs-Sang (Laurits Skov/Karl A. Vøttrup)}

Solhvervs-Sang

1. Den mørke Jord blev atter lys

For Solen kom tilbage.

Den bange Sjæl blev fri for Gys

- Det gaar mod Lysets Dage.

2. Vor gamle Tro paa Solens Magt

Blev ikke gjort til Skamme

Paa ny staa Lyset tro sin Vagt

Om Nordens gamle Stamme.

3. Hvor kernedansk at tænke paa

At Lyset er vor Fælle

Hvert Gry skal Mørket tavst forgaa

Bag Hjulets gyldne Vælde.
Sonnenwend-Lied

1. Die dunkle Erde wurde wieder hell

Als die Sonne zurückkehrte.

Die ängstliche Seele wurde von Schaudern befreit

Die mit dem Licht des Tages verschwinden.

2. Unser alter Glaube an die Macht der Sonne

Wurde nicht zur Schande.

Aufs Neue steht das Licht treu seine Wacht

Über des Nordens alte Stämme

3. Wie echt dänisch es ist, darüber nachzudenken,

dass das Licht unser Gefährte ist.

Jedes Morgengrauen soll das Dunkel still vertreiben

Hinter des Rades goldene Macht.

4. Ja, erhebt mit Freude deine dänische Stimme

Und preiset das ewige Wunder

Auf s Neue geht die Sonne im Osten auf

Und heilt die Wunden der Welt!

„Solvhervs-Sang“ erschien 1942 in der kleinen Sammlung „Dansker-Sange“. Enthalten ist in dieser Ausgabe mit „Vugge-Vise“ („Wiegenlied“) ein weiteres von Skov und Vøttrup vertontes Lied. Der Titel „Solvhervs-Sang“ mit dem Verweis auf die Sonnenwende bezieht sich direkt auf ein zentrales Bild. Einerseits wird damit ein Wendepunkt oder eine Art Aufbruchstimmung angedeutet, andererseits wird ein direkter Bezug zum deutschen Nationalsozialismus hergestellt. Die Sonnenwende, d.h. die Sommersonnen- oder auch die Wintersonnenwende wurden nach altgermanischem Brauch durch große Feste begangen und im „Dritten Reich“ als offizielle Gedenktage geführt. Damit sollte, der NS-Ideologie folgend, der Einklang mit der Natur besonders hervorgehoben werden.

Der Aspekt der Natur spielt auch in „Solhvervs-Sang“ die zentrale Rolle. In herausragender Weise kommt im Text das Symbol des Strahlens durch die Worte 
„Licht“ („Lys“) und „Sonne“ („Sol“) vor. Dies verweist direkt auf die Gedichtsammlungen der zeitgenössischen dänischen Dichter, die nicht in Verbindung mit der DNSAP standen, wie Mogens Lorentzen (1892-1953), Hans Hartvig Seedorff Pedersen (1892-1986), Kai Hoffmann (1874-1949), Axel Juel (1883-1948) und Søren Hallar (1887-1950). In ihrer Lyrik wird mit ganz ähnlichen Elementen Nationalstolz heraufbeschworen: Dänemark wird stets als das Land des Sonnenscheins und des Sommers gepriesen und somit poetisch idealisiert. ${ }^{41}$

Die Schilderung der Landschaft war für die dänischen Lieder während der Besatzungszeit prägend. Im Lobpreis der Schönheit und Vielfalt des Landes sollte auf dänische Qualitäten und Vorzüge geschlossen werden. Die Darstellung teilt sich in zwei Themenfelder. Das erste schildert Dänemark als das ewige Land des Sommers und des Glücks. Der zweite große Gedankenbogen besteht aus Beschreibungen der Landschaft und der Witterung, die die Hoffnung auf eine baldige Besserung und Lösung thematisieren. Damit wird die baldige Befreiung antizipiert und symbolisch der Zustand der dänischen Gesellschaft und des Volkes beschrieben. Die Schilderung der dänischen Landschaft fungiert damit nicht nur als Huldigung, sondern auch als die Vision auf die bevorstehende politische Wende. Besonders in den Neujahrs- und Frühjahrsgedichten der Besatzungszeit, darunter auch das populäre Freiheitslied „En Vinter, lang og mørk og haard“ (Sven Møller Kristensen, 1900-1991/Knudåge Riisager, 1897-1974) („Ein Winter, lang, dunkel und hart“), kommt dieser symbolische Anspruch der dänischen Landschaft zum Vorschein. ${ }^{42}$ Exakt jenes Bild von der Strahl- und Wachstumskraft des Nordens unter der ,nationalsozialistischen Sonne schildert Skov in „Solhvervs-Sang“. Darauf deutet bereits die durch den Sonnenaufgang verklärte Idylle auf dem Titelbild hin (Abbildung 2).

Auffällig ist im Liedtext ebenso der Rückbezug auf die „alten Stämme des Nordens". Auch in den antinationalsozialistischen Liedern spielte die begeisterte Betonung der Zugehörigkeit der Dänen zum übrigen Norden eine große Rolle. Der „Norden“ wurde als zusammenhängendes Gebilde der Länder Dänemark, Schweden, Norwegen, Finnland und Island verstanden. Das Schlagwort von der „Nordischen Gemeinschaft" war in den Jahren der Besatzung allgegenwärtig. Auch Frits Clausen unterstrich in seinen Reden permanent die Inspiration aus der gemeinsamen nordischen Mythologie. Im Herbst 1940 erging bereits der Aufruf zur Sammlung von Freiwilligen aus Dänemark, Norwegen und dem Deutschen Reich in die SSStandarte „Nordland“. Danach wurde das „Frikorps Danmark“ errichtet, das Hitlers Russland-Feldzug unterstützte. Laurits Skov dichtete in „Hilsen til Frikorps Danmark" 1942, das jedes Land, das den „germanischen Waffengurt“ („Germaners Vaaben-Bælte") trage, dem Norden in Ewigkeit Saat und Wachstumskraft geben wür-

\footnotetext{
${ }^{41}$ Vgl. dazu die Ausführungen bei Jensen, „Besættelsenstidens digte“, 207-28.

${ }^{42}$ Vgl. ebd., 244.
} 
de. ${ }^{43}$ In „Solhvervs-Sang“ erfolgt ein weiterer Rückbezug auf die „nordischen“ Wurzeln durch die Abbildung eines Dolmens: Diese aus riesigen Steinblöcken errichteten Bauwerke dienten als Grabstätte in der Zeit der Megalithkultur der Jungsteinzeit und der Bronzezeit und sind bis heute in Dänemark zu sehen.

Wesentlich im Text ist jedoch der allgegenwärtige, pseudoreligiöse Gedanke der Erlösung, der vor allem hinter dem Symbol der Sonne steht. Die beiden letzten Zeilen („Paa ny staar Solen op i Øst/Og læger Verdens Vunder!“) beinhalten das Versprechen, die "Wunden der Welt" zu heilen, wobei das Wortspiel der „Wunde“ deutlich den Erlösergedanken trägt. ${ }^{44}$ Der geographische Verweis auf den Osten zeigt den Aktualitätsbezug, indem Hitlers Russland-Feldzug besungen und glorifiziert wird. Im Verhältnis zu diesen überdimensionierten Aussagen und Versprechungen steht die Schlichtheit des Gesang- und Klaviersatzes in einem klaren Kontrast (Abbildung 3). Die Melodie- und Harmonieführung entsprechen einem volksmusikalischen Duktus. Dazu gehören ein geringer Ambitus der Melodie von einer Oktave und leicht singbare Intervalle. Auch die Harmonik bewegt sich ausschließlich in nah verwandten Tonarten. Allein die Tempobezeichnung „Moderato“ verweist auf einen ruhigen und getragenen Charakter des Vortrags.

Darin kommt etwas Pathetisches, Hymnenartiges zum Ausdruck. Die gesamte, berechenbare Anlage des Satzes ist somit eindeutig auf die Deklamation des Textes ausgerichtet, was die syllabische Vertonung unterstreicht. Der Gedanke Vøttrups hinter dieser Komposition war vermutlich jener, in erster Linie den Inhalt des SkovGedichtes zu transportieren, dem sich die Musik unterzuordnen hatte. In einem zweiten Schritt jedoch sollte die eingängige Melodie helfen, den Text besser zu memorieren und emotional zu konnotieren.

\footnotetext{
${ }^{43}$ Gedicht zur Heimkehr des Frikorps Danmark, 8. September 1942, abgedruckt in Jul i Norden. Kopenhagen u. Bovrup: DNSAP's Forlag, 1942.

${ }^{44}$ Im letzten Vers der vierten Strophe wird mit dem dänischen Wort „vunde“ und der Ableitung vom deutschen Wort „Wunde“ gespielt. Dabei handelt es sich um eine ältere Form im Dänischen, die vom mittelniederdeutschen Wort „Wunde“ stammt. Es wird hier zur Betonung der deutsch-nordischen Einigkeit statt des gebräuchlichen dänischen Wortes „Sår“ benutzt, das insbesondere die Wunden Jesu Christi am Kreuz bezeichnet.
} 


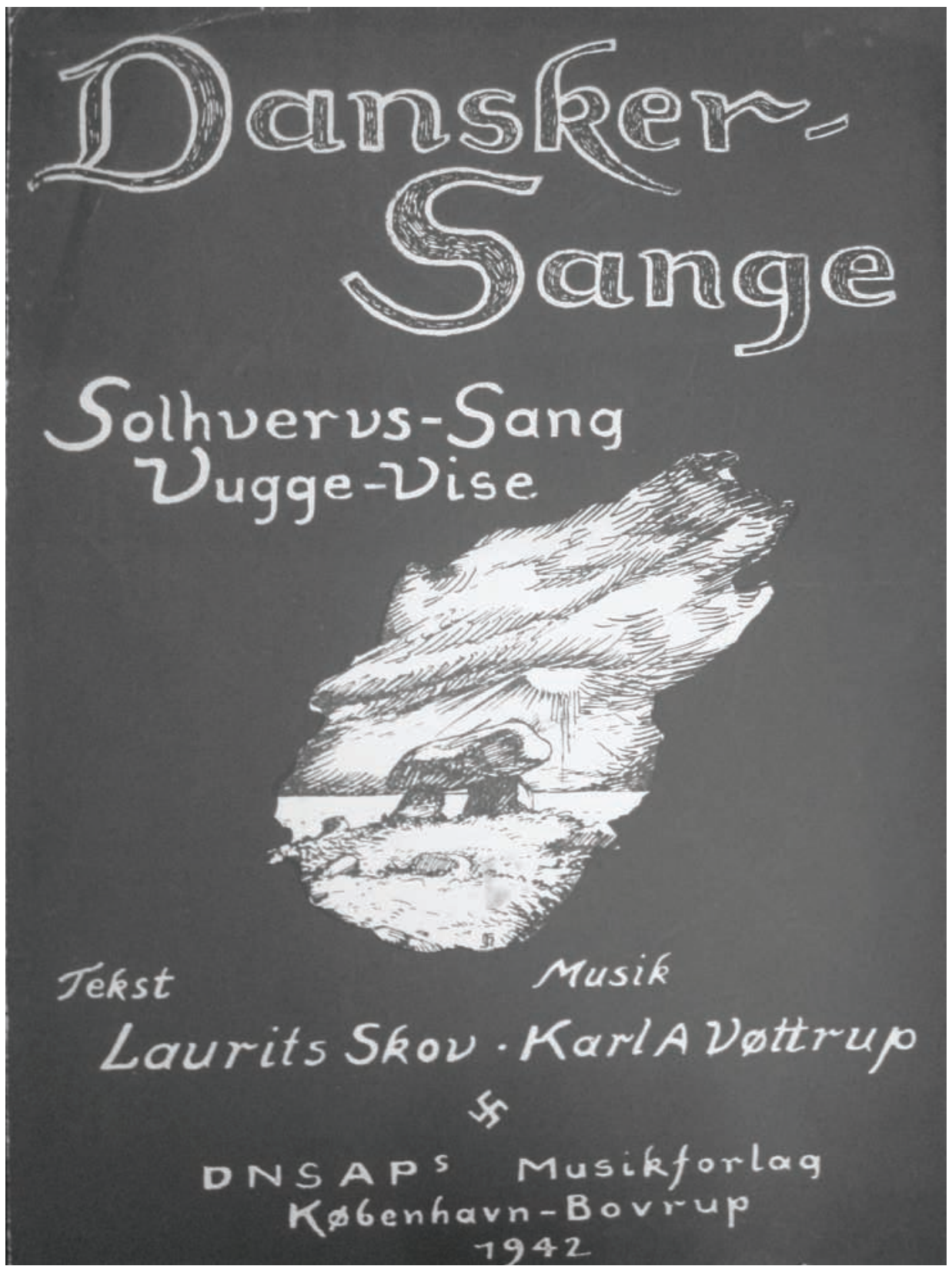

Abbildung 2: Dansker-Sange (Titelblatt), DNSAP's Musikforlag, Kopenhagen und Bovrup 1942; Archiv des Museums des dänischen Widerstands Kopenhagen („Frihedsmuseet København“) 


\section{SOLHVERVSSANG}

Tekst: LAURITS SKOV

Musik: KARL A. VaTtRUP
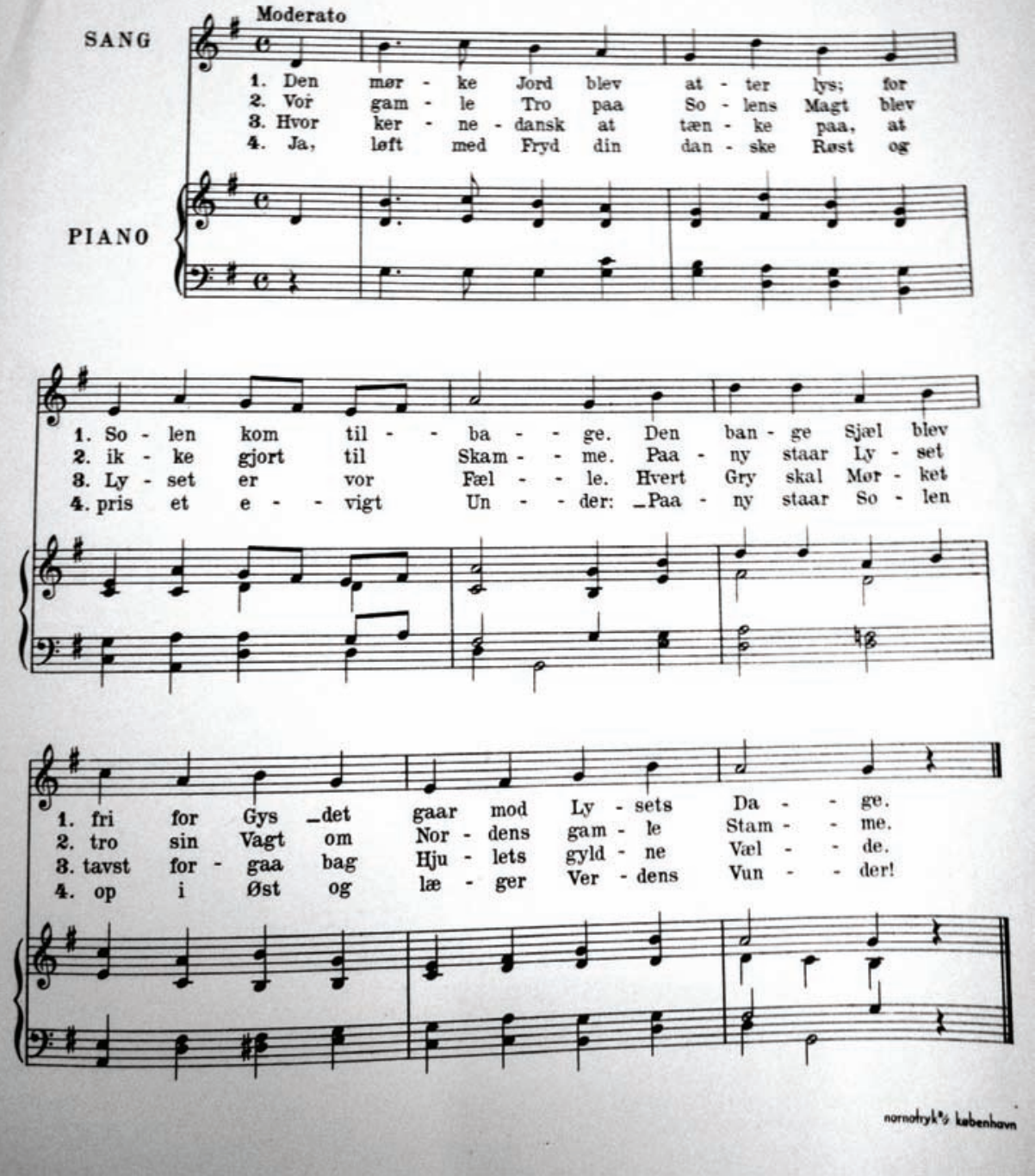

Abbildung 3: Laurits Skov/Karl A. Vøttrup - Solhvervs-Sang (aus: Dansker-Sange, DNSAP's Musikforlag, Kopenhagen und Bovrup 1942; Archiv des Museums des dänischen Widerstands Kopenhagen „Frihedsmuseet København“) 


\section{Politisierung des „Nordischen“}

Der Zweite Weltkrieg wurde zum kulturellen Kampf erklärt, um die besetzten Länder ideologisch wie kulturell zu beherrschen. Vor Kriegsausbruch wurde die Betonung der Verbundenheit zwischen den Völkern durch den „Nordischen Gedanken“ offen und unverhohlen propagiert. Nach der Besetzung Dänemarks wich dieser Aktionismus allerdings einer Zurückhaltung, die sich aus der Kriegspolitik heraus erklärt. Die „Werbung“ für die „Deutschen“ erfolgte nun nicht mehr durch die Besatzungsmacht selbst, da dies angesichts des aggressiven Potenzials der Situation nicht opportun erschien. Stattdessen übernahmen innerdänische, parteiliche Organe diese Vermittlungsarbeit, indem der „Nordische Gedanke“ in die Vorstellung von einer „Nordischen Musik“ eingeschleust und über sie verbreitet werden sollte. Insbesondere das Bild des „Erlösers“ Hitler kommunizierte die Veränderung der propagierten Werte. Nicht mehr die Gemeinschaft infolge des „Nordischen Gedankens“ stand im Mittelpunkt, sondern die direkte Inanspruchnahme der Führerrolle in dieser nordischen Gemeinschaft wurde ausgewiesen und auf die Person Hitlers projiziert.

Die Musikpropaganda der DNSAP lehnte sich eng an das deutsche Vorbild an. Lieder stellten das wesentliche Repertoire um ideologische Inhalte zu verbreiten und die Massen zu mobilisieren. Dazu erfolgte der Rückgriff auf populäre Lieder aus der Sammlung der Volkhochschul-Liederbücher, die mit neuen Texten versehen oder in einen anderen Kontext gestellt wurden. Das Phänomen der Natur und deren Erscheinungen spielte eine wesentliche Rolle, um das „Nordische“ transportieren zu können. Die von Tage Wind applizierte Vorstellung des der Natur entspringenden „dänischen Tons“ sollte sich als Klangmerkmal herausschälen und nachfolgend identitätsstiftend wirken.

Erstaunlich war, dass die dänische NS-Partei einen eigenen Musikverlag gründete, um selbstständig Werke in Auftrag zu geben und publizieren zu können. Prinzipiell änderte sich in Art und Stil der Kompositionen und der Textinhalte wenig im Vergleich zu jenen in den Liederbüchern der frühen 1930er Jahre. Vermutlich war es das Ziel, Lieder zu benutzen, die nicht mit anderen Zusammenhängen konnotiert waren, um dafür neue „Ideen“ bzw. eine konkret diffamierende Rassenideologie installieren und transportieren zu können. Dies sollte mit modifizierten, statt mit vertrauten Mitteln geschehen. Dieser Vorgang zeigt etwas von den hohen Ambitionen der dänischen Nationalsozialisten, um sich im eigenen Land und gegen den Deutschenhass durchzusetzen. Vor diesem Hintergrund wurden sowohl die Idee von der Nation als auch die Mechanismen zur Sicherung der Nation infolge der Vereinnahmung durch den dänischen Nationalsozialismus zu rassistischen Zwecken pervertiert.

Wie aber die oben genannten Wahlergebnisse der DNSAP bereits angedeutet haben, funktionierte der Hebel, NS-Propaganda durch Musik zu betreiben, um die Bevölkerung zu vereinnahmen, kaum. Der Missbrauch von Musik zu ideologischen 
Zwecken wurde durch das Gegenmodell des dänischen Alsang absorbiert. Im gemeinschaftlichen Singen jener Lieder, die auch die DNSAP zu funktionalisieren suchte, kam so etwas wie stummer Protest gegenüber der deutschen Besatzungsmacht und den dänischen Nationalsozialisten zum Ausdruck. Darin stärkten die Dänen ihr Selbstbewusstsein und stellten sich damit der geplanten Vereinnahmung durch den deutschen wie dänischen Nationalsozialismus entgegen. Die Lieder über Dänemark erreichten somit eine rituelle Bedeutung für das Aufleben des Gemeinschaftsgedankens und damit zur Stiftung von Identität.

\section{Literatur}

Almgren, Birgitta, Jan Hecker-Stampehl, Ernst Piper. „Alfred Rosenberg und die Nordische Gesellschaft“. Nordeuropa-Forum 2 (2008): 7-51.

„Danmarks Nationalsocialistiske Arbejderparti“. Aufgerufen am 4. November 2013. http://danmarkshistorien.dk/leksikon-og-kilder/vis/materiale/danmarks -nationalsocialistiske-arbejderparti-dnsap.

Eichenauer, Richard. Musik und Rasse. München: J.F. Lehmann, 1932.

Folkehøjskolens Sangbog, hg. von Heinrich Nutzhorn, Ejnar Skovrup und Foreningen for Højskoler og Landbrugsskoler, 14. Aufl., Nr. 428 und Nr. 441. Odense: Foreningens Forlag, 1959.

Frandsen, Steen Bo Frandsen. Dänemark - der kleine Nachbar im Norden. Aspekte der deutsch-dänischen Beziehungen im 19. und 20. Jahrhundert. Darmstadt: Wissenschaftliche Buchgesellschaft, 1994.

„Frits Clausen: Danmarks Nationalsocialistiske Arbejderpartis Partiprogram, September 1933. Danmarks Historien“. Aufgerufen am 4. November 2013. http://dan-markshistorien.dk/leksikon-og-kilder/vis/materiale/danmarksnationalsocialistiske-arbejderpartis-partiprogram-1933.

"Føreren har ordet!" Frits Clausen om sig selv og DNSAP, hg. von John T. Lauridsen. Kopenhagen: Museum Tusculanums Forlag, 2003.

Gleissner, Ruth-Maria. Der unpolitische Komponist als Politikum. Die Rezeption von Jean Sibelius im NS-Staat. Frankfurt/M.: Peter Lang, 2002.

Günther, Hans F. K. Der Nordische Gedanke unter den Deutschen, 2. umgearb. Aufl. München: J. F. Lehmann, 1927.

Heinitz, Wilhelm. „Musik des Nordens' oder ,Nordische Musik'?“, Der Norden 15 (1938): 271-78. 
Jensen, Thorkild Borup. „Besættelsenstidens digte og sange som udtryk for national oplevelse og bevisthed“. In Dansk Identitetshistorie. Bd. 4., hg. von Ole Feldbæk, 9-391. Kopenhagen: C. A. Reitzel, 1992.

Jul i Norden. Kopenhagen u. Bovrup: DNSAP’s Forlag, 1942.

Kirchhoff, Hans. „Die dänische Staatkollaboration“. In Okkupation und Kollaboration (1938-1945). Beiträge zu Konzepten und Praxis der Kollaboration in der deutschen Okkupationspolitik, hg. von Werner Röhr, 101-18. Berlin und Heidelberg: Hüthig, 1994.

„Kunstnere, som vi bør undgaa“, De frie Danske 1942, Nr. 2, 2.

Lammers, Karl Christian. „Kultur- und Kunstpolitik in Dänemark“. In Kultur Propaganda - Öffentlichkeit. Intentionen deutscher Besatzungspolitik und Reaktionen auf die Okkupation, hg. von Wolfgang Benz, Gerhard Otto und Annabella Weismann, 105-20. Berlin: Metropol-Verlag, 1998.

Lange Schmidt, Fr. Nu er gryet paa vej over vang [für Gesang und Klavier]. Kopenhagen und Bovrup: DNSAP's Musikforlag (undatiert).

Larsen, N. Fedrelandet, 9. April 1940.

Lauridsen, John T. De danske nazister 1930-45. En forskningsoversigt. [Kopenhagen:] Kongelige Bibliotek, 1995.

Lutzhöft, Hans-Jürgen. Der Nordische Gedanke in Deutschland 1920-1940. Stuttgart: Klett, 1971.

„Månedens fokus: Den Danske Sangskat. Edition Wilhelm Hansen“. Aufgerufen am 4. November 2013. http://www.ewh.dk/sites/wh150/fokus/fokus04.htm.

Skov, Laurits. „Korstog i Norden“, Jul i Norden 1941 (Jahrbuch der DNSAP).

Skov, Laurits, Karl A. Vøttrup. Dansker-Sange [für Gesang und Klavier]. Kopenhagen und Bovrup: DNSAP's Musikforlag 1942.

— Minde-Runer. Recitativ og Kor. Den danske Dåds Døde til Minde [für vierstimmigen Männerchor und vier Luren. [Enthält eine deutsche Übersetzung aus dem Dänischen von Louis von Kohl]. Kopenhagen und Bovrup: DNSAP‘s Musikforlag, 1942.

Trommer, Aage. „Das Bild der Deutschen in der illegalen Presse Dänemarks“. In Kultur - Propaganda - Öffentlichkeit. Intentionen deutscher Besatzungspolitik und Reaktionen auf die Okkupation, hg. von Wolfgang Benz, Gerhard Otto und Annabella Weismann, 123-34. Berlin: Metropol-Verlag, 1998. 
Wasserloos, Yvonne. Kulturgezeiten. Niels W. Gade und C.F.E. Horneman in Leipzig und Kopenhagen. Hildesheim, Zürich u. New York: Olms, 2004.

Wind, Tage. „Dänische Musik und Europa“. Der Norden 20 (1943): 265-69. 


\section{„Was ließen jene, die vor uns schon waren...?“ Musik in der Bündischen Jugend nach 1945}

Simon Nußbruch (Hamburg)

Früher oder später stellt sich für manche Eltern die Frage, ob sie ihr Kind bei den Pfadfindern oder einer ähnlichen Organisation mitmachen lassen sollen. ${ }^{1}$ Dabei ist es in Deutschland gut möglich, dass sich die in Frage kommende Gruppe mit dem Adjektiv „bündisch“ belegt, was gemeinhin bedeutet, dass sich diese Gruppe auf die deutsche Jugendbewegung (Wandervogel, Freideutsche Jugend, Pfadfinder, Jungenschaften) bezieht, und damit in einer inzwischen über 100jährigen, kontinuierlichen Tradition steht ${ }^{2}$ Bis 1945 ist das Phänomen der deutschen Jugendbewegung außerordentlich reichhaltig dokumentiert; ${ }^{3}$ u.a. fasst Walter Laqueurs Studie „Die deut-

\footnotetext{
${ }^{1}$ Der Vortrag, auf dem der vorliegende Text basiert, fasste die Ergebnisse einer Magisterarbeit aus dem Jahre 2011 zusammen, welche Ausgangspunkt und Grundlage eines aktuellen Dissertationsprojekts darstellt. Der Text hebt dabei besonders einen Punkt der vorgestellten Untersuchung hervor, in dem durch Quellenkritik und musikalische Werkanalyse aus dem Notentext des Liedes „Was ließen jene“ musikimmanente Traditionslinien der deutschen Jugendbewegung herausgearbeitet werden.

${ }^{2}$ Vgl. z.B. „Deutscher Pfadfinderbund DPB“, aufgerufen am 5. September 2013. http://www.deut scher-pfadfinderbund.de.

${ }^{3}$ Vgl. z.B.: Archiv der deutschen Jugendbewegung (Hg.), Bibliographie zur Geschichte der Jugendbewegung. Quellen und Darstellungen (Schwalbach/Taunus: Wochenschau, 2009).
} 
sche Jugendbewegung " ${ }^{\text { }}$ deren historische Entwicklung gut zusammen: von den Anfängen des Wandervogel um 1900 zur Bündischen Jugend der 1920er Jahre und von da ab, mit einigen Ausnahmen, 1933 ins Jungvolk und die anderen NSJugendorganisationen. Dabei ist auf den ersten Blick besonders um 1933 der Unterschied von Bündischer Jugend und den NS-Jugendorganisationen sowohl morphologisch als auch im Hinblick auf Aktivitäten wie Lager, Fahrten, Gruppenstunden, Geländespiele, und vor allem auf das gemeinsame Singen nicht besonders groß. ${ }^{5}$ Umso erstaunlicher erscheint es daher, daß sich nach dem Zusammenbruch des NSStaates 1945 bis heute eine Vielzahl von Gruppen und Bünden in der Tradition der deutschen Jugendbewegung sieht. Darunter sind einige politisch und weltanschaulich höchst bedenkliche und fragwürdige Gruppierungen wie die rechtsradikale Wikingjugend, oder auch der streng hierarchisch organisierte Nerother Wandervogel. Diese Gruppierungen bilden zahlenmäßig jedoch nur einen sehr kleinen Teil der Bündischen Jugend nach 1945. In der Regel jedoch handelt es sich bei den Mitgliedern dieser Bünde wenn nicht gar um links-alternative, so doch um politisch korrekt einzustufende, vorwiegend junge Menschen. ${ }^{6}$

Auch bei diesen Nachfahren der deutschen Jugendbewegung, der hier so bezeichneten Bündischen Jugend nach 1945, spielt Musik, und vor allem das gemeinsame Singen eine große Rolle. Das äußert sich nicht zuletzt in einem um die 10.000 Lieder umfassenden, spezifischen Liedrepertoire, das sich im Laufe von über hundert Jahren gebildet hat, und das sich bis heute in zahlreichen Liedsammlungen und Liederbüchern niederschlägt. Diese Lieder werden in der Regel auswendig mit Gitarrenbegleitung gesungen, was bedeutet, dass nach bestimmten Vorgaben ausgesuchte Liedtexte und Melodien zu diesem Zweck erlernt und internalisiert werden. Nach bisherigen Forschungsergebnissen zum Themenkomplex Musik in der Bündischen Jugend nach 1945 geht es dabei in erster Linie um die Erzeugung eines gemeinsamen Musikerlebnisses, im Sinne eines Erlebens von Gemeinschaft durch Musik. Dabei wird allgemein die teilweise kritisch zu hinterfragende historische Provenienz der Melodien, Texte und Praktiken in Kauf genommen.

Nun stellte sich vor dem geschilderten geschichtlichen Hintergrund die Frage, warum dieses Phänomen der Musik der Bündischen Jugend nach 1945 vom gesellschaftlichen und wissenschaftlichen Diskurs verhältnismäßig unbeanstandet, bzw.

\footnotetext{
${ }^{4}$ Walter Laqueur, Die deutsche Jugendbewegung. Eine historische Studie (Köln: Verlag Wissenschaft und Politik, 1978).

${ }^{5}$ Vgl. Karin Stoverock, „Bündische Lieder in der Hitler-Jugend“, in Lieder in Politik und Alltag des Nationalsozialismus, hg. von Gottfried Niethart und George Broderick (Frankfurt: P. Lang, 1999), 35-60.

${ }^{6}$ Vgl. z.B. die sogenannte „Mannheimer Resolution“, die am 15. Januar 1993 in der Zeitung Die Zeit als Reaktion auf die fremdenfeindlichen Übergriffe in Hoyerswerda, Rostock und Mölln erschien und von der überwiegenden Mehrheit der bündischen Gruppen und Einzelpersonen unterzeichnet wurde.
} 
speziell von der Musikwissenschaft fast gänzlich unbeachtet bleibt. Zumindest ergab der Forschungsbericht zu dem Thema eine äußerst dünne Ausbeute an einschlägiger Literatur ${ }^{7}$. Angesichts einer hohen gesellschaftlichen Sensibilität in punkto Nationalsozialismus auf der einen Seite und der bis heute uneingeschränkten Popularität, der Menge, Verbreitung und wichtigen Rolle dieser Musik für eine nicht geringe Zahl von Menschen im heutigen Deutschland auf der anderen, erschien das ungewöhnlich und fiel auf. So wäre doch eigentlich zu hinterfragen, wie es möglich ist, dass dieselben jungen Menschen, die tagsüber an einer Demonstration gegen rechte Gewalt teilnehmen, abends mit Fackeln um ein Feuer stehen und Lieder singen, die schon die Hitlerjugend gerne gesungen hat? Welche Rolle spielt dabei die Musik?

Dieser Frage wurde nachgegangen, indem nicht nur die Melodien, Texte und Praktiken, sondern auch Urheber, Entstehung, Entwicklung, Rezeption sowie die äußeren Umstände und diskursiven Bedingungen der tatsächlichen und potentiellen Klangereignisse untersucht wurden. Im Fokus standen hierbei der Zusammenhang von Merkmalen der jugendbewegten Traditionslinien und des heutigen bündischen Selbstverständnisses, die diese Musik bestimmen.

\section{Überblick}

Zu diesem Zweck bot sich die Methode der Liedmonographie eines paradigmatischen Liedes nach den Kriterien an, wie sie im Historisch Kritischen Liederlexikon des DVA in Freiburg zum Einsatz kommen. ${ }^{8}$ Ausgewählt wurde dazu nach Art einer geologischen Bodenprobe das 1962 entstandene Lied „Was ließen jene, die vor uns schon waren", dessen hymnischer und gleichzeitig intimer Charakter in den Kern bündischen Selbstverständnisses zu weisen schien (Vgl. Notenbeispiel 1). So wurden zunächst Autor, Entstehung, Rezeptionsverlauf und Quellen, dann Text und Musik und schließlich die praktische Ausführung des Liedes eingehend untersucht. Dass Was ließen jene ein spezifisch bündisches Lied darstellt, war leicht daran erkennbar, dass

- der Autor ein bekannter und einflussreicher bündischer Liederdichter war;

- das Lied seit seiner Entstehung 1962 allgemein bekannt und beliebt ist und zeitweise gar als Hymne der Bündischen Jugend nach 1945 be-

\footnotetext{
${ }^{7}$ Der Forschungsstand zum Themenfeld Musik in der Jugendbewegung wurde in der hier referierten Magisterarbeit eingehend diskutiert (Simon Nußbruch, ,,,Was ließen jene, die vor uns schon waren“: ein Beispiel für die Musik der Bündischen Jugend nach 1945“ (Magisterarbeit, Universität Hamburg, 2011), 20-34.

8 „Editionskonzept Historisch Kritisches Liederlexikon“, aufgerufen am 30. Juni 2010. http://www. liederlexikon.de/ueber_liederlexikon_de/editkonz.
} 
zeichnet wird, weshalb die Rezeption auch fast ausschließlich innerhalb der Bündischen Jugend stattfindet;

der Text auf die bündische Erlebniswelt zugeschnitten ist und durch die Verwendung spezifischer Codes nur im bündischen Kontext verständlich ist;

die Gestaltung der musikalischen Grundlage typische bündische Merkmale aufweist;

übliche und mögliche Interpretationen ebenfalls ausschließlich auf die Bündische Jugend nach 1945 zugeschnitten sind, nämlich im internen Rahmen, als Einleitung oder Ausklang feierlicher Veranstaltungen oder am Feuerkreis in feierlicher Runde.

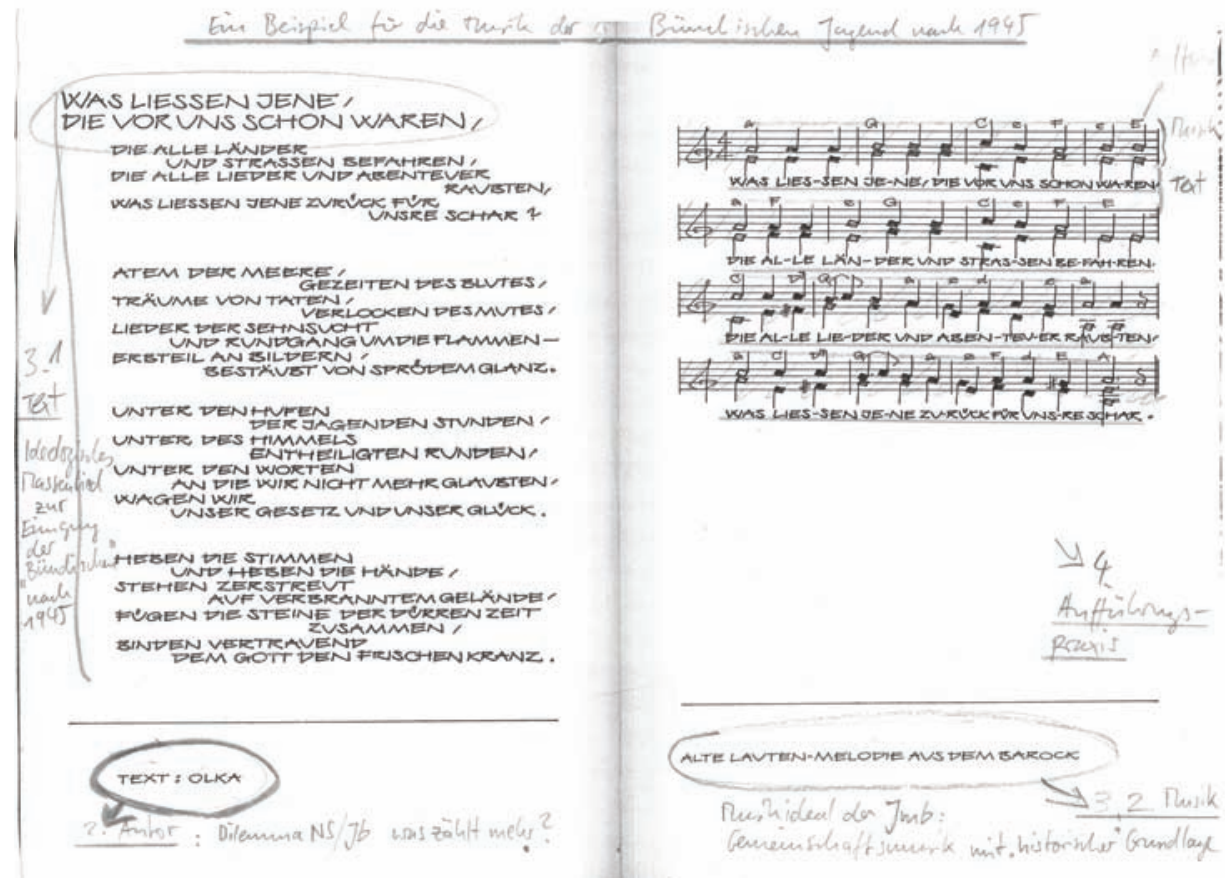

Notenbeispiel 1: Faksimile Scholz 1962 mit hs. Eintragungen S.N.

Das ungute Gefühl, dass sich bei manchem angesichts dieses prominenten Beispiels bündischer Musikpraxis einstellen mag, ist aus mehreren Gründen berechtigt, da sich darin tatsächlich eine Reihe von Überschneidungen und Relationen zum NS nachweisen lässt. Wie sich im Zuge der Arbeit herausstellte, war der Autor zwar Bündischer, aber auch SS-Mann; ist Was ließen jene auch bei politisch am äußersten rechten Rand angesiedelten bündischen Gruppierungen beliebt; 
folgt der Text der dramaturgischen Form eines ideologischen Massenliedes und verwendet zum Teil NS-Metaphorik; rekurriert die musikalische Gestaltung auf verschiedene Weise auf eine während der NS-Zeit populäre Form alter Musik;

sorgen die Ausführung im Feuerkreis und die feierliche Atmosphäre dafür, dass die Musik hier eine rituelle Funktion ähnlich wie bei NSFeierlichkeiten erfüllt.

Für sich genommen wäre zwar keiner der Punkte unbedingt als Bezug zur NSVergangenheit zu werten, und jeder der Punkte wäre für sich genommen erklär-, bzw. entschuldbar. In der Kombination dieser Punkte ist der NS-Zusammenhang jedoch nicht von der Hand zu weisen. Hier liegt auch der eigentliche Kern der Problematik.

Es wäre jedoch ein Kurzschluss, aus diesen Gründen das Lied und damit das Repertoire und die Musikpraxis, in der es eine zentrale Stellung einnimmt, lediglich als kaum verbrämtes Relikt oder gar Ausdruck neonazistischer Gesinnung zu betrachten. Vielmehr dient das Lied Was ließen jene als geheimes Zeichen oder „emotionales Arkanum “9 einer spezifisch bündischen Ideologie, die unabhängig von der politischen Couleur in der breiten Mitte der deutschen Nachkriegsgesellschaft anzusiedeln ist. Durch ein gemeinsames Musikideal dieser Ideologie werden die in den anderen Elementen des Liedes auftauchenden NS-Relationen nicht nur überdeckt, sondern in einen anderen Kontext überführt - den der deutschen Jugendbewegung - und erscheinen damit bis heute legitimiert. In der Tat stammen viele der oben angeführten NS-Konnotationen ursprünglich aus der Jugendbewegung. Es handelt sich bei dem Lied also trotz der zahlreichen Konnotationen interessanterweise nicht etwa um originär „rechte“ oder gar „Nazimusik“, sondern um ein Beispiel einer viel älteren, kontinuierlichen Musiktradition, in welcher die Jahre des NS-Regimes lediglich eine Episode darstellen.

In der Fortführung dieser Tradition im Rahmen der Bündischen Jugend nach 1945 wird indes ein Dilemma zwischen dem Ideal der persönlichen Freiheit und bündischer Ideologie deutlich: So ist das Singen eines eigenen, selbstgewählten und selbst gemachten Repertoires einerseits Zeichen einer oft betonten individuellen Eigenständigkeit und verweist auf einen neuen Weg der Persönlichkeitsentwicklung abseits gesellschaftlicher Normen und Zwänge, der von Offenheit gegenüber allen Menschen geprägt ist. Auf der anderen Seite werden Merkmale einer Ideologie sichtbar, die Eigenständigkeit nur in der Gemeinschaft erlaubt, neue Wege unter Rückgriff auf alte Formen zu gehen versucht und sich durch eigene, spezifische Normen und Regeln von anderen Menschen abgrenzt. Demnach bleiben innerhalb der Ge-

\footnotetext{
${ }^{9}$ Der Ausdruck stammt von dem Historiker Jürgen Reulecke, der sich intensiv mit dem Feld deutsche Jugendbewegung befasst, anlässlich eines Workshops zur Jugendbewegungsforschung im April 2013 auf Burg Ludwigstein, dem Sitz des Archivs der Deutschen Jugendbewegung (AdJb).
} 
meinschaft der Bündischen Jugend Repertoire und Musikpraxis deshalb unbeanstandet, weil dort spezifische, in dieser - bislang lediglich unterstellten und angedeuteten - bündischen Ideologie wurzelnde Sinndeutungen bestehen.

Außerhalb, also in der Breite der Gesellschaft, die nicht in irgendeiner Form mit dieser Gemeinschaft in Berührung kommt, bleibt bündische Musik nach 1945 in der Regel schlichtweg unbeachtet und unbekannt. Dazu sieht man sich in der einschlägigen Literatur fast durchweg mit positiven Aussagen konfrontiert, da die historische und gesellschaftspolitische Deutungshoheit auf diesem Feld klar auf Seiten der Apologeten, also der Bündischen selbst liegt.

Dass eine kritische musiksoziologische Untersuchung dieses interessanten Phänomens bis heute aussteht, hängt wohl leider auch mit der erst in den letzten Jahren zunehmend reflektierten Tatsache zusammen, dass speziell die deutsche Musikwissenschaft nach 1945, dem Jahr „der Katastrophe ${ }^{\text {“10 }}$, bekanntermaßen jeglichen zeitgeschichtlichen Bezug ihrer Forschungsfelder zu vermeiden suchte ${ }^{11}$. Demnach lag auch die musikwissenschaftliche Auseinandersetzung mit dem Kontext der Jugendbewegung und ihrer, zumindest bis 1945 , unüberseh- und unüberhörbaren alltäglichen Musikpraxis noch bis vor nicht allzu langer Zeit außerhalb des eng abgesteckten methodischen und thematischen Rahmens der deutschen Nachkriegsmusikforschung. Dabei ist sowohl die Thematik von musikhistorischem Interesse als auch eine eingehende Untersuchung dieser Musik der historischen Musikwissenschaft ohne weiteres möglich und ergiebig, wie das nachfolgende Beispiel zu veranschaulichen sucht.

\section{Forschung}

Bei der liedmonographischen Arbeit zu Was ließen jene brachten gerade Methoden der historischen Musikwissenschaft Ergebnisse zu Tage, die anderen dazu sicherlich ebenso geeigneten wissenschaftlichen Disziplinen wohl verborgen bleiben müssen; nicht zuletzt deswegen, weil der Musikwissenschaft gut brauchbare Methoden und verbindliche Termini zur Verfügung stehen, die die Erklärung und Deutung musikalischer Sachverhalte ermöglichen. Nach dem vorhergegangenen kursorischen Einblick in die Ergebnisse meiner bisherigen Arbeit zur Musik der Bündischen Jugend nach 1945 sollen die folgenden Ausführungen daher exemplarisch einige der angewandten Methoden musikwissenschaftlicher Rezeptionsforschung und musikalischer Analyse und die sich daraus ergebenden Erkenntnisse verdeutlichen. Der dazu

\footnotetext{
${ }^{10}$ Vgl. Friedrich Blume, „Zum Geleit“, Die Musikforschung 1/1 (1948), 1.

${ }^{11}$ Ein jüngeres Beispiel für die Bemühungen der deutschen Musikwissenschaft in dieser Richtung war beispielsweise die interdisziplinäre wissenschaftliche Tagung „Musikwissenschaft - Nachkriegskultur Vergangenheitspolitik“ der Gesellschaft für Musikforschung, Mannheim, 20./21. Januar 2012.
} 
gewählte Ausschnitt aus dem zweiten Teil der Magisterarbeit, in dem das Lied unter dem Werkaspekt betrachtet wird, beschäftigt sich daher ausschließlich mit der musikalischen Grundlage des Liedes, dem Notentext.

\section{Art und Herkunftsbezeichnungen der musikalischen Grundlage}

Bei der Musik des Liedes Was ließen jene handelt es sich nicht um eine Originalkomposition, sondern um die Umarbeitung eines vierstimmigen instrumentalen Tanzstückes des 16. Jahrhunderts, der 6. Allemande ${ }^{12}$ aus dem 1551 erschienen dritten Teil der insgesamt elfbändigen Reihe musyck boexken des Antwerpener Komponisten und Notendruckers Tielman ${ }^{13}$ Susato in einen zweistimmigen Vokalsatz mit akkordischer Instrumentalbegleitung. ${ }^{14}$ Der Sachverhalt, dass Unterhaltungsmusik aus dem 16. Jahrhundert die musikalische Grundlage zu einem Lied der Bündischen Jugend nach 1945 bildet, mag zunächst eigentümlich erscheinen, weist jedoch in typischer Weise bis zu den Anfängen der Jugendbewegung und zum Musikideal des alten Volkslieds zurück. ${ }^{15}$ So finden sich schon im ersten und bedeutendsten musikalischen Manifest des Wandervogels, Hans Breuers Liederbuch Der Zupfgeigenhansl, gleich auf den ersten Seiten die Lieder „Innsbruck ich muß dich lassen “aus der Sammlung frische teutsche Liedlein (1539) von Georg Foster und „Es steht ein Lind in jenem Tal" nach der Sammlung souterliedekens (1540) von Clemens Non Papa. ${ }^{16}$ Die Lieder erscheinen dort einstimmig notiert und mit Akkordsymbolen für die Gitarrenbegleitung versehen, die eine musikalische Umsetzung durch einfachste Harmonisierungen der Oberstimme in funktionaler Kadenzharmonik nahelegen. ${ }^{17}$ Diese Harmonisierungen sollten zwar nach individuellem Vermögen des Ausführenden mög-

\footnotetext{
${ }^{12}$ Die originale Bezeichnung lautet „Den VI. Allemaigne“ (nach: Howard Mayer Brown, Instrumental Music Printed before 1600. A Bibliographie (Cambridge, MA: Harvard, 1965), 132; im Folgenden wird jedoch der gebräuchliche Terminus „Allemande“ verwendet. (Vgl.: F. J. Giesbert (Hg.), Tielman Susato. Danserye. Altniederländisches Tanzmusikbüchlein vom Jahre 1551. In Spielpartitur für 4 Blockflöten oder beliebige Melodie-Instrumente. Bd. 2 (Mainz: Schott, 1936), 39).

${ }^{13}$ Auch: Thielman, Tylman, Thylman, Tilman, Thilman (vgl.: Sofie Taes, „Susato, Tielman“, in Die Musik in Geschichte und Gegenwart. Allgemeine Enzyklopädie der Musik, 2., neu-bearbeitete Ausgabe, hg. von Ludwig Finscher, Personenteil, Bd. 16, Kassel und Stuttgart: Bärenreiter, 2006, 301); im Folgenden wird die dort an erster Stelle stehende Variante „Tielman“ verwendet.

${ }^{14}$ Zur ausführlichen Quellenangabe des Originaldrucks vgl. Nußbruch, Was ließen jene, IV.

${ }^{15}$ Vgl. Hans Breuer, „Vorwort zur 1. Auflage“, in Der Zupfgeigenhansl (Leipzig: Röder, 1913), o. S.

${ }^{16}$ Vgl. Breuer, Zupfgeigenhansl, 5.

${ }^{17}$ Ulf Jöde, Die Entwicklung des Liedsatzes in der Jugendmusikbewegung. (Wolfenbüttel/Zürich: Möseler, 1969), $13 f$.
} 
lichst zum Zwecke der Lebendigkeit des Vortrags erweitert und optimiert werden, ${ }^{18}$ konnten aber die schon früh kritisierte „Schrumschrumbegleitung ${ }^{\text {“19 }}$ in der Praxis vielfach nicht vermeiden. Unter anderem aus der Kritik dieser oft unbefriedigenden Umsetzung erwächst innerhalb des „Formenkanons der Freideutschen Jugend“ ${ }^{\text {“20 }}$ in den 1910er Jahren eine intensivere Auseinandersetzung mit der ursprünglichen Satztechnik der „alten Volkslieder" des 16. Jahrhunderts, ${ }^{21}$ die sich in zahlreichen Arrangements für die Begleitung der Lieder auf der „Laute“22 niederschlägt. Gleichzeitig erfolgt innerhalb der Freideutschen Jugend mit ersten eigenen Musikproduktionen der so genannten „Neutöner “233 die Abkehr vom Ausschließlichkeitsanspruch des „alten Volkslieds“. Musikalisch markiert diese Abkehr den Beginn einer eigenen Satztechnik der späteren Jugendmusikbewegung, die sich jedoch noch immer an den mehrstimmigen „Volksliedern" des 15. bis 17. Jahrhunderts orientierte, in deren Satztechnik man das Ideal einer Polyphonie gleichwertiger Stimmen zu erkennen meinte. ${ }^{24} \mathrm{Da}$ jedoch die meist hohe Stimmenzahl dieser Werke die praktische Nutzbarkeit dieser Musik für das Laienmusizieren erschwerte, versuchte man, die Stimmenzahl möglichst zu reduzieren und gleichzeitig die Eigenständigkeit der einzelnen Stimme zu erhalten. ${ }^{25}$ Die Vertonung des Liedes Was ließen jene von Erich Scholz steht demnach schon allein dadurch, dass sie auf ein Musikstück des 16. Jahrhunderts zurückgreift, diese mit Akkordbezeichnungen versieht und als zweistimmigen Satz präsentiert, in mehrfacher Hinsicht in der musikalischen Tradition der Jugendmusikbewegung.

Einen weiteren Ansatzpunkt musikwissenschaftlicher Arbeit bieten die Herkunftsbezeichnungen des Liedes in den Liedquellen zu Was ließen jene. Dort findet sich in Bezug auf die Herkunft des musikalischen Materials meist lediglich die Angabe „Alte Lauten-Melodie aus dem Barock“ (Vgl. Notenbeispiel 1) oder eine ähnliche Formulierung gleichen Inhalts. Einzig die neuere Liedsammlung Codex Patomomomensis gibt Quelle, Urheber und Erscheinungsdatum der „Weise“ des Liedes annähernd korrekt an: „Weise: nach ,Den 6. Allemaigne‘ aus ,Dansereye‘ [sic] von Tiel-

\footnotetext{
${ }^{18}$ Vgl. Breuer, Vorwort zur 1. Auflage, o. S.

${ }^{19}$ Jöde, Jugendmusikbewegung, Anm. 16, 270.

${ }^{20}$ Sven Kommer, „Musik in der Jugendbewegung“, in Handbuch Jugend und Musik, hg. von Dieter Baake, (Opladen: Leske und Budrich, 1998), 196.

${ }^{21}$ Vgl. Breuer, Vorwort zur 1. Auflage, o. S.

${ }^{22}$ Auf die Eigentümlichkeit der Bezeichnung „Laute“ für eine Gitarre in Lautenform wird weiter unten noch eingegangen.

${ }^{23} \mathrm{Vgl}$. Kommer, „Musik in der Jugendbewegung“, 203.

${ }^{24} \mathrm{Vgl}$. Jöde, Jugendmusikbewegung, 307.

${ }^{25}$ Vgl. ebd., 261.
} 
man Susato (1500-1561), 1551. “26 In diesem Zusammenhang ist die Tatsache interessant, dass es sich bei der 6. Allemande von Tielman Susato weder um Musik der Barockzeit noch ursprünglich um eine „Lauten-Melodie“ handelt, sodass selbst die spärlichen Angaben zur Herkunft der Musik des Liedes Was ließen jene in den meisten Liedquellen wenn nicht falsch, so doch irreführend für die musikhistorische Einordnung der musikalischen Grundlage des Liedes sind. Vielmehr sind die Angaben „Alte Lauten-Melodie aus dem Barock“'27, „Melodie nach einem Lautensatz aus der Barockzeit " ${ }^{\text {"28 }}$ sowie die ähnlich lautenden Angaben zur Herkunft des musikalischen Materials von Was ließen jene in den meisten anderen Liedquellen gleich in zweierlei Hinsicht inkorrekt. Zum einen liegt diesen Angaben vor dem Hintergrund des nachweisbaren Ursprungs des musikalischen Materials ein recht weit gefasster musikalischer Barockbegriff zugrunde. ${ }^{29}$ Zum anderen ist der Satz nach der derzeitigen Quellenlage bis ins 20. Jahrhundert nicht als Lauten- oder Gitarrensatz überliefert. Die fast durchgängig verwendete Angabe „Lauten-Melodie “30 oder „Lautensatz ${ }^{\text {“31 }}$ müsste sich demnach von einer späteren Bearbeitung des Satzes ableiten. Zusätzlich lassen die Formulierungen „Lautenmelodie" und „Lautensatz" auf eine Bearbeitung im Umfeld der Jugendmusikbewegung schließen, in welchem die Bezeichnung „Laute“ eine neue Zuschreibung erhielt und meist nicht mit dem bis Anfang des 20. Jahrhunderts gültigen instrumentenkundlichen Terminus identisch ist. ${ }^{32}$ Bei dem so bezeichneten Instrument handelt es sich im Kontext der Jugendbewegung meist um eine sechssaitige Gitarre in Lautenform, also eine antikisierte „Klampfe“ oder „Zupfgeige“. Dieses „instrumentenkundliche Missverständnis“, dass „die Tendenz der Wandervögel zu romantischen Idealisierungen ${ }^{“ 33}$ zeigt, ist zwar in Bezug auf die Ju-

\footnotetext{
${ }^{26}$ Tim Oliver Becker, Paul Rode, Codex Patomomomensis (Hamburg: Zauberwald, 2008), 161. Der scherzhafte Name leitet sich von den Fahrtennamen der beiden Herausgeber Tim Oliver Becker (Pato) und Paul Rode (Momo) ab.

${ }^{27}$ Vgl. schrift 9 (1962), o.S.

${ }^{28}$ Erich Scholz, Olkas Lieder (Heidenheim/Brenz: Südmarkverlag, 1984), 73.

${ }^{29}$ Vgl. Silke Leopold, „Barock“, in Die Musik in Geschichte und Gegenwart. Allgemeine Enzyklopädie der Musik, 2., neu-bearbeitete Ausgabe, hg. von Ludwig Finscher, Sachteil, Bd. 1 (Kassel und Stuttgart: Bärenreiter, 1994), 1235-56. Den frühesten Beginn der Ära des Barock setzt Leopold mit Ende des 16. Jahrhunderts an. In der Musikgeschichte bezeichnet der Begriff jedoch in der Regel den Zeitraum zwischen 1570 und 1730, vgl. Karl H. Wörner, Geschichte der Musik. Ein Studien und Nachschlagebuch (Göttingen: Vandenhoeck und Ruprecht, 1993), $184 \mathrm{f}$.

${ }^{30}$ schrift 9, o.S.

${ }^{31}$ Scholz, Olkas Lieder, 73.

${ }^{32}$ Vgl. Peter Päffgen, „Lauten“, in Die Musik in Geschichte und Gegenwart. Allgemeine Enzyklopädie der Musik, 2., neu-bearbeitete Ausgabe, hg. von Ludwig Finscher, Sachteil, Bd. 5 (Kassel und Stuttgart: Bärenreiter, 1996), 975.

${ }^{33}$ Kommer, „Musik in der Jugendbewegung“, 205.
} 
gendmusikbewegung zu differenzieren. So versuchte das mit dem Begriff der Laute verbundene Repertoire innerhalb der Jugendmusikbewegung ,an der früheren, eigentlichen Lautenkunst besonders des 16./ 17. Jahrhunderts geistig anzuknüpfen" ${ }^{\text {"34 }}$ und somit dieser Idealisierungstendenz einen musikhistorisch fundierten Bezugsrahmen zu verleihen. Dieser bezog sich jedoch weniger auf den tatsächlichen musikhistorischen Kontext, sondern stand vielmehr unter der Prämisse, Parallelen zwischen der Musikpraxis des 16. Jahrhunderts und der des Wandervogels nachzuweisen, in der die Jugendmusikbewegung das Ideal der "Gemeinschaftsmusik“35 ursprünglich verwirklicht sah. Der Hinweis auf die „Laute“ im Umfeld der Bündischen Jugend nach 1945 ist somit eher als Hinweis auf die Tradition einer jugendbewegten Musikhistoriografie denn als historisch korrekte Anmerkung zu bewerten. Aus der inkorrekten Formulierung der Angaben zur Herkunft des musikalischen Materials zu Was ließen jene wird somit deutlich, dass der genaue historische Rahmen der Komposition in der Bündischen Jugend nach 1945 als eher unwichtig betrachtet wird. ${ }^{36}$

Umso interessanter erscheint vor diesem Hintergrund die zuvor erwähnten Liedersammlung Codex Patomomomensis von 2008. Als Quelle von Was ließen jene werden hier die „Dansereye $\left[\right.$ sic] von Tielman Susato “ genannt. ${ }^{37}$ Hier lädt die genaue Herkunftsbezeichnung der musikalischen Grundlage zur Überprüfung durch Methoden der historischen Musikwissenschaft förmlich ein. Der Ausdruck „Danserye“ ist die inzwischen gängige Bezeichnung für den 1551 erschienenen dritten Teil der insgesamt elfbändigen Reihe der musyck boexken von Tielman Susato, einer Sammlung instrumentaler Tanzmusik. ${ }^{38}$ Dieses in vier Stimmbüchern gedruckte Werk ${ }^{39}$ enthält ausschließlich Instrumentalmusik, darunter auch die 6. Allemande, auf welche sich die Vertonung von Was ließen jene zurückführen lässt. Das rezeptionsgeschichtliche Stema dieser Allemande ist verhältnismäßig dürftig. Die bei Brown erwähnte Verbindung mit der augenscheinlich auf einem Chanson beruhenden $\mathrm{Al}$ -

\footnotetext{
${ }^{34}$ Hilmar Höckner, Die Musik der deutschen Jugendbewegung (Wolfenbüttel: Kallmeyer, 1927), 148.

${ }^{35}$ Vgl. Dorothea Kolland, Die Jugendmusikbewegung. "Gemeinschaftsmusik" - Theorie und Praxis. (Stuttgart: Metzler, 1979).

${ }^{36}$ Die genauen Angaben im Codex Patomomomensis stellen in diesem Zusammenhang eine Ausnahme dar. So kann anhand der übrigen Angaben in den Liedquellen als sicher gelten, dass über ein halbes Jahrhundert lang die dort zu findenden Herkunftsbezeichnungen des Satzes für ausreichend erachtet wurden.

${ }^{37}$ Becker/Rode, Codex Patomomomensis, 161.

${ }^{38}$ Die Sammlung erfreut sich im Übrigen einer bemerkenswerten Beliebtheit im heutigen Musikrepertoire. So finden sich beispielsweise auf der Internetplattform YouTube zahlreiche Aufnahmen von Tänzen aus der so benannten Sammlung in verschiedenen Besetzungen bis hin zu Techno-/DanceBearbeitungen.
}

${ }^{39}$ Vgl. Brown, Bibliographie, 132. 
mande. La mon amy la in der ebenfalls 1551 erschienen Sammlung von Tanzsätzen in Gitarren-Tabulatur von Adrian Le Roy konnte bisher nicht verifiziert werden. ${ }^{40} \mathrm{Ne}-$ ben dem ungesicherten Hinweis auf die Verbindung der Allemande Nr. 6 mit der Almande. La mon amy la findet sich im zweiten Teil des Orgel-Tabulaturbuches des Dresdner Hoforganisten August Nörminger von 1598 unter der Bezeichnung Ein feiner Deuttscher Tantz ${ }^{41}$ ein Satz, der in Umfang, Form, Rhythmus und Harmonie große Ähnlichkeit zu der 6. Allemande aufweist. ${ }^{42}$ Eine weitere, wenn auch spätere Verbreitung des Stückes außerhalb der musyck boexken ist somit zumindest in einem Falle nachgewiesen. Jedoch lässt die Bezeichnung bei Nörminger wiederum keine Rückschlüsse darauf zu, ob es sich tatsächlich um einen im späten 16. Jahrhundert populären „deutschen“ Tanz handelt, der hier von Nörminger aufgegriffen und bearbeitet wurde, oder ob die Aufnahme dieses Tanzes in seine Sammlung als Rezeptionsbeleg der 6. Allemande von Susato gelten kann. In beiden Fällen wäre jedoch die Möglichkeit nicht ausgeschlossen, dass es sich nicht um eine Originalkomposition Susatos handelt. Ob das musikalische Material des Liedes Was ließen jene auf einer Idee Tielmann Susatos basiert oder auf einer anderen musikalischen Quelle, die von Susato in seiner Funktion als Musikverleger lediglich bearbeitet, gedruckt und herausgegeben wurde, bleibt daher fraglich. Nach Ute Meißner enthalten lediglich drei der zahlreichen von Susato gedruckten Bücher ausschließlich eigene Kompositionen, wovon allerdings eines der 1551 erschienene dritte Teil der Reihe musyck boexken ist. ${ }^{43}$ Nach heutigem Wissensstand als gesichert gelten kann lediglich, dass der dritte Teil der musyck boexken „vorwiegend vierstimmig homophone, auf bekannten Liedern basierende Tanzsätze, die Susato selbst ausgearbeitet hat" ${ }^{44}$ enthält. Weitere Rezeptionsbelege finden sich laut Meißner erst wieder im musikwissenschaftlichen Zusammenhang bei Eitner (1903) ${ }^{45}$ und Mohr $(1932)^{46}$ und als „Spielmusik“ bei

${ }^{40}$ Vgl. ebd. Zu dem betreffenden Instrument vgl. Daniel Heartz, „Parisian Music Publishing under Henry II: A Propos of Four Recently Discovered Guitar Books“, Musical Quarterly 46 (1960), 44867.

${ }^{41}$ Vgl. Wilhelm Merian, Der Tanz in den Deutschen Tabulaturbüchern. Mit thematischen Verzeichnissen, Beispielen zur Intavolationspraxis und einer Studie über die Anfänge des Klavierstils. Reprografie der Ausgabe Leipzig: 1927 (Hildesheim: Olms, 1968), 242.

${ }^{42}$ Ernst Mohr, Die Allemande. Eine Untersuchung ibrer Entwicklung von den Anfängen bis zu Bach und Händel. Bd. 1 (Zürich: Hug, 1932), 29.

${ }^{43}$ Vgl. Ute Meißner, Der Antwerpener Notendrucker Tylman Susato. Eine bibliographische Studie zur niederländischen Chansonpublikation in der ersten Hälfte des 16. Jahrhunderts (Berlin: Merseburger, 1967), 123.

${ }^{44}$ Taes, „Susato“, 303.

${ }^{45}$ Robert Eitner, „Tylman Susato“, in ders., Biographisch-Bibliographisches Quellenlexikon der Musiker und Musikgelehrten der christlichen Zeitrechnung bis zur Mitte des 19. Jahrhunderts. Bd. 9 (Leipzig: Breitkopf und Härtel, 1903), 331. 
Simon Nußbruch

Giesbert (1936). ${ }^{47}$ Während bei Eitners frühen Transkriptionen von Allemanden aus dem dritten musyck boexken gerade die 6. Allemande, also die Grundlage von Was ließen jene, fehlt, ${ }^{48}$ findet sich bei Mohr eine Transkription des in D-dorisch stehenden Stückes in vierstimmigem Klaviersatz. Die Übertragung Giesberts im Rahmen einer Gesamtausgabe des dritten musyck boexken unter dem Titel Danserye unterscheidet sich vom Inhalt des Notentextes zwar kaum von der Übertragung Mohrs. Letztere erschien jedoch nur im Rahmen musikwissenschaftlicher Forschungsliteratur, die Übertragung Giesberts in vierstimmige „Spielpartitur “ ${ }^{“ 49}$ war dagegen gezielt für den praktischen Gebrauch für Laienmusiker konzipiert und publiziert ${ }^{50}$ (vgl. Notenbeispiel 2).

Als ebenso wenig eindeutig wie die Urheberschaft Susatos für die 6. Allemande erweist sich die Antwort auf die Frage, ob und in welchem Umfang die Vertonung des Liedes Was ließen jene auf Erich Scholz zurückgeht. Vor dem Hintergrund seiner umfangreichen Liedproduktion ist dies zwar mit hoher Wahrscheinlichkeit anzunehmen. Besonders das Verfahren, Musikstücke aller Art in Liedmelodien zu transformieren und mit einem eigenen Text zu unterlegen, ist bei zahlreichen seiner Lieder nachzuweisen. ${ }^{51}$ Da die biografischen Quellen zu Erich Scholz keinerlei Hinweise auf ein gezieltes Quellenstudium alter Musik enthalten, ist allerdings anzunehmen, dass er die im Rahmen musikwissenschaftlicher Fachliteratur erschienenen Übertragungen der 6. Allemande von Merian (1929) und Mohr (1932) nicht kannte. Dass Scholz die 6. Allemande stets als „Lautensatz“ bezeichnet, lässt zudem eine spätere Bearbeitung für Laute oder ein ähnliches Zupfinstrument als Rezeptionsgrundlage des Satzes von Was ließen jene am wahrscheinlichsten erscheinen. Als Grundlage dieser angenommenen Bearbeitung wären zwar auch die fast identische Übertragung Mohrs von 1932 oder gar die Originalausgabe der Stimmbücher von 1551 denkbar. ${ }^{52}$ Aufgrund der schwierigen Zugänglichkeit dieser Quellen im Vergleich zu der ein breites musikalisches Publikum ansprechenden Ausgabe Giesberts erscheint dies jedoch weniger wahrscheinlich, sodass die angenommene Lautenbear-

\footnotetext{
${ }^{46}$ Mohr, Allemande, Bd. 2, 5.

${ }^{47}$ F.J. Giesbert (Hg.), Danserye. Bd. 2, 39.

${ }^{48} \mathrm{Vgl}$. Monatshefte für Musikwissenschaft 6/7 (1875), 89ff.

${ }^{49}$ Vgl. Giesbert, Tielman Susato. Danserye.

${ }^{50}$ Die Gesamtausgabe des dritten musyck boexken erschien bei B. Schott's Söhne, Mainz 1936, in der Reihe „Musik für Blockflöten“.

${ }^{51}$ Vgl. z. B. Scholz Olkas Lieder, 30, 90, 105; fraglich bleibt dabei allerdings, ob der zweistimmige, kontrapunktische Satz des Liedes von Erich Scholz selbst stammt oder auf die Mithilfe Dritter zurückgeht. Hier stoßen die Methoden der Historischen Musikwissenschaft an ihre Grenzen und müssen durch persönliche Nachfragen im Feld ergänzt werden.

52 Vgl. Brown, Bibliographie, 133, Anm. 1: „A complete set of part books was in D: Bds [= Berliner Staatsbibliothek]“. Die Vergangenheitsform bezieht sich dabei vermutlich auf die Zeit vor 1945.
} 
beitung, durch die Erich Scholz vermutlich mit der 6. Allemande in Berührung kam, mit ziemlicher Sicherheit auf der populären Übertragung des dritten musyck boexken von Giesbert 1936 beruht. $^{53}$
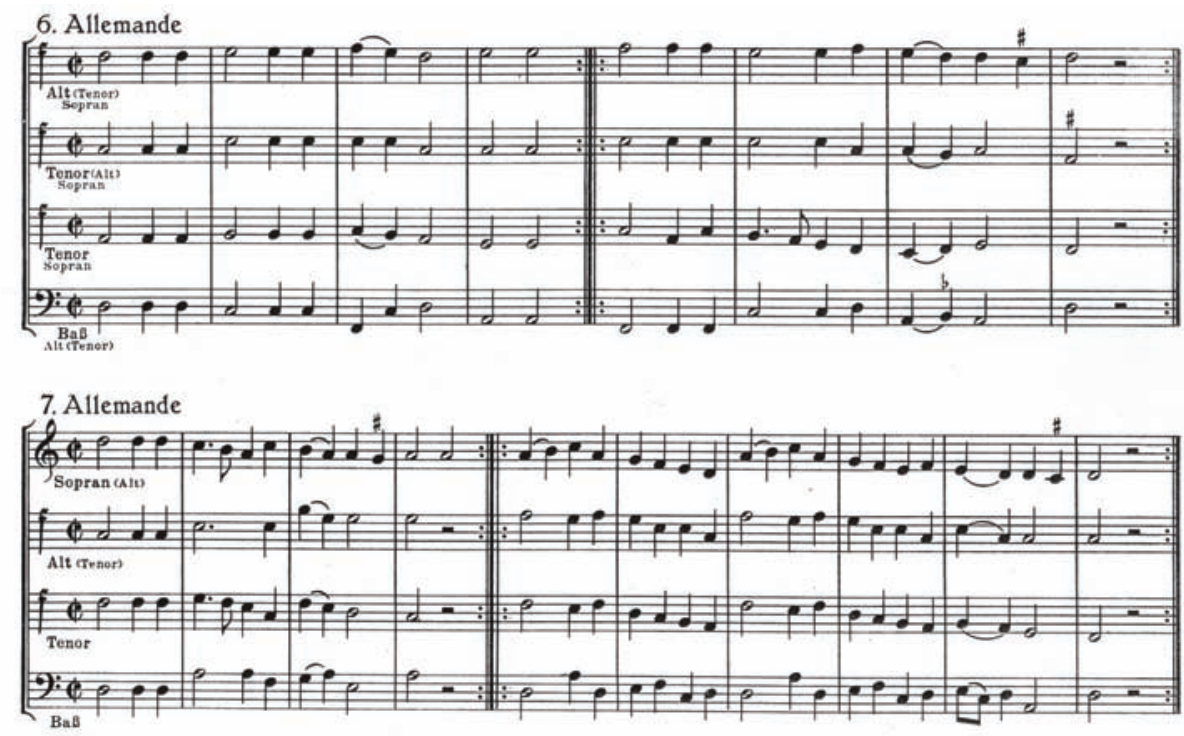

Notenbeispiel 2: Faksimile Giesbert 1936, S.N.

Ein weiteres Indiz für die mittelbare Ableitung des Satzes von Was ließen jene aus der Übertragung Giesberts bietet die Angabe zu dem in der gleichen Ausgabe der Zeitschrift schrift erschienene Lied Aber am Abend im Liederbuch Der Turm von 1966: „Worte von olka (Erich Scholz), Weise als vierstimmiges Flötenstück ,Danserye' [sic] bei Pablo [sic] Susato, Niederlande 1553 [sic] Eigentum des Voggenreiter Verlags. " 54 Interessant an diesen Angaben sind neben den zahlreichen unkorrekten Angaben ${ }^{55}$ in diesem Zusammenhang vor allem der Ausweis als „vierstimmiges Flötenstück“ und die Bezeichnung „Danserye“, die ziemlich eindeutig auf die Giesbertsche Gesamt-

\footnotetext{
${ }^{53}$ Hier möchte ich den hilfreichen Diskussionsbeitrag von Frau Prof. Rebecca Grotjahn nicht unerwähnt lassen, die darauf hinwies, dass die Popularisierung der Danserye als Spiel- und Gebrauchsmusik in gewisser Weise auch im Zusammenhang mit der NS-Ideologie steht. S.N.

${ }^{54}$ Konrad Schilling, Helmut König, Herbert Hoss, Der Turm B. Folklore aus allen Ländern. (Bad Godesberg: Voggenreiter, 1966), 1044.

${ }^{55} \mathrm{Zu}$ nennen wären hier a) die Verwechslung von Satz- und Werktitel, b) das falsche Erscheinungsjahr c) der Vorname „Pablo“, der vermutlich auf eine Namensverwechslung mit dem Violinvirtuosen Pablo Sarasate zurückzuführen ist; das Lied Aber am Abend basiert im Übrigen auf der 9. Ronde des dritten Teils der musyck boexken.
} 
ausgabe des dritten musyck boexken von 1936 verweisen. Dagegen finden sich in derselben Quelle einige Seiten vorher die folgenden, üblichen Angaben: „Worte von olka (Erich Scholz), Weise einer alten Lautenmelodie aus dem Barock [...] ${ }^{“ 56}$ Der gemeinsame Ursprung des musikalischen Materials der beiden Lieder ist eigenartigerweise auch in weiteren Liedquellen durch die Angaben nicht kenntlich gemacht, sodass offen bleiben muss, ob die Verwendung der beiden Susato-Stücke durch Erich Scholz auf derselben Rezeptionsgrundlage beruht. Als hinreichend nachgewiesen kann jedoch anhand dieser Indizien die Übertragung Giesberts als die entscheidende Rezeptionsgrundlage des Satzes von Was ließen jene gelten.

\section{Transformationstechniken}

Ob die Transformation des vierstimmigen Instrumentalsatzes in einen zweistimmigen Liedsatz mit akkordischer Instrumentalbegleitung von Erich Scholz stammt ist zwar, wie gesagt, nicht mit Sicherheit festzustellen. Für die musikalische Analyse der musikalischen Parameter wie Melodie, Form, Metrik, Harmonik etc. spielt diese Tatsache allerdings auch keine entscheidende Rolle. Wichtig ist hierfür nur, und das konnte anhand der zahlreichen vorliegenden Liedquellen aus über vier Jahrzehnten nach den Vorgaben des Historisch-kritischen Liederlexikons akribisch ermittelt und bewiesen werden, dass die zuerst veröffentlichte musikalische Version des Liedes bis heute die am meisten rezipierte ist (vgl. Notenbeispiel 1). Diese Version des Liedes wurde nun mit der sowohl verhältnismäßig textgetreuen als auch weit verbreiteten Übertragung der 6. Allemande von Giesbert aus dem Jahre 1936 verglichen (vgl. Notenbeispiel 3). Besonderes Augenmerk galt dabei den hierin verwendeten und für bündische Musik signifikanten Transformationstechniken, die vom Bearbeiter bewusst oder unbewusst eingesetzt wurden. Beim Vergleich fallen eine Reihe von Transformationen ins Auge, von denen hier drei näher betrachtet werden: erstens die Umwandlung eines Instrumentalsatzes in einen textierten Vokalsatz, zweitens die Reduktion des Satzes von ursprünglich vier auf zwei Stimmen, und drittens die akkordische Instrumentalbegleitung, die durch die über den Noten stehenden Akkordsymbole angedeutet wird ${ }^{57}$.

\footnotetext{
${ }^{56}$ Schilling, König, Hoss, Turm B, 1019.

${ }^{57}$ Weitere Transformationen, wie die Transposition des Satzes auf verschiedene Tonstufen sowie die Änderung der Metrumsangabe von 2/2 (Giesbert 1936) in 4/4 (Scholz 1962), wurden in der Analyse ebenfalls ausführlich behandelt.
} 


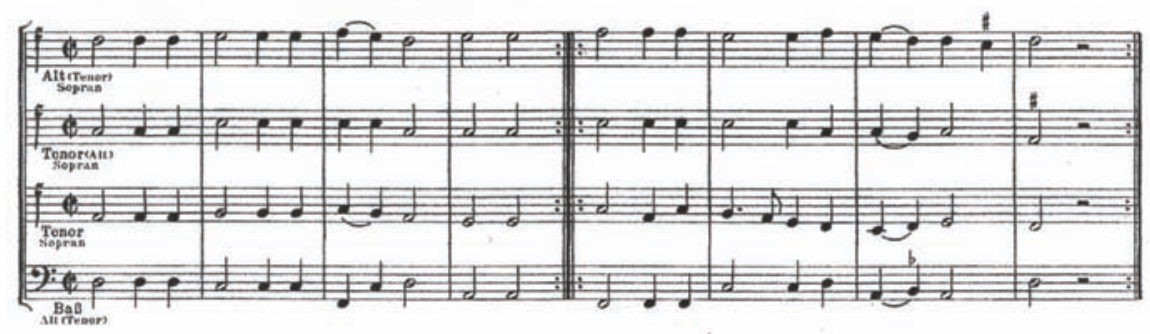

Erich Scholz 1962

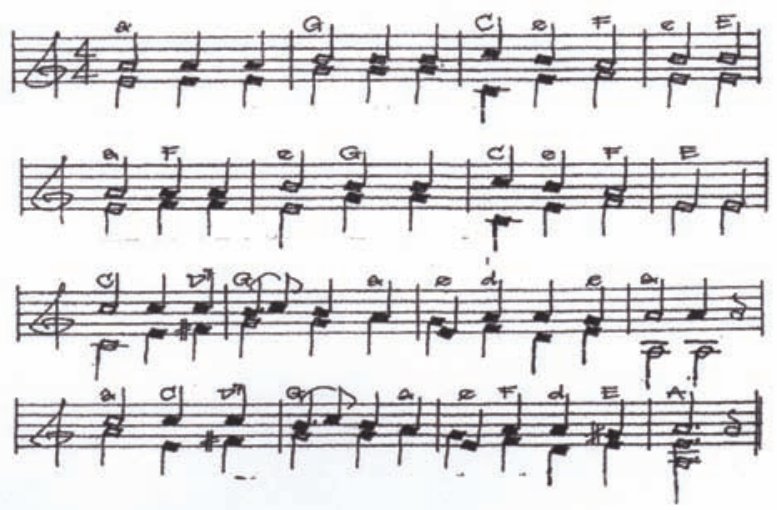

Notenbeispiel 3: Was ließen jene. Transformation der musikalischen Grundlage, S.N.

Zunächst ist zu sagen, dass die erste der hier genannten Transformationen, die eines Instrumentalsatzes in einen textierten Vokalsatz, als Ausnahmeerscheinung im Repertoire der Bündischen Jugend zu betrachten ist. So finden sich zumindest weder Beispiele für eine derartige Technik in den Quellenangaben zu den Liedern in den einschlägigen Liederbüchern der Jugendbewegung noch in den Schriften der Jugendmusikbewegung vor $1933 .{ }^{58}$ Auch in den wenigen Aufsätzen zur bündischen

${ }^{58} \mathrm{Vgl}$. Jöde, Jugendmusikbewegung. 
Liedproduktion nach 1945 wird diese Transformationstechnik nicht erwähnt. ${ }^{59}$ Sie wurde jedoch speziell von Erich Scholz in zahlreichen anderen seiner Lieder sowie in dem Lied Aber am Abend laden wir uns ein ${ }^{60}$ ebenfalls auf ein Stück aus den dritten musyck boexken von Tielman Susato, angewandt. Die Umwandlung instrumentaler Tanzmusik des 16. Jahrhunderts in Lieder mit eigenem Text kann somit als persönliches Merkmal des bündischen Liedermachers Scholz gewertet werden und stellt keine typische Technik der Liedproduktion innerhalb der Bündischen Jugend nach 1945 dar.

Dagegen deutet die zweite Transformationstechnik, die Reduktion von vier auf zwei Stimmen, auf eine typische kompositorische Praxis der Jugendmusikbewegung hin, welche in der Arbeit Ulf Jödes über Die Entwicklung des Liedsatzes in der deutschen Jugendmusikbewegung analysiert wird. Diese Entwicklung geht von einer „volksmäßigen Mehrstimmigkeit" ${ }^{\text {“1 }}$ aus, in der die Begleitstimmen lediglich den „Widerhall“62 der Melodie darstellen. Der sich schließlich aus der „volksmäßigen Mehrstimmigkeit" herleitenden, künstlerisch gestalteten Polyphonie gleichberechtigter Stimmen stellt Jöde die bis dahin verbreitete Technik mehrstimmigen Laiensingens gegenüber, durch fehlende Stimmen hervorgerufene Lücken im Satz funktionsharmonisch zu ergänzen. Da diese Technik im Zuge der „neuen MusikGesinnung "63 als zunehmend ungenügend betrachtet wurde, suchte man nach anderen Möglichkeiten, mehrstimmiges Singen einerseits zu vereinfachen und andererseits das Wesen der Mehrstimmigkeit im Sinne der neuen Musikgesinnung im Satz beizubehalten und so den Ausführenden fasslich zu machen.

Inwieweit die von Ulf Jöde beschriebenen satztechnischen Ideale auf die Vertonung des Liedes Was ließen jene zutreffen, zeigen daher vornehmlich die Transformationen des musikalischen Materials der 6. Allemande, die durch die Umwandlung des vierstimmigen in einen zweistimmigen Satz zu beobachten sind. Dabei war festzustellen, dass die Umwandlung des vierstimmigen Satzes der Allemande in den zweistimmigen Satz des Liedes Was ließen jene prinzipiell dadurch erfolgt, dass der

\footnotetext{
${ }^{59}$ Vgl. Michael Fritz, „Neue Innerlichkeit? - Gedanken eines Neubündischen über die Entwicklung des ,bündischen Singens' seit 1970“, der eisbrecher 1 (1988), 18ff.; Helmut König, „Der ,Zupfgeigenhansl'und seine Nachfolger. Drei Phasen der Jugendbewegung im Spiegel repräsentativer Liederbücher“, in „Mit uns zieht die neue Zeit... “. Der Wandervogel in der deutschen Jugendbewegung, hg. von Ullrich Herrmann (Weinheim, München: Juventa, 2006), 232-75.

${ }^{60}$ Vgl. Schilling, König, Hoss, Turm B, 1044.

${ }^{61}$ Jöde, Jugendmusikbewegung, 12.

${ }^{62}$ Ebd., Zitat Fritz Jöde.

${ }^{63}$ Fritz Jöde, „Die neue Musik-Gesinnung“, in Grundschriften der deutschen Jugendbewegung, hg. von Werner Kindt (Düsseldorf, Köln: Diederichs, 1963), 204ff.
} 
superius $^{64}$ des vierstimmigen Satzes als Oberstimme beibehalten wird, während aus den drei übrigen Stimmen eine zweite Stimme konstruiert wird. Dabei wird vor allem auf das Tonmaterial des bassus zurückgegriffen. Dieses Prinzip wird jedoch keineswegs durchgängig angewandt, sondern durch eine Reihe von Ausnahmen durchbrochen. Dabei handelt es sich um Änderungen in der Stimmführung, zum einen durch die Kombination mit anderen Stimmen, zum anderen durch das Einfügen von Tönen und melodischen Wendungen in die zweite Stimme, die sich nicht aus dem vierstimmigen Satz herleiten lassen.

\section{Drei signifikante Transformationen}

Die so konstruierten Stimmen des Liedes stellen folglich eine Mischung aus dem Tonmaterial des vierstimmigen Satzes von Susato und Einfügungen durch den bündischen Bearbeiter dar. Die genauere Untersuchung dieser für die bündische Kompositionstechnik signifikanten Transformationen führt zu drei kompositionstechnischen Kategorien, unter die sich die feststellbaren Einzelphänomene einordnen lassen: eine vom Begleitungsideal des Zupfgeigenhansl abgeleitete elaborierte Wandervogel-Harmonik, das Primat der Melodie aus der Jugendmusikbewegung und schließlich die offene Kategorie einer (spät)bündischen Romantik, die in den bündischen Originalkompositionen seit den 1920er Jahren zutage tritt. ${ }^{65}$

\subsection{Die elaborierte Wandervogel-Harmonik}

Unter die erste Kategorie der elaborierten Wandervogel-Harmonik sind zwei signifikante Transformationen des Satzes zu rechnen:

1. die Erhöhung f zu fis in T. 9 und T. 13 und die sich dadurch ergebende „doppeldominantische“ Wendung zum Klang g' des ersten Schlages von T. 10 und T. 14;

2. die Umwandlung des Quart-Vorhalts auf Schlag drei und vier in T. 11 in die subdominantisch zu deutende Quinte durch Veränderung der halben Note e' in zwei Viertelnoten d' - e'.

\footnotetext{
${ }^{64}$ Die hier verwendete Übertragung Giesberts benennt die Stimmen des Satzes nach der intendierten Ausführung durch Instrumental-Ensemble, durch wahlweise "große Besetzung“ (Alt/Tenor/Tenor/ Bass) oder „kleine Besetzung“ (Sopran/Sopran/Sopran/Alt; Giesbert 1936: Vorwort). Zur besseren Identifizierung der Stimmen werden diese im Folgenden jedoch nach den Stimmbüchern des dritten musyck boexken von 1551 mit superius/altusl tenorlbassus bezeichnet.

${ }^{65}$ Diese Kategorien sind jedoch lediglich als erste Richtlinien zu verstehen, anhand derer man bestimmten kompositorischen Prinzipien des Liedrepertoires der Bündischen Jugend im Einzelnen nachgehen könnte, nicht etwa als empirisch fundierte Begriffsbildungen.
} 
Diese Art der funktionsharmonischen Begleitung einer Melodie durch Erweiterungen der Grundfunktionen verweist auf die seit Erscheinen des Zupfgeigenhansl im Wandervogel verbreiteten Vorstellungen einer differenzierten und durchdachten Harmonisierung, mit der man das Wesen des „alten Volksliedes“ zusätzlich unterstreichen wollte. Diese Begleittechnik erwartet vom Ausführenden „eine reichere, kräftigere Harmonisierung aus der Weise selbst herauszuholen“, "66 wobei „Brahms' Volksliedbearbeitungen [...] unübertreffliche Muster ${ }^{\text {“67 }}$ bieten.

Obwohl, wie auch im vorliegenden Falle, in der Praxis vielfach in diesem Sinne angewandt, fand ein solcher Umgang mit „alten Volksliedern“ jedoch sowohl durch die allgemeine Ablehnung des Wandervogels gegenüber allem, was unter den „Kampfbegriff, 19. Jahrhundert “"68 fiel, als auch im Zuge der zunehmenden Theoretisierung durch die Jugendmusikbewegung in Richtung einer „Neuen Musikgesinnung“ wenig Zuspruch. Die kategorische Ablehnung solcher „Mätzchen“ wie „unausstehliche, chromatische Gänge (die im echten Volkslied unmöglich sind), weichliche Septimen- und Nonenakkorde, womöglich alteriert (Gefühl!) “69 verfestigte sich im Laufe der 1920er Jahre und führte zum „inneren Strukturwandel im Singen und Musizieren der Jugendmusikbewegung [...], die den Weg zur Gemeinsamkeit gleichberechtigter Stimmen suchte. ${ }^{\text {70 }}$

\subsection{Das Primat der Melodie}

Unter diese zweite Kategorie, das sich in der Jugendmusikbewegung herausbildende „Primat der Melodie“, ist die formale Umgestaltung der beiden Stimmen des Liedsatzes zu rechnen, die durch geringfügige Änderungen des Tonmaterials erzeugt wird. Um beide Stimmen melodisch gleichwertig zu gestalten, werden hier zwei signifikante Transformationen vorgenommen. Zum einen wird die formale Struktur von zwei mal vier Takten aufgelöst, indem jeweils die vier der Wiederholung entsprechenden Takte des Liedsatzes in beiden Stimmen leicht, aber entscheidend verändert werden:

1. durch die Veränderung der Oberstimme von h' in T. 4 zu e' in T. 8;

2. durch Veränderungen in der zweiten Stimme von e' in T. 1 auf Schlag drei und vier zu $\mathrm{f}$ in T. 4;

\footnotetext{
${ }^{66} \mathrm{Vgl}$. Jöde, Jugendmusikbewegung, Anm. 21, 271.

${ }^{67}$ Ebd.

${ }^{68}$ Hilmar Höckner, „Jugendmusik“, in: Riemann Musiklexikon, Sachteil (Mainz: Schott, 1967), $431 \mathrm{f}$.

${ }^{69} \mathrm{Vgl}$. Jöde, Jugendmusikbewegung, 108.

${ }^{70}$ Ebd., 110.
} 
3. durch Hinzufügen eines Klanges durch Verdoppelung des Oktavklangs aa' in beiden Stimmen in T. 12 auf Schlag drei; $;^{71}$

4. durch Veränderung in der zweiten Stimme von c' in T. 9 auf Schlag eins zu a' in T. 13.

Dadurch entstehen im Gegensatz zu den zwei wiederholten, viertaktigen Halbsätzen der Tanzform AABB zwei achttaktige Liedabschnitte AA'BB', da der wiederholte Teil A' durch diese Veränderung anders abschließt als A. Zusätzlich wird durch das Hinzufügen eines Klanges in T. 12 die symmetrische Struktur des Tanzsatzes von AA:BB, also 2:2, aufgelöst und in eine asymmetrische Form AA'B:B', also ein Verhältnis 3:1, umgewandelt. Zum anderen entstehen durch geringfügige Veränderung des Tonmaterials zusätzliche Intervalle, die beiden Stimmen eine gewisse melodische Eigenständigkeit verleihen:

1. durch die Veränderung der Oberstimme von h' in T. 4 zu e' in T. 8 entsteht ein Sextsprung aufwärts zum c" des darauf folgenden Taktes;

2. durch Veränderung in der zweiten Stimme von c' in T. 9 auf Schlag eins zu a' in T. 13 entsteht ein Oktavsprung aufwärts vom a des vorhergehenden Taktes.

Schließlich erfährt die Oberstimme des Liedsatzes gegenüber dem superius des Tanzsatzes eine deutlich melodischere Konturierung durch das Einfügen einer längeren melodischen Figur h' - c'" - h' - a' - g' in T. 10f. und T. 14f., die aus der ansonsten kaum verwendeten tenor-Stimme des Tanzsatzes entnommen wurde. Beide Stimmen des Satzes erhalten durch diese geringfügigen Veränderungen und Umstellungen des ursprünglichen Tonmaterials eine eigene melodische Identität, sodass sie das Lied jeweils eigenständig repräsentieren können, ohne aufeinander angewiesen zu sein. ${ }^{72}$ Aus den dieser Kategorie zuzuordnenden Transformationen ergeben sich demnach aus dem vierstimmig-homophonen, zweiteiligen Tanzsatz der Allemande zwei gleichberechtigte Melodiestimmen der vierteiligen Liedform von Was ließen je$n e$, die miteinander harmonierend den Satz des Liedes bilden. Die hier feststellbare Kategorie des „Primats der Melodie“ ist somit deutlich dem Musikideal der Jugendmusikbewegung verpflichtet und zeigt, dass die Vertonung des Liedes Was ließen jene zu einem großen Teil auf dem Ideal der „Gemeinsamkeit gleichberechtigter Stimmen ${ }^{\text {"773 }}$ beruht.

\footnotetext{
${ }^{71}$ Die seltsame Schreibweise der Notenwerte von Viertelnote plus Viertelpause in der Ober- und halbe Note in der Unterstimme in T. 12 glättet sich im weiteren Rezeptionsverlauf des Liedes in jeweils eine halbe Note in Ober- und Unterstimme.

${ }^{72}$ Nur zur Verdeutlichung, nicht zum Beweis dieses Phänomens sei angemerkt, dass in der Praxis die konstruierte zweite Stimme des Satzes das Lied Was ließen jene zuweilen deutlicher repräsentiert als die dem superius nachempfundene erste Stimme.

${ }^{73}$ Jöde, Jugendmusikbewegung, 110.
} 


\subsection{Die (spät-)bündische Romantik}

Unter die dritte Kategorie der „(spät-)bündischen Romantik“ fallen hingegen signifikante Transformationen, die sowohl zu einer im romantisch-funktionsharmonischen Sinne „elaborierten Wandervogel-Begleitung“ als auch zum Ideal des „Primats der Melodie“ der Jugendmusikbewegung teilweise im Widerspruch stehen. Die Benennung dieser Kategorie bedarf jedoch zunächst der folgenden Erläuterung und Rechtfertigung.

In der Mehrzahl der umfangreichen Literatur zur deutschen Jugendbewegung ist es unbestritten, dass sämtliche Ausprägungen der deutschen Jugendbewegung auf mehr oder weniger „romantischen " Vorstellungen beruhten, ${ }^{74}$ sodass die Bezeichnung „bündische Romantik“ im Grunde einen Pleonasmus darstellt. Die Ausprägung dieser als romantisch bezeichneten Vorstellungen erfuhr jedoch im Laufe der historischen Entwicklung der Jugendbewegung eine entscheidende Veränderung. Die romantischen Ideale der Wandervögel lagen zumeist außerhalb ihrer selbst, etwa im Ideal des fahrenden Scholaren, oder, in musikalischer Hinsicht, im Ideal des „alten Volksliedes“. Die hier gemeinte „bündische“ Romantik bezieht sich hingegen in weit höherem Maße als die romantischen Ideale des Wandervogels auf die Gemeinschaft innerhalb der verschiedenen Gruppen und Bünde selbst, die somit als Ideal verklärt wird. Dieses hier als „bündische Romantik“ benannte Selbstgefühl äußert sich musikalisch in einer umfangreichen Liedproduktion, die musikalisch eigenen Gesetzmäßigkeiten gehorcht. ${ }^{75}$ Mit dem in Klammern gestellten Praefix „spät-“ soll zudem angezeigt werden, dass es sich hierbei um eine im Grunde bis heute gültige Kategorie handelt, die in der Phase der historischen Bündischen Jugend ihren Ausgangspunkt hat.

Die musikalischen Merkmale dieser spezifisch bündischen Liedproduktion sind bis zu dieser Arbeit nicht wissenschaftlich untersucht worden, weshalb die signifikanten Transformationen im Liedsatz von Was ließen jene, die unter die Kategorie der ,(spät)bündischen Romantik“ zu zählen sind, sich nur auf eigene Erkenntnisse und Beurteilungen des Verfassers stützen lassen, die hier erstmals präsentiert werden.

Danach finden sich im zweistimmigen Satz des Liedes Was ließen jene drei, für die Musik der Bündischen Jugend nach 1945 signifikante, Transformationen:

1. Durch die Veränderung der zweiten Stimme in T. 3 von g' - a' zu e' - $f$ auf Schlag drei und vier entstehen statt eines Terz-Klangs g' - h' und eines Prim-Klangs a' - a' ein Quintklang e' - h' und ein Terzklang $\mathrm{f}$ - $\mathrm{a}^{\prime}$.

2. Durch die Veränderung der zweiten Stimme in T. 5 von e' $\mathrm{zu} f$ auf Schlag drei und vier entsteht statt eines gleich bleibenden Quart-Klanges $e^{\prime}-a^{\prime}$ wie in T. 1 ebenfalls ein Terzklang $f^{\prime}-a^{\prime}$.

\footnotetext{
${ }^{74} \mathrm{Vgl}$. Kommer, „Musik in der Jugendbewegung“, 198.

${ }^{75}$ Vgl. ebd., 209ff.
} 
3. Durch die Veränderung in der zweiten Stimme in T. 13 von c' in a' auf Schlag eins entsteht statt des Oktavklangs c' - c" der Terzklang a' - c". Zudem sind die Veränderungen des Tonmaterials, aus dem die zweite Stimme des Liedsatzes konstruiert ist, nur möglich durch die im Zuge der Transposition von D nach A erfolgte Änderung des Tongeschlechts von D-Dorisch nach A-Moll, da nur dort der Ton f leitereigen ist und der Klang f - a' ohne Vorzeichenwechsel entstehen kann. Die sich daraus ergebenden Klänge sind jedoch weder als funktionsharmonische Begleitung im Sinne der Kategorie der „elaborierten Wandervogeltechnik“ noch durch die Kategorie des „Primats der Melodie“ in der Jugendmusikbewegung zu deuten. So repräsentiert der Terzklang f - a einen F-Dur-Akkord, was zwar der harmonischen Funktion des Tonika-Gegenklanges zu A-Moll entspricht, in diesem Zusammenhang jedoch kaum im Sinne einer vereinfachten, kadenzierenden Harmonik $\mathrm{zu}$ interpretieren ist.

Dass aus der durch den Tanzsatz vorgegebenen Akkordfolge C-Dur, A-Moll in T. 3 im Liedsatz die Akkordfolge C-Dur, E-Moll, F-Dur abgeleitet wird, wäre nach der Kadenzharmonik des 19. Jahrhunderts zwar durchaus denkbar, im Zusammenhang mit dem Wandervogel und seiner Ablehnung allzu augenfälliger Anlehnungen an die kunstmusikalische Kompositionspraxis des 19. Jahrhunderts jedoch höchst unwahrscheinlich. Des Weiteren besteht aus melodischer Hinsicht, also im Hinblick auf das „Primat der Melodie“, keine zwingende Notwendigkeit für die genannten drei Transformationen, welche die ursprünglichen Harmonien des vierstimmigen Satzes deutlich in Richtung einer „nicht-alten“ Tonsprache verändern. Diese sich durch eine derart eindeutige Transformation des Tongeschlechts ergebenden Klänge bilden offensichtlich eine eigene signifikante Transformationskategorie, die weder auf die elaborierte Wandervogel-Harmonik noch auf das Primat der Melodie in der Jugendmusikbewegung, sondern dezidiert auf eine eigene Tonsprache der Bündischen Jugend verweist, die sich um 1930 herauszubilden beginnt.

Durch die zuletzt beschriebenen Transformationen des Satzes entsteht ein harmonischer Ablauf, welcher durch die Tonfolge a', g', (e'), f, e' in der zweiten Stimme des Liedsatzes bestimmt wird (T. 13-16). In der Kombination mit der ersten Stimme ergibt sich so ein Zusammenklang, welcher der Akkordfolge A-Moll, G-Dur, FDur, E-Dur entspricht. Durch diesen passacaglia-ähnlichen harmonischen Ablauf wird eine Art „spanischer Einschlag“ in der Harmonik spürbar, welcher der $\mathrm{Mu}$ sikauffassung der frühen Wandervögel und der Jugendmusikbewegung sowie ihrer Orientierung am „alten, deutschen Volkslied“ fremd erscheinen muss. Dagegen kommen durch diese signifikante Transformation der Harmonik des Satzes der 6. Allemande zwei Merkmale eines Wandels der Musikpraxis zum Vorschein, die gegen Ende der 1920er Jahre in der Bündischen Jugend zu beobachten sind: zum einen der Einfluss des Nerother Wandervogels und seiner spezifischen Singkultur und zum anderen die sich daraus vor allem in den Jungenschaften abzeichnende zunehmende Internationalisierung des Liedgutes und der Musizierpraxis. 


\subsection{Die musikalische Trendwende um 1930}

Auf die beiden genannten Merkmale einer Trendwende der bündischen Musikpraxis macht Sven Kommer aufmerksam, der mit dem Einfluss des Nerother Wandervogels und der Internationalisierung des Liedgutes gleichfalls einen Wandel der Musikauffassung der Jugendbewegung in den 1920er Jahren konstatiert, die sich vor allem in der deutlichen Zunahme der Bedeutung der eigenen Liedproduktion niederschlägt. ${ }^{76}$ In der "nicht-bündischen“, wissenschaftlichen Literatur nach 1945 ist der Aspekt der eigenen Liedproduktion jedoch bis auf Kommers Aufsatz kaum behandelt. Meist wird dagegen rückblickend aus Arbeiten zur Jugendmusik im NS-Staat der militaristisch-kämpferische Aspekt des Liedguts der Bündischen Jugend dieser Zeit betont.

Dagegen beschäftigen sich eine Reihe von wissenschaftlichen Autoren mit bündischem Hintergrund mit der Unterscheidung zwischen den Idealen der Jugendmusik, wie sie beispielsweise von Höckner beschrieben werden, ${ }^{77}$ und der sich zunehmend davon distanzierenden Musikpraxis innerhalb der Gruppen und Gruppierungen der Bündischen Jugend in der zweiten Phase der Jugendbewegung. Während Jürgen Reulecke speziell auf die Eigenkompositionen der so genannten „Männerbundlieder“ der Bündischen Jugend der 1920er und 30er Jahre als „mentalitätsgeschichtliche Innovation " ${ }^{\text {"78 }}$ gegenüber der frühen Jugendbewegung eingeht, wird in Stefan Krolles „Regionalstudie“ zum Nerother Wandervogel der Einfluss der Internationalisierung eindrücklich bestätigt. Vor allem im Zusammenhang mit Was ließen jene und Erich Scholz findet sich dort der bemerkenswerte Satz:

Diese Trendwende [Offenheit für ausländisches Liedgut durch die Weltfahrten der Nerother Ende der 1920er Jahre; S. N.] bestätigt auch Erich Scholz (Olka), der, ebenfalls der Bündischen Jugend angehörend, viele eigenkomponierte und eigengetextete Lieder in den bündischen Liederhorizont einbrachte [Anm. 576:] Brief von Erich Scholz an den Verfasser, vom 09.01.1989. ${ }^{79}$

Daraus wird unter anderem deutlich, dass Erich Scholz, der Verfasser des Liedes Was ließen jene, schon damals in seiner Eigenschaft als Liedermacher innerhalb verschiedener Jungenschaftsbünde Teil jener Trendwende war, die sich Krolle zufolge in den

\footnotetext{
${ }^{76} \mathrm{Vgl}$. Kommer, „Musik in der Jugendbewegung“, $210 \mathrm{f}$.

${ }^{77}$ Vgl. Höckner, „Jugendmusik“, 432.

${ }^{78}$ Vgl. Jürgen Reulecke, „,Wir reiten die Sehnsucht tot` oder: Melancholie als Droge. Anmerkungen zum bündischen Liedgut", in Männergeschichte - Geschlechtergeschichte. Männlichkeit im Wandel der Moderne, hg. von Thomas Kühne (Frankfurt am Main, New York: Campus, 1996), 156-73.

${ }^{79}$ Stefan Krolle, Musisch-kulturelle Etappen der deutschen Jugendbewegung von 1919-1964. Eine Regionalstudie (Münster: Lit, 2004), 163.
} 
Jahren nach 1945 vor allem mit den musikalischen Aktivitäten auf Burg Waldeck fortsetzte. Ein Beispiel für diesen zumindest musikalischen Zusammenhang und seine Fortsetzung nach 1945 bietet etwa das Lied Die Stunde der Orangen: einerseits durch dessen nachweisliche Rezeption durch Scholz, ${ }^{80}$ andererseits durch die Herkunft des Liedes aus dem Nerother Wandervogel. ${ }^{81}$ Im Gegensatz zur Darstellung Wolfgang Lindners, der in der Liedpraxis der neu gegründeten Bünde unmittelbar nach 1945 vornehmlich erhebliche Überschneidungen mit dem NS-Liedgut konstatiert ${ }^{82}$ betont Krolle am Beispiel des Nerother Wandervogels und der Arbeitsgemeinschaft Burg Waldeck vor allem die Kanonisierung internationalen Liedguts in den „Liedpool“83 der gesamten Bündischen Jugend nach 1945. Geht man wie Krolle davon aus, dass der Nerother Wandervogel seit Ende der 1920er Jahre musikalisch stark auf die anderen, vornehmlich jungenschaftlich orientierten Bünde abstrahlte und die Burg Waldeck zwischen 1945 und 1964 ein wichtiges musikalisches Zentrum der Bündischen Jugend war, wird plausibel, dass es sich bei der dritten Kategorie der signifikanten Transformationen, die sich im Liedsatz feststellen lassen, der (spät)bündischen Romantik, um eine vornehmlich vom „nerothanen Sangesstil“" ${ }^{\text {(84 }}$ geprägte Kategorie innerhalb des bündischen Liedschaffens handelt.

\section{Zusammenfassung und Ausblick}

Nach einem kurzen Einblick in die Vielschichtigkeit des Forschungsgebietes wurde versucht zu zeigen, in wieweit Methoden der Historischen Musikwissenschaft wie Quellenkunde, Rezeptionsgeschichte und musikalische Analyse für eine Untersuchung der Musik der Bündischen Jugend nach 1945 nützlich, wenn nicht gar unerlässlich sind. Die Ergebnisse des hier demonstrierten Forschungsansatzes seien hier kurz zusammengefasst. Zunächst ist festzustellen, dass der Bezug des Liedes Was ließen jene zur Musik des 16. Jahrhunderts im Rezeptionsfeld der Bündischen Jugend nach 1945 keineswegs ungewöhnlich ist, da es sich so in eine lange Tradition der Auseinandersetzung mit Alter Musik einreiht. Vor diesem Hintergrund verweisen die meisten Angaben zum musikalischen Material des Liedes Was ließen jene auf die

\footnotetext{
${ }^{80} \mathrm{Vgl}$. Scholz, Olkas Lieder, $86 f$.

${ }^{81}$ Vgl. Krolle Regionalstudie, 335, sowie Becker und Rode, Codex Patomomomensis, 180, T. 9-13: Die angesprochene Harmonik und die Akkordfolge der Melodieversion mit „spanischem“ Einschlag werden hier gut deutlich.

${ }^{82}$ Vgl. Wolfgang Lindner, Jugendbewegung als Äußerung lebensideologischer Mentalität. Die mentalitätsgeschichtlichen Präferenzen der deutschen Jugendbewegung im Spiegel ihrer Liedertexte (Hamburg: Kovac, 2003), 462.

${ }^{83}$ Krolle, Regionalstudie, 42.

${ }^{84}$ Krolle, Regionalstudie, 47.
} 
Verquickung von Musikauffassung und ideologischer Tendenz, die sich in den ersten beiden Phasen der Jugendbewegung Anfang des 20. Jahrhunderts herausgebildet hatte: zum einen das Ideal der Gemeinschaft und zum anderen die Tendenz, in der Musik einer weit zurückliegenden historischen Periode dieses Ideal als schon einmal verwirklicht zu betrachten. Die lapidare Kürze der Angaben („Alte Lautenmelodie“) sowie deren unbeanstandete Inkorrektheit in Bezug auf ursprüngliche Funktion („Lautenmelodie“) und tatsächlichen musikhistorischen Kontext (,... aus dem Barock") bestätigen dazu die Annahme, dass bei dieser Art der Verwendung alter Musik weniger die tatsächlichen musikalischen Gegebenheiten der jeweiligen historischen Periode als vielmehr die Vorstellung dieser Periode als eine bessere Vergangenheit im Vordergrund stehen, die sich auf die Kurzformel irgendwie alt $=$ gut bringen lässt. Dies geschieht zum einen, indem der Person des Komponisten meist wenig Beachtung geschenkt und die Komposition anonymisiert wird, zum anderen, indem die Kompositionszeit nicht benannt, sondern durch die Attribute „alt“ und die in diesem Fall sogar fälschliche Bezeichnung „barock“ in eine unbestimmte Vergangenheit verlagert wird. Die tatsächlichen Entstehungsumstände und biografischen Begebenheiten werden somit ausgeblendet. Die genaueren Herkunftsbezeichnungen der musikalischen Grundlage in einigen neueren Liedquellen sind zwar aufschlussreich in Bezug auf die tatsächliche Rezeptionsgrundlage, die so rezeptionsgeschichtlich korrekt ermittelt werden und dem Nimbus des irgendwie Alten entrissen werden konnte. Wegen des Ausnahmecharakters solcher genauen Angaben lässt sich daraus jedoch nach derzeitigem Kenntnisstand keine Tendenz der Bündischen Jugend zur verstärkten Auseinandersetzung mit dem eigenen Geschichtsbild ableiten.

Schließlich wurde deutlich, dass es sich bei der Umwandlung eines Instrumentalsatzes in einen Vokalsatz zwar um eine individuelle Transformationstechnik des Autors handelt, die jedoch wesentliche Merkmale einer bündischen Kompositionstechnik erkennen lässt, welche sich aus den verschiedenen Traditionslinien der Jugendbewegung speist. Anhand des Vergleichs von musikwissenschaftlicher Übertragung und bündischer Transformation und Rezeption des Satzes konnten Merkmale dieser Traditionslinien extrahiert werden. Diese Merkmale bilden drei Kategorien signifikanter Transformationen, die mit jeweils unterschiedlichen Stationen jugendbewegter Musikpraxis verknüpft sind und hier elaborierte Wandervogeltechnik, Primat der Melodie und (spät-)bündische Romantik genannt wurden. Diese Kategorien besitzen jedoch bis auf weiteres lediglich Beispielcharakter für eingehendere musikalische Inhaltsstrukturanalysen.

Interessanterweise finden sich in der Vertonung des Liedes zwar zahlreiche Bezüge zur Vergangenheit der ersten beiden Phasen der Jugendbewegung ${ }^{85}$, jedoch lassen sich, vielleicht bis auf die Verwendung einer 1936 erschienenen „Spielmusik“, kaum Konnotationen zur Musikpraxis im Dritten Reich feststellen. Der Topos der Musik

\footnotetext{
${ }^{85}$ Vgl. Nußbruch, Was ließen jene, $7 \mathrm{ff}$.
} 
erscheint somit fast gänzlich ungetrübt von den Schatten der Vergangenheit ${ }^{86}$, als welche etwa das 19. Jahrhundert, dessen Musik die verachteten Gesellschaftsverhältnisse widerspiegelt ${ }^{87}$, oder das NS-Regime, das die Jugendbewegung nachhaltig stigmatisierte, betrachtet werden. Durch die Musik wird somit ein Geschichtsbild transportiert, das gewisse blinde Flecken an den Stellen enthält, mit denen sich die Bündische Jugend nach 1945 musikalisch nicht in Verbindung bringen lassen möchte. Dafür werden auf verschiedene Weise Konnotationen an eine unbestimmte Vergangenheit erzeugt, die hier noch einmal in Kurzform aufgeführt seien:

der Bezug auf:

Musik des 16. Jahrhunderts markiert den ungefähren Zeitraum des jugendbewegten Musikideals.

Lautenmusik verweist auf die ideelle Verbindung von damaliger und heutiger Musikpraxis.

einen anonymen Komponisten zeigt die Musik, damals wie heute, als Produkt einer Gemeinschaft.

den Wandervogel stellt eine Reminiszenz an die Wurzeln der Jugendbewegung dar.

die Jugendmusikbewegung drückt musikalisch das Gemeinschaftsideal der Bündischen Jugend nach 1945 aus.

den Nerother Wandervogel und die Jungenschaften bestärkt die eigene Identität als weltläufig und unabhängig.

Wie man sehen kann, offenbart der hier demonstrierte musikphilologische Zugang eine Reihe von Anknüpfungspunkten an Traditionslinien der deutschen Jugendbewegung, die allein schon die musikalische Grundlage des Liedes als ein starkes Identifikationsobjekt der Bündischen Jugend nach 1945 erkennen lassen.

Nicht erkennen lässt dieser Zugang freilich, inwiefern diese Traditionslinien von den Rezipienten des Liedes, den Angehörigen der Bündischen Jugend nach 1945, in der Musik wieder erkannt und reflektiert werden. Hier stoßen die Methoden der historischen Musikwissenschaft an ihre Grenzen und müssen durch Methoden der qualitativen empirischen Musikforschung (Feldforschung, Interviews, Diskursanalyse) ergänzt werden. Nach Art weiterer liedmonographischer Sondierungen des an der Oberfläche äußerst unübersichtlichen Feldes der deutschen Jugendbewegung sollten daher zunächst weitere Liedmonographien eine kritische Analyse des Repertoires, wie sie oben angedeutet wurde, ermöglichen. In nächster Zeit wird eine eingehende musikethnographische Untersuchung dieser heute noch lebendigen Musikpraxis dem Ziel dienen, der gesellschaftlichen Tragweite des Phänomens der Bündischen Jugend nach 1945 auf dem Gebiet der Musik auf den Grund zu gehen.

\footnotetext{
${ }^{86}$ Ganz im Gegensatz etwa zum Liedtext, vgl. Nußbruch, Was ließen jene, 60ff.

${ }^{87}$ Ebd., $21 \mathrm{ff}$.
} 


\section{Literatur}

Archiv der deutschen Jugendbewegung. Bibliographie zur Geschichte der Jugendbewegung. Quellen und Darstellungen. Schwalbach/Taunus: Wochenschau, 2009.

Becker, Tim und Paul Rode. Codex Patomomomensis. Hamburg: Zauberwald, 2008.

Blume, Friedrich. Vorwort zu Die Musikforschung 1 (1945): 1ff.

Breuer, Hans. „Vorwort zur 1. Auflage“, in Der Zupfgeigenhansl. Leipzig: Röder, 1913, o.S.

Brown, Howard Mayer. Instrumental Music Printed before 1600. A Bibliographie. Cambridge, MA: Harvard, 1965.

Deutscher Pfadfinderbund DPB. Aufgerufen am 5. September 2013. http://www. deutscher-pfadfinderbund.de.

Editionskonzept Historisch Kritisches Liederlexikon. Aufgerufen am 30. Juni 2010. http://www.liederlexikon.de.

Eitner, Robert. „Tylman Susato“. In ders., Biographisch-Bibliographisches Quellenlexikon der Musiker und Musikgelehrten der christlichen Zeitrechnung bis zur Mitte des 19.Jahrhunderts, Bd. 9, 331. Leipzig: Breitkopf und Härtel, 1903.

Fritz, Michael. „Neue Innerlichkeit? - Gedanken eines Neubündischen über die Entwicklung des ,bündischen Singens` seit 1970“, der eisbrecher 1 (1988), 18ff.

Giesbert, F. J. Tielman Susato. Danserye. Altniederländisches Tanzmusikbüchlein vom Jahre 1551. In Spielpartitur für 4 Blockflöten oder beliebige MelodieInstrumente. 2 Bde., Mainz: Schott, 1936.

Heartz, Daniel. „Parisian Music Publishing under Henry II: A Propos of Four Recently Discovered Guitar Books“. Musical Quarterly 46, (1960): 448-67.

Höckner, Hilmar. „Jugendmusik“. In Riemann Musiklexikon. Sachteil, 431ff. Mainz: Schott, 1967.

— Die Musik der deutschen Jugendbewegung. Wolfenbüttel: Kallmeyer, 1927.

Jöde, Fritz. „Die neue Musik-Gesinnung“. In Grundschriften der deutschen Jugendbewegung, hg. von Werner Kindt, 204ff. Düsseldorf, Köln: Diederichs, 1963.

Jöde, Ulf. Die Entwicklung des Liedsatzes in der Jugendmusikbewegung. Wolfenbüttel und Zürich: Möseler, 1969.

Kolland, Dorothea. Die Jugendmusikbewegung. „Gemeinschaftsmusik“- Theorie und Praxis. Stuttgart: Metzler, 1979. 
Kommer, Sven. „Musik in der Jugendbewegung“. In Handbuch Jugend und Musik, hg. von Dieter Baake, 195-216. Opladen: Leske und Budrich, 1998.

König, Helmut. „Der ,Zupfgeigenhanslund“ seine Nachfolger. Drei Phasen der Jugendbewegung im Spiegel repräsentativer Liederbücher“. In „Mit uns zieht die neue Zeit... ". Der Wandervogel in der deutschen Jugendbewegung, hg. von Ulrich Herrmann, 232-75. Weinheim, München: Juventa, 2006.

Krolle, Stefan. Musisch-kulturelle Etappen der deutschen Jugendbewegung von 1919 1964. Eine Regionalstudie. Münster: Lit, 2004.

Laqueur, Walter. Die deutsche Jugendbewegung. Eine historische Studie. Köln: Verlag Wissenschaft und Politik, 1978.

Leopold, Silke. „Barock“. In Die Musik in Geschichte und Gegenwart. Allgemeine Enzyklopädie der Musik, 2., neu-bearbeitete Ausgabe, hg. von Ludwig Finscher, Sachteil, Bd. 1, 1235-56. Kassel und Stuttgart: Bärenreiter, 1997.

Lindner, Wolfgang. Jugendbewegung als Äußerung lebensideologischer Mentalität. Die mentalitätsgeschichtlichen Präferenzen der deutschen Jugendbewegung im Spiegel ihrer Liedertexte. Hamburg: Kovac, 2003.

Meißner, Ute. Der Antwerpener Notendrucker Tylman Susato. Eine bibliographische Studie zur niederländischen Chansonpublikation in der ersten Hälfte des 16. Jahrhunderts. 2 Bde., Berlin: Merseburger, 1967.

Merian, Wilhelm. Der Tanz in den Deutschen Tabulaturbüchern. Mit thematischen Verzeichnissen, Beispielen zur Intavolationspraxis und einer Studie über die Anfänge des Klavierstils. Hildesheim: Olms, 1968 (Reprografie der Ausgabe Leipzig, 1927).

Mohr, Ernst. Die Allemande. Eine Untersuchung ihrer Entwicklung von den Anfängen bis zu Bach und Händel. 2 Bde., Zürich: Hug, 1932.

Monatshefte für Musikwissenschaft 6/7 (1875).

Nußbruch, Simon. „„Was ließen jene, die vor uns schon waren“: ein Beispiel für die Musik der Bündischen Jugend nach 1945“. Magisterarbeit, Universität Hamburg, 2011.

Päffgen, Peter. „Lauten“. In Die Musik in Geschichte und Gegenwart. Allgemeine Enzyklopädie der Musik, 2., neu-bearbeitete Ausgabe, hg. von Ludwig Finscher, Sachteil, Bd. 5, 975ff. Kassel und Stuttgart: Bärenreiter, 1996. 
Reulecke, Jürgen. „Wir reiten die Sehnsucht tot ${ }^{`}$ oder: Melancholie als Droge. Anmerkungen zum bündischen Liedgut", in Männergeschichte - Geschlechtergeschichte. Männlichkeit im Wandel der Moderne, hg. von Thomas Kühne, 156-73. Frankfurt am Main, New York: Campus, 1996.

Schilling Konrad, Helmut König, Herbert Hoss. Der Turm B. Folklore aus allen Ländern. Bad Godesberg: Voggenreiter, 1966.

Scholz, Erich. Olkas Lieder. Heidenheim/Brenz: Südmarkverlag, 1984.

schrift 9. O.O., Bund deutscher Jungenschaften, 1962.

Stoverock, Karin. „Bündische Lieder in der Hitler-Jugend“, in Lieder in Politik und Alltag des Nationalsozialismus, hg. von Gottfried Niethart und George Broderick, 35-60. Frankfurt: P. Lang, 1999.

Taes, Sofie. „Susato, Tielman“. In Die Musik in Geschichte und Gegenwart. Allgemeine Enzyklopädie der Musik, 2., neu-bearbeitete Ausgabe, hg. von Ludwig Finscher, Personenteil, Bd. 16, 301ff. Kassel und Stuttgart: Bärenreiter, 2006.

Wörner, Karl H. Geschichte der Musik. Ein Studien und Nachschlagebuch. Göttingen: Vandenhoeck und Ruprecht, 1993. 


\title{
Methoden musikalischer Opposition in Portugal während der Salazar-Diktatur bei Jorge Peixinho und José Afonso
}

\author{
Gilbert Stöck (Leipzig)
}

In den drei bislang besonders gut untersuchten Diktaturen des 20. Jahrhunderts („Deutsches Reich“ 1933-1945, Sowjetunion, Deutsche Demokratische Republik) ${ }^{1}$ traten Strategien zutage, avancierte Musik und ihre Vertreter, vor allem im Gefolge der sogenannten Wiener Schule um Arnold Schönberg (1874-1951), zu diskreditieren. Zur NS-Zeit wurden sie als jüdisch-bolschewistisch, im Staatssozialismus als spätbürgerlich-dekadent bezeichnet. In den sozialistisch geprägten Ländern wurde zudem versucht, eine eigene sozialistische Kunstästhetik in Form des Sozialistischen Realismus durchzusetzen - bekanntlich scheiterte dieser Versuch jedoch. Die Gretchenfrage an ein diktatorisches Regime, „Wie hältst Du’s mit der Dodekaphonie?", stellt sich bei jeder Beschäftigung mit den Musikverhältnissen unter solchen politischen Vorzeichen, ohne das Musikleben aber nur auf diesen einen Parameter reduzieren zu wollen. ${ }^{2}$

\footnotetext{
${ }^{1}$ Auf eine Ausdifferenzierung der Unterschiede und Gemeinsamkeiten zwischen den genannten Gesellschaftssystemen wird hier verzichtet. Die in der Klammer aufeinanderfolgende Aufzählung intendiert kein Ignorieren der unterschiedlichen Herrschaftskonzepte.

${ }^{2}$ Auf eine ausladende Bibliographie zur Musikgeschichte der genannten Herrschaftssysteme wird hier verzichtet. Relativ aktuelle Publikationstitel zum Thema sind Matthias Tischer, Komponieren für und
} 
Die unbedingte Gleichsetzung von musikalischer Avantgarde und politischer Opposition, und die damit verbundene Schlussfolgerung, traditionalistische ästhetische Konzepte verwiesen ,natürlich' auf Politisch-Opportunes, sind in ihrem strikten Anspruch nicht aufrecht zu erhalten, ${ }^{3}$ auch wenn in den oben genannten Gesellschaftssystemen durchaus solche Tendenzen aufgespürt werden können. Es gibt eben auch Möglichkeiten musikalischer Opposition mit Mitteln, die den musikalischen und inhaltlichen Nachvollzug bewusst einfach gewährleisten sollen: Musik, die sich nicht an ein Fachpublikum wendet, sondern an ein ,breites' Publikum mit unterschiedlicher musikalischer Vorkenntnis. Solche Musik vermittelt Kritisches nicht durch fein nuancierte Symbolik, sondern durch das Erzeugen einer affirmativen Haltung gegenüber der im Text vermittelten, zuweilen verschlüsselten Botschaft.

Aufgrund der bislang zurückhaltenden Aufarbeitung der Musikgeschichte Portugals im 20. Jahrhundert lassen sich differenzierende Aussagen für die Musikszene zur Zeit von António de Oliveira Salazar (1889-1970) und Marcelo Caetano (19061980) nur vorsichtig treffen. Es gibt indes Anzeichen, dass die Unterdrückung bzw. der Versuch der Unterdrückung avancierter musikalischer Verfahren, wie zur Zeit des Nationalsozialismus' und der sozialistischen Staaten, in Portugal anders verlief. Salazar und António Ferro (1895-1956), sein wichtigster Ideologe im Bereich der Kultur, ${ }^{4}$ verzichteten anscheinend auf den Versuch, eine Generaldebatte über Musikästhetik und die musikalische Avantgarde zu führen. Somit war der Weg zur Entwicklung eines breiten Feldes unterschiedlicher und simultan ausgelebter Stilrich-

wider den Staat (= KlangZeiten 6, Köln u.a.: Böhlau, 2009); Lénine, Staline et la musique. Catalogue de l'exposition Paris 2010-2011, hg. von Cité de la Musique (Paris: Fayard, 2010); Musikwissenschaft und kalter Krieg. Das Beispiel DDR, hg. von Nina Noeske und Matthias Tischer (= KlangZeiten 7, Köln u.a.: Böhlau, 2010); Ulrich Drüner und Georg Günther, Musik und „Drittes Reich“. Fallbeispiele 1910 bis 1960 zu Herkunft, Höhepunkt und Nachwirkungen des Nationalsozialismus in der Musik (Köln u.a.: Böhlau, 2012); Maren Goltz, Musikstudium in der Diktatur. Das Landeskonservatorium der Musik/die Staatliche Hochschule für Musik Leipzig in der Zeit des Nationalsozialismus 1933-1945 (Stuttgart: Steiner, 2013) und Katrin Stöck, Musiktheater in der DDR (= KlangZeiten 10, Köln u.a.: Böhlau, 2013).

${ }^{3}$ Christoph Flamm, „Musik, Diktatur, Geschichtsschreibung. Fünf Anmerkungen“, in Musikwissenschaft und kalter Krieg. Das Beispiel DDR, hg. von Nina Noeske und Matthias Tischer (= KlangZeiten 7, Köln u.a.: Böhlau 2010), 131-41. Flamms Beitrag zeigt anhand der Betrachtung von Komponisten wie Nicolas Medtner und Ottorino Respighi (134-36), wie sehr sich unser Fach vom Automatismus, ästhetische Tradition mit politischer Reaktion gleichzusetzen, negativ beeindrucken ließ.

${ }^{4}$ Jorge Ramos do Ó, Os anos de Ferro. O dispositivo cultural durante a „Política do Espírito“ 1933-1949. Ideologia, instituiçōes, agentes e práticas (= Histórias de Portugal 45, Lissabon: Estampa, 1999), einführend in Salazars Auffassung von Propaganda und das Verhältnis zwischen Salazar und Ferro siehe dort S. 17-39. 
tungen möglich - von neoromantischen Tendenzen bis zur Avantgarde. ${ }^{5}$ Werke renommierter Komponisten der Avantgarde konnten studiert und aufgeführt werden, solange sie keine regimekritischen Positionen einnahmen. Darüber hinaus begannen Komponisten wie Emmanuel Nunes (1941-2012), der in jungen Jahren nach Paris ging, und Jorge Peixinho (1940-1995) kurz vor 1960, intensiver musikalische Tendenzen der europäischen Nachkriegsmoderne zu rezipieren. ${ }^{6}$ Salazar und seine Regierung ließen sie gewähren, förderten aber auch nicht die Entwicklung und Verbreitung avancierter Musik in Portugal, so dass Komponisten und Musiker zumeist schwierigen ökonomischen Zwängen unterlagen, wenn sie Werke schaffen und aufführen wollten. Es ist vor allem der „Fundação Calouste Gulbenkian“ zu verdanken, dass sich diese Situation ab 1956 durch Hilfestellungen wie etwa Werkaufträge und Konzertreihen verbesserte. ${ }^{7}$

Die Strategie des Regimes hingegen zielte eher darauf ab, zwischen Hochkultur und Volkskultur zu differenzieren. Erstere umspannte ein Repertoire von Werken des ,klassischen Erbes' und Werken, die besonders vergangene ruhmreiche Epochen portugiesischer Geschichte oder auch die Verklärung des Landlebens thematisierten; hierzu zählten u.a. die Werke, die für die unter Salazar gegründete Ballettgruppe „Verde Gaio“ komponiert wurden. ${ }^{8}$ Auf diese Weise verstandene Hochkultur war

${ }^{5}$ José Eduardo Rocha, „14 anotaçóes sobre Música Contemporanea Portuguesa“, in Historia da música portuguesa, hg. von João de Freitas Branco (Mem Martins: Europa-América, $\left.{ }^{4} 2005\right), 345-52$; 356-73, 376-85; Manuel Carlos de Brito und Salwa El-Shawan Castelo-Branco, „Portugal“, in Die Musik in Geschichte und Gegenwart. Allgemeine Enzyklopädie der Musik, 2., neu-bearbeitete Ausgabe, hg. von Ludwig Finscher, Sachteil, Bd. 7 (Kassel und Stuttgart: Bärenreiter, 1997), 1713f.; Gilbert Stöck, „Komponieren in Portugal in den 1960er Jahren. Beobachtungen zu Fernando Lopes-Graça, Emmanuel Nunes und Jorge Peixinho", Die Musikforschung 66 (2013), 56-66.

${ }^{6}$ Rocha, „14 anotações“, 364-67; de Brito und Castelo-Branco, „Portugal“, 1714.

${ }^{7}$ Rui Vieira Nery, „Fundaçâo Calouste Gulbenkian“, in Enciclopédia da música em Portugal no século XX, Bd. 2, hg. von Salwa El-Shawan Castelo-Branco (Lissabon: Círculo de Leitores, 2010), 535-48; João de Freitas Branco, Historia da múscia portuguesa (Mem Martins: Europa-América, ${ }^{4} 2005$ ), 309; Francisco Monteiro, „The Portuguese Darmstadt Generation: The Piano Music of the Portuguese Avant-Garde" (Dissertation, University of Sheffield, 2002), 72f. Zu erwähnen wäre, dass der weitreichende Einfluss der Gulbenkian-Stiftung auf das Musikleben Portugals zuweilen kritisch gesehen wurde. Diese Debatte kompiliert und erläutert António Pinho Vargas (Música e poder. Para uma sociologia da ausência da música portuguesa no contexto europeu, [Coimbra: Almedina, 2011], 420-44).

${ }^{8}$ Maria de Sáo José Côrte-Real, „Musical Priorities in the cultural policy of ,Estado Novo“", Revista portuguesa de musicologia 12 (2002): 238 und 244f.: Ballette von Ruy Coelho (D. Sebastião und Inês de Castro) und Frederico de Freitas (Dança da menina Tonta und Imagens da Terra e do Mar), außer den Werken für „Verde Gaio“ kann hierzu auch das Oratorium Fátima von Ruy Coelho gezählt werden (Mário Vieira de Carvalho, Denken ist Sterben. Sozialgeschichte des Opernhauses Lissabon [= Musiksoziologie 5, Kassel und Stuttgart: Bärenreiter, 1999], 277ff.). Siehe einführend dazu Vitor Pavão dos San- 
den Eliten vorbehalten und wurde entsprechend glamourös zelebriert. ${ }^{9}$ Volkskultur, die sich an eine breite Öffentlichkeit wendet, wurde im Rahmen der sogenannten ,Folklorisierung' durch staatliche Behörden gefördert, um durch die Konstruktion des ,typisch` Portugiesischen Identifikationsmuster für die Bevölkerung - als Legitimation des portugiesischen ,Estado Novo' und dessen ,gütige' Lenkung durch Salazar - anbieten zu können. Gerade die Entstehung der „Ranchos Folcloricos“ und die Entwicklung des Fado-Gesangs können hier paradigmatisch genannt werden. ${ }^{10}$ Das wichtigste politische Organ zur Förderung der künstlerischen ,Folklorisierung' war das 1933 gegründete "Secretariado da Propaganda Nacional“ (SPN). ${ }^{11}$

Eine der weiteren Aufgaben des SPN war, neben der Organisation folkloristischer Aktivitäten, die Observierung der Kunstszene durch die Zensur. Die „Direcção Geral dos Serviços de Espectáculos", war eine Behörde innerhalb des SPN und beeinflusste das künstlerische Geschehen u.a. durch Kontrollen von Konzert- und Rundfunkprogrammen. ${ }^{12}$ Die Lenkung des Musiklebens erfolgte schließlich auch durch die portugiesische Musikergewerkschaft unter der Führung von Ivo Cruz (19011985). Hier versuchte der Staat zentralistische Regelungen durchzusetzen. Die Gewerkschaft baute ein musikalisches Auftragswesen auf, versuchte tiefgehend in Vertragsverhandlungen einzugreifen und führte Lizenzausweise für professionelle Musiker ein, um kontrollieren zu können, wer öffentlich musikalisch in Erscheinung

tos, „Verde Gaio. Uma Companhia Portuguesa de Bailado (1940-1950)“, in Verde Gaio. Uma Companhia Portuguesa de Bailado (1940-1950), hg. von Vitor Pavão dos Santos (Lissabon: IPM, 1999), 13-84 und Maria Luísa Roubaud, „O Verde Gaio - Uma política do corpo no Estado Novo“, in Vozes do povo - a folclorização em Portugal, hg. Salwa El-Shawan Castelo-Branco und Jorge Freitas Branco (Oeiras: Celta Editora, 2003), 337-53.

${ }^{9}$ Carvalho, Denken ist Sterben, 268-79; Côrte-Real, „Musical Priorities“, 233, 238 und 241.

${ }^{10}$ Siehe hierzu einführend Vozes do povo - a folclorização em Portugal, hg. von Salwa El-Shawan Castelo-Branco und Jorge Freitas Branco (Oeiras: Celta Editora, 2003), insbesondere Salwa El-Shawan Castelo-Branco und Jorge Freitas Branco, „Folclorização em Portugal. Uma perspectiva“, 1-21 und Vera Marques Alves „O SNI e os ranchos folclóricos“, 191-205, sowie Maria de Săo José Côrte-Real, „Cultural Policy and Musical Expression in Lisbon in the Transition From Dictatorship to Democracy (1960s-1980s)“ (Dissertation, Columbia University, New York, 2000), insbesondere 19-42, 89-102 und 153-204.

${ }^{11}$ SPN, ab 1945 „Secretariado Nacional de Informação“ (SNI), ab 1968 „Secretaria de Estado da Informação e Turismo“ (SEIT). Siehe hierzu Alves „O SNI“, 191-205 und Daniel Melo, A cultura popular no Estado Novo (Coimbra: Angelus Novus, 2010), 23f.

${ }^{12}$ Kian-Harald Karimi, Auf der Suche nach dem verlorenen Theater. Das portugiesische Gegenwartsdrama unter der politischen Zensur (1960-1974) (= Bonner Romanistische Arbeiten 40, Frankfurt am Main: Lang, 1991), 174-80. 
trat. ${ }^{13}$ Außerhalb dieser sanktionierten Bereiche gab es eine von staatlicher Initiative freiere und daher kritisch beäugte Kunstszene, wie die weiter unten an José Afonso (1929-1987) beispielhaft erörterte Liedermacher-Szene.

Komponisten, die politisch oppositionell agierten, konnten kaum mit öffentlicher Unterstützung rechnen, Interpreten zur Aufführung ihrer Werke zu finden. Sie waren darauf angewiesen, sich unter erschwerten Bedingungen Gehör zu verschaffen. Fernando Lopes-Graça (1906-1994) und Jorge Peixinho halfen sich durch die Gründung eigener Ensembles und Konzertreihen, denen sie vorstanden und mit denen sie unter anderem eigene Kompositionen zur Aufführung bringen konnten. Während Lopes-Graça 1942 die „Concertos Sonata“ und 1946 den „Coro do Grupo Dramático Lisbonense" gründete, ${ }^{14}$ versammelte Peixinho 1970 um sich einige Interpreten, ${ }^{15}$ um mit ihnen die "Grupo de Música Contemporânea de Lisboa" zu gründen.

Der Zensur und den Veröffentlichungs- und Verbreitungsproblemen ihrer Kunst zum Trotz, suchten Komponisten und Interpreten auf unterschiedliche Art und Weise Möglichkeiten, ihrem Unmut gegenüber dem existierenden Regime und ihrer oppositionellen politischen Geisteshaltung Ausdruck zu verleihen. Zwei unterschiedliche Verfahren musikalischer Auflehnung werden im Folgenden für zwei unterschiedliche Genres anhand von Werken von Jorge Peixinho und José Afonso näher erläutert. ${ }^{16}$

\footnotetext{
${ }^{13}$ Es wurde auch versucht, Musiker in Kinos zwangseinzustellen, um die Arbeitslosigkeit unter Musikern zu verringern. So sollte in den Pausen von Filmvorführungen Livemusik erklingen. Die Gewerkschaft plante hier genaue Regelungen: welche Saalgröße wie viele Musiker erfordere usw. Dieses Ansinnen wurde im Endeffekt aber aufgrund weiter Proteste der Kinobetreiber nicht realisiert (Manuel Deniz Silva, ,„La musique a besoin d'une dictature“. Musique et politique dans les premières années de l'Etat Nouveau (1926-1945)“, Bd. 1 [Dissertation, Université de Paris VIII, 2005, 255-64]).

${ }^{14}$ Mário Vieira de Carvalho, Pensar a música, mudar o mundo - Fernando Lopes-Graça (Porto: Campo das Letras, 2006), 18 und 41; ders., „Politics of Identity and Counter-Hegemony. Lopes-Graça and the Concept of National Music“, Music \& Politics 6/1 (2012): 10. Der „Coro do Grupo Dramático Lisbonense“ nahm den Namen „Côro da Academia de Amadores de Música“ an, heute heißt er „Coro Lopes-Graça da Academia de Amadores de Musica“.

${ }^{15}$ Catarina Latino und Rui Cabral Lopes, „Grupo de Música Contemporânea de Lisboa“,Enciclopédia da música em Portugal no século XX, Bd. 2, 588. Zur Gruppe zählte u.a. die bedeutende portugiesische Komponistin Clotilde Rosa.

${ }^{16}$ Natürlich zählen auch Bereiche des Schaffens von Fernando Lopes-Graça hierzu. Auf die Erörterung seiner Methoden, sich künstlerisch gegen die Diktatur zu wenden, wird hier verzichtet, da es hierzu bereits einige Publikationen - nicht nur auf Portugiesisch - gibt (beispielsweise Mário Vieira de Carvalho, „Lebendige Aktion` gegen ,geträumte Aktion` - Musik und antifaschistischer Wiederstand in Portugal“", in Festschrift für Georg Knepler zum 90. Geburtstag, Bd. 2: Musik - Revolution, hg. von Hanns-Werner Heister (Hamburg: von Bockel, 1997), 325-47; ders., Pensar a música; ders.,
} 


\section{Jorge Peixinho}

Das politische Antriebsaggregat für Peixinho ${ }^{17}$ und andere bedeutende Komponisten Portugals, beispielsweise Fernando Lopes-Graça, und anfangs auch für Emmanuel Nunes, war die „Partido Comunista Português“ und ihr zäher Versuch, das SalazarRegime - trotz Parteiverbotes - zu bekämpfen. ${ }^{18}$ Grundsätzlich war Peixinho kein Komponist, der seine politischen Überzeugungen mit Hilfe deutlicher Symbolik innerhalb seines künstlerischen Schaffens zum Ausdruck brachte. Vielmehr intendierte für ihn avanciertes Schaffen per se eine revolutionäre, politisch links orientierte Haltung. ${ }^{19}$ Doch schuf er besonders vom Ende der 1960er Jahre bis 1974 mehrere Werke, die deutlicher als sonst üblich in seinem Schaffen, politische Implikationen vermitteln. Dabei attackierte Peixinho Caetano und sein Regime nicht direkt, sondern

„Between Political Engagement and Aesthetic Autonomy. Fernando Lopes-Graça’s Dialectical Approach to Music and Politics, “20th-Century Music 8 (2011): 175-202; ders., „Politics of Identity“, 112).

${ }^{17}$ Peixinho lebte von 1940-1995 und war, nach seinem Studium am Nationalkonservatorium u.a. Schüler von Luigi Nono in Venedig und Goffredo Petrassi in Rom. In den 1960er Jahren studierte er zudem in Basel und Darmstadt auch bei Pierre Boulez und Karlheinz Stockhausen. Ab den 1970er Jahren war er als Komponist, Pädagoge und Schriftsteller maßgeblich in die portugiesische Musikszene eingebunden. Siehe einführend Mário Vieira de Carvalho, „Jorge Peixinho“, in $K d G$ (9. Nachlieferung, Februar 1996), Evgueni Zoudilkine, „Peixinho, Jorge“, in Enciclopédia da Música em Portugal no Século XX, Bd. 3, 977-80; Mário Vieira de Carvalho, „Jorge Peixinho. Entdeckung einer musikalischen Persönlichkeit“, in Musik-Kontexte. Festschrift für Hanns-Werner Heister, Bd. 1, hg. von Thomas Phleps und Wieland Reich (Münster: Monsenstein und Vannerdat, 2011), 150-64; Mémoires... Miroirs. Conferências do Simpósio Internacional Jorge Peixinho Lisboa 2010, hg. von Paulo de Assis (Lissabon: Colibri, 2012) und Stöck, „Komponieren in Portugal“, 56-66.

${ }^{18}$ Die Kommunistische Partei Portugals wurde 1921 gegründet und schon bald danach, nach der Machtergreifung von Salazar im Jahre 1926, verboten. Ab diesem Zeitpunkt agierte sie bis April 1974 im Untergrund (António Henrique de Oliveira Marques, Geschichte Portugals und des portugiesischen Weltreichs (Lissabon: Presença, 1995; dt. Stuttgart: Alfred Kröner, 2001), 558f. und 563; Fernando Rosas, O Estado Novo (1926-1974) (= História de Portugal7, Lissabon: Estampa, 1998), 483f.).

19 „Se a música contemporânea, para Jorge Peixinho, era instrinsecamente [sic] revolucionária, não havia que submetê-la aos ditames do imediatismo político. A relaçáo da política com a sua obra restringiu-se ao uso da escrita musical e da palavra a ela associada para veicular, estrutural ou pontualmente, simpatias ou convicçóes ideológicas do compositor.“ (Manuel Pedro Ferreira, „A obra de Jorge Peixinho - problemática e recepçáo", in Jorge Peixinho in memoriam, hg. von José Machado [Lissabon: Caminho, 2002], 247). Siehe hierzu auch Cristina Delgado Teixeira, Música, estética e sociedade nos escritos de Jorge Peixinho (= Ensaios Musicológicos 1, Lissabon: Colibri, 2006), 100ff., 101: „A sua música dá testemunho do seu tempo e revela-nos as suas emoções, interroga-se e interroga-nos, apela a uma permanente atitude crítica.“ 
behandelte in einigen Kompositionen Themen, die politisch linksorientierte Positionen unterstützten. Hierzu zählen ${ }^{20}$

Quatro peças para Setembro negro (JP $054^{21}$ 1972; Kammerensemble): Statement für die Palästinensische Befreiungsorganisation PLO. Als Schwarzer September wurden Auseinandersetzungen zwischen dem jordanischen Militär und der PLO im Jahre 1970 bezeichnet, bei denen es um ein Kräftemessen in Jordanien ging. Der Konflikt endete mit einem Friedensschluss zwischen König Hussein von Jordanien (1935-1999) und Jassir Arafat (1929-2004) als Vorsitzendem der PLO.

Elegia a Amilcar Cabral (JP 058 a und b, 1973; elektroakustische Komposition): Ehrung für den Anführer der Widerstandsbewegung in Guinea-Bissau, einer Provinz Portugals. Cabral (1924-1973) wurde im Januar 1973 von einem Mitglied der separatistischen Gruppe „Partido Africano da Independência da Guiné e Cabo Verde“ (PAIGC) erschossen - wenige Monate, bevor Guinea-Bissau unabhängig wurde und somit die Ziele Cabrals erreicht wurden.

Morrer em Santiago (JP 060, 1973; 6 Perkussionisten): Statement gegen die Diktatur von General Pinochet (1915-2006) in Chile seit dem Putsch vom 11. September 1973, bei dem bekanntlich der kommunistische Staatschef Salvador Allende (1908-1973) gestürzt wurde. Dies hatte gerade bei kommunistischen Politikern und Regierungen weltweit heftige Proteste ausgelöst.

$C D E$ (JP 040, 1970; Klar., V., Vc., Klav.): Dieses, den musikalischen Satz stabilisierende c - d - e, das dem Stück den Namen gibt, ist wohl eine unausgesprochene Unterstützung der „Comissão Democrática Eleitoral“ (eben abgekürzt: CDE). Die "Comissão Democrática Eleitoral“ war die führende politische Opposition in Vorbereitung nationaler Wahlen in Portugal und wurde vor allem durch kommunistische Kräfte angeführt. ${ }^{22}$ Peixinho arbeitete eng mit der „Comissão Democrática Eleitoral“ zusammen.

\footnotetext{
${ }^{20}$ Vgl. Jorge Lima Barreto, „Há mil peixinhos a nadar. Da arte de Jorge Peixinho e uma entrevista“, in Jorge Peixinho in memoriam, hg. José Machado (Lissabon: Caminho, 2002), 199, Ferreira, „A obra de Jorge Peixinho“, 247; Teixeira, Música, estética, 105ff.; Carvalho, „Jorge Peixinho“, 153 und Gilbert Stöck: „Jorge Peixinho's ,CDE“ - On the Relationship between Music and Cultural Policy“, in Mémoires... Miroirs. Conferências do Simpósio Internacional Jorge Peixinho Lisboa 2010, hg. von Paulo de Assis (Lissabon: Colibri, 2012), 31-45.

${ }^{21}$ Die Werkverzeichnis-Nummern stammen aus Cristina Delgado Teixeira u.a., „Catálogos da obra de Jorge Peixinho", in Jorge Peixinho in memoriam, hg. von José Machado (Lissabon: Caminho, 2002), 321-69.

${ }^{22}$ Hier engagierte sich auch der unten vorgestellte Liedermacher José Afonso (Maria de Sáo José Côrte-Real, „Afonso, José“, in Enciclopédia da música em Portugal no século XX, Bd. 1, 16). Ergänzend sei gesagt, dass sich in der Zeit vor Wahlen das Salazar-Regime etwas liberaler gab, die Zensur lockerte usw. Die Kandidaten der Opposition legten aber regelmäßig innerhalb der CDE knapp vor den Wah-
} 
In $C D E$ setzt Peixinho einerseits auf Techniken wie Zitate durch Verschlüsselung von Buchstaben zu Tonbuchstaben (CDE, LiBErDADE, CHE GuEvArA .... $)^{23}$ und greift andererseits auf musikalische Zitate anderer Werke zurück. Das streckenweise dodekaphon angelegte Werk ist in 44 zuweilen sehr heterogen angelegte Abschnitte aufgeteilt, wobei aber in 29 Abschnitten die diatonische Reihe c-d-e oder deren Transposition deutlich hervortritt. Natürlich ist die Folge oder die Schichtung von Ganztonschritten keine Seltenheit in europäisch-,abendländischer 'Musik, aber die Textur in $C D E$ hebt diese Töne sukzessiv oder simultan recht deutlich hervor. Das c - d - e erscheint zumeist in Haltetönen, die als eine Art Klangteppich fungieren. Sie erlauben eine darüber liegende, zuweilen sehr bewegt und brüchig verlaufende klangliche Artikulation - das c - d - e stabilisiert somit weite Teile des Werkes. Die Haltetöne selbst werden oftmals durch vielfältige Artikulation und Dynamik variiert. Diese diatonische Progression ist zuweilen durch das fis erweitert. Die Erweiterung von c - d - e zu c - d - e - fis führt zur Vergrößerung des Ambitus von großer Terz zu übermäßigen Quart. Die übermäßige Quart spielt in 8 der 44 Abschnitte eine klangprägende Rolle, beispielsweise ganz am Ende des Stücks. Das c - d - e - fis erinnert natürlich an den Choral Es ist genug, der spätestens durch die Verarbeitung von Johann Sebastian Bach (1685-1750) - beispielsweise in der Kantate BWV 60 - berühmt wurde.

Im Kontext der bereits besprochenen Symbolik könnte dieses musikalische Zitat durchaus als Peixinhos Hinweis verstanden werden, dass es mit der Diktatur und der Herrschaft von Caetano nun genug sei. ${ }^{24}$ Dass Peixinho eine ausgezeichnete Kenntnis von europäischer Musikgeschichte hatte, bezeugen zahlreiche Stellungnahmen, Artikel und nicht zuletzt musikalische Zitate in seinen Werken, die auf historische Vorbilder verweisen. ${ }^{25}$ Vielleicht kannte er den Choral auch über die Vermittlung durch Alban Bergs (1885-1935) Violinkonzert.

len die Kandidatur nieder, da es aussichtslos erschien, dass freie Wahlen durchgeführt würden. (Marques, Geschichte Portugals, 564).

${ }^{23}$ Auf das „CHE“- und „LIBERDADE“-Symbol hat bereits Hans-Klaus Jungheinrich hingewiesen (Hans-Klaus Jungheinrich, „Ein Stück Begrenztes, das dennoch vom Unbegrenzten zeugt. Ein Hinweis auf neue Musik in Portugal“, Jahresring 29 (1982/83): 85). Weitere analytische Ausführungen finden sich bei Alejandro Erlich-Oliva, „Strauss homenageia Peixinho (II)“, in Jorge Peixinho in memoriam, hg. von José Machado (Lissabon: Caminho, 2002), 301-303 und Stöck: „Jorge Peixinho's ,CDE““, 31-45.

${ }^{24}$ Zudem erscheinen vor allem in Werken der 1970er Jahre besonders oft musikalische Zitate, so dass dies ein weiteres Indiz für einen bewussten Bezug auf Johann Sebastian Bach sein könnte (Teixeira, Música, estética, 165).

${ }^{25}$ Z.B. in „As Quatro Estaçôes“, JP 044 b, 1972 (Teixeira, Música, estética, 166f.). Hinweise auf Peixinhos musikgeschichtliches Wissen sind aufgearbeitet in Teixeira, Música, estética, 115-26 (dezidierter Bezug auf Johann Sebastian Bach auf S. 116) und in zahlreichen Aufsätzen und Interviews, veröf- 


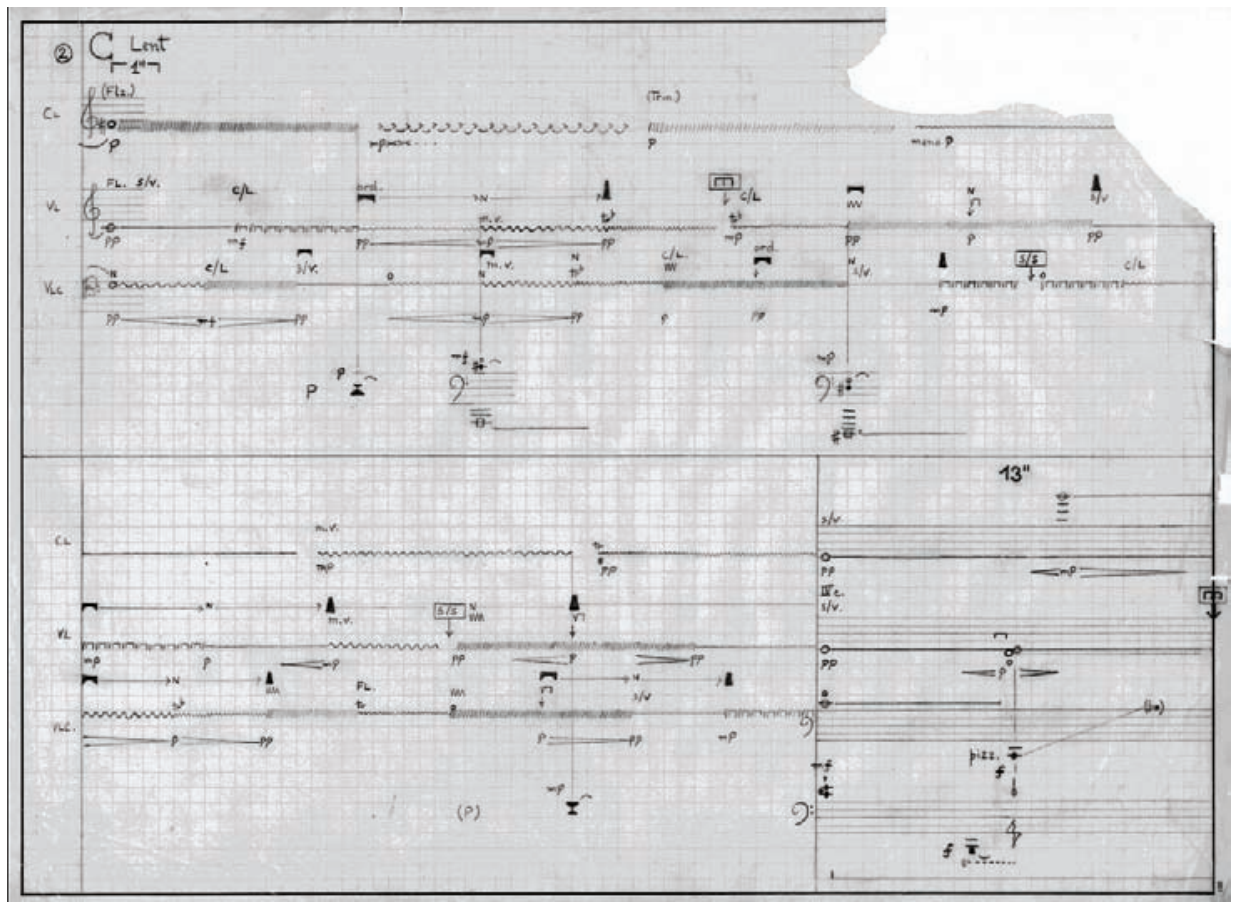

Abbildung 1: CDE: Abschnitt 2 mit Variation der Artikulation (Flatterzunge, verschiedene Vibrati, Triller) und der Dynamik ${ }^{26}$

Erschließt sich der Kontext des Bach-Chorals für den Hörer auditiv durch Kenntnis des musikalischen Repertoires, bleiben die ersten Verschlüsselungen sehr artifiziell nur für denjenigen zu dechiffrieren, der die Partitur studiert und zugleich die in Portugal - wie auch anderswo - üblichen Tonbezeichnungen durch die deutschen bzw. englischen Tonbuchstaben zu ersetzen weiß. ${ }^{27}$ Wenn man so will: Peixinho nähert sich dem Konzept einer modernen ,musica reservata', die es der aufdeckenden Zensur schwer machen will. ${ }^{28}$

fentlicht in Jorge Peixinho, Escritos e entrevistas, hg. von Cristina Delgado Teixeira und Paulo de Assis (Porto: Casa da Música, 2010).

${ }^{26}$ Das Faksimile stammt von der online bereitgestellten Partitur des Centro de Investigação \& Informação da Música Portuguesa (www.mic.pt; letzter Zugang 22. Juli 2015).

${ }^{27}$ Die Töne c-d-e heißen in der portugiesischen Fachterminologie dó-re-mi, und somit erfordert die Zuordnung des Werktitels zu konkreten Tönen eine Übersetzung.

${ }^{28}$ Zudem wurden bei den Aufführungen bis zur Revolution die Titel nur unvollständig abgedruckt, z.

B. Morrer em ... (Carvalho, „Jorge Peixinho“, 153). 


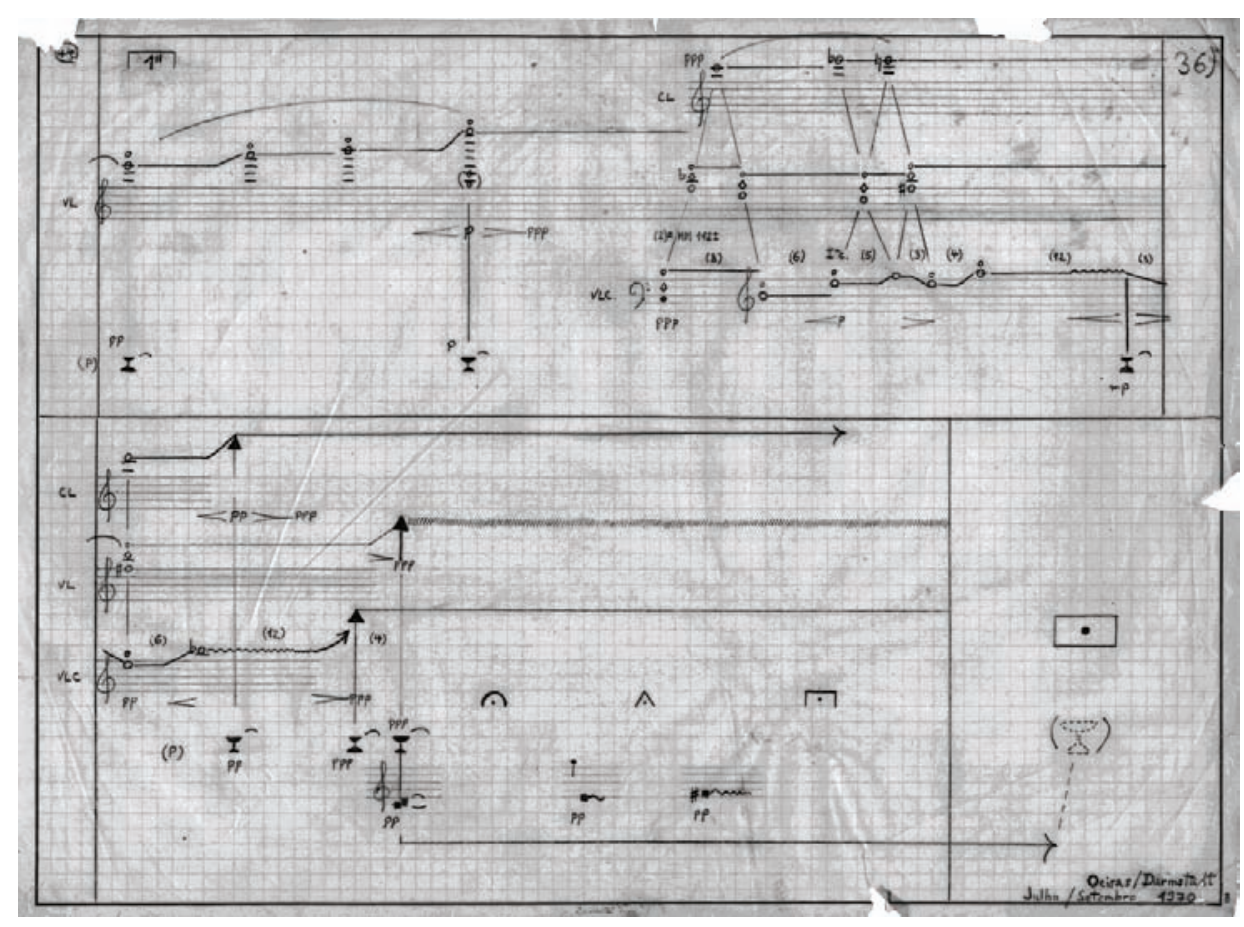

Abbildung 2: CDE: Letztes Blatt der Partitur: c - d - e - fis als Ausklang der Komposition ${ }^{29}$

Die hier kurz angesprochenen Werke von Peixinho offenbaren einen besonderen Typus politischer Musik: Kein offensichtliches Mobilisieren großer Bevölkerungskreise ist hier erwünscht, sondern ein stilles Einschwören und Sich-Vergewissern mit eng Vertrauten, das Kraft und Ausdauer spenden möchte. Ob Peixinho solche Werke mit politischen Andeutungen um 1970 aus persönlichem, bislang unbekanntem Antrieb schrieb oder dafür andere Gründe hatte, kann noch nicht abschließend eingeschätzt werden. Vor einigen Jahren kam in einem wiederentdeckten Brief Peixinhos an Clotilde Rosa $\left({ }^{*} 1930\right)$ vom 31. Januar $1973^{30}$ ans Tageslicht, dass er gerade die Kolonialkriege verabscheute. Vielleicht erweckten diese Kriege in ihm das Bedürfnis, politische Werke zu schreiben, aber vielleicht waren es auch die Drangsalierungen, denen Peixinho aufgrund der ,Bearbeitung' seitens der Geheimpolizei ausgesetzt war und die er mit oben genannten Werken beantwortete.

\footnotetext{
${ }^{29}$ Das Faksimile stammt von der online bereitgestellten Partitur des Centro de Investigação \& Informaçáo da Música Portuguesa (www.mic.pt; letzter Zugang 22. Juli 2015).

${ }^{30}$ Carvalho, ,Jorge Peixinho“, 152.
} 
Auffallend ist, dass diese Phase in Peixinhos Schaffen fast deckungsgleich mit der Herrschaftszeit von Marcelo Caetano zusammenfällt. Es kann zumindest vermutet werden, dass Peixinho eine Phase der politischen Unsicherheit in Portugal nutzte, um Werke mit deutlich politischem Anspruch zu schaffen. Dies wird umso schlüssiger, als in der Literatur die erste Phase der Herrschaft von Caetano als relativ liberal bezeichnet wird - mit einer etwas weniger strengen Zensur und mit einer größeren Zurückhaltung der Geheimpolizei PIDE ${ }^{31}$ bei der Gewaltausübung. ${ }^{32}$

\section{José Afonso}

Das Lied Grândola, vila morena hat in Portugal Geschichte geschrieben. Es stammt von José Afonso ${ }^{33}$, einem vor allem in Portugal berühmten Liedermacher, und handelt von der Stadt Grândola (Alentejo) und seinen in Brüderlichkeit und Gleichberechtigung lebenden Einwohnern, die die Herrschaft selbst in Händen tragen. Das Lied wurde am 25. April 1974 um etwa 00.30 Uhr vom Sender „Radio Renascença“ in ganz Portugal gesendet. ${ }^{34}$

\footnotetext{
${ }^{31}$ Policía Internacional e de Defensa do Estado.

${ }^{32}$ Mário Soares, ein bedeutender politischer Oppositioneller, durfte kurzzeitig aus der Verbannung nach Lissabon zurückkehren (Marques, Geschichte Portugals, $571 \mathrm{ff}$.; Rosas, O Estado Novo, 485ff.).

${ }^{33}$ José Afonso lebte von 1929 bis 1987. Seine Kindheit verbrachte er teilweise in Angola und Mosambik, in den 1940er Jahren begann er im Stile des Fado von Coimbra zu singen. Ab spätestens den 1950er Jahren erhielten seine Lieder stärker politische Inhalte. Nach ersten Schallplattenproduktionen wurde er von der PIDE beobachtet und verfolgt, 1967 wurde er als Lehrer am Liceu Nacional de Setúbal abgesetzt. 1968 erging das zeitweilige Verbot, seine Lieder im Rundfunk zu senden, auch einige Schallplatten mussten im Ausland aufgenommen werden. Anfang der 1970er Jahre wuchs sein Ruhm in Portugal, und Afonso erhielt zahlreiche Einladungen für Festivals im Ausland. Er war zwischen dem 30. April und dem 21. Mai 1973 im Gefängnis Caxias bei Lissabon inhaftiert (Côrte-Real, „Afonso, Joséc, 16f. und Irene Flunser Pimentel und Joaquim Vieira, José Afonso [Lissabon: Círculo de Leitores, 2010], 92f., 103f. und 108f.).

${ }^{34}$ Grândola, vila morena wurde im Mai 1964 während einer Reise zur „Sociedade Musical Fraternidade Operária Grandolense“ komponiert und erschien auf der 1971 in Paris produzierten Schallplatte Cantigas do Maio (orfeu). Zum ersten Mal sang es Afonso 1972 während eines geheimen Treffens mit Widerstandsstudenten in Santiago de Compostela (Côrte-Real, „Afonso, José“, 17; dies., „Canção de intervençâo", in Enciclopédia da música em Portugal no século XX, Bd. 1, 224; Maria Inês Nogueira Igrejas Moreira, A música tradicional na obra de José Afonso [Dissertation, Universidade Nova de Lisboa, 2009], 64f., Pimentel und Vieira, José Afonso, $71 \mathrm{ff.}$.).
} 
Grândola, vila morena

Grândola, vila morena

Terra da fraternidade

$\mathrm{O}$ povo é quem mais ordena

Dentro de ti, ó cidade

Dentro de ti, ó cidade

O povo é quem mais ordena

Terra da fraternidade

Grândola, vila morena

Em cada esquina um amigo

Em cada rosto igualdade

Grândola, vila morena

Terra da fraternidade

Terra da fraternidade

Grândola, vila morena

Em cada rosto igualdade

O povo é quem mais ordena

À sombra duma azinheira

Que já não sabia a idade

Jurei ter por companheira

Grândola a tua vontade

Grândola a tua vontade

Jurei ter por companheira

À sombra duma azinheira

Que já não sabia a idade
Grândola, braunes Städtchen

Grândola, braunes Städtchen

Ort der Brüderlichkeit

Das Volk ist es, das am meisten befiehlt

In Dir, o Stadt.

In Dir, o Stadt

Ist es das Volk, das am meisten befiehlt

Ort der Brüderlichkeit

Grândola, braunes Städtchen

An jeder Ecke ein Freund

Gleichheit in jedem Gesicht

Grândola, braunes Städtchen

Ort der Brüderlichkeit

Ort der Brüderlichkeit

Grândola, braunes Städtchen

Gleichheit in jedem Gesicht

Das Volk ist es, das am meisten befiehlt

Im Schatten einer Steineiche

Die ihr Alter schon nicht mehr wusste

schwor ich mir, Grândola

Deinen Willen als Gefährten zu haben

Deinen Willen als Gefährten zu haben schwor ich mir, Grândola

Im Schatte einer Steineiche

Die ihr Alter schon nicht mehr wusste 


\section{Grândola, vila morena}

José Afonso (1929-1987)
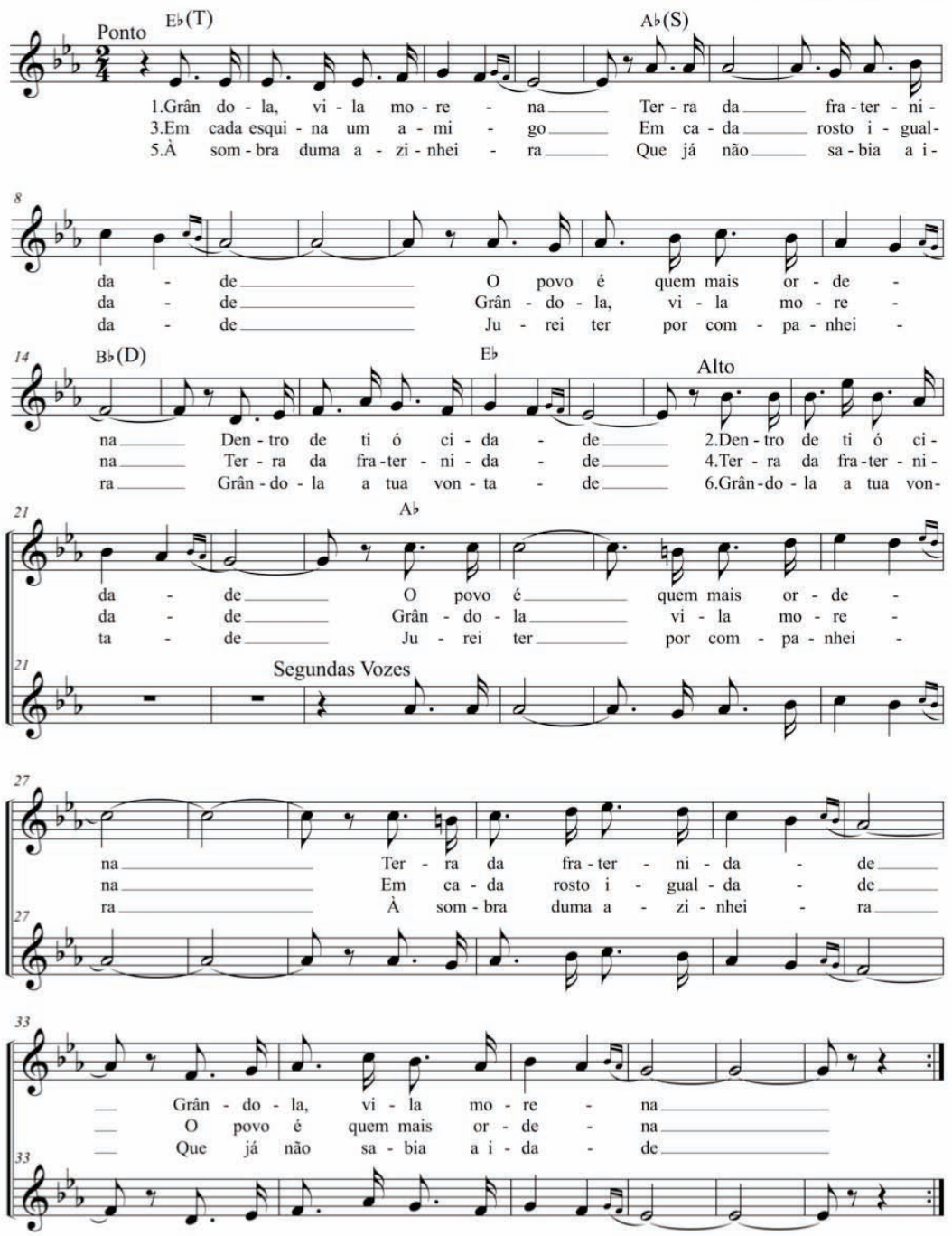

Notenbeispiel 1: Grândola, vila morena: ${ }^{35}$ Text und Musik: José Afonso

35 Übersetzung Gilbert Stöck, Verszeilen 19-21 Übersetzung Mário Vieira de Carvalho. Die Übersetzung weicht an zahlreichen Stellen von derjenigen in Eh, Zeca Afonso! Lieder und Texte aus Portugal (hg. Heidi Bergmann und Dieter Offenhäußer [Freiburg im Breisgau: Druckwerkstatt im Grün, 1980], 61) aufgrund inhaltlicher Erwägungen ab. 
An diesem 25. April 1974 leitete dieses Lied den Sturz der faschistischen Diktatur ein: Es bildete das im Vorfeld von hohen Militärs abgesprochene zweite Zeichen, die Besetzung strategisch wichtiger Institutionen und Gebäude in Lissabon vorzunehmen. ${ }^{36}$ Die Verteidigungslinien des regimetreuen Militärs wurden in den darauffolgenden Stunden ohne Waffengewalt gestürmt, und Marcelo Caetano, der ab 1968 regierende Nachfolger Salazars, zog sich in eine Kaserne am Largo do Carmo zurück. Dort ergab er sich, wurde gefangen genommen und fand schließlich Asyl in Brasilien. Die sogenannte, Nelkenrevolution' war somit geglückt.

Grândola, vila morena ist ein typisches Interventionslied, das sich gegen Salazars Estado Novo richtet und vom politischen Lied durch Verzicht auf „Slogans und direkte Agitation" unterscheidet ${ }^{37}$. So vermied José Afonso in zahlreichen Liedern, auch in Grândola, Negatives zu thematisieren, und umging die Zensur durch die Vermittlung von Hoffnung und Zuversicht auf das Kommende ${ }^{38}$. Das Lied ist als Strophenlied konzipiert und besteht aus zwei sehr ähnlichen Abschnitten, die sich korrespondierend auf die Strophen 1, 3 und 5 bzw. 2, 4 und 6 verteilen. ${ }^{39}$ Der musikalische Gestus erinnert mit einigen Merkmalen an portugiesische Volkslieder, vor allem aus dem Alentejo. ${ }^{40}$ Musikalische Analogien gerade zur Volksmusik des Alentejo scheinen bewusst gewählt worden zu sein, da Grândola ja auch zu dieser Region zählt. Folgende Analogien treten besonders hervor: ${ }^{41} \mathrm{Im}$ Lied wird die Solostimme während der Strophen durch hinzutretende Sänger, die die Gesangslinie durch

\footnotetext{
${ }^{36}$ Das erste musikalische Zeichen als Verständigungsmittel der Truppenteile war das Lied E depois do adeus, gesungen von Paulo de Carvalho und gesendet am 24. April, um 22.55 Uhr von den „Emissores Associados de Lisboa“ (Côrte-Real, „Canção de intervençăo“, 224).

${ }^{37} \mathrm{Zu}$ dieser Differenzierung siehe Elfriede Engelmayer, Utopie und Vergangenheit. Das Liedwerk des portugiesischen Sängers José Afonso (Wien: VWGÖ, 1985), 25f. Siehe auch Côrte-Real, „Canção de intervençấo“, 220-228, insbesondere 224 und Moreira, A música tradicional, 5-10.

${ }^{38}$ Engelmayer, Utopie und Vergangenheit, 181f. Dass Afonso durch die Zensurbehörde „Secretariado Nacional da Informaçāo" beobachtet wurde, dokumentiert Côrte-Real (Cultural Policy, 281 und im Anhang 13, 413f.).

${ }^{39}$ Siehe dazu die analytischen Ausführungen bei Moreira, A música tradicional, 66-70.

40 „,Grândola 'remete-nos imediatamente para o âmbito do cante alentejano" (Moreira, $A$ música tradicional, 93). Die Stilistik in diesem Lied verdeutlicht grundsätzlich Afonsos Synthese von musikalischen Elementen, wie dem Fado de Coimbra und der Volksmusik der Beira-Region (Côrte-Real, „Afonso, José“, 17; dies., „Canção de intervenção“, 220f.).

${ }^{41}$ Das textliche Stilmittel der Umkehr der Verszeilen, das in Grândola, vila morena sehr auffällig ist (zwei Verszeilen erscheinen sogar in allen der vier Verszeilen: „Grândola, vila morena" [Verszeile 1: Strophe I; 2:IV; 3: III; 4: II] und - komplementär dazu - „Terra da fraternidade“ [1: IV; 2: I; 3: II; 4: III]) ist in vielen portugiesischen Gesängen ausgeprägt und nicht typisch für die Volksmusik des Alentejo (freundlicher Hinweis von der Musikethnologin Maria José Barriga).
} 
Oberstimmenterzen „ausschmücken“, ergänzt. ${ }^{42}$ In den geradzahligen Strophen erfolgt ein responsorialer Wechsel zwischen einem Quasi-Vorsänger und dem hinzutretenden Chor. Die Satzfaktur pendelt daher ständig zwischen Ein- und Mehrstimmigkeit. ${ }^{43}$

Der Beginn der geradzahligen Strophen erfolgt, bevor die Chorstimmen einsetzen, durch einen Solosänger in Quintlage, somit erhöht im Vergleich zu den ungeradzahligen Strophen. Dies entspricht dem Wechsel zwischen dem ,Ponto' (Strophen 1, 3 und 5), dem ,Alto' (Strophen 2,4 und 6) und den ,Segundas Vozes' als Chor. ${ }^{44}$ Als rhythmischer Impulsgeber fungiert das stetige Geräusch schreitender Menschen, das besonders für den Gesang der Region Alentejo charakteristisch ist. ${ }^{45}$

Der Eindruck des ,Ländlichen ' wird möglicherweise auch dadurch verstärkt, dass die in Grândola, vila morena besonders hervortretende Subdominante ${ }^{46}$ auf die Alte-

${ }^{42}$ Zumindest singt bei der Version des Liedes auf der LP Cantigas do Maio der Männerchor die melodische Hauptstimme. Es gibt auch Live-Mitschnitte, die verdeutlichen, dass Afonso die Hauptstimme des Liedes singt und der Chor, oftmals die anwesenden Zuhörer während des Konzertes, die Oberstimmenterzen singen, bzw. die Zuhörer sich spontan auf die jeweiligen beiden Stimmen verteilen. Das Hinzutreten des Chores zur Sologesangslinie im Abstand einer Terz in Volksliedern des Alentejo beschreibt und dokumentiert António Marvão in transkribierten Beispielen (Origens e características do folclore musical alentejano [Cucujāes: \{Selbstverlag\}, 1966], 4 und Anhang). Alle acht publizierten Transkriptionen ähneln sich im Aufbau: Es beginnt ein Solist, und der Chor setzt dann im Terzabstand im zweiten Teil der jeweiligen Strophe ein. Siehe auch die weiteren von Marvão überlieferten Volkslieder im Cancioneiro Alentejano. Corais majestosos, coreográficos e religiosos do Baixo Alentejo (Braga: Tip. da Editorial Franciscana, 1955, passim).

${ }^{43}$ Die Formstruktur solcher Gesänge beschreibt João Ranita da Nazaré (Música tradicional portuguesa. Cantares do Baixo Alentejo [Lissabon: Inst. da Cultura Portuguesa, 1979], passim, insbesondere 34-39 und 55-60). Siehe auch Marvão, Origens, 4 und Anhang, und Engelmayer, Utopie und Vergangenheit, 66. Auch die große Mehrheit der von João Ranita da Nazaré (Momentos vocais do Baixo Alentejo [Lissabon: Imp. Nacional da Moeda, 1986]) aufgenommenen und transkribierten Lieder der Region zeugen von dieser Praxis der im Laufe der Strophen im Terzabstand hinzutretenden weiteren Sänger. Einige Lieder, wie beispielsweise Na mesma campa nasceram (48f.), Ó água que vais correndo (66f.), Ó serpa pois tu não ouves (72f.), Amores daquela banda (86f., hier Ähnlichkeiten zumindest in den ungeradzahligen Strophen), Ouve 'strela de a manhã (188f.), Ó luar da meia-noite (312f.) und Ó minha mãe, minha mãe (340f.) haben zudem durch die Dominanz des punktierten Rhythmus' innerhalb der melodischen Linie und dem verzögerten Choreinsatz in den geradzahligen Strophen eine besonders große Ähnlichkeit im Aufbau, Klangbild und Faktur mit Grândola, vila morena.

${ }^{44}$ Moreira, A música tradicional, $67 \mathrm{f}$.

${ }^{45}$ Ebd., 66 und 70. Der marschhafte Charakter des Liedes wird durch den das Lied eröffnenden und schließenden Klang von gleichmäßig (und ,hartnäckig') auf Schotter streitenden Personen und durch die Punktierungen der Gesangslinie unterstrichen.

${ }^{46}$ Der Choreinsatz erfolgt ,kräftig' auf der Subdominante. 
ration der Quarte verzichtet. Die vierte Stufe der Subdominante (die siebente der Tonika) bleibt leitereigen, wodurch sich die lydische Skala as - b - c - d ergibt, was wiederum ein Charakteristikum mancher Lieder aus dem Alentejo ist. ${ }^{47}$

Gerade die Chorpassagen erweisen sich als identifikationsstiftend, da der Chor sozusagen als Vertreter aller singfreudigen Anwesenden fungiert und dadurch affirmativ zum spontanen Mitsingen einlädt. Zusätzlich wird das Mitsingen durch die quasi intonationshafte Eröffnung der jeweils ersten Verszeile der geradzahligen Strophen durch den ,Alto ${ }^{\text {p provoziert. }}{ }^{48}$ Die Rezeption des Gemeinten erfolgt derart nicht nur durch das bloße verstehende Hören, sondern zudem sinnlich durch das aktive, gemeinsame Singen. Es nimmt daher nicht wunder, dass das Salazar-Regime gerade diese Gattung besonders kritisch beargwöhnte. ${ }^{49}$ Die Interventionslieder von José Afonso und Gleichgesinnten richten sich an eine breite Öffentlichkeit, der künstlerische Anspruch war darauf ausgelegt, die Rezeption und den affirmativen und aktiven musikalischen Nachvollzug zu erleichtern. Der Bezug zur Volksmusik wurde von Afonso wohl gewählt, um musikalische Identifikationsmodelle anzubieten, die das Verständnis des Textgehaltes erleichtern.

Aufgrund des Erfolges solcher Strategien, die sich an seiner Breitenwirkung und Beliebtheit zeigen, wurde Afonso von der Geheimpolizei PIDE verfolgt. Er war aber seit den 1960er Jahren zu bekannt, um ihn vollständig der Öffentlichkeit entziehen zu können. Trotzdem vollführte er bei jedem Liedtext eine Gradwanderung zwischen dem gerade noch Erlaubten und dem Überschreiten des Erlaubten, und setzte sich der Gefahr aus, von der portugiesischen Justiz gepackt zu werden. Er hatte auch oftmals - wie oben erläutert - Drangsalierungen zu ertragen, beispielsweise durch Sendeverbote, Lehrverbot an Schulen und Inhaftierung. ${ }^{50}$

\footnotetext{
${ }^{47}$ Siehe hierzu Nazaré, Música tradicional, 62-65 und Marvão, Origens, Anhang. Lydische Modi finden sich in einigen der hier dokumentierten Liedern, wie Ao romper da bela aurora und $A$ ribeira do sol posto. Ein Detail sei in diesem Kontext genannt: in Takt 25 und 29 alteriert Afonso auf der Studioaufnahme das b' zum h', um zur Hauptmelodiestimme die große Terz $\mathrm{g}-\mathrm{h}$ zu bilden, dieses h bildet zugleich den Leitton zum danach in der Oberstimme auftretenden $c^{\prime \prime}$. Diese Hochalteration, die zur sehr auffälligen Oberstimmenführung $\mathrm{c}-\mathrm{h}-\mathrm{c}-\mathrm{d}$ - es führt, erscheint in keiner der mir bekannten Notenausgaben, selbst Moreira nimmt in ihrer Dissertation nicht darauf Bezug (A música tradicional, 69).

${ }^{48}$ Die Fortsetzung gemeinsam mit dem Chor wirkt dadurch ,logischer', als wenn der Chor gleich am Beginn der geradzahligen Strophen einsetzte.

${ }^{49}$ Côrte-Real, „Cançấo de intervenção “, $223 \mathrm{f}$.

${ }^{50}$ Côrte-Real, „Afonso, José“, $16 f$.
} 


\section{Schlussbemerkungen}

Salazars Überlegung, avancierte Musik gewähren zu lassen, führte nicht - im Sinne eines unausgesprochenen Stillschweigeabkommens - dazu, dass diese Szene auf kritische Statements verzichtete. Anhand einiger Werke von Jorge Peixinho wird dieser Impuls offenbar. Inwieweit die zensierenden Behörden des Salazar-Regimes solche Symbolik nicht bemerkten, oder sie bewusst nicht verfolgten, bleibt vorerst offen. ${ }^{51}$ Das Salazar-Regime steuerte das Musikschaffen möglicherweise weniger durch Bestrafung oder Unterdrückung des Ungeliebten, als vielmehr durch Förderung der konformen Komponisten, beispielsweise durch Auftragswerke für die Ballettkompanie „Verde Gaio“. Unliebsame Komponisten und Musiker wurden quasi ignoriert, solange sie nicht allzu kritische Töne anschlugen. Bei Afonso und Lopes-Graça, die die für das Regime gefährliche Kombination von hoher Bekanntheit bzw. hohem Ansehen bei der Bevölkerung und deutlich artikulierter Gesellschaftskritik aufwiesen, führte dies auch durchaus zu körperlicher und seelischer Verletzung in Form von Verhinderung der freien Berufsausübung und Freiheitsentzug.

Im Bereich der Szene des politischen Liedes griff die Staatsmacht zu zuweilen drastischen Mitteln, da das ,Zielpublikum' breit gestreut war und die vermittelten Inhalte deutlicher artikuliert wurden als bei avancierter Musik. Hier witterte die Staatsmacht eine große öffentliche Gefahr durch die affirmative Wirkung auf die Massen. Gerade die Begeisterung, die Aufführungen von José Afonsos Grândola, vila morena vor und nach dem 25. April 1974 in Portugal auslöste (und im Übrigen heute noch auslöst $)^{52}$, und oftmals das Publikum zum spontanen Mitsingen animierte, lässt erkennen, wie sehr die Einschätzung der diktatorischen Machthaber hinsichtlich des aufwühlenden und ,bedrohlichen' Potentials solcher Musik richtig war.

Letztendlich konnten sich Salazar und Caetano sicher sein, dass zumindest die Szene avancierter Musik in Portugal - wie auch anderswo - nur marginal rezipiert wurde und im öffentlichen politischen bzw. kulturpolitischen Diskurs in Portugal eine im Vergleich zu anderen Künsten untergeordnete Rolle spielten. In diesem

\footnotetext{
${ }^{51}$ Peixinho verweist zudem beispielhaft darauf, dass nicht jeder Komponist, der sich gelegentlich künstlerisch mit politischen Statements zu Wort meldet, als politischer Komponist, dessen schöpferische Hautquelle die politische Agitation ist, betrachtet werden darf.

${ }^{52}$ In einem Konzert am 29. März 1974 durfte Afonso im Rahmen des „Encontro da Cançâo Portuguesa" aufgrund zensurierender Eingriffe auf das Konzertprogramm nur zwei Lieder singen; eines davon war Grândola, vila morena. Grândola wurde an diesem Abend vom Publikum frenetisch mitgesungen, „à maneira de um grupo alentejano“ und geriet damit zu einem Höhepunkt des Konzertes (Pimentel und Vieira, José Afonso, 110 und 119). Spätestens hier wurde bereits deutlich, wie hoch die affirmative Kraft des Liedes war. Der dem Lied anscheinend innewohnende ,revolutionäre` Geist lebt bis heute fort. Gegenwärtig wird bei Kundgebungen von den Demonstranten oftmals Grândola, vila morena gesungen, um den Unmut mit den bestehenden Herrschaftsverhältnissen kund zu tun.
} 
Merkmal ähneln die portugiesischen Verhältnisse denjenigen in der DDR und in der Sowjetunion, wo nach Versuchen, den ästhetischen Kurs und Diskurs systematisch zu steuern, spätestens ab den 1970er Jahren avancierte Musik nicht mehr unterdrückt werden konnte und in „Nischen“ existieren durfte.

\section{Literatur}

Alves, Vera Marques. „O SNI e os ranchos folclóricos“. In Vozes do povo - a folclorização em Portugal, hg. von Salwa El-Shawan Castelo-Branco und Jorge Freitas Branco, 191-205. Oeiras: Celta Editora, 2003.

Assis, Paulo de (Hg.). Mémoires... Miroirs. Conferências do Simpósio Internacional Jorge Peixinho Lisboa 2010. Lissabon: Colibri, 2012.

Barreto, Jorge Lima. „Há mil peixinhos a nadar. Da arte de Jorge Peixinho e uma entrevista“. In Jorge Peixinho in memoriam, hg. von José Machado, 196-202. Lissabon: Caminho, 2002.

Bergmann, Heidi und Dieter Offenhäußer (Hg.). Eh, Zeca Afonso! Lieder und Texte aus Portugal. Freiburg im Breisgau: Druckwerkstatt im Grün, 1980.

Branco, João de Freitas. Hístoria da múscia portuguesa. Mem Martins: EuropaAmérica, ${ }^{4} 2005$.

Brito, Manuel Carlos de und Salwa El-Shawan Castelo-Branco. „Portugal“. In Die Musik in Geschichte und Gegenwart. Allgemeine Enzyklopädie der Musik, 2., neu-bearbeitete Ausgabe, hg. von Ludwig Finscher, Sachteil, Bd. 7, 1704-30. Kassel und Stuttgart: Bärenreiter, 1997.

Carvalho, Mário Vieira de. „Jorge Peixinho“, in $K d G$ 9. Nachlieferung (Februar 1996).

— ",Lebendige Aktion` gegen ,geträumte Aktion` - Musik und antifaschistischer Wiederstand in Portugal“". In Festschrift für Georg Knepler zum 90. Geburtstag, Bd. 2: Musik - Revolution, hg. von Hanns-Werner Heister, 325-47. Hamburg: von Bockel, 1997.

— Denken ist Sterben. Sozialgeschichte des Opernhauses Lissabon. Kassel und Stuttgart: Bärenreiter, 1999.

- Pensar a música, mudar o mundo - Fernando Lopes-Graça. Porto: Campo das Letras, 2006.

- „Between Political Engagement and Aesthetic Autonomy. Fernando LopesGraça's Dialectical Approach to Music and Politics“. 20th-Century Music 8 (2011): 175-202. 
—_ „Jorge Peixinho. Entdeckung einer musikalischen Persönlichkeit“. In MusikKontexte. Festschrift für Hanns-Werner Heister, Bd. 1, hg. von Thomas Phleps und Wieland Reich, 150-64. Münster: Monsenstein und Vannerdat, 2011.

— „Politics of Identity and Counter-Hegemony. Lopes-Graça and the Concept of National Music". Music \& Politics 6/1 (2012): 1-12.

Castelo-Branco, Salwa El-Shawan und Jorge Freitas Branco (Hg.). Vozes do povoa folclorização em Portugal. Oeiras: Celta Editora, 2003.

Castelo-Branco, Salwa El-Shawan und Jorge Freitas Branco. „Folclorização em Portugal. Uma perspectiva“. In Vozes do povo - a folclorização em Portugal, hg. von Salwa El-Shawan Castelo-Branco und Jorge Freitas Branco, 1-21. Oeiras: Celta Editora, 2003.

Cité de la Musique (Hg.). Lénine, Staline et la musique. Catalogue de l'exposition Paris 2010-2011. Paris: Fayard, 2010.

Côrte-Real, Maria de Sáo José. „Cultural Policy and Musical Expression in Lisbon in the Transition From Dictatorship to Democracy (1960s-1980s)“. PhD Diss., Columbia University, New York, 2000.

— „Musical Priorities in the cultural policy of ,Estado Novo““. Revista portuguesa de musicologia 12 (2002): 227-52.

— „Canção de intervenção“. In Enciclopédia da música em Portugal no século XX, Bd. 1, hg. von Salwa El-Shawan Castelo-Branco, 220-28. Lissabon: Círculo de Leitores, 2010.

—— „Afonso, José“. In Enciclopédia da música em Portugal no século XX, Bd. 1, hg. von Salwa El-Shawan Castelo-Branco, 14-18. Lissabon: Círculo de Leitores, 2010 .

Drüner, Ulrich und Georg Günther. Musik und „Drittes Reich“. Fallbeispiele 1910 bis 1960 zu Herkunft, Höhepunkt und Nachwirkungen des Nationalsozialismus in der Musik. Köln u.a.: Böhlau, 2012.

Engelmayer, Elfriede. Utopie und Vergangenheit. Das Liedwerk des portugiesischen Sängers José Afonso. Wien: VWGÖ, 1985.

Erlich-Oliva, Alejandro. „Strauss homenageia Peixinho (II)“. In Jorge Peixinho in memoriam, hg. von José Machado, 301-3. Lissabon: Caminho, 2002.

Ferreira, Manuel Pedro. „A obra de Jorge Peixinho - problemática e recepçáo“. In Jorge Peixinho in memoriam, hg. von José Machad, 223-86. Lissabon: Caminho, 2002. 
Flamm, Christoph. „Musik, Diktatur, Geschichtsschreibung. Fünf Anmerkungen“. In Musikwissenschaft und kalter Krieg. Das Beispiel DDR, hg. von Nina Noeske und Matthias Tischer, 131-141. Köln u.a.: Böhlau 2010.

Goltz, Maren. Musikstudium in der Diktatur. Das Landeskonservatorium der Musik/Die Staatliche Hochschule für Musik Leipzig in der Zeit des Nationalsozialismus 1933-1945. Stuttgart: Steiner, 2013.

Jungheinrich, Hans-Klaus. „Ein Stück Begrenztes, das dennoch vom Unbegrenzten zeugt. Ein Hinweis auf neue Musik in Portugal“. Jahresring 29 (1982/83): $80-85$.

Karimi, Kian-Harald. Auf der Suche nach dem verlorenen Theater. Das portugiesische Gegenwartsdrama unter der politischen Zensur (1960-1974). Frankfurt am Main: Lang, 1991.

Latino, Catarina und Rui Cabral Lopes. „Grupo de Música Contemporânea de Lisboa“. In Enciclopédia da música em Portugal no século XX, Bd. 2, hg. von Salwa El-Shawan Castelo-Branco, 588. Lissabon: Círculo de Leitores, 2010.

Marques, António Henrique de Oliveira. Geschichte Portugals und des portugiesischen Weltreichs. Lissabon: Presença, 1995; dt. Stuttgart: Alfred Kröner, 2001.

Marváo, António. Cancioneiro Alentejano. Corais majestosos, coreográficos e religiosos do Baixo Alentejo, Braga: Tip. da Editorial Franciscana, 1955.

- Origens e caracteristicas do folclore musical alentejano, Cucujães: [Selbstverlag] 1966.

Melo, Daniel. A cultura popular no Estado Novo. Coimbra: Angelus Novus, 2010.

Monteiro, Francisco. „The Portuguese Darmstadt Generation: The Piano Music of the Portuguese Avant-Garde“. PhD Diss., University of Sheffield, 2002.

Moreira, Maria Inês Nogueira Igrejas. „A música tradicional na obra de José Afonso“. PhD Diss., Universidade Nova de Lisboa, 2009.

Nazaré, João Ranita da. Música tradicional portuguesa. Cantares do Baixo Alentejo. Lissabon: Inst. da Cultura Portuguesa, 1979.

—Momentos vocais do Baixo Alentejo. Lissabon: Imp. Nacional da Moeda, 1986.

Nery, Rui Vieira. „Fundação Calouste Gulbenkian“. In Enciclopédia da música em Portugal no século XX, Bd. 2, hg. von Salwa El-Shawan Castelo-Branco, 53548. Lissabon: Círculo de Leitores, 2010.

Noeske, Nina und Matthias Tischer (Hg.). Musikwissenschaft und kalter Krieg. Das Beispiel DDR. Köln u.a.: Böhlau, 2010. 
Ó, Jorge Ramos do. Os anos de Ferro. O dispositivo cultural durante a „Política do Espirito" 1933-1949. Ideologia, instituiçôes, agentes e práticas. Lissabon: Estampa, 1999.

Pimentel, Irene Flunser und Joaquim Vieira. José Afonso. Lissabon: Círculo de Leitores, 2010.

Rocha, José Eduardo. „14 anotaçôes sobre Música Contemporanea Portuguesa“. In João de Freitas Branco. Historia da música portuguesa, 345-92. Mem Martins: Europa-América, ${ }^{4} 2005$.

Rosas, Fernando. O Estado Novo (1926-1974) (= História de Portugal 7), hg. von José Mattoso. Lissabon: Estampa, 1998.

Roubaud, Maria Luísa. „O Verde Gaio - Uma política do corpo no Estado Novo“. In Vozes do povo - a folclorização em Portugal, hg. von Salwa El-Shawan Castelo-Branco und Jorge Freitas Branco, 337-53. Oeiras: Celta Editora, 2003.

Santos, Vitor Pavão dos. „Verde Gaio. Uma Companhia Portuguesa de Bailado (1940-1950)“. In Verde Gaio. Uma Companhia Portuguesa de Bailado (19401950), hg. von Vitor Pavão dos Santos, 13-84. Lissabon: IPM, 1999.

Silva, Manuel Deniz. „„La musique a besoin d'une dictature“. Musique et politique dans les premières années de l'Etat Nouveau (1926-1945)“. PhD Diss., Université de Paris VIII, 2005.

Stöck, Gilbert. „Jorge Peixinho's 'CDE' - On the Relationship between Music and Cultural Policy“. In Mémoires... Miroirs. Conferências do Simpósio Internacional Jorge Peixinho Lisboa 2010, hg. von Paulo de Assis, 31-45. Lissabon: Colibri, 2012.

— „Komponieren in Portugal in den 1960er Jahren. Beobachtungen zu Fernando Lopes-Graça, Emmanuel Nunes und Jorge Peixinho“. Die Musikforschung 66 (2013): 56-66.

Stöck, Katrin. Musiktheater in der DDR. Köln u.a.: Böhlau, 2013.

Teixeira, Cristina Delgado et. al. „Catálogos da obra de Jorge Peixinho“. In Jorge Peixinho in memoriam, hg. von José Machado, 321-69. Lissabon: Caminho, 2002.

Teixeira, Cristina Delgado. Música, estética e sociedade nos escritos de Jorge Peixinho. Lissabon: Colibri, 2006.

Teixeira, Cristina Delgado und Paulo de Assis (Hg.). Jorge Peixinho, Escritos e entrevistas. Porto: Casa da Música, 2010. 
Tischer, Matthias. Komponieren für und wider den Staat. Köln u.a.: Böhlau, 2009.

Vargas, António Pinho. Música e poder. Para uma sociologia da ausência da música portuguesa no contexto europeu. Coimbra: Almedina, 2011.

Zoudilkine, Evgueni. „Peixinho, Jorge“. In Enciclopédia da Música em Portugal no Século XX, Bd. 3, hg. von Salwa El-Shawan Castelo-Branco, 977-80. Lissabon: Círculo de Leitores, 2010. 


\title{
'The Stakes Are Too High For You to Stay Home': Divergent Uses of Music in TV Political Ads in the 1964 U.S. Presidential Election
}

\author{
Paul Christiansen (Portland, ME)
}

Over three elections throughout the 1960s, we can see drastic changes in the use of music in political ads. In 1960, music was used much the same way as it was used in political ads from the previous decade. That is, it is typically absent and where present, it works in direct, uncomplicated ways. Music in television political ads in 1952, 1956, and 1960 had consisted of commercial-like jingles, jazz songs, and organ music like that heard in early radio dramas. Campaigns began to employ music more intentionally in 1964, most especially the Barry Goldwater (1909-1998) campaign, which seemed to sense early on music's power to persuade through poetic appeal rather than discursive argument. By 1968, political ad music begins to consistently function rhetorically; for example, to construct poetic arguments on its own, quite apart from textual and visual elements. Shown as text at the end of his ads, Richard Nixon's (1913-1994) 1968 slogan - 'This time vote like your whole world depended on it' - implored voters with the same urgency as Democratic incumbent Lyndon Johnson's slogan (1908-1973) in 1964, 'The stakes are too high for you to stay home'. Thus, 1964 marks an important bridge between the tentative efforts of 1960 and the cynical manipulation with music that we witness in 1968.

In its most recognizable form, the negative political television advertisement in the U.S. seems to have been invented by the 1964 presidential campaign. Never be- 
fore had ads talking about the opponent been so vitriolic, and with the infamous Daisy ad, ${ }^{1}$ Johnson's campaign literally chose the nuclear option. Music is present in ads from both campaigns, but is used quite differently. In Johnson's spots, music seems a distraction - all but two of his ads lack it. Recognizing its persuasive power, Goldwater uses music more frequently, and to greater effect in ads such as Morality and America's Image, which feature militaristic drum cadences and cymbal crashes, 'scare music,' and patriotic music.

\section{Voting Booth - Lyndon Johnson}

This ad starts with a camera following a man walking down a hallway in what appears to be a school; viewers later learn that his destination is a polling location (apparently a room in the school). Distorted music is heard that sounds as though reproduced through a transistor radio or slightly damaged reel-to-reel tape. The first tune is 'Hot Time in the Old Town Tonight', ${ }^{2}$ which immediately dissolves into what sounds like political convention noises, which in turn yield to John Philip Sousa's (1854-1932) Washington Post march. This is followed by more convention sounds - cheers, applause, amplified speeches.

However, when the man opens the door to the polling station, the music and sounds stop abruptly, as if to indicate that the man's thoughts are now focused, laserlike, on the task at hand, that the polling location is much too sacred a place for outside distractions. He doffs his hat only seconds before he enters, indicating a move from a public into a private space - typically, men wore hats outdoors in the early 1960s and would take them off upon entering a building. Yet here, the hallway, though indoors, is still metaphorically a public space (this is borne out by the raucous music sounding as he traverses the hallway). The man leaves the public arena only when he opens the door to the polling room.

Here he enters the private space, the space reserved for the man's innermost thoughts, namely: Who deserves my vote? The camera angle has shifted to show the man's face for the first time; the camera has been awaiting his arrival. As the man signs his name at the desk and approaches the voting booth with ballot in hand, the narrator says, 'When it's all over, and you're in the voting booth on November 3rd, keep this in mind: America is stronger and more prosperous than ever before. And we're at peace'. ${ }^{3}$ (The last statement about being at peace seems at first an afterthought, but in fact it is the lynchpin of the ad, for the Johnson campaign sought to

\footnotetext{
${ }^{1}$ All of the ads referred to in this paper are accessible on the website www.livingroomcandidate.org.

${ }^{2}$ Notably, in the very next election the Nixon campaign used this tune in an ad as anthymeme to comment wordlessly on the chaos and disorder of the 1968 Democratic Convention in Chicago.

${ }^{3}$ This statement is heard at 00:37.
} 
cast Goldwater as an extremist who would lead America back into war. Of course, the irony of Johnson touting his record on peace is fully clear only in retrospect.) When the man pulls the booth curtain crisply behind him, we see the text 'Vote for President Johnson on Nov. 3' on the screen as the narrator intones, 'Vote for President Johnson on November $3^{\text {rd }}$. The stakes are too high for you to stay home'. ${ }^{4}$

Music in this ad comprises mere background, representing the tumult of presidential politics. Distortion of the music is mirrored visually by canted camera framing as the man walks down the hallway. Both visually and aurally, the first part of the ad seems to depict a world out of sync. In this context, it might be inferred that one of Voting Booth's intended meanings is that the democratic process of voting remains in its own rarefied atmosphere, high above the din of quotidian political wrangling, and that voters should be careful not to get caught up in the hoopla surrounding Goldwater and his sometimes exceedingly provocative and flamboyant statements. Voting Booth enjoins voters to 'be serious' and to disregard campaign bluster in order to listen to their inner voice. In Voting Booth, music represents chaos; silence, careful reflection.

\section{Poverty - Lyndon Johnson}

Produced by the Democratic National Committee, the ad Poverty, like Voting Booth, uses music only as accompaniment to the voiceover and seems to only have been used as a soundtrack to an ad about poverty as a social condition. Poverty makes use of 1930s Delta blues guitar music accompanied by rhythmic foot stomps, marking a steady beat. The playing is so simple, it sounds as though it is being played on a diddley bow. As the music plays and the voiceover is heard, the camera tracks across stills depicting poor (mostly white) children, and at times zooms in and out on faces. These pictures are reminiscent of the Farm Security Administration/Office of War Information pictures taken between 1935 and 1944, and they call to mind Franklin Roosevelt's (1882-1945) New Deal, a widely popular Democratic government initiative. Subjects in Poverty's pictures are not all clearly identifiable as penurious rural Southerners, but neither are they clearly anything else. Acoustic blues guitar and foot stomps unequivocally situate the pictures in the poorest area of the U.S., the South. And not just the South, but the Deep South. And not just any time, but the Great Depression, which hit the Deep South hardest of all.

In his January 1964 State of the Union address, Johnson had introduced the War on Poverty, which formed a significant part of his Great Society initiative. Not surprisingly, his campaign sought to highlight this in his advertising. Having ushered the Civil Rights Act of 1964 through Congress and signed it, Johnson felt vulnerable

\footnotetext{
${ }^{4}$ This concluding statement is made at 00:53.
} 
in the South as Election Day drew near. The door was open for other primary candidates to step in and take the Democratic nomination, and the one who made Johnson nervous was George Wallace (1919-1998), a Dixiecrat from Alabama. So the Johnson campaign sought to publicize its War on Poverty with this ad, in an effort to appeal to Southerners who felt betrayed by the passage of the Civil Rights Act. Blues music symbolizes the desperation of the destitute, and here along with the images it seems to say on behalf of Johnson, 'I'm a Southerner, I empathize, and I plan to do something about it.'

Of course much of the Great Society legislation for which Johnson is known was passed during his second term. So he did not have much of a record to go on as a poverty fighter as the November 1964 election approached - indeed, he had been President for less than a year - and his legislative record gave no clear hint that he would make a War on Poverty a presidential priority. Poverty helped to establish with some voters Johnson's bona fides as an anti-poverty crusader. Music is the sine qua non of the ad Poverty, and as in Voting Booth, music signifies something negative: in this case, hopeless desperation.

\section{Morality - Barry Goldwater}

Goldwater's Morality begins with a political cartoon of the U.S. Capitol Building with the dome flipped open and Bobby Baker (1928-) reaching into it (presumably removing untold sums of money). At the same time, while insistent brass play a loud and percussive syncopated motive against a cymbal crash, military drum cadences, and bass drum, the screen goes black and in a cartoon-like font the following words appear, one after the other: 'GRAFT! SWINDLE! JUVENILE DELINQUENCY! CRIME! RIOTS!' These words are interspersed with images of a farmhouse, Billie Sol Estes (1925-2013) (like Bobby Baker, his name appears on screen), demonstrations, a line of young men who appear to be criminals during a perp walk, a man fighting with baton-wielding police officers, a man being carried by police, and the east side of the U.S. Capitol Building with trees and cars in the foreground. Bobby Baker and Billie Sol Estes, the faces of corruption and fraud scandals that implicated the Johnson Administration, reminded voters of one of the drawbacks of an incumbent president.

Almost all of the initial images are poorly lit or in darkness. Halfway through the ad, Goldwater himself appears, seated in a well-lit office with a window curtain behind him and a picture behind him to his left. Like a stern father figure, he speaks seriously to the audience about law and order. Goldwater speaks to the camera without music for the second half. The dark-light contrast, signifying the divide between Democrats and Republicans, mirrors the transition from music to its absence. As with Johnson's Voting Booth, music in this ad is presented as a distraction. Even 
Goldwater's campaign slogan (heard in Morality as well as in other ads), 'In your heart, you know he's right', seems to support this notion. The implication of the slogan is that, as extreme as some of Goldwater's positions or quotes may seem, he is merely stating uncomfortable truths that we would rather not admit. Listen to your heart away from the tumult and hubbub of everyday life and you will know how you must vote. Since Johnson's ad campaign implied the same thing, viewers might be forgiven for not knowing which inner voice to heed.

Dramatic effects in this ad reflect the colossal clash of values that Goldwater presented as contrasting Democratic and Republican values. Pandemonium and terror in the first part of the ad is countered by sanity and rectitude in the second half, as evinced by Goldwater. In his nomination acceptance speech at the Republican Convention that year, Goldwater had not modulated his rhetoric to appear more moderate to the general electorate; rather, he embraced his extremist label: 'I would remind you that extremism in the defense of liberty is no vice. And let me remind you also that moderation in the pursuit of justice is no virtue'.

In this negative ad, music is the argument, the scaffolding on which the text and images are hung: Morality is, albeit clumsily, using music rhetorically. Images and voiceover lend the music context, giving the negativity of the music something to attach to. Morality strives to portray Goldwater as the more responsible candidate. To our twenty-first-century sensibility, the overall effect is comically unsubtle, but the ad adheres to conventions that obtained in the early 1960s. In fact, all of the ad's elements (music, voiceover, images, and text) tap conventions from B-movie trailers such as that for the 1958 film Monster on the Campus. ${ }^{5}$

\section{Negativity in Political Ads}

Producers of political ads have always striven to generate strong emotional reactions in viewers, strong enough to impel them to action. Intentionality is crucial - even the tiniest gesture is planned to achieve maximum effect. These emotional appeals must be carefully calibrated, though, as ads perceived to be unjustly negative, offensive, or tasteless can and do backfire. Like composers, ad creators begin by deciding on a few themes that they want to focus on (for example, universal health care together with the right to choose). ${ }^{6}$ Often, these themes are presented in counterpoint to each other, developed, and recapitulated over the course of a campaign. In a well-conceived campaign, especially like that of Ronald Reagan in 1984, but even to a certain extent

\footnotetext{
${ }^{5}$ Matthew Killmeier has my gratitude for this insight.

${ }^{6}$ Research has shown that campaigns that introduce too many issues into their agenda risk confusing voters, see Darrell M. West, Air Wars: Television Advertising in Election Campaigns, 1952-2008, 5th edition (Washington, DC: CQ Press, 2010), 26.
} 
that of Goldwater in 1964, the ads taken as a whole can seem carefully coordinated, like movements in a classical symphony. The campaign ads have a harmonious cumulative effect, each part contributing to the overall impact of several months of coordinated political efforts and targeted ad buys. In other words, they are orchestrated.

Most TV presidential political ads in 1964 trafficked in fear; such ads form a category unto themselves. Political scientist Ted Brader's empirical research found music to be an effective element in campaign advertisements that appeal to fear. ${ }^{7}$ Fear appeals contributed to the likelihood of political novices withdrawing from political participation, while they inspired the politically initiated to act. Overall, 'fear ads elicited the highest level of anxiety', and 'menacing music and imagery strengthened reactions of fear and anxiety to the negative message'. ${ }^{8}$ In a similar vein, Carol Krumhansl's experimental research found that subjects could identify fear within particular pieces of music.' While listening to excerpts identified as 'fearful music', subjects experienced significant changes in pulse rate and amplitude. ${ }^{10}$

Negative ads often evoke primal emotions. Critiques of negativity in political advertising abound, but some scholars argue strongly in favor of negative political advertising. In their study 'Eliminating the Negative? Categories of Analysis for Political Advertisements', Kathleen Hall Jamieson, Paul Waldman, and Susan Sherr claim that political ads are more informative than they are given credit for and that negative ads in particular give voters more information about issues than strict advocacy ads. ${ }^{11}$ Yet even if we concede that negative ads usually present more factual evidence in support of their claims than positive ads, the standard remains low. Moreover, if negative ads tend to be more informative than positive ads, as Jamieson et al. contend, such ads are also sometimes misleading, providing misinformation in place of information. In essence, they can be much worse than uninformative. But most importantly, by examining only rational appeals in negative or positive ads, we are miss-

\footnotetext{
${ }^{7}$ Ted Brader, Campaigning for Hearts and Minds (Chicago: University of Chicago Press, 2006).

${ }^{8}$ Ibid., 86.

${ }^{9}$ Carol L. Krumhansl, 'An Exploratory Study of Musical Emotions and Psychophysiology', Canadian Journal of Experimental Psychology 51 (1997): 336-52.

${ }^{10}$ Additional explanation for how fear is processed in the brain can be found in Jenefer Robinson, Deeper than Reason: Emotion and Its Role in Literature, Music, and Art (Oxford: Clarendon Press, 2005), 47-52; and Laurel J. Trainor and Louis A. Schmidt, 'Processing Emotions Induced by Music', in The Cognitive Neuroscience of Music, eds. Isabelle Peretz and Robert J. Zatorre (Oxford: Oxford University Press, 2003), 310-24.

${ }^{11}$ Kathleen Jamieson, Paul Waldman, and Susan Sherr, 'Eliminating the Negative? Categories of Analysis for Political Advertisements,' in Crowded Airwaves: Campaign Advertising in Elections, eds. James A. Thurber, Candice J. Nelson and David Dulio (Washington: Brookings Institution Press, 2000), 44-64.
} 
ing the true thrust of political ads: appeal to emotion. Herein lies true power of political ads, and music unapologetically appeals to emotion.

\section{Tuning In}

Music is not the sole actor of significance in political ads - they are much too complex to allow for simplistic explanations. But there are forces at work in TV spots that we ill understand and as a result are much more powerful than we have heretofore been willing to admit. The 'sonorous envelope', ${ }^{12}$ to use Didier Anzieu's term, of a contemporary political ad is often highly symbolic and rife with rich and contradictory meanings, and when sound combines with image, what remains is a complicated objet d'art potentially of historical, social, and cultural significance.

In a fallacy known commonly as the 'third-person effect' or the Dunning-Kruger effect, people typically impute naïvieté with regard to advertising to others, while imagining that they themselves are immune to such persuasion. ${ }^{13}$ Roderick P. Hart observes that people experience politics emotionally rather than rationally; TV really does charm and seduce, rather than inform or educate. ${ }^{14}$ Such an assertion seems so self-evident as to hardly need stating. Yet the ability of political ads to short-circuit logical thought is often grossly underestimated. For example, a poor working-class voter might vote against his family's economic interest in electing a candidate from the party that says that it opposes same-sex marriage, even though this issue does not directly affect him, or he may favor the party because it opposes restrictions on firearms that he cannot afford to purchase anyway.

As Hart states, American TV viewers fancy themselves politically savvy, when in reality most are woefully uninformed or misinformed, citing studies that indicate that TV messages do not particularly inform viewers. ${ }^{15}$ In one study, people who claimed that they paid close attention to senate campaigns were at a loss when asked to state candidates' issue stands. ${ }^{16}$ Two other studies indicated that viewers shown dramatic news segments focusing on specific, concrete examples could not see the

\footnotetext{
${ }^{12}$ Didier Anzieu, The Skin Ego, trans. Chris Turner (New Haven, CT: Yale University Press, 1989), 163.

${ }^{13}$ West, Air Wars, 17.

${ }^{14}$ Roderick P. Hart, Seducing America: How Television Charms the Modern Voter, rev. ed. (Thousand Oaks, CA: Sage, 1999).

${ }^{15}$ Hart, Seducing America, 12-13.

${ }^{16}$ Steven A. Peterson, Political Behavior: Patterns in Everyday Life (Newbury Park, CA: Sage, 1990), 230, as cited in Hart, Seducing America, 72.
} 
forest for the trees. ${ }^{17}$ So, American TV viewers' ill-placed confidence in their imperviousness primes them to be influenced by political ads, particularly by the least understood element of ads, music.

\section{Music's Ineffability}

A candidate can hardly criticize an opponent for using music that shows the candidate in an unflattering light. For one thing, it would be difficult to determine exactly what assertion or accusation is being made. If an ad asserts that the opponent voted two years ago to cut defense spending by $5 \%$ or that her husband's chairmanship of the board of a company whose fate is being decided by Congress is a clear conflict of interest, those claims are easily verified or disproven. There are no 'truth-inadvertising' dictates for music used in television commercials or political ads. Music deftly sidesteps attempts to assess its effects in political terms.

But rhetorical appeals can at least be parsed for content. Arguments can be identified and we can determine whether they are supported by evidence or not. Music, on the other hand, does not play by the same rules and does not offer up its secrets to traditional rhetorical analysis. Music cannot be parsed in the same way as rhetorical arguments. What exactly does a deceptive cadence mean in the context of a political ad? Or a Picardy third? Or a bass clarinet obbligato? What do these things mean in connection with the images and voiceover? And how can a candidate counter any of it? For too long, music's role in political persuasion, seemingly well understood by campaign professionals, has remained terra incognita, underexplored in the scholarly sphere.

Finally, it cannot escape the perceptive observer that during sixty years of television political ads in presidential general elections in the U.S., the Republican Party has simply been more creative and innovative in its use of music in television political advertisements. Savvy about advertising was not spread equally between the two parties - Republicans understood and accepted its tenets much sooner than Democrats. Although he was unsuccessful as a candidate, Goldwater's ads foreshadow the intensely negative but ultimately successful campaigns of George H. W. Bush in 1998 and George W. Bush in 2004.

It looks as though negative advertising, as it began in 1964, is here to stay. Campaign advisers love 'going negative', which they see as a powerful tool. Bill Clinton

\footnotetext{
${ }^{17}$ Shanto Iyengar and Donald R. Kinder, News that Matters: Television and American Public Opinion (Chicago: University of Chicago Press, 1987), 42; and Michael A. Milburn and Anne B. McGrail, 'The Dramatic Presentation of News and its Effects on Cognitive Complexity', paper presented at the annual convention of the American Political Science Association, San Francisco, CA, August 1990, both references as cited in Hart, Seducing America, 72.
} 
campaign adviser Mark Penn has said 'Clever negative advertising works. That is reality. The tactic meets with media and pundit disapproval and spawns accusations of negativity, but the reality is that a clever negative ad can be devastatingly effective'. ${ }^{18}$

\section{Transcripts of Ads Discussed}

\section{Voting Booth - Johnson}

[Band music, cheering, muffled sounds of speeches being made in background]

MAN: ... you know his... you know what he stands for....

ANNOUNCER: When it's all over and you're in the voting booth on November $3 \mathrm{rd}$, keep this in mind: America is stronger and more prosperous than ever before, and we're at peace. Vote for President Johnson on November 3rd. The stakes are too high for you to stay home.

\section{Poverty - Johnson}

MALE NARRATOR: Poverty is not a trait of character. It is created anew in each generation but not by heredity: by circumstances. Today, millions of American families are caught in circumstances beyond their control. Their children will be compelled to live lives of poverty unless the cycle is broken. President Johnson's war on poverty has this one goal: to provide everyone a chance to grow and make his own way, a chance at education, a chance at training, a chance at a fruitful life. For the first time in the history of America this can be done. Vote for President Johnson on November 3 rd. The stakes are too high for you to stay home.

\section{Morality - Goldwater}

MALE NARRATOR \#1: Graft!

[TEXT: BILLIE SOL ESTES]

MALE NARRATOR \# 1: Swindles! Juvenile Delinquency! Crime! Riots!

\footnotetext{
${ }^{18}$ Mark Penn, 'Negative Ads: They Really Do Work', www.politico.com (August 11, 2008), as quoted in Travis N. Ridout and Michael M. Franz, The Persuasive Power of Campaign Advertising (Philadelphia: Temple University Press, 2011), 3.
} 
MALE NARRATOR \#2: Hear what Barry Goldwater has to say about our lack of moral leadership.

GOLDWATER: The leadership of this nation has a clear and immediate challenge to go to work effectively and go to work immediately to restore proper respect for law and order in this land — and not just prior to election day either. America's greatness is the greatness of her people, and let this generation, then, make a new mark for that greatness. Let this generation of Americans set a standard of responsibility that will inspire the world.

MALE NARRATOR \#2: In your heart, you know he's right. Vote for Barry Goldwater.

\section{Literature}

Anzieu, Didier. The Skin Ego. Translated by Chris Turner. New Haven, CT: Yale University Press, 1989.

Brader, Ted. Campaigning for Hearts and Minds. Chicago: University of Chicago Press, 2006.

Hart, Roderick P. Seducing America: How Television Charms the Modern Voter, revised edition. Thousand Oaks, CA: Sage, 1999.

Iyengar, Shanto and Donald R. Kinder. News that Matters: Television and American Public Opinion. Chicago: University of Chicago Press, 1987.

Jamieson, Kathleen, Paul Waldman, and Susan Sherr. 'Eliminating the Negative? Categories of Analysis for Political Advertisements'. In Crowded Airwaves: Campaign Advertising in Elections, edited by James A. Thurber, Candice J. Nelson and David Dulio, 44-64. Washington: Brookings Institution Press, 2000 .

Krumhansl, Carol L. 'An Exploratory Study of Musical Emotions and Psychophysiology'. Canadian Journal of Experimental Psychology 51 (1997): 336-52.

Milburn Michael A. and Anne B. McGrail. 'The Dramatic Presentation of News and its Effects on Cognitive Complexity'. Paper presented at the annual convention of the American Political Science Association, San Francisco, CA, August 1990.

Penn, Mark. 'Negative Ads: They Really Do Work'. Accessed August 11, 2008. http://www.politico.com. 
Peterson, Steven A. Political Behavior: Patterns in Everyday Life. Newbury Park, CA: Sage, 1990.

Ridout, Travis N. and Michael M. Franz. The Persuasive Power of Campaign Advertising. Philadelphia: Temple University Press, 2011.

Robinson, Jenefer. Deeper than Reason: Emotion and Its Role in Literature, Music, and Art. Oxford: Clarendon Press, 2005.

Trainor, Laurel J. and Louis A. Schmidt. 'Processing Emotions Induced by Music'. In The Cognitive Neuroscience of Music, edited by Isabelle Peretz and Robert J. Zatorre, 310-24. Oxford: Oxford University Press, 2003.

West, Darrell M. Air Wars: Television Advertising in Election Campaigns, 19522008, 5th edition. Washington, DC: CQ Press, 2010. 

II (Musikalische) Konstruktionen von eigener und fremder Identität 



\title{
'Das Land ohne Musik'? National Musical Identity in Victorian and Edwardian England
}

\author{
Matthew Gardner (Frankfurt am Main)
}

Musical life in Victorian England was divided. On the one hand, concert repertoire flourished as a result of the large number of commercial concert halls that were the envy of Europe, fed by a steady supply of first-rate artists and modern, continental music; on the other hand there was a distinct lack of new music by British composers included in the programmes. In a period where Britain was establishing itself as the leading world power, owing not only to its vast global Empire, but also the Industrial Revolution, the lack of home-grown composers was a problem, remaining, until the end of the century, one of the few areas of cultural life where the Victorians did not excel on an international level. Evidence of the extent of the problem can be found in various contemporary texts, highlighting both the view of British commentators on their own musical culture and the external view by foreigners. In 1907, looking back on British music history, Cecil Sharp (1859-1924), England's leading collector of folksongs, for example, neatly summarized the problem:

Since the death of Purcell [...] the educated classes have patronized the music of the foreigner, to the exclusion of that of the Englishman. Foreign vocalists, singing in a foreign tongue, have for two centuries monopolized the operatic stage; while English concert platforms have, during the same period, been exclusively occupied by alien singers and instrumentalists, singing and playing compositions of European writers. ${ }^{1}$

\footnotetext{
${ }^{1}$ Cecil J. Sharp, English Folk-Song: Some Conclusions (London: Novello, 1907), 129.
} 
The Nineteenth Century, so rich in the domain of literature, poetry and the sciences, brought to light no English musician of real eminence. ${ }^{2}$

The subject of national music had also been the topic of two studies by the German musicologist and organologist Carl [Karl] Engel (1818-1882), who lived and worked in England from 1884-5. Following his Introduction to the Study of National Music (1866), in which he concentrates more on music theory than cultural issues, ${ }^{3}$ he complied a commentary with bibliographical references on the 'The Literature of National Music', published in nine instalments between July 1878 and March 1879 in The Musical Times and Singing-Class Circular. ${ }^{4}$ In the introduction found in the first instalment, Engel describes what he understands to be national music suggesting that it is broadly dictated by public taste (i.e. emotions), but also that public taste consequently encourages the cultivation of these national styles. ${ }^{5}$

As regards the term National Music, it must be remembered that, taken in its widest sense, it designates any music which, being composed in the peculiar taste of the nation to which it appertains, appeals more powerfully than other music to the feelings of that nation, and is consequently preeminently cultivated in a certain country. In this sense Haydn, Mozart, and Beethoven may be regarded as representatives of German National Music; Rossini, Bellini, and Donizetti of Italian National Music; Auber, Boïeldieu, and Hérold of French National Music. ${ }^{6}$

He goes on to argue that, despite the associations drawn above with art music, the characteristics of national music in fact present themselves more commonly in the popular songs and dance-tunes traditionally preserved by the country-people and the lower classes of society, which form the great majority of a nation'. ${ }^{7}$ His commentated bibliography, like Sharp's study from 1907, therefore also concentrates on these

\footnotetext{
${ }^{2}$ Sharp, English Folk-Song, 128.

${ }^{3}$ Carl Engel, An Introduction to the Study of National Music: Comprising Researches into Popular Songs, Traditions, and Customs (London: Longmans, Green, Reader, and Dyer, 1866).

${ }^{4}$ Carl Engel, 'The Literature of National Music', The Musical Times and Singing-Class Circular, 19/425 (1878): 374-77; 19/426 (1878): 432-35; $19 / 427$ (1878): 484-87; 19/428 (1878): 531-35; 19/429 (1878): 587-89; 19/430 (1878): 654-57; 20/431 (1879): 11-14; 20/432 (1879): 69-72; 20/433 (1879): 133-36. The complete bibliography was also published separately with some additions and alterations in 1879 as: Carl Engel, The Literature of National Music (London: Novello, Ewer \& Co., 1879).

${ }^{5}$ See Robert Stradling and Meirion Hughes, The English Musical Renaissance 1860-1940: Construction and Deconstruction (London and New York: Routledge 1993), 63.

${ }^{6}$ Engel, 'The Literature of National Music', The Musical Times, 19/425 (1878): 374.

${ }^{7}$ Ibid.
} 
types of music, highlighting publications of popular and folk music. Britain is not included in his initial list of 'art music' composers (as quoted above) who represent specific nations, and Engel also faced a similar problem when discussing English folksong. The reason for this becomes evident in the third instalment of Engel's series published in September 1878 where he discusses the 'British Isles', noting that national music in the form of printed collections, mostly of folk music, can be found for Scotland, Wales and Ireland, but that 'it seems rather singular that England should not possess any printed collection of its national songs with the airs as they are sung at the present day; while almost every other European nation possesses several comprehensive works of this kind'. ${ }^{8}$ According to Engel, the apparent lack of national tunes was owing to them having been mostly transmitted orally, outside large towns and cities, and consequently that they have never been printed and transcribed.9 Although he goes on to name a few minor contemporary publications, he notes that anything more significant falls into the category of 'songs which were popular in former centuries' listing publications such as John Playford's (1623-1686/7) The Dancing Master, first published in 1651 and reaching its 17 th edition in $1721 .{ }^{10}$ So, while Britain may not have had a Beethoven, Donizetti, or Boieldieu it did still possess national music in the sense of folk traditions and popular melodies, which later in the century were of critical importance to the development of Ralph Vaughan Williams's (1872-1958) compositional style and of a modern British musical language from the 1890 s.

German writers, coming from their own musical culture, which had produced numerous leading composers of symphonic music during the nineteenth century, continued to see Britain as a country that lacked its own national musical style and world-leading composers well into the early twentieth century, even after the problem had already begun to be resolved thanks to the efforts of composers such as Edward Elgar (1857-1934), Vaughan Williams and Gustav Holst (1874-1934). In 1904 for example, the German essayist Oscar A. H. Schmitz (1873-1931) entitled his book Das Land ohne Musik: englische Gesellschaftsprobleme, in which he presents a critical study of English culture. Although he includes substantial praise of various aspects of English life, he notes that:

Ich habe lange gesucht, was es eigentlich für ein Mangel ist, der immer wieder hinter so vielen englischen Vorzügen fühlbar wird und so erstarrend wirkt.

[...]

\footnotetext{
${ }^{8}$ Engel, 'The Literature of National Music', The Musical Times, 19/427 (1878): 486.

${ }^{9}$ Ibid., 487.

${ }^{10}$ Ibid.; John Playford, The English Dancing Master: Or, Plaine and easie Rules for the Dancing of Country Dances, with the Tune to each Dance (London: Thomas Harper, 1651). Later editions bore the title The Dancing Master.
} 
Und schließlich habe ich etwas gefunden, was die Engländer von allen anderen Kulturvölkern in geradezu erstaunlichem Maß unterscheidet, einen Mangel, den jeder zugibt also gar keine neue Entdeckung - dessen Tragweite aber wohl noch nicht betont worden ist: Die Engländer sind das einzige Kulturvolk ohne eigene Musik (Gassenhauer ausgenommen). ${ }^{11}$

By 1924, however, the music critic Adolf Weißmann (1873-1929) could write in the Musikblätter des Anbruch that the situation in England had changed considerably:

Betreten wir den Boden Englands, so finden wir die Lage der Musik wesentlich verändert. England hatte bis zum Beginn des neuen Jahrhunderts als bedenkenloser Abnehmer Deutschlands gegolten. Je sicherer den Engländern seit drei Jahrhunderten eine epochenmachende Leistung in der Musik versagt blieb, desto williger leistete es dem Lande Gefolgschaft, das für die Musik tonangebend war und blieb.

[...]

Doch unterschätzen wir nicht, was auch in England getan wird, um ein Musikpublikum von unten aufzubauen. ${ }^{12}$

[...]

Es ist auch nicht zu leugnen, daß die englische Musik, soll sie wirklich zur Eigenart erstarken, doch aus anderen Quellen schöpfen muß. Angedeutet ist dies schon durch den älteren Ralph Vaughan Williams, der, ganz abseits von der Heerstraße der Unentwegten, auf das englische Volkstum zurückgeht, und es meisterlich mit dem Impressionistischen verknüpft. Seine London Symphony, die man von diesem Standpunkt aus würdigen kann, wird darum als kennzeichnend zu gelten haben. ${ }^{13}$

\section{Origin of the Problems}

Although a frequent reason given for England's problems with music in the early Victorian period was that the country failed to produce an English Beethoven, the problems perhaps go back as far as the early eighteenth century. The nineteenth century was not the first time England found itself in a position without a composer of national importance to rival those of the continent. When in 1695 Henry Purcell died in his mid-thirties, Britain was, as Sharp observed (see above), left without its leading musical genius. The void left by Purcell's death, despite various failed at-

\footnotetext{
${ }^{11}$ Oscar A. H. Schmitz, Das Land ohne Musik: englische Gesellschaftsprobleme (Munich: Georg Müller, 1904, 4th edition 1914), 30.

${ }^{12}$ Adolf Weißmann, 'Der Stand der Musik in England und Amerika', Musikblätter des Anbruch 6/5 (1924): 179.

${ }^{13}$ Ibid., 180.
} 
tempts by English composers such as John Eccles (c. 1668-1735) or Thomas Clayton (1673-1725), was filled from 1713 by the German composer George Frideric Handel (1685-1759) who had first visited London two years earlier, but was to make the city his permanent home until his death in 1759 . It took until the 1730s for Handel to be seen as a national composer by his contemporaries and during the 1720 s, although in a period where it was unusual for a dead composer to receive much attention after their death, Henry Purcell (1659-1695) was already being remembered as a national composer, gaining a place alongside literary giants of the seventeenth century, such as John Dryden (1631-1700) and John Milton (16081674). ${ }^{14}$ While Handel initially concentrated primarily on Italian opera in London, making it difficult for the British public to 'adopt' him, from 1732, partly through chance, he developed the new genre of English oratorio which was to set him on the path to becoming England's national composer of choice. In 1738 he was the first living composer in England to be immortalized by a life-size statue by Louis-François Roubiliac (1702-1762), put on display in Vauxhall Gardens and in 1760, one year after his death, was also the first composer to be documented through a full-length biography by John Mainwaring (1724-1807). From the 1720s Handel also regularly provided music for important royal family occasions (such as the 1727 coronation, royal weddings and funerals, and national celebrations). ${ }^{15}$ The later eighteenth century did not see people tire of his music, partly through the interest and support of King George III (1738-1820, reigned 1760-1820) - a well-known Handel enthusiast. ${ }^{16}$ In 1784, the 100th anniversary of Handel's birth was celebrated with a commemoration at Westminster Abbey, and he was the first composer in England for whom an attempt at a complete works edition was made by the composer Samuel Arnold (1740-1802) between 1787 and 1797, of which 180 issues were published. Handel's music was also still being used for significant royal events: in 1795 for the wedding of Prince George (1762-1830, the future King George IV) and Princess Caroline of Brunswick (1768-1821), and in 1821 for the coronation of George IV, at which an entire scene from the English oratorio Saul was performed alongside the 'Hallelujah' chorus from Messiah, as well as new compositions from Thomas Attwood 1783-1856) and William Knyvett (1779-1856), in addition to music from

\footnotetext{
${ }^{14}$ See Robert Manson Myers, Handel, Dryden, and Milton (London: Bowes \& Bowes, 1956).

${ }^{15}$ The statue survives in the collection of the Victoria and Albert Museum, London (Museum no. A.31965); [John Mainwaring], Memoirs of the Life of the Late George Frederic Handel. To which is added, A Catalogue of his Works, and Observations upon them (London: R. and J. Dodsley, 1760). For Handel's music for royal occasions see Donald Burrows, Handel and The English Chapel Royal (Oxford: Oxford University Press, 2005).

${ }^{16}$ See, for example, Eva Zöllner, "'He hears no other music if he can help it”: George III. und die Händelbegeisterung am englischen Hof in der zweiten Hälfte des 18. Jahrhunderts', Händel-Jahrbuch 49 (2003): 239-50.
} 
previous coronations by William Boyce (1711-1779) and William Child (1606/71697), amongst others. ${ }^{17}$

\section{Handel as the National Composer in Victorian Britain}

By the second half of the nineteenth century Handel had become a national institution of previously unknown proportions for a musician. This can be seen not only through the influence of Handel's music on visiting composers in London after his death (for example, Mozart's re-scoring of Messiah and Alexander's Feast; or Mendelssohn's interest in English oratorio), but also through the Handel festivals which took place in London during the second half of the century. ${ }^{18}$ The first of these festivals was in 1857 at the Crystal Palace, which had been designed by Joseph Paxton (18031865) and constructed in 1851 for the World Exhibition. ${ }^{19}$ The festivals continued into the twentieth century mostly on a triennial basis: following the first festival in 1857 , there was a festival every three years from 1859 to 1883 , however in 1885 the pattern was broken to accommodate the 200th anniversary of Handel's birth, after which the festivals were held every three years until 1912. With the growing interest in music and the nation's passion for Handel, the Crystal Palace with its enormous footprint of $79,212 \mathrm{~m}^{2}$ provided an ideal location, which no other building in England could compete with. ${ }^{20}$ The result was that to fill the space, the performing forces needed to be increased; consequently in 1883 around 3,900 performers were involved, and for the 1885 festival 87,796 people attended over four evenings - this meant that for each performance between 17,000 and 27,000 people must have been present. ${ }^{21}$ After the First World War the festivals resumed between 1920 and 1926. The national importance of the festivals is, however, also highlighted by the way in which the vast number of performers were drawn together. Members of the choir and orchestra were not only drafted from London, but also from cities and towns across

\footnotetext{
${ }^{17}$ For details of the 1821 coronation see Matthias Range, Music and Ceremonial at British Coronations from James I to Elizabeth II (Cambridge: Cambridge University Press, 2012), 180-98.

${ }^{18}$ For an assessment of Mendelssohn's activities in London, see Colin Timothy Eatock, Mendelssohn and Victorian England (Farnham: Ashgate, 2009).

${ }^{19}$ For an overview of the Crystal Palace Handel Festivals see Michael Musgrave, The Musical Life of the Crystal Palace (Cambridge: Cambridge University Press, 1995) and Annette Landgraf, 'Der Kristallpalast und seine Bedeutung für die Aufführung von Händels Musik', Händel-Jahrbuch 55 (2009): 275-86.

${ }^{20}$ Ibid., 275.

${ }^{21}$ Ibid., $276 f$.
} 
the country. ${ }^{22}$ It is then, hardly surprising, that in around 1913 George Bernard Shaw (1856-1950) could write that 'Handel is not a mere composer in England: he is an institution. What is more, he is a scared sacred institution' ${ }^{23}$ Furthermore, in the first edition of George Grove's A Dictionary of Music and Musicians, Julian Marshall described Handel as 'one of the greatest composers the world has ever seen', ${ }^{24}$ reflecting the position that Handel had gained in the consciousness of the nation, not only as a result of the Crystal Palace performances, but also through the efforts of amateur choral societies across the country, which regularly performed his oratorios with the help of J. Alfred (1810-1896) and Vincent Novello's (1781-1861) music editions. ${ }^{25}$ While this may sound like Handel was the only composer to enjoy success in London, his large-scale choral music was being performed around other classics such as Haydn's Creation and Mendelssohn's Elijah, ${ }^{26}$ and, partly as a result of Mendelssohn's presence in London owing to his role in Bach reception, interest among opponents of Handel's music also developed for Johann Sebastian Bach (1685-

${ }^{22}$ For a list of the 1883 performing forces and the locations from which the singers were drawn see 'The Handel Festival', The Musical Times and Singing-Class Circular, 24/485 (1883): 377 and Landgraf, 'Der Kristallpalast und seine Bedeutung für die Aufführung von Händels Musik', 276.

${ }^{23}$ The statement opened a 'Causerie on Handel in England' written for a society of musicians in France and translated into English for publication in the American Ainslee's Magazine. See George Bernard Shaw, Shaw's Music: The Complete Musical Criticism, ed. Dan H. Laurence, vol. 3 (London: Max Reinhardt, The Bodley Head, 1981), 638.

${ }^{24}$ Julian Marshall, 'Handel, George Frederick', in A Dictionary of Music and Musicians (A.D. 14501880) By Eminent Writers, English and Foreign, ed. George Grove, vol. 1 (London: Macmillan, 1879), 647. Marshall also notes that 'The series of works [English oratorios] which have immortalised Handel's name only began now [from 1740], when he was fifty-five years old' (p. 651) and that 'It is as a vocal and, above all, as a choral writer, that Handel is supreme. No one ever developed the resources of the chorus as he did; and his compositions of this class remain to this day unapproachable'. The importance of Handel can also be seen in the number of additional articles in Grove's Dictionary associated with the composer, including the Commemoration of Handel, Handel Festivals, HändelGesellschaft, The Handel Society and the Handel and Haydn Society. See William Henry Husk 'Handel, Commemoration of, 'Handel Festival'; George Grove 'Händel-Gesellschaft', 'Handel, Society The'; and F. H. Jenks 'Handel and Haydn Society, The', in A Dictionary of Music and Musicians, ed. Grove, vol. 1, 657-71.

${ }^{25}$ See Donald Burrows, 'Making the "classic” Accessible: Vincent Novello’s Vocal Scores of Handel's Oratorios', Händel-Jahrbuch 53 (2007): 103-20 and Victoria L. Cooper, The House of Novello (Aldershot: Ashgate 2003).

${ }^{26}$ See also Donald Burrows, 'Turning the Handel', Musicorum 14 (2013), 'Haendel après Haendel: Construction, renommée, influence de Haendel et de la figure haendélienne': 20. For an overview of the oratorio in nineteenth-century Britain see Barbara Mohn, Das englische Oratorium im 19. Jahrhundert: Quellen, Traditionen, Entwicklungen (Paderborn: Schöningh, 2000). 
1750). In 1849, for example, the London Bach Society was founded and soon afterwards performances of the St Matthew Passion and B Minor Mass took place in 1854 and 1876 respectively, in an attempt to topple Handel's dominance. ${ }^{27}$

That England is a land without music as Schmitz suggested (see above) is therefore untrue, England had a national composer in the Victorian period, the problem was that Handel had been dead for a century and was German by birth, but he remained the leading representative of English music. At the same time, the other composers who were popular (Mendelssohn, Bach, Haydn) were also all foreigners. Handel and Bach could not provide any new works and nineteenth-century composers would have had a difficult job emulating them. The problem in Victorian Britain was, therefore, not so much that Britain was a land without music, but a land without its own modern art music with an identifiable national musical style, relying instead on Handel's outdated works. This problem was clearly something that people were aware of, as it is, for example, summed up in the article on Handel by J. A. Fuller Maitland (1856-1936) and W. Barclay Squire (1855-1927) in the first edition of Dictionary of National Biography, published between 1885 and 1904:

In England he [Handel] is regarded with a veneration which acknowledges no faults. Abroad he has been condemned as old-fashioned and out-of-date, and has been undeservedly neglected. [...] His influence upon modern music is very slight; there is not a single development of modern musical form which can be traced back to him, and for a time the supremacy of his music served only to paralyse musical progress in this country. ${ }^{28}$

The obvious solution was for Britain to encourage and support contemporary native composers, encouraging the development of a new, up-to-date British musical language but with traditional roots. However, in a country where foreign imports had formed a large part of leading musical culture since the beginning of the eighteenth century, it was not possible to simply produce a British composer to rival those on the continent. The process was a slow one and the approach multifaceted, with some elements being a natural continuation of the development of cultural life in Victorian Britain, but with others perhaps representing more conscious attempts to support British music and its composers.

\footnotetext{
${ }^{27}$ See Burrows, 'Turning the Handel', 21.

${ }^{28}$ J. A. Fuller Maitland and W. Barclay Squire, 'Handel, George Frederick', in Dictionary of National Biography, ed. Leslie Stephen and Sidney Lee, vol. 24 (New York: Macmillan; London: Smith, Elder and Co., 1890), 289-90.
} 


\section{Creating British Music}

One of the first steps in the process of supporting contemporary composers was to establish an improved infrastructure for the education of budding composers and musicians. Previously, musical education had largely relied on private tuition from native or visiting musicians and composers, but with the formation of academies or institutions in Britain, it was possible to develop a more concise and managed teaching regime. The establishment of musical institutions and societies in support of music was, again, nothing particularly new to the nineteenth century. In the eighteenth century, musical clubs in support of the performance of certain repertoires had been popular - for example, the Academy of Vocal (later Ancient) Musick, founded in 1727, or the Concert of Ancient Musick which was established in 1776, performing music that was at least 20 years old. In 1834 the Society of British Musicians was formed with the sole aim of encouraging and supporting British music and musicians. Only musicians who were British by birth could become members and only British music was performed at its concerts. The society was, however, dissolved in 1865 owing to dwindling support, partly owing to an unwillingness to broaden their horizons and include some non-British music and musicians.

The foundation of institutions specifically for the education of professional musicians was a more successful development. ${ }^{29}$ One of the earliest of these institutions was the Royal Academy of Music (RAM), founded in 1822 under the patronage of King George IV, which opened the following year. This was followed in 1873 with the foundation of the National Training School for Music, which opened in 1876 with the composer Arthur Sullivan (1842-1900) as its principal. In 1878 a plan was put forward to amalgamate the School with the RAM, but this was defeated; however in 1882 it was replaced by the Royal College of Music (RCM). The RCM opened in 1883 founded by royal charter by the then Prince of Wales (1841-1910, later Edward VII) and under the direction of George Grove (1820-1900). Some of the original 50 staff were drawn, as one might expect, from a first generation of new British composers, often referred to as the first wave of the 'English musical renaissance' and included Charles Villiers Stanford (1852-1924), Hubert Parry (1848-1918) and Sullivan. ${ }^{30}$ It was at the RCM that some of the most influential figures in the development of British music at the turn of the twentieth century were trained, including

\footnotetext{
${ }^{29}$ For popular music education see Bernarr Rainbow, 'The Rise of Popular Music Education in Nineteenth-Century England', in The Lost Chord: Essays in Victorian Music, ed. in Nicholas Temperley (Bloomington: Indiana University Press, 1989), 17-41.

${ }^{30}$ For biographies of Parry and Stanford and their contributions to the 'English musical renaissance' see: Jeremy Dibble, C. Hubert H. Parry: His Life and Music (Oxford: Clarendon Press, 1992); Jeremy Dibble, Charles Villiers Stanford (Oxford: Oxford University Press, 2002); and Paul Rodmell, Charles Villiers Stanford (Aldershot: Ashgate, 2002).
} 
Vaughan Williams and Holst. One of the main aims of the RCM was to provide a structured education and career path for musicians and composers who did not want to follow the more traditional route of church or cathedral choirs and universities, as Stanford and Parry had done, and the college consequently was permitted to offer degrees and diplomas in music under its royal charter. Various other educational establishments were also founded during the same period, including the Guildhall School of Music (1880), Trinity College of Music (1875) and the Royal Military School of Music, which opened in $1857 .{ }^{31}$ Interest in music research had also been slowly growing throughout the century, which had initially been inspired in the later part of the eighteenth century with the pioneering music histories published by Charles Burney (1726-1814) and John Hawkins (1719-1789). ${ }^{32}$ The nineteenth century additionally saw the establishment of musical magazines such as The Musical Times and Singing-Class Circular (published monthly from 1844); and between 1879 and 1889 Grove published his comprehensive dictionary of music, in which he partly sought to promote English composers from before $1850 .{ }^{33}$ In the first part of the twentieth century further academic journals on music were established, such as The Musical Quarterly (1915) and Music and Letters (1920), all of which provided additional support and incentive for composers and audiences to pursue British music.

In order to 'create' a British musical style, some composers looked to the past for inspiration. Parry and Stanford had both been trained in the English church music tradition and it is therefore unsurprising that they both produced a substantial amount of English church music of their own. During the second half of the nineteenth century a general revival of interest in English church music developed, which led to a high standard of choral music resuming at Cathedrals and churches, having fallen into decline during the late eighteenth and early nineteenth centuries. In 1870, for example, the accomplished church musician John Stainer (1840-1901) was appointed as organist of St Paul's Cathedral, implementing a choir of 40 choristers and daily sung services resumed. This renewed interest in church music and the contin-

\footnotetext{
${ }^{31}$ For an overview of educational institutions in nineteenth-century London, see Bernarr Rainbow and Anthony Kemp, 'London (i), §VIII: Educational institutions', in Grove Music Online. Oxford Music Online. Oxford University Press, accessed 22 February 2015, http://www.oxfordmusiconline. $\mathrm{com} / \mathrm{subscriber/article/grove/music/16904pg8.} \mathrm{For} \mathrm{details} \mathrm{of} \mathrm{some} \mathrm{British} \mathrm{music} \mathrm{institutions} \mathrm{in} \mathrm{and}$ outside London, see Paul Rodmell, ed., Music and Institutions in Nineteenth-Century Britain (Farnham: Ashgate, 2012).

${ }^{32}$ Charles Burney, A General History of Music from the Earliest Ages to the Present Period, 4 vols. (London: 1776-1789) and John Hawkins, A General History of the Science and Practice of Music, 5 vols.(London: 1776).

${ }^{33}$ See Stradling and Hughes, The English Musical Renaissance 1860-1940, 21; and George Grove ed., A Dictionary of Music and Musicians (A.D. 1450-1880) By Eminent Writers, English and Foreign, 4 vols. (London: Macmillan, 1879-1889).
} 
ued development of research into music history also resulted in a revival of church music from the Tudor period - which as Cecil Sharp noted in 1907, was the last time England was a leader of European music before Purcell. ${ }^{34}$

Prior to Purcell, however, musical England held a proud position among the nations of Europe. Her madrigal composers of the sixteenth and early seventeenth centuries were unsurpassed, while her writers of sacred music of the same period stood very nearly as high in the estimation of Europe. ${ }^{35}$

During the early part of his career, Vaughan Williams was clearly one composer who was aware of a need for producing music that would appeal to and convince the British public of its 'Englishness'. ${ }^{36}$ While his writing also owes a considerable debt to a variety of international composers, including Bach, Debussy, Mahler and Brahms, amongst others, in his pre-First World War works, a conscious effort to engage with English musical culture, tapping into the subconscious of his listeners, is clearly present. The influence of the Tudor revival on symphonic music can perhaps best be appreciated in one of Vaughan Williams's most well-known early works. The Fantasia on a Theme by Thomas Tallis, premiered in 1910, takes its musical theme from the Tudor composer Thomas Tallis (c. 1505-1585), originally written as one of nine homophonic psalm tunes for Archbishop Matthew Parker's (1504-1575) Psalter, published in $1567 .{ }^{37}$ The tune, as with a number of other Tudor melodies, had been included in The English Hymnal in 1906, which partly as a result of the revival of church music was a necessary addition to church music, and of which Vaughan Williams was the musical editor. ${ }^{38}$ Using a simple piece of Tudor church music in a large-scale piece of symphonic writing was a way of establishing a connection between symphonic music and the unique English choral tradition, fitting for the performance location of the premiere in Gloucester Cathedral as part of the Three

\footnotetext{
${ }^{34}$ For a discussion of the Tudor revival in England and its effect on contemporary composition, see Stradling and Hughes, The English Musical Renaissance 1860-1940, 61-7.

${ }^{35}$ Sharp, English Folk-Song, 128.

${ }^{36}$ For a discussion of the term 'Englishness' and its associated problems, see Julian Onderdonk, 'The Composer and Society: Family, Politics, Nation', in The Cambridge Companion to Vaughan Williams, ed. Alain Frogley and Aidan J. Thomson (Cambridge: Cambridge University Press, 2013), 9-28.

${ }^{37}$ Matthew Parker, The Whole Psalter Translated into English Metre (London: 1567).

${ }^{38}$ The English Hymnal with Tunes (London: Oxford University Press, [1906]). For Tallis's third mode melody, see no. 92, p. 130. Although drawing on a range of musical sources from across Europe, the hymnbook also incorporated English folk melodies and tunes drawn from the entire history of English church music.
} 
Choirs Festival. ${ }^{39}$ The Tallis Fantasia received a generally positive review in The Times, with comments such as 'the work is wonderful because it seems to lift one into some unknown region of musical thought and feeling'; however, there was also some criticism about its place in the development of symphonic music: 'Throughout its course one is never quite sure whether one is listening to something very old or very new $[\ldots]$ one is living in two centuries at once. [...] [I]t cannot be assigned to a time or a school, but it is full of the visions which have haunted the seers of all times'. ${ }^{40}$ While the reviewer suggests that the combination of the old church music style and everything that has since 'enriched' them, is what makes the 'Fantasia so delightful to listen to' they also note that:

We can recall no piece of pure instrumental music produced at Three Choirs Festival which has seemed to belong to its surroundings so entirely as does this Fantasia. It could never thrive in a modern concert room, but in the quieter atmosphere of the Cathedral the mind falls readily into the reflective attitude necessary for the enjoyment of every unexpected transition from chord to chord. ${ }^{41}$

The influence of the Tudor revival is not limited to the Fantasia, or to other early works by Vaughan Williams, but can also be seen, for example, in his Three Elizabethan Songs (published 1913), Five Tudor Portraits (1935), or Fantasia on Greensleeves (1934), adapted from Sir John in Love (first performed in 1929).

While the Tudor revival provided one source of inspiration for Vaughan Williams, English folksong offered another strand, in which it was possible to give his music a 'typically English' ingredient. ${ }^{42}$ Stemming once again from his work for The

\footnotetext{
${ }^{39}$ During the same period, Vaughan Williams also engaged with composers such as Orlando Gibbons (1583-1625) and Purcell, editing, for example, two volumes of the Purcell Society edition of Welcome Songs in 1905 and 1910 respectively.

${ }^{40}$ The Times, 7 September 1910, Issue 39371: 11. The Times Digital Archive, accessed 12 January 2015.

${ }^{41}$ Ibid. Vaughan Williams returned to the Fantasia in 1919 making some substantial revisions. For a detailed analysis of the Fantasia see Anthony Pople, 'Vaughan Williams, Tallis, and the Phantasy Principle', in Vaughan Williams Studies, ed. Alain Frogley (Cambridge: Cambridge University Press, 1996), 47-80.

${ }^{42}$ As Alain Frogley has shown, Vaughan Williams's reputation as a nationalist composer is, in simple terms, based on four key elements: firstly, his published writings; secondly, his fascination with English folksong and hymn tunes; thirdly; education and the influence on his music of various English sources, such as Literature, folksong, Tudor and Jacobean music; and fourthly English literature of the sixteenth and seventeenth centuries. See Alain Frogley, 'Constructing Englishness in Music: National Character and the Reception of Ralph Vaughan Williams', in Vaughan Williams Studies, ed. Frogley, 5.
} 
English Hymnal, he used many of the folk included in the hymnal in various orchestral works. Examples include his Norfolk Rhapsodies (1905-6), Fantasia on English Folk Songs (1910, lost) and Fantasia on Sussex Folk Tunes (1929), which, also, in works such as the Norfolk Rhapsodies or The Lark Ascending (1914) relate to the English landscape. Vaughan Williams's interest in folksong and musical traditions was furthermore something he frequently commented on and his own views are well documented in his writings and teaching. ${ }^{43}$

Moving away from folksong and Tudor church music, Vaughan Williams's first two symphonies embody England through the medium of programme music. His first symphony, A Sea Symphony, which was written slowly over seven years, invites a connection through its title and musical imagery to Britain's long naval tradition and relationship with the sea. The symphony, which was premiered on 12 October 1910 at Leeds, just one month after the Tallis Fantasia had been performed at Gloucester, perceives, as James Day describes, the sea as:

a vast natural force both separating and uniting the continents, deep, majestic, and ostensibly limitless, the arena for human endeavour and achievement and the symbol of man's never-ending spiritual quest to reach out for, explore and understand the unknown, both within himself and in the universe at large. ${ }^{44}$

The symphony can therefore not only be connected to the sea, as being something typically British, but an allegory could perhaps also be drawn to Britain's achievements throughout the Industrial Revolution and Victorian period. Furthermore, $A$ Sea Symphony is a choral symphony, placing it partly in the tradition of large-scale choral works, such as the Crystal Palace oratorio performances. Vaughan Williams was therefore tapping into a number of elements of Britain's musical and historical past to create a musical present. While his first symphony looked to the sea, Vaughan William's second symphony uses London as the inspiration for some of its thematic material. A London Symphony was first performed on 17 March 1914 at Queen's Hall and uses musical imagery to remind the listener of London life, giving a nod to the city which Vaughan Williams considered his home. The most recognizable element for modern audiences are the chimes of Big Ben which can be heard at the opening of the first movement. ${ }^{45}$ Vaughan Williams was certainly not the first British composer

\footnotetext{
${ }^{43}$ See for example, Ralph Vaughan Williams, National Music and other Essays (Oxford: Oxford University Press, 1963, second edition 1986).

${ }^{44}$ James Day, Vaughan Williams (Oxford: Oxford University Press, 1998), 185.

${ }^{45}$ For a detailed analysis of the symphonies see Lionel Pike, Vaughan Williams and the Symphony (London: Toccata Press, 2003) and Michael Kennedy, The Works of Ralph Vaughan Williams (London: Oxford University Press, 1964). Despite Vaughan Williams's own objection to an association
} 
of the late nineteenth century to use programme music as a way of suggesting 'Englishness'; Parry, for example, had subtitled his third symphony 'The English' in 1889. However, that Vaughan Williams's first two symphonies have a clear British theme is perhaps telling of his commitment to experimenting with and developing a style to which British audiences could relate.

In contrast to Vaughan Williams, Elgar engaged with the tradition of English oratorio, recognizing that the genre was worth developing further. As shown above, oratorios were an integral part of British musical life in the second half of the nineteenth century through the Handel commemorations and the 'classic' status gained by Haydn's Creation and Mendelssohn's Elijah. Elgar's oratorios The Light of Life (1896), The Dream of Gerontius (1900), The Apostles (1903) and The Kingdom (1906) are consequently a further example of how a composer could develop a new modern style, while remaining faithful to national music traditions in Britain. ${ }^{46}$ Furthermore, the British public were being given the opportunity to hear oratorios by a British composer, written in a contemporary style. Given the popularity of oratorio in England, it was perhaps only a matter of time before a new-generation composer produced oratorios of their own. Elgar, of course, also engaged with what might be considered national traditions in other ways, for example through his choral music for the English church or the connection between the Pomp and Circumstance marches and the tradition of British military music.

The outbreak of the First Wold War interrupted most aspects of musical life in Britain and after the war the compositional style of British composers began to take a new direction towards modernism, gradually leaving the past behind. ${ }^{47}$ Nevertheless, English traditions, which Vaughan Williams himself recognized as being so important, were not completely forgotten, and the next generation of British composers also showed an interest in the past - for example, Benjamin Britten's (1913-1976) enthusiasm for Purcell's music. Thanks to the efforts of Victorian and Edwardian composers in establishing educational institutions, encouraging British composition, their rediscovery of traditional British music, such as folksong, and the music of generations past, integrating it into their own works, it was possible for George Bernard

\footnotetext{
being drawn with his music and the genre of programme symphonies, according to Pike, his view changed as he grew older. See Pike, Vaughan Williams, 47.

${ }^{46}$ For a detailed study of Elgar's engagement with the nineteenth-century oratorio tradition see Charles Edward McGuire, Elgar's Oratorios: The Creation of an Epic Narrative (Aldershot: Ashgate, 2002). For the influence of the German symphony tradition on Elgar's music see Michael Gassmann, Edward Elgar und die deutsche symphonische Tradition (Hildesheim: Olms, 2002).

${ }^{47}$ See, for example, Annika Forkert, 'Musical Modernism in the "Land Without Music": The Limits in Elgar and Holst', Jahrbuch für Europäische Ethnologie 3 (2012): 123-44 and J. P. E. Harper-Scott, Edward Elgar, Modernist (Cambridge: Cambridge University Press, 2006).
} 
Shaw to write in 1913, in contrast to Schmitz's statement that England was 'das Land ohne Musik', that:

England, after two centuries of imitative negligibility, has suddenly flung into the field a cohort of composers whose methods have made a technical revolution in musical composition. [...] Messrs Bax, Ireland, Cyril Scott, Holst, Goosens, Vaughan Williams, Frank Bridge, Boughton, Holbrooke, Howells and the rest. ${ }^{48}$

\section{Literature}

Burney, Charles. A General History of Music from the Earliest Ages to the Present Period, 4 vols. London: 1776-1789.

Burrows, Donald. Handel and The English Chapel Royal. Oxford: Oxford University Press, 2005.

Burrows, Donald. 'Making the "Classic" Accessible: Vincent Novello's Vocal Scores of Handel's Oratorios'. Händel-Jahrbuch 53 (2007): 103-20.

Burrows, Donald. 'Turning the Handel'. Musicorum 14 (2013), 'Haendel après Haendel: Construction, renommée, influence de Haendel et de la figure haendélienne’: 15-24.

Cooper, Victoria L. The House of Novello. Aldershot: Ashgate, 2003.

Day, James. Vaughan Williams. Oxford: Oxford University Press, 1998.

Dibble, Jeremy. Charles Villiers Stanford. Oxford: Oxford University Press, 2002.

Dibble, Jeremy. C. Hubert H. Parry: His Life and Music. Oxford: Clarendon Press, 1992.

Eatock, Colin Timothy. Mendelssohn and Victorian England. Farnham: Ashgate, 2009.

Engel, Carl. 'The Literature of National Music'. The Musical Times and SingingClass Circular 19/425 (1878): 374-77; $19 / 426$ (1878): 432-35; 19/427 (1878): 484-87; $19 / 428$ (1878): 531-35; $19 / 429$ (1878): 587-89; $19 / 430$ (1878): 654-57; 20/431 (1879): 11-14; 20/432 (1879): 69-72; 20/433 (1879): 133-36.

Engel, Carl. An Introduction to the Study of National Music: Comprising Researches into Popular Songs, Traditions, and Customs. London: Longmans, Green, Reader, and Dyer, 1866.

\footnotetext{
${ }^{48}$ Shaw, Shaw's Music: The Complete Musical Criticism, ed. Laurence, vol. 3, 415-16.
} 
Engel, Carl. The Literature of National Music. London: Novello, Ewer \& Co., 1879.

The English Hymnal with Tunes. London: Oxford University Press, [1906].

Forkert, Annika. 'Musical Modernism in the "Land Without Music": The Limits in Elgar and Holst'. Jahrbuch für Europäische Ethnologie 3 (2012): 123-144.

Frogley, Alain. 'Constructing Englishness in Music: National Character and the Reception of Ralph Vaughan Williams'. In Vaughan Williams Studies, edited by Alain Frogley, 1-22. Cambridge: Cambridge University Press, 1996.

Gassmann, Michael. Edward Elgar und die deutsche symphonische Tradition. Hildesheim: Olms, 2002.

Grove, George, ed. A Dictionary of Music and Musicians (A.D. 1450-1880) By Eminent Writers, English and Foreign. 4 vols. London: Macmillan, 18791889.

Grove, George. 'Händel-Gesellschaft', 'Handel, Society The'. In A Dictionary of Music and Musicians (A.D. 1450-1880) By Eminent Writers, English and Foreign, edited by George Grove, vol. 1, 658f. London: Macmillan, 1879.

'The Handel Festival'. The Musical Times and Singing-Class Circular, 24/485 (1883): 377-8.

Harper-Scott, J. P. E. Edward Elgar, Modernist. Cambridge: Cambridge University Press, 2006.

Hawkins, John. A General History of the Science and Practice of Music, 5 vols. London: 1776.

Husk, William Henry. 'Handel, Commemoration of, 'Handel Festival'. In A Dictionary of Music and Musicians (A.D. 1450-1880) By Eminent Writers, English and Foreign, edited by George Grove, vol. 1, 657-58. London: Macmillan, 1879.

Jenks, F. H. 'Handel and Haydn Society, The'. In A Dictionary of Music and Musicians (A.D. 1450-1880) By Eminent Writers, English and Foreign, edited by George Grove, vol. 1, 659-61. London: Macmillan, 1879.

Kennedy, Michael. The Works of Ralph Vaughan Williams. London: Oxford University Press, 1964.

Landgraf, Annette. 'Der Kristallpalast und seine Bedeutung für die Aufführung von Händels Musik'. Händel-Jahrbuch 55 (2009): 275-86. 
[Mainwaring, John]. Memoirs of the Life of the Late George Frederic Handel. To which is added, A Catalogue of his Works, and Observations upon them. London: R. and J. Dodsley, 1760.

Maitland, J. A. Fuller and W. Barclay Squire. 'Handel, George Frederick'. In Dictionary of National Biography, edited by Leslie Stephen and Sidney Lee, vol. 24, 277-291. New York: Macmillan; London: Smith, Elder and Co., 1890.

Manson Myers, Robert. Handel, Dryden, and Milton. London: Bowes \& Bowes, 1956.

Marshall, Julian. 'Handel, George Frederick'. In A Dictionary of Music and Musicians (A.D. 1450-1880) By Eminent Writers, English and Foreign, edited by George Grove, vol. 1 647-57. London: Macmillan, 1879.

McGuire, Charles Edward. Elgar's Oratorios: The Creation of an Epic Narrative. Aldershot: Ashgate, 2002).

Musgrave, Michael. The Musical Life of the Crystal Palace. Cambridge: Cambridge University Press, 1995.

Mohn, Barbara. Das englische Oratorium im 19. Jahrhundert: Quellen, Traditionen, Entwicklungen. Paderborn: Schöningh, 2000.

Onderdonk, Julian. 'The Composer and Society: Family, Politics, Nation'. In The Cambridge Companion to Vaughan Williams, edited by Alain Frogley and Aidan J. Thomson, 9-28. Cambridge: Cambridge University Press, 2013.

Parker, Matthew. The Whole Psalter Translated into English Metre. London: 1567.

Pike, Lionel. Vaughan Williams and the Symphony. London: Toccata Press, 2003.

Playford, John. The English Dancing Master: Or, Plaine and easie Rules for the Dancing of Country Dances, with the Tune to each Dance. London: Thomas Harper, 1651.

Pople, Anthony. 'Vaughan Williams, Tallis, and the Phantasy Principle'. In Vaughan Williams Studies, edited by Alain Frogley, 47-80. Cambridge: Cambridge University Press, 1996.

Rainbow, Bernarr and Anthony Kemp. 'London (i), \$VIII: Educational institutions'. In Grove Music Online. Oxford Music Online. Oxford University Press, accessed 22 February 2015, http://www.oxfordmusiconline.com/subscriber/ article/grove/music/16904pg8.

Rainbow, Bernarr. 'The Rise of Popular Music Education in Nineteenth-Century England'. In The Lost Chord: Essays in Victorian Music, edited by Nicholas Temperley, 17-41. Bloomington: Indiana University Press, 1989. 
Range, Matthias. Music and Ceremonial at British Coronations from James I to Elizabeth II. Cambridge: Cambridge University Press, 2012.

Rodmell, Paul. Charles Villiers Stanford. Aldershot: Ashgate, 2002.

-, ed. Music and Institutions in Nineteenth-Century Britain. Farnham: Ashgate 2012.

Schmitz, Oscar A. H. Das Land Ohne Musik: englische Gesellschaftsprobleme. Munich: Georg Müller, 1904, 4th edition 1914.

Sharp, Cecil J. English Folk-Song: Some Conclusions. London: Novello, 1907.

Shaw, George Bernard, Shaw's Music: The Complete Musical Criticism, edited by Dan H. Laurence, 3 vols. London: Max Reinhardt, The Bodley Head, 1981.

Solie, Ruth A. 'Music'. In The Cambridge Companion to Victorian Culture, edited by Francis O'Gorman, 101-18. Cambridge: Cambridge University Press, 2010.

The Times. The Times Digital Archive.

Vaughan Williams, Ralph. National Music and other Essays. Oxford: Oxford University Press, 1963, second edition 1986.

Weißmann, Adolf. 'Der Stand der Musik in England und Amerika'. Musikblätter des Anbruch 6/5 (1924): 178-82.

Zöllner, Eva. "'He hears no other music if he can help it": George III. und die Händelbegeisterung am englischen Hof in der zweiten Hälfte des 18. Jahrhunderts'. Händel-Jahrbuch 49 (2003): 239-50. 


\title{
Reflections of European Culture in the Grey Collection (National Library of South Africa)
}

\author{
Rebekka Sandmeier (Cape Town)
}

The Grey Collection at the National Library of South Africa, Cape Town, houses among other items - early prints as well as medieval and Renaissance manuscripts from Europe, some of which include music notation. ${ }^{1}$ How and why these European items found their way into the collection raises questions about the the purpose of the collection at the time it was set up, and what its value could be today. ${ }^{2}$

Born in England, George Grey (1812-1898) acquired a thorough training in the army and led two expeditions in Western Australia between 1837 and 1839. In 1840 he subsequently became governor of South Australia and later of New Zealand in 1845. Grey was governor of the Cape Colony for two periods, from 1854 to 1859 and again from 1860 to 1861 . Following his term in the Cape he was again sent to

\footnotetext{
${ }^{1}$ The RISM siglum for the National Library of South Africa (Cape Town) is ZA-Csa. However, the manuscripts in the Grey Collection of the NLSA containing musical notation have not yet been catalogued in RISM.

${ }^{2}$ The article is based on the paper 'The Idea of European Culture as Conveyed in the Grey Collection (National Library of South Africa)' presented at the annual congress of the Gesellschaft für Musikforschung in Göttingen in 2012. The character of spoken delivery has been kept in the text adding the scholarly apparatus only.
} 
New Zealand before returning to England in $1894 .{ }^{3}$ During his time as governor of the Cape Colony, Grey strove for peaceful settlements between the English Colony and the Boer Republics, and was recalled to England in 1859/60 owing to his plans for a union between the Boer Republics and the English colony. His actions towards indigenous people were ambiguous: on the one hand he promoted peace treaties between the English and the Xhosa in the Cape, and the English and the Zulu in Natal, on the other hand he also saw and realised the opportunities to gain land for the colony, for example following the 'Great Xhosa Cattle-Killing'. ${ }^{4}$

Within the colony Grey improved administration and infrastructure, such as roads, railways, irrigation and hospitals, and he encouraged general education run by missionaries to be made available to colonists. When he left the Cape Colony to become governor of New Zealand in 1861, he donated his private collection of books and manuscripts to the South African Public Library.

I have the honour to enclose, for the information of His Excellency the LieutnantGovernor, a copy of a letter from His Excellency Sir George Grey, announcing the donation of his valuable Library of rare Books and Manuscripts to the South African Public Library, Cape Town, and stating the conditions on which the munificent gift is bestowed. ${ }^{5}$

For the indigenous people within the Cape Colony all of these privileges were also accessible, but on one condition: they had to take on European culture and religion, to co-operate and therefore to become dependent on white rule. ${ }^{6}$ As a result, historians are confronted by an ambivalent picture of Grey's personality and government, which has been interpreted in various ways. During colonial and apartheid times he was seen as a benevolent benefactor of indigenous people. ${ }^{7}$ However, in the 1990s the political aspects of his governance were re-evaluated by Jeff Peires promoting a more critical view of his government. ${ }^{8}$

\footnotetext{
3 'Sir George Grey', 'Australia', 'New Zealand', 'South Africa', Encyclopaedia Britannica Online Academic Edition, accessed 11 September 2013, http://www.britannica.com.

${ }^{4}$ See Jeff Peires, The Dead Will Arise: Nongqawuse and the Great Xhosa Cattle-Killing of 1856-7 (Jeppestown: Jonathan Ball, 2003), 263-91.

${ }^{5}$ George Grey, letter to Egidius Benedictus Watermeyer. Published in The Cape of Good Hope Government Gazette, 24 December 1861.

${ }^{6}$ Peires, The Dead Will Arise, 292-326.

${ }^{7}$ For example James Milne, The Romance of a Pro-Consul being the Personal Life and Memoirs of the Right Hon. Sir George Grey, K.C.B. (London: Chatto \& Windus, 1899), 123-71, or James Rutherford, Sir George Grey, K.C.B., 1812-1898: A Study in Colonial Government (London: Cassell 1961), 291442.

${ }^{8}$ Peires, The Dead Will Arise.
} 
The collection, which Grey donated to the South African Library, can be divided into two distinct sections: on the one hand there are books on African languages and publications in African languages, all of which date from the nineteenth century, on the other hand there are items of European origin, mostly comprising of early printed books, incunabula and manuscripts. ${ }^{9}$ Research on the collection centres mainly on the European section, even though the Africana section houses the most outstanding items in the collection. Scholars of Italian, German, and English language and literature have published on the manuscripts and early printed books in the collection. ${ }^{10}$ The German musicologist, Christoph Stroux, investigated the manuscripts in the collection - especially the liturgical items and those containing music notation. ${ }^{11}$

Grey pursued different acquisition strategies for the various sections in the collection: he already started to collect Africana before he was appointed governor to the Cape Colony, and in New Zealand had also shown an interest in indigenous languages. ${ }^{12}$ Once he had arrived in Cape Town, he used government connections and networks to acquire books. He approached the missionaries who had studied and printed books in indigenous languages, and had a desiderata list printed and distributed. Wilhelm Heinrich Bleek (1827-1875), a philologist, who had studied in Bonn and Berlin, was appointed as Grey's interpreter and translator in 1856. However, his real task was to organise the Africana collection and in 1858 and 1859 he published a catalogue of its contents, ${ }^{13}$ as well as becoming the curator of that section at the South African Public Library when Grey left for New Zealand. ${ }^{14}$ The printing of a desiderata list and the employment of a curator for the collection shows that Africana items

\footnotetext{
${ }^{9}$ There are two catalogues of the entire collection, both dating from the nineteenth century: Wilhelm Bleek, The Library of His Excellency Sir George Grey, 4 vols. (London: Trübner, 1858-62), and Theophilus Hahn, An Index to the Grey Collection in the South African Public Library (Cape Town: Saul Solomon, 1884).

${ }^{10}$ See for example: Edoardo Bizzarri, 'Inediti italiani della "Grey Collection", Rinascita 4 (1941): 860-71; Harald Dawe, 'Interessantes für Germanisten in den Beständen der South African Library in Kapstadt', Acta Germanica 15 (1982): 159-65; A Lionel Isaacs, 'Early English printed Books in the Grey Collection', Quarterly Bulletin of the South African Library 6 (1951/52): 76-85.

${ }^{11}$ Christoph Stroux was instrumental in preparing many of the entries in the most recent catalogue of the manuscripts in the Grey Collection: Carol Steyn, The Medieval and Renaissance Manuscripts in the Grey Collection of the National Library of South Africa, Cape Town, 2 vols. (Salzburg: Institut für Anglistik und Amerikanistik, Universität Salzburg, 2002). His extensive handwritten notes (not yet catalogued) on the manuscripts are now at the National Library of South Africa, Cape Town.

${ }^{12}$ Donald J. Kerr, Amassing Treasures for All Times: Sir George Grey, Colonial Bookman and Collector (Delaware/Dunedin: Oakknoll Press/Otago University Press 2006), 75-91.

${ }^{13}$ Bleek, The Library, vols. 1 and 2 (1858-59).

14 'Wilhelm Bleek', Encyclopaedia Britannica Online Academic Edition, accessed 16 September 2013, http://www.britannica.com.
} 
were collected systematically. Grey was aiming for a complete collection of everything that had ever been printed in or about African languages.

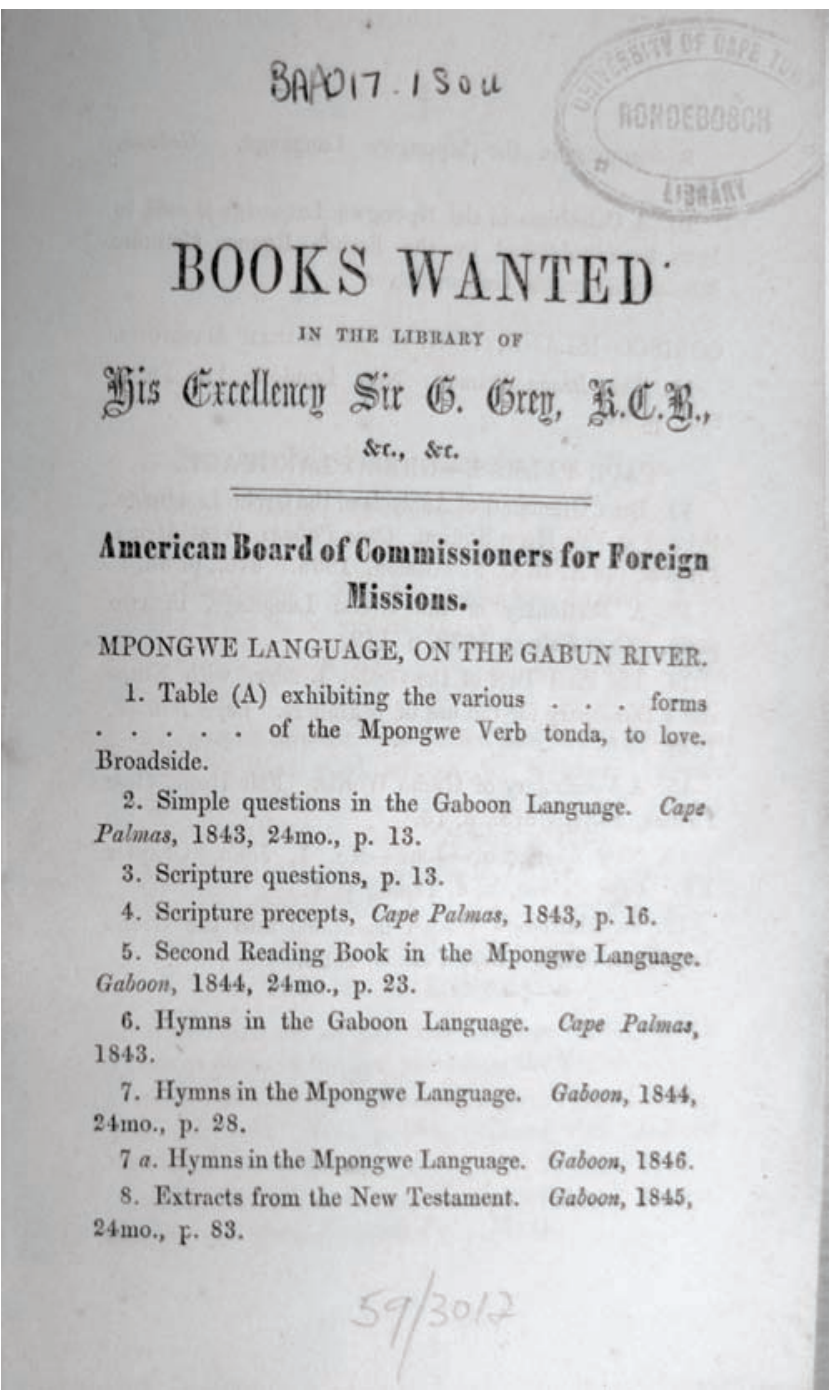

Figure 1: Title page, Books Wanted in the Library of His Excellency Sir George Grey, Cape Town: Pike, 185?

In comparison the European section in the collection was not acquired systematically. Some titles Grey brought with him when he came to Cape Town, however in 1848 a fire had destroyed his New Zealand collection, so that most of the items in the 
Cape Town collection must have been purchased between 1855 and 1861. Grey regularly corresponded with antiquarian book dealers in England and, through Bleek, in Germany as well as perusing their auction catalogues. ${ }^{15}$ It has been established that some of the Italian manuscripts had been stolen by the infamous Guglielmo Libri (1803-1869) and came into the Grey's possession through the antiquarian book dealer Bernard Quaritch (1819-1899) ${ }^{16}$ However, acquiring antiquarian items for a collection in Africa was not always easy - though Grey sifted meticulously through catalogues and ordered accordingly, the postal service to Europe was exceedingly slow, so that often his letter arrived too late and the items he requested were already sold. He therefore told dealers what he already had in his collection and what he was looking for, and relied on their expertise and recommendations.

The books I am anxious to procure at present are Caxton manuscripts and any of the very earliest printed works, especially Black books. Most of the classics I have [???], but the Editio princeps of Horace and Vergil I still want \& I presume I am unlikely to get them. Any English books printed in the $15^{\text {th }}$ century I would be glad of, also copies of any early English poets. ${ }^{17}$

\section{The Content of the European Section}

Even though the acquisition of items in the European section of the Grey Collection in Cape Town took place in a slightly haphazard way, it is known what type of items Grey was seeking to add to his collection. Concerning the acquisition of early printed books, Grey tells the antiquarian bookseller (see above quote) that he is looking for English imprints, especially Caxton, for any early English poets, for any other black letter books and for first prints (not necessarily English) of classical authors. However, in relation to the Medieval and Renaissance manuscripts it is only possible to guess that Grey was looking for similar items as in his Auckland collection, which, unlike the Cape Town collection, shows a systematic acquisition of manuscripts. In the Auckland collection Grey collected mainly hymnals and psalters, belles lettres and bibles. ${ }^{18}$

Yet the collection in Cape Town reflects Grey's aims in acquisition only to a certain extent: due to the slow postal service and tough competition among book collec-

\footnotetext{
${ }^{15}$ Kerr, Amassing Treasures for All Times, 135-52.

${ }^{16}$ Christoph Stroux, 'The Story of Guglielmo Libri', Quarterly Bulletin of the South African Library 44 (1989/90): 112-15.

${ }^{17}$ George Grey, letter to T. and W. Boone, 28 August 1857. Quoted from Kerr, Amassing Treasures for All Times, 261.

${ }^{18}$ Kerr, Amassing Treasures for All Times, 205-50.
} 
tors, Grey could only get very little of what he was looking for in relation to early printed books. ${ }^{19}$ There are a few first and second editions by German printers ${ }^{20}$ and most early printed books are of a liturgical or theological nature, such as bibles, ${ }^{21}$ the writings of Martin Luther (1483-1546), ${ }^{22}$ or classical authors both from classical antiquity and the Middle Ages. ${ }^{23}$ The books are written in Latin or vernacular languages such as Italian, German, Dutch and English. However, among the early prints there is still a high proportion of early English books, ${ }^{24}$ the gem of which is a first edition of Geoffrey Chaucer's (c. 1343-1400) works. ${ }^{25}$ The manuscripts in the collection date mainly from the thirteenth to the fifteenth century. ${ }^{26}$ Many of them are illustrated and most of them are liturgical. Apart from manuscripts in Latin, French, German and Italian, some manuscripts are written in Greek or Hebrew script. ${ }^{27}$ The non-liturgical manuscripts include the writings of classical authors both from classical antiquity ${ }^{28}$ and the Middle Ages. ${ }^{29}$

This general overview of the content of the European section within the Grey Collection clearly shows that musical items did not form a priority in Grey's acquisi-

\footnotetext{
${ }^{19}$ According to the Short-Title Catalogue of Early Printed Books in South African Libraries 1470-1550 (Cape Town: South African Library, 1977).

${ }^{20}$ For example Johannes Andreae, Super arborius consanguinitatis affinitatis necnon spiritualis cognationis (Nürnberg: Friedrich Creussner, 1477); John Bale, Illustrium maioris Britanniae scriptorum [...] (Wesel: Derick van der Straten, 1548); Jean Calvin, Institvtio Christianae religionis nvnc uere denum suo titulo respondens (Strassburg: Wendelin Rihel, 1539).
}

${ }^{21}$ Short-Title Catalogue, 4-5.

${ }^{22}$ For example Das tauff buchlin verdeutscht durch Mart. Luther (Wittenberg: Nickel Schirlentz, 1523); Von der Freyheit eynes Christen menschen (Wittenberg: [n.p.], 1523); Vom kriege widder die Türcken (Wittenberg: Hans Weiss, 1528 [1529?]).

${ }^{23}$ For example Aesop Appologi, Boethius De consolatione, Cicero Orationes, Ovidius Opera and Plutachus Vitae illustrium virorum; Boccaccio De casibus virorum illustrium, Dante Le terze rime, Machiavelli Historie fiorentine, and Petrarca Canzioniere and Historia Griseldis.

${ }^{24}$ Printed by Thomas Berthelet (2), William Bonham, John Byddell, William Caxton, William Copland, John Day, Thomas Godfray, Johannes and William Rastell, and Wynkyn de Worde (3).

${ }^{25}$ The Workes of Geffray Chaucer newly printed with divers workes which were never in print before as in the Tables more plainly doth appere (London: Thomas Godfray, 1532).

${ }^{26}$ According to Steyn, The Medieval and Renaissance Manuscripts.

${ }^{27}$ Gospel Lectionaries in Greek (Ms Grey 4c1 and 4c6), Bibles in Hebrew (Ms Grey 6b1 and 48b2).

${ }^{28}$ For example Cicero, Horace, Pseudo-Plutarch, Macrobius, Jerome, Vergerio and Bardo, [Miscellany of ancient and humanistic texts] (Ms Grey 3c11), Landino, Maximianus, Venatius Fortunatus, Lactantius, Ovid, Beccadelli, Marsuppi, [Miscellany of ancient and humanistic poems] (Ms Grey 3c12).

${ }^{29}$ For example Dante La divina commedia (Ms Grey 3c25), Boccaccio Elegio di madonna fiammetta (Ms Grey 3c9), Petrarca Canzone, Sonecti e Triomphi (Ms Grey 3c22). 
tion and collection strategy. ${ }^{30}$ Most of the music in the collection is plainchant and found in liturgical books, with some fragments of musical notation in bindings of other books, and only one manuscript containing polyphonic music. ${ }^{31}$

Table 1: Music notation in the manuscripts of the Grey Collection ${ }^{32}$

\begin{tabular}{|c|c|c|c|c|}
\hline Type & Shelfmark & Provenance & Time & Notation \\
\hline \multirow[t]{2}{*}{ Evangeliary } & Ms Grey 4c1 & Greece & $12^{\text {th }}$ century & Ekphonetic \\
\hline & Ms Grey $6 \mathrm{~b} 3$ & $\begin{array}{l}\text { Germany/ } \\
\text { Netherlands }\end{array}$ & 1520 & $\begin{array}{l}\text { Square/Go } \\
\text { thic }\end{array}$ \\
\hline \multirow[t]{2}{*}{ Gradual } & Ms Grey 7a27 & $\begin{array}{l}\text { Roggenburg/ } \\
\text { Augsburg }\end{array}$ & $13^{\text {th }}$ century & $\begin{array}{l}\text { Square/Me } \\
\text { tz }\end{array}$ \\
\hline & $\begin{array}{l}\text { Ms Grey } \\
48 \mathrm{~b} 3\end{array}$ & Italy & $\begin{array}{l}15^{\text {th }} / 16^{\text {th }} \text { cen- } \\
\text { tury }\end{array}$ & Square \\
\hline \multirow[t]{2}{*}{$\begin{array}{l}\text { Psalter and } \\
\text { Hymnal }\end{array}$} & Ms Grey $6 \mathrm{~b} 4$ & $\begin{array}{l}\text { Central Italian } \\
\text { (Rieti) }\end{array}$ & $13^{\text {th }}$ century & $\begin{array}{l}\text { Central } \\
\text { Italian }\end{array}$ \\
\hline & Ms Grey $6 \mathrm{~b} 2$ & Central Italy & $14^{\text {th }}$ century & Square \\
\hline \multirow[t]{3}{*}{ Antiphoner } & Ms Grey 4b5 & Münster & $13^{\text {th }}$ century & Gothic \\
\hline & Ms Grey 4c7 & Dijon & $15^{\text {th }}$ century & Square \\
\hline & Ms Grey 3c23 & France & $16^{\text {th }}$ century & Square \\
\hline \multirow[t]{2}{*}{ Processional } & Ms Grey 2a17 & $\begin{array}{l}\text { Southern } \\
\text { Germany }\end{array}$ & $16^{\text {th }}$ century & Square \\
\hline & Ms Grey 7a28 & $\begin{array}{l}\text { Southern } \\
\text { Germany }\end{array}$ & 1523 & Square \\
\hline Versiculary & $\begin{array}{l}\text { Ms Grey } \\
6 \mathrm{~b} 12\end{array}$ & Belgium & $16^{\text {th }}$ century & Square \\
\hline Laudarium & $\begin{array}{l}\text { Ms Grey } \\
3 \text { b12 }\end{array}$ & Italy & $16^{\text {th }}$ century & $\begin{array}{l}\text { White } \\
\text { mensural }\end{array}$ \\
\hline
\end{tabular}

The only exception to this apparent aim for diversity is a cluster of manuscripts associated with the church of Santa Cecilia in Trastevere, Rome. ${ }^{33}$ The Homiliary,

${ }^{30}$ The same holds true for the Africana section in the collection, which to the author's knowledge contains at least one hymnbook (Xhosa) with music notation.

${ }^{31}$ Giulio Cattin, 'Nuova fonte italiana della polifonia intorno al 1500 (Ms Cape Town, Grey 3b12)' Acta musicologica 45 (1973): 165-221. The manuscript is edited in Giulio Cattin (ed.), Italian Laude \& Latin Unica in MS Cape Town, Grey 3612 (Stuttgart: Hänssler, 1977).

${ }^{32}$ Table according to Christoph Stroux, 'Music in the Manuscripts of the Grey Collection of the South African Library, Cape Town', manuscript, National Library of South Africa, Cape Town. Fragments and music in early printed books are not included in the table. 
which contains no music notation, was written during the eleventh century - possibly at the church of Santa Cecilia, and it was certianly used there. ${ }^{34}$ The Legendary, which also contains no music notation, was written for the church during the late eleventh or early twelfth century. ${ }^{35}$ The Vatican Library houses a seventeenthcentury copy of this manuscript ${ }^{36}$ which forms a companion volume to the Gradual from the church of Santa Cecilia in the Martin Bodmer Collection. ${ }^{37}$

\section{Table 2: Manuscripts associated with the church of Santa Cecilia in the Grey Collection}

\begin{tabular}{|l|l|l|l|l|}
\hline Type & Shelfmark & $\begin{array}{l}\text { Santa Cecilia } \\
\text { connection }\end{array}$ & Time & Notation \\
\hline Homiliary & Ms Grey 6b8 & $\begin{array}{l}\text { Written at } \\
\text { church? }\end{array}$ & $11^{\text {th }}$ century & $\begin{array}{l}\text { Contains no } \\
\text { music notation }\end{array}$ \\
\hline Legendary & $\begin{array}{l}\text { Ms Grey } \\
48 \mathrm{~b} 4-5\end{array}$ & $\begin{array}{l}\text { Written at } \\
\text { church }\end{array}$ & $\begin{array}{l}11^{\text {th }} / 12^{\text {th }} \\
\text { century }\end{array}$ & $\begin{array}{l}\text { Contains no } \\
\text { music notation }\end{array}$ \\
\hline $\begin{array}{l}\text { Psalter and } \\
\text { Hymnal }\end{array}$ & Ms Grey 6b4 & $\begin{array}{l}\text { Used at } \\
\text { church }\end{array}$ & $13^{\text {th }}$ century & Central Italian \\
\hline $\begin{array}{l}\text { Psalter and } \\
\text { Hymnal }\end{array}$ & Ms Grey 6b2 & $\begin{array}{l}\text { Used at } \\
\text { church }\end{array}$ & $14^{\text {th }}$ century & Square \\
\hline
\end{tabular}

The two composite office books were written around 1300 and used at the church. ${ }^{38}$ These manuscripts give insight into liturgical practices at a particular church in Rome during the transitional period from old Roman to Gregorian chant. A research project investigating the manuscripts and their place in Roman liturgical history has

\footnotetext{
${ }^{33}$ Christoph Stroux, 'Santa Cecilia's Books at the Cape of Good Hope: A Preliminary Report', Ars Nova 17 (1985): 51-63.

${ }^{34}$ Stroux, 'Santa Cecilia's Books at the Cape of Good Hope', 51-63.

35 Christoph Stroux, 'The Legendary of Santa Cecilia in Trastevere and its Background' (paper presented at the annual conference of the South African Association for Patristic and Byzantine Studies, Johannesburg, November 1990), manuscript, National Library of South Africa, Cape Town.

${ }^{36}$ Vat. lat. 6075-6076.

${ }^{37}$ Max Lütolf, Das Graduale von Santa Cecilia in Trastevere, 2 vols. (Cologny-Geneve: Fondation Martin Bodmer, 1987).

${ }^{38}$ Morné Bezuidenhout, 'Two Unknown Sources of Roman Chant in the Late Middle Ages: The Manuscripts Grey $6 \mathrm{~b} 2$ and 6b4', in Trasmissione e recezione delle forme di cultura musicale: Atti del XIV Congresso della Societa Internazionale di Musicologia Bologna 1987, ed. Angelo Pompilio (Torino: EDT, 1990), vol. 2, 77-91.
} 
been initiated at the South African College of Music, UCT by Dr Morné Bezuidenhout and the author in co-operation with the National Library of South Africa.

\section{Images of Europe in the Grey Collection}

The musical items in the European section of the Grey Collection are curiously misaligned with the trends in musical life in Britain at the time of their acquisition. ${ }^{39}$ In very general terms music research in Britain during the middle of the nineteenth century shows interest in its own and other music cultures: the collection and transcription of traditional music both in Britain and the colonies commences at this time and the interest in one's own music lead to research into English music history. The institutionalisation of both can be seen in the foundation of the Royal Musical Association in 1874 as well as in the festivals celebrating the centenary of George Frideric Handel's (1685-1759) death and the bicentenary of his birth in 1859 and 1885. At the same time a mass movement for music education using the tonic sol-fa system created the conditions for the foundation of many choral societies. This movement lead to the combination of educational, national and religious aims in many societies and choir festivals - with English oratorio becoming the genre of expression for all of these. ${ }^{40}$

These trends and developments are not reflected in the collection - or at least not directly. Part of the reason for this lies in Grey's acquisition strategy for items in the European section of the collection: music notation forms a welcome addition in the type of manuscript he seeks to purchase; it is not his priority to acquire books or manuscripts with music notation. However, since many of the manuscripts he acquired are liturgical books, they include music. Here the reason for the absence of secular music and the dearth of polyphonic music in the collection can be found. The only manuscript with polyphonic music (Ms Grey 3b12) contains Italian laude as well as many contrafacta replacing the texts of popular French and Italian secular songs with Latin or Italian sacred texts. On folios $84^{\mathrm{v}}-85^{\mathrm{r}}$, for example, the text of Johannes Ghiselin's (before 1460?-after 1507) De tous biens plaine is substituted by a text from Proverbs 26: 'Cum defecerint ligna, extinguetur ignis: et susurrone subtracto, iurgia conquiescunt [...] Verba susurronis quasi simplicia et perveniunt ipsa ad

\footnotetext{
${ }^{39}$ The European provenance of the music manuscripts in the Grey Collection is discussed in Carol Steyn, 'The Music Manuscripts of the Grey Collection in Cape Town and their European Connections', Fontes Artis Musicae 59 (2011): 45-56.

${ }^{40}$ Barbara Mohn, Das Englische Oratorium im 19. Jahrhundert: Quellen, Traditionen, Entwicklungen (Paderborn: Schöningh, 2000), 44-80.
} 
intima cordis ${ }^{311}$ Grey's description of the manuscript shows his interest in it as a bibliophile and at the same time reveals a layman's ideas about its musical content:

Very elegantly written in an Italian hand, with musical notes. Besides Latin hymns which are arranged for two, three, and four voices, this manuscript contains, in the Italian language [list of compositions follows]. Early Italian musical manuscripts, written upon vellum, are exceedingly scarce. In this volume, consisting of 141 leaves of pure vellum, there is also a great curiosity, namely a Mottetto [sic!], partly written in Latin and partly in Italian. From an inspection of this manuscript, it appears that at the time, for the sake of euphony, the singers used even to change the vowels; for instance, instead of singing de e e 1 cor mio, as they should do actually, they sang de o o 1 , which is very singular. ${ }^{42}$

All of these factors produce a view of music within European culture, which is quite removed from the role music played within contemporary British culture: Seen through the European section of the Grey Collection, European music was written during the Middle Ages or the Renaissance, it is sacred and predominantly liturgical plainchant.

A similar discrepancy with current European culture can be seen in the collection as a whole. Even though Douglas Varley calls the Grey Collection a 'mirror of Western culture', ${ }^{43}$ this statement is not true, when the collection is compared to current cultural trends in Europe at the time of its collection. It certainly does not reflect European culture in the middle of the nineteenth century, but it does reflect European thoughts and ideas about culture and civilisation at that time. The collection as a whole relates to several developments in nineteenth-century Britain: firstly the interest in ethnological studies, especially languages and cultures; secondly humanitarianism and a drive for education for all and thirdly the view of religion, specifically Christianity, as the basis of civilisation. All of these aspects can be linked to ideas of evolutionism as put forward, for example, by Lewis H. Morgan, who sees education and religion as mankind's means of progression from ignorance via barbarism to civilisation. ${ }^{44}$ Grey's speech on the $26^{\text {th }}$ anniversary of the South African Library in 1855 , reflects these concepts:

\footnotetext{
${ }^{41}$ Cattin, 'Nuova fonte italiana', 208.

${ }^{42}$ George Grey, letter to Egidius Benedictus Watermeyer. Published in The Cape of Good Hope Government Gazette, December 24, 1861.

${ }^{43}$ Douglas H. Varley, 'The Grey Collection: Mirror of Western Culture', in The South African Library 1818-1868, ed. C Pama (Cape Town: Balkema, 1968), 35-40.

44 'Evolutionism', 'Lewis Henry Morgan', Encyclopaedia Britannica Online Academic Edition, accessed 18 September 2013, http://www.britannica.com.
} 
The highest degree of civilisation may subsist with the greatest degree of vice, and of human want and misery. We should not undervalue human learning, and should gratefully accept the aids and advantages it affords us; delighting also in the many sources of mental recreation which it opens up to us, enjoying these in moderation, as we do all other good gifts. But we should never forget that it is a spiritual education for eternity which is man's chief duty here upon earth, and that it is only from this source that permanent happiness or improvement can spring. ${ }^{45}$

The European section of collection in particular is also informed by Thomas Carlyle's thoughts about the unity of mankind and the ability of every person to grow through education and work. ${ }^{46}$ According to Carlyle the hero, the person who leads an exemplary life, need not be military or political, but can also be a 'man of letters', since in books nothing, no work, no thoughts, no ideas are ever lost.

In Books lies the soul of the whole Past Time; the articulate audible voice of the Past, when the body and material substance of it has altogether vanished like a dream. [...] All that Mankind has done, thought, gained or been: it is lying as in magic preservation in the pages of Books. They are the chosen possession of men. [...] It [the art of writing] related, with a wondrous new contiguity and perpetual closeness, the Past and Distant with the Present in time and place; all times and all places with this our actual Here and Now. ${ }^{47}$

Grey bought the complete works of Carlyle for his library in 1866 and echoes Carlyle's words in his manuscript 'Old Books':

Dear old book that hast for nigh four centuries presented these and such like words of comfort, to so many men, in so many lands, and that now in South Africa as I sit lone upon this Christmas morn dost recall to my mind in this far land, that the strong planes of yon rocky mountain are the Lord's [...]

\footnotetext{
${ }^{45}$ George Grey, 'Speech on the $26^{\text {th }}$ Anniversary of the South African Public Library 1855'. Quoted from Kerr, Amassing Treasures for All Times, 159.

${ }^{46}$ Robert Thornton, 'The Elusive Unity of Sir G. Grey's Library', African Studies 42 (1983): 79-89.

${ }^{47}$ Thomas Carlyle, 'Lecture V: The Hero as Man of Letters. Johnson, Rousseau, Burns', On Heroes and Hero Worship and the Heroic in History, accessed 19 September 2013, http://ebooks.adelaide. edu.au/c/carlyle/thomas/on_heroes/chapter5.html.
} 
Faithful old volume that hast for nigh four centuries, never ceased thus to speak divine truths, in City, and in desert, in Palaces, which from thy gorgeousness thou must have over time dwelt in, or in the lonely mountain side where thou now talkest to me. ${ }^{48}$

Grey apparently strove to be a hero (in the sense of Carlyle) both as a man of letters and as a politician. The library thus becomes the perfect endowment for the people of South Africa alongside his political legacy. European thought is reflected not so much in the content of the collection, but rather in its purpose and its donation to the people of South Africa.

\section{The Purpose of the Collection}

Grey's desire to become a hero in Carlyle's terms, can also be seen in the rationale of the collection. However, the two sections, Africana and Europeana, were collected with quite a different purpose in mind: the Africana section was striving to be an exhaustive collection of material in and about indigenous languages. It was built systematically into a scholarly, philological collection with the help of a specialist. This section was intended for the personal use of Grey while he was governor of the Cape Colony as well as for scholarly research at the time and in the future. The European section on the other hand originated in the private interest of Grey as a bibliophile, and in his plans to conduct his own research on the manuscripts in the collection:

For thirty years one of the chief delights of my life has been to collect a Library, which I hoped would form the charm and recreation of my middle life and of my old age. Thus I have gone on indulging dreams of a tranquil and literary life, which was to be a compensation for the constant activity of my early years. A part of this plan was to publish, from ancient manuscripts, new editions of works, which I regarded as being capable of great improvement. ${ }^{49}$

Here Carlyle's thought that no ideas get lost in history surfaces again. In addition, Grey reasons that man has custodianship of these ideas for future generations. For this reason the purpose of the collection changed over time. It started as a private collection and this aspect is especially visible in the European section, which shows Grey's personal interest, for example, in Caxton prints and early English poets. The private collection of old books and manuscripts shows Grey's aim of conserving

\footnotetext{
${ }^{48}$ George Grey, [Old Books], manuscript c. 1860. Quoted from Kerr, Amassing Treasures for All Times, 257.

${ }^{49}$ George Grey, letter to Egidius Benedictus Watermeyer. Published in The Cape of Good Hope Government Gazette, December 24, 1861.
} 
knowledge. By donating his private collection to the South African Public Library the purpose of conservation changes to one of research and education. The collection is seen as an investment into the future of the Cape Colony.

What I have laid up for myself I can neither use nor enjoy, yet it is selfishly shut up from other men, who might profitably use it and greatly enjoy it. I had hoped that, after my death, this Library, being left to some new country, might prove to it a treasure of great value, to some extend helping to form the mind of each of its generations, as they came following on. [...] I believe South Africa will be a great country, that Cape Town, or its vicinity, will, for many reasons, be the point of chief education for its young men. ${ }^{50}$

Even though the value of the individual books and manuscripts or the collection as a whole may not be immediately visible, it forms a reservoir for future research discovering ideas inherent in the collection.

Nor let us forget that knowledge is progressive; that the next age may be more learned than that which pre-ceded it; and that observed facts which, in the present state of human knowledge, cannot be so combined with others, as to prove of any great or striking utility, may, even within a few years from this time, be found of very great value and worth, for that generation more learned, more wise than ourselves, for whose advent we are now preparing the material and intellectual world. ${ }^{51}$

The manuscripts related to the church of Santa Cecilia in Trastevere, Rome, are such a discovery: these liturgical items, which came into Grey's collection by coincidence and whose music notation was seen as an added extra, were only rediscovered in $1984^{52}$ and today represent some of the few extant sources on Roman liturgical practice in the Middle Ages from one particular church. The donation also had pragmatic reasons. Both parts of the collection are to be used for the furtherance of knowledge. The Africana section as the basis for an ethnological museum focusing on research into indigenous culture; the European section as a public library, the basis for education and possibly a university. Today the Grey Collection at the National Library of South Africa, Cape Town, presents a difficult inheritance. The ideas underlying the collection, evolutionism and Carlyle's ideas, form the legitimation of

\footnotetext{
${ }^{50}$ George Grey, letter to Egidius Benedictus Watermeyer. Published in The Cape of Good Hope Government Gazette, December 24, 1861.

${ }^{51}$ George Grey, 'Address to the Members of the New Zealand Society', September 26, 1851. Quoted from Kerr, Amassing Treasures for All Times, 155.

${ }^{52}$ Francois Dolbeau, 'Le légendier de Sainte-Cécile-au-Trastévère retrouvé au Cap', Analecta Bollandiana 102 (1984): 302.
} 
British imperialism and Apartheid. ${ }^{53}$ All see the different races as various developmental stages of civilisation, and argue that the more civilised nations must assume guardianship for indigenous people. How to deal with the European inheritance in the underlying idea of the collection in a postcolonial context, is a question as yet unresolved.

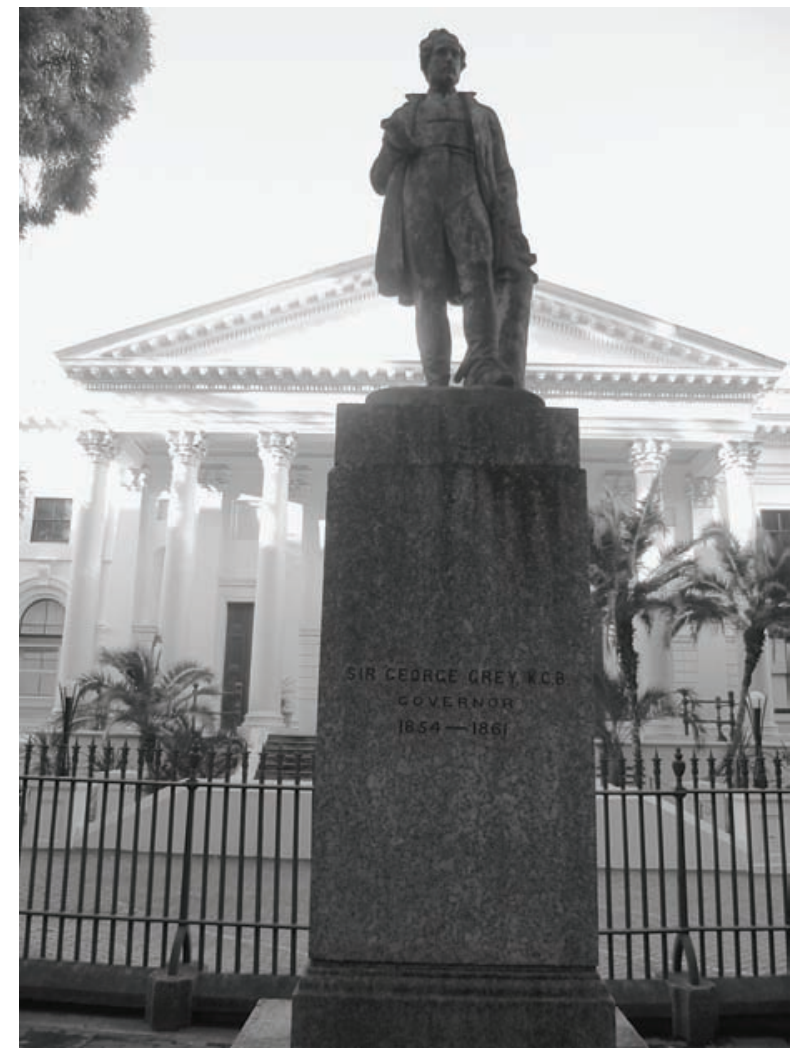

Figure 2: Statue of Sir George Grey in front of the National Library of South Africa, Cape Town, 2012

\footnotetext{
${ }^{53}$ In 1949 the Federal Council of the Nederdiutse Gereformeerde Kerk issued a statement on separate development: '[The aim of apartheid is not...] oppression but development, growth, upliftment, more privileges and rights according to one's own abilities, talent and potential. [...] Whether we like it or not we are guardians of the coloureds and the natives too and we shall have the right to give reckoning to God about our guardianship.' Quoted from Johann Kinghorn, 'Modernization and Apartheid: The Afrikaner Churches', in Christianity on South Africa: A Political, Social and Cultural History, ed. Richard Elphick and Rodeny Davenport (Cape Town: David Philips, 1997), 145.
} 


\section{Literature}

'Australia'. Encyclopaedia Britannica Online Academic Edition. Accessed 11 September 2013. http://www.britannica.com.

Bezuidenhout, Morné. 'Two Unknown Sources of Roman Chant in the Late Middle Ages: The Manuscripts Grey $6 \mathrm{~b} 2$ and 6b4'. In Trasmissione e recezione delle forme di cultura musicale: Atti del XIV Congresso della Societa Internazionale di Musicologia Bologna 1987, edited by Angelo Pompilio, vol. 2, 77-91. Torino: EDT, 1990.

Bizzarri, Edoardo. 'Inediti italiani della 'Grey Collection”. Rinascita 4 (1941): $860-71$.

Bleek, Wilhelm. The Library of His Excellency Sir George Grey. 4 vols. London: Trübner, 1858-62.

'Bleek, Wilhelm'. Encyclopaedia Britannica Online Academic Edition. Accessed 16 September 2013. http://www.britannica.com.

Books Wanted in the Library of His Excellency Sir George Grey (Cape Town: Pike, 185 ?).

Carlyle, Thomas. 'Lecture V: The Hero as Man of Letters. Johnson, Rousseau, Burns'. In On Heroes and Hero Worship and the Heroic in History. Accessed 19 September 2013. http://ebooks.adelaide.edu.au/c/carlyle/thomas/on_heroes/ chapter5.html.

Cattin, Giulio, ed. Italian Laude \& Latin Unica in MS Cape Town, Grey 3612. Stuttgart: Hänssler, 1977.

Cattin, Giulio. 'Nuova fonte italiana della polifonia intorno al 1500 (Ms Cape Town, Grey 3b12)'. Acta musicologica 45 (1973): 165-221.

Dawe, Harald. 'Interessantes für Germanisten in den Beständen der South African Library in Kapstadt'. Acta Germanica 15 (1982): 159-65.

Dolbeau, Francois. 'Le légendier de Sainte-Cécile-au-Trastévère retrouvé au Cap'. Analecta Bollandiana 102 (1984): 302.

'Evolutionism'. Encyclopaedia Britannica Online Academic Edition. Accessed September 18, 2013. http://www.britannica.com.

Grey, George. Letter to Egidius Benedictus Watermeyer. The Cape of Good Hope Government Gazette, 24 December 1861.

'Grey, Sir George'. Encyclopaedia Britannica Online Academic Edition. Accessed 11 September 2013. http://www.britannica.com. 
Hahn, Theophilus. An Index to the Grey Collection in the South African Public Library. Cape Town: Saul Solomon, 1884.

Isaacs, A Lionel. 'Early English printed Books in the Grey Collection'. Quarterly Bulletin of the South African Library 6 (1951/52): 76-85.

Kerr, Donald J. Amassing Treasures for All Times: Sir George Grey, Colonial Bookman and Collector. Delaware/Dunedin: Oakknoll Press/Otago University Press 2006.

Kinghorn, Johann. 'Modernization and Apartheid: The Afrikaner Churches'. In Christianity on South Africa: A Political, Social and Cultural History, edited by Richard Elphick and Rodeny Davenport, 135-54. Cape Town: David Philips, 1997.

Lütolf, Max. Das Graduale von Santa Cecilia in Trastevere. 2 volumes. ColognyGeneve: Fondation Martin Bodmer, 1987.

Milne, James. The Romance of a Pro-Consul being the Personal Life and Memooirs of the Right Hon. Sir George Grey, K.C.B. London: Chatto \& Windus, 1899.

Mohn, Barbara. Das Englische Oratorium im 19. Jahrhundert: Quellen, Traditionen, Entwicklungen. Paderborn: Schöningh, 2000.

'Morgan, Lewis Henry'. Encyclopaedia Britannica Online Academic Edition. Accessed 18 September 2013. http://www.britannica.com.

'New Zealand'. Encyclopaedia Britannica Online Academic Edition. Accessed 11 September 2013. http://www.britannica.com.

Peires, Jeff. The Dead Will Arise: Nongqawuse and the Great Xhosa Cattle-Killing of 1856-7. Jeppestown: Jonathan Ball, 2003.

Rutherford, James. Sir George Grey, K.C.B., 1812-1898: A Study in Colonial Government. London: Cassell 1961.

Short-Title Catalogue of Early Printed Books in South African Libraries 1470-1550. Cape Town: South African Library, 1977.

'South Africa'. Encyclopaedia Britannica Online Academic Edition. Accessed 11 September 2013. http://www.britannica.com.

Steyn, Carol. The Medieval and Renaissance Manuscripts in the Grey Collection of the National Library of South Africa, Cape Town. 2 vols. Salzburg: Institut für Anglistik und Amerikanistik, Universität Salzburg, 2002.

Steyn, Carol. 'The Music Manuscripts of the Grey Collection in Cape Town and their European Connections'. Fontes Artis Musicae 59 (2011): 45-56. 
Stroux, Christoph. 'Music in the Manuscripts of the Grey Collection of the South African Library, Cape Town'. Manuscript. National Library of South Africa, Cape Town.

- 'Santa Cecilia's Books at the Cape of Good Hope: A Preliminary Report'. Ars Nova 17 (1985): 51-63.

- 'The Legendary of Santa Cecilia in Trastevere and its Background'. Paper read at the annual conference of the South African Association for Patristic and Byzantine Studies, Johannesburg 1990. Manuscript. National Library of South Africa, Cape Town.

- 'The Story of Guglielmo Libri'. Quarterly Bulletin of the South African Library 44 (1989/90): 112-15.

Thornton, Robert. 'The Elusive Unity of Sir G. Grey's Library'. African Studies 42 (1983): 79-89.

Varley, Douglas H. 'The Grey Collection: Mirror of Western Culture'. In The South African Library 1818-1868, ed. C Pama, 35-40. Cape Town: Balkema, 1968. 



\title{
Jazz and the Emergence of the African-Roots Theory
}

\author{
Mario Dunkel (Dortmund)
}

When and where the writing of jazz history began is a difficult question to answer. One may argue that it saw its beginnings in the mid-1910s, with the emergence of the first opinion pieces about jazz. However, these often promotional texts contained little more than historical speculations based on popular racial stereotyping. One may be tempted to argue, then, that the origins of jazz historiography can be located in the first monographs on the history of jazz. In the latter case, scholars of jazz writings face another dilemma, since determining what constitutes the first monograph on the history of jazz can turn into a rather complicated endeavor. Was the first book on the history of jazz Paul Whiteman's 1926 Jazz, or is the book too much of an autobiography to be considered serious historiography? ${ }^{1}$ If one dismisses Whiteman's Jazz should one rather concentrate on André Couroy and André Schaeffner's 1926 Le jazz, a book that is devoid of autobiographical elements, but similarly lacks a thorough study of 1920s jazz cultures, neglecting some of the most significant jazz musicians of that time period? ${ }^{2}$ Or should one begin with the first monographs on hot jazz, Robert Goffin's Aux frontiers du jazz (1932) and Hugues Panassié's Le jazz hot (1934), two books that at least come a little closer to the African American-centric (rather than European American or Afrocentric) definition of jazz that dominates contemporary jazz historiography? ${ }^{3}$

\footnotetext{
${ }^{1}$ Paul Whiteman and Mary Margaret McBride, Jazz (New York: Sears \& Co., 1926).

${ }^{2}$ André Couroy and André Schaeffner, Le jazz (Paris: Éditions Claude Aveline, 1926).

${ }^{3}$ Robert Goffin, Aux frontières du jazz (Paris: Sagittaire, 1932); Hugues Panassié, Le jazz hot (Paris: Éditions R.-A. Corrêa, 1934).
} 
This article suggests that the beginnings of the historiography of jazz need to be located elsewhere. It would be misleading to assume that the historiography of jazz simply began with the emergence and the identification of jazz music. When jazz was recognized as a significant cultural phenomenon after the massive success of the Original Dixieland Jass Band's first jazz record in 1917, many basic concepts of jazz categorization were already in place. In order to investigate the early historiography of jazz, it is therefore necessary to also trace the contingencies that conditioned the first appropriations of jazz music and its history. Besides being grounded in the social and cultural transformations of American modernism in the 1910s and 1920s, the music's early historical explanations were the result of a historically grown repertoire of concepts. They harked back to such late eighteenth-century concepts of folk music as were developed by the German folklorist Johann Gottfried Herder (1744-1803), to eighteenth-century racialism, as well as to nineteenth-century conceptualizations of region, nation, gender, and class. This article seeks to trace the history of the African-roots theory, i.e. the idea that jazz music saw its beginnings not in Europe or the U.S., but that it was rooted in Africa. In order to understand the emergence of this theory, it is necessary to investigate discourses of race and nation that lie at the heart of American music historiography in the early twentieth century.

In the years after jazz's initial recognition in the mid-1910s, attempts to explain the music's origins fell into three larger groups that existed throughout Europe and the U.S. The first group of texts claimed that jazz music had European origins. Proponents of this theory usually agreed that jazz was only a poor, degenerated imitation of European music, making elaborations on the history of jazz superfluous, since they denied the music's basic historical relevance. This group is important primarily as a touchstone for the development of counter-narratives that challenged this theory. ${ }^{4} \mathrm{~A}$ second group of writings held that jazz had originated on the American continent and was therefore an essentially American music. ${ }^{5}$ Seeing the potential of jazz as

\footnotetext{
${ }^{4}$ If many authors agreed that jazz had European origins, they were divided about where exactly these origins could be located. Writers in this first group included Harcourt Farmer and the Belgian composer Arthur Hoérée. See Harcourt Farmer, 'The Marche Funebre of "Jazz," Musical America (1920), reproduced in Jazz in Print, edited by Karl Koenig, 144ff. See Arthur Hoérée, 'Le Jazz,' La Revue Musicale 12 (October 1927): 213-41. For an expansive anthology of early jazz articles including theories about jazz's origins, see Karl Koenig, ed., Jazz in Print (1859-1929) (Hillsdale: Pendragon Press, 2002).

${ }^{5}$ Some of the earliest proponents of the theory that jazz was an essentially American music included the composer Howard Brockway (1870-1951), the music critic Carl Engel, and the promoters of symphonic jazz around Paul Whiteman and Henry O. Osgood. See 'Delving into the Genealogy of Jazz,' Current Opinion (August 1919), reproduced in Jazz in Print, edited by Karl Koenig, 134ff.; see Carl Engel, "Jazz: A Musical Discussion”, The Atlantic Monthly 130/2 (August 1922): 182ff. On Whiteman and Osgood see Mario Dunkel, "W. C. Handy, Abbe Niles, and (Auto-) Biographical Po-
} 
America's first national music, these texts were more interested in jazz's historical development than Eurocentric writings on jazz. This group included a number of conflicting theories concerning the music's chief inventors, its relevance as folk music, its racial heritage, and its temporal and spatial origins. However, writers generally agreed that jazz was a distinctly American phenomenon. The third group of jazz history writers deemed jazz to be an essentially African residue which, albeit having slightly changed its appearance, had outlasted slavery and was finally appreciated in the early-twentieth century. ${ }^{6}$ Downplaying or denying the importance of American conditions, writers who fall into this category foregrounded what they deemed to be the music's pre-industrial and trans-historical African character. To these writers, jazz music seemed to tap a pure, primordial essence of mankind, yet unspoiled by the clutches of modernized and mechanized industrial societies. These three theories concerning jazz's heritage were not mutually exclusive, but rather existed in various combinations, so that jazz could alternately be seen as a music of African origins that was subsequently Americanized through acculturation, or as a white American invention that was corrupted by its African American imitators.

\section{The Slave Songs: A Product of Antebellum America?}

The concern of American historiographers with African American music dates back to antebellum America when both black and white writers started to address African American music in fictional and non-fictional texts. Even though black music had existed in the Americas since the arrival of the first slaves, it was not until the midnineteenth century that writers began to regard it as an object worthy of serious investigation. ${ }^{7}$ Several factors led to an increased interest in black music. First, the 1830s and 1840s were marked by a powerful discourse of nationalism in American culture. If there could be an independent American national literature, as Ralph Waldo Emerson demanded, would it also be possible to find sources for an idiomatically American music? Second, increasing mobility due to the building of the railroad system brought about an increase in cross-cultural encounters and exchanges. Many musicians and minstrel troupes traveled across the country, spreading their music

sitioning in the Whiteman Era," Popular Music and Society. Special Issue on Musical Autobiography, edited by Martin Butler and Daniel Stein (forthcoming).

${ }^{6}$ The most Afrocentric writers in this group were French ethnologists such as André Schaeffner and André Cœuroy (discussed later in this article). One of the most nuanced early texts on the relationship between jazz and African music is Nicholas G. J. Ballanta's article "Jazz Music and Its Relation to African Music," Musical Courier (June 1922), reproduced in Jazz in Print, edited by Karl Koenig, 188ff.

${ }^{7}$ See Ronald Radano, Lying Up a Nation: Race and Black Music (Chicago: University of Chicago Press, 2003), 167-77. 
throughout the U.S. and exporting some of it to Europe. Especially the Civil War, an event which was fundamental to the emergence of the earliest systematic accounts of black music, propelled intercultural, interracial, and musical encounters. Third, in the early-nineteenth century, the increasing popularity of minstrelsy gave African American music and its derivatives an unprecedented presence in American public life, leading to the music's frequent association with popular African American Zip Coon, Uncle Tom, and Jim Crow stereotypes of idiocy, submissiveness, and barbarity. ${ }^{8}$

An important strand in the historiography of African American music emerged as a response to these stereotypes. Frederick Douglass's (1818-1895) 1845 slave narrative (Narrative of the Life of Frederick Douglass, an American Slave) presented an early challenge to the popular mockery of African Americans and their music. ${ }^{9}$ Douglass's autobiographical text included a re-appropriation of the slave songs as a sonic representation of what he called the slaves' 'sorrows of [the] heart'. As an amateur violinist himself, Douglass argued that it was important not to conceive of the slave songs as the expression of the slaves' irrationality, happiness, or contentment. Quite the contrary, slave songs were both a 'testimony against slavery', bearing witness to the inhumane conditions of slavery, and a religious expression, a 'prayer to God for deliverance from chains', as he put it. ${ }^{10}$

Douglass's writings were fundamental to the theory that the origins of a distinct African American music were neither just African nor merely European, but that they could be found in the conditions of chattel slavery itself. According to Douglass's descriptions, the slaves managed 'to weave something of the Great House Farm', the place where Douglass grew up, '[i]nto all of their songs', therefore incorporating their social existence into their music. Slave songs were invented by the slaves and rather than being ridiculous or unintelligible, as most people believed, they were 'full of meaning to [the slaves]', containing 'the horrible character of slavery'. ${ }^{11}$

Not only did Douglass's Narrative popularize the idea of slavery's impact on African American music, introducing it to a group of abolitionist writers who would go on to provide the first systematic accounts of African American music, but it also rendered possible the use of the music as a political tool in the abolitionists' struggle against slavery. After hearing a speech by Douglass in 1848, the abolitionist Thomas Wentworth Higginson (1823-1911) was thrilled by the speaker and convinced that

\footnotetext{
${ }^{8}$ See Eileen Southern, The Music of Black Americans: A History (New York: W. W. Norton, 1997), $90 \mathrm{ff}$.

${ }^{9}$ Frederick Douglass, Narrative of the Life of Frederick Douglass, An American Slave, Written by Himself (Boston: Published at the Anti-Slavery Office, 1845); Ronald Radano, 'Denoting Difference: The Writing of the Slave Spirituals', Critical Inquiry 22/3 (1996): 507.

${ }^{10}$ Douglass, Narrative of the Life of Frederick Douglass, 26.

${ }^{11}$ Ibid.
} 
he had to engage in a more radical activism. Higginson said he 'felt after hearing Douglass, as if I were a recreant to humanity, to let one Sunday pass in the professed preaching of Christianity, and leave the name of SLAVERY unmentioned .... And so help me God I never will again'. ${ }^{12}$ The similarities between Higginson's later description of the 'negro spirituals' and Douglass's conceptualization of the slave songs suggest that Douglass's autobiographical texts made a lasting impression on Higginson. Not only did it impact his political activism, but it also conditioned his understanding of African American music.

Higginson was the first American writer to systematically describe African American music as an object of research and a distinct and valuable genre of quasiRomantic art, comparing it to Walter Scott's (1771-1832) collection of Scottish Border ballads. ${ }^{13}$ Otherwise known as the colonel of the first federally-authorized African American regiment during the Civil War, Higginson was a champion of the rights of African Americans and women. According to Higginson, the Civil War had brought not only violence, devastation, and death, but also 'a strange fulfillment of dreams of other days', introducing him to the hidden treasures of African American music. ${ }^{14}$ During the Civil War, Higginson wrote down the lyrics of some of the chants sung by African American soldiers in his regiment. After having returned to the North, he published thirty-seven 'songs' in The Atlantic Monthly, thereby introducing many Americans to mediated versions of ostensibly authentic African American music. His article 'Negro Spirituals' celebrated African American music to a degree that was unknown before, praising it on the same level as the best of naïve Romantic poetry and authorizing it with Higginson's mere reputation as a prominent (white) literary critic and public figure. ${ }^{15}$

Concerning the question of the heritage of the songs, Higginson agreed with Douglass's point that the slave songs were at least partly created by African Americans, an idea that was well-received among abolitionists. ${ }^{16}$ In 'Negro Spirituals' Higginson related a story according to which he had once tried to discover the origins of a tune sung by an African American singer. Asking the singer where he had picked up his song, Higginson was surprised to hear him reply that 'Some good spirituals [...]

\footnotetext{
${ }^{12}$ Quoted in Tilden G. Edelstein, Strange Enthusiasm: A Life of Thomas Wentworth Higginson (New Haven: Yale University Press, 1968), 88 (emphasis and ellipsis in the original).

${ }^{13}$ Walter Scott, Minstrelsy of the Scottish Border, Consisting of Historical and Romantic Ballads. Vol. I and II (London: Ballantyne, 1802); Walter Scott, Minstrelsy of the Scottish Border, Consisting of Historical and Romantic Ballads. Vol. III (London: Ballantyne, 1803).

${ }^{14}$ Thomas W. Higginson, 'Negro Spirituals', The Atlantic Monthly 19/116 (1867): 685.

${ }^{15}$ Radano, 'Denoting Difference: The Writing of the Slave Spirituals,' 518.

${ }^{16}$ William F. Allen, 'General Characteristics of Slave Music', in Readings in Black American Music, ed. Eileen Southern (New York: W. W. Norton, 1983), 159.
} 
are start jess out o' curiosity. I been a-raise a sing, myself, once'.${ }^{17}$ From this statement, the song collector concluded that not only had he found an unwritten poem, but that he had also encountered the poet himself. African American songs were not mere imitations of European music; the lyrics had almost certainly been invented by African Americans themselves. However, the origins of the music remained a mystery to Higginson. While some words seemed to come from Africa, the music appeared to resemble European folk music. The uncertainty of the music's roots however only added to its mysterious, enchanting character.

\section{The Africanization of African American Music}

When in 1867 the former abolitionists William Francis Allen (1830-1889), Charles Pickard Ware (1840-1921) and Lucy McKim Garrison (1842-1877) published the first compendium of African American music, Higginson served as the three editors' primary advisor. They agreed that slave songs were a racial expression with 'a tinge of [the singers'] native Africa', as Allen put it in his introduction. ${ }^{18}$ As the compendium's title Slave Songs of the United States suggests, a discourse of nationalism was gaining prominence in texts on African American music. The increased interest in African American music indeed concurred with the rise of American artistic nationalism (as a response to European nationalisms) in the latter half of the nineteenth century. The discourse of nationalism corresponded to the establishment of a much more elaborate African-roots theory of African American music. The Africanization of the concept of African American music paradoxically began to corroborate the music's U.S.-Americanization. Seen through the turn-of-the-century prism of racialism, however, the idea that the theory of the music's African roots legitimized the slave songs as an American possession seemed logical. ${ }^{19}$

The legacy of nineteenth-century racialism and its impact on the African-roots theory is apparent in the writings of the American music critic and folklorist Henry Edward Krehbiel (1854-1923), who was the first writer to propose an elaborate African-roots theory of African American music. In 1913, Krehbiel wrote a riposte to the dominant early German and Austrian approaches to African American music. Ac-

\footnotetext{
${ }^{17}$ Higginson, 'Negro Spirituals,' 692.

${ }^{18}$ William F. Allen, Charles Pickard Ware, and Lucy McKim Garrison, eds., Slave Songs of the United States (New York: A. Simpson, 1867), viii.

${ }^{19} \mathrm{I}$ use the concept of racialism in Tsvetan Todorov's sense as 'a movement of ideas born in Western Europe whose period of flowering extends from the mid-eighteenth century to the mid-twentieth,' including the belief that individuals are determined by their biological constitution. Racialism is different from racism in that it refers to doctrine rather than behavior. See Todorov, Nationalism, Racism, and Exoticism in French Thought (Cambridge: Harvard University Press, 1993), 91-4.
} 
cording to Krehbiel, the major goal of his study was to 'disprove the theory which has been frequently advanced that the songs are not original creations of the slaves, but only the fruit of the negro's innate faculty for imitation' ${ }^{20} \mathrm{He}$ explicitly referred to the book Primitive Music by the Austrian musicologist Richard Wallaschek (18601917), a study which had fueled an origins controversy after its initial publication in $1893 .{ }^{21}$ Wallaschek had argued that 'negro songs [...] as a rule [...] are mere imitations of European compositions which the negroes have picked up and served up again with slight variations'. ${ }^{22}$ Krehbiel provided a scathing critique of Wallaschek's book, claiming that rather than being based on scientific research, Wallaschek's study was a mere presentation of anti-American sentiments common among Germans. 'The truth is that, like many another complacent German savant, Dr. Wallaschek thinks Americans are barbarians' ${ }^{23}$ Krehbiel tried to disprove Wallaschek's argument by detailing the essentially African elements of the music of African Americans in the U.S. In chapter five, 'Music Among the Africans', Krehbiel provided the first detailed account of how exactly different types of African music might have traveled from Africa to the U.S. where they merged with other types of music, however retaining many of their racio-musical characteristics. In light of the loss of African languages in the U.S., African American music, according to Krehbiel, was what he called a 'marvelous conservator. ${ }^{24}$ It demonstrated that African American slaves had not succumbed entirely to the obliterating effects of slavery. From Africa, some primordially African music had been transported to the U.S., where what Krehbiel called Afro-American folksongs first emerged. Combining the theory of African 'roots' with a nationalist rhetoric of American 'origins', Krehbiel deftly dovetailed the commonplace racio-musical division between a white, civilized Self and a black, uncivilized Other with a national one. According to Krehbiel, a fundamental difference existed not only between black and white characteristics, but equally so between American and European features. The notion of African roots implied that the music was completely independent from European types of music. Thus did Krehbiel's theory of African roots corroborate the idea that African American music was an American possession.

In addition to such academic controversies, references to the music's African roots had also become much more conspicuous in American popular culture. In the late nineteenth-century, the well-known American journalist Lafcadio Hearn had

\footnotetext{
${ }^{20}$ Henry Edward Krehbiel. Afro-American Folk Songs: A Study in Racial and National Music (New York: Frederick Ungar Publishing, 1962), ix.

${ }^{21}$ Mellonee Victoria Burnim and Portia K. Maultsby, eds., African American Music: An Introduction (London: Routledge, 2006), 11.

${ }^{22}$ Krehbiel, Afro-American Folk Songs, 11.

${ }^{23}$ Ibid., 14.

${ }^{24}$ Ibid., 9.
} 
written about life among blacks in New Orleans and the Caribbean. In 1906, two years after Hearn's death, a remarkable public debate arose as to the writer's view on the origins of African American music. A friend of Hearn, Krehbiel argued passionately that the late Hearn's opinion concurred with his own view that African American music - or 'Creole music', as Hearn called the music of Louisiana - was not an imitation of European forms, but that it was a black hybrid art with African roots. ${ }^{25}$ The rise of modernity moreover saw the emergence of an idea of a racialized black rhythm in popular music, so that such rhythmically-oriented types of music as ragtime and later jazz were commonly seen in these racialized terms. The idea of African rhythm gained great popularity immediately before the emergence of jazz. In 1912, Edgar Rice Burroughs (1875-1950) published the first episodes of Tarzan of the Apes, which in 1914 appeared as a novel and in 1918 was turned into a silent movie. In Tarzan rhythmic drumming repeatedly figured as a sonic marker of a racial, African savageness. In the novel, Tarzan was described as 'the only human being who ever joined in the fierce, mad, intoxicating revel of the Dum-Dum'. ${ }^{26}$

\section{The African-Roots Theory in Early Jazz Historiography}

When the first texts on jazz appeared in the late 1910s, racialist images of African drumming as well as ideas about the national character of music were transferred to jazz. Early jazz critics who emphasized the music's African roots projected onto jazz a conglomerate of Krehbiel's and other folklorists' views and those that existed within U.S. popular culture. Walter Kingsley's (1876-1926) influential 1917 article in the New York Sun on the history of jazz, 'Whence Comes Jazz,' is a highly significant and influential example for the way in which inherited concepts of race and nation were projected onto jazz music. ${ }^{27}$ Kingsley claimed:

The word [jazz] is African in origin. It is common on the Gold Coast of Africa and in the hinterland of Cape Coast Castle [...]. In the old plantation days, when the slaves were having one of their rare holidays and the fun languished, some West Coast African would cry out, "Jaz her up," and this would be the cue for fast and furious fun. ${ }^{28}$

\footnotetext{
${ }^{25}$ Krehbiel, 'Lafcadio Hearn and Congo Music', The Musician (1906), reproduced in Jazz in Print, edited by Karl Koenig, $78 f$.

${ }^{26}$ Edgar Rice Burroughs. Tarzan of the Apes (New York: Grosset and Dunlap, 1914), 83; See also Radano, Lying Up a Nation, 254 and 270-4.

${ }^{27}$ Walter Kingsley, 'Whence Comes Jazz', The New York Sun, 5 August 1917, 3.

${ }^{28}$ Kingsley, 'Whence Comes Jazz', 3.
} 
Remarkably, this mixed bag of stereotyped associations would remain the one major text on jazz's prehistory for more than fifteen years. Three weeks after its first publication in the New York Sun, The Literary Digest reprinted much of Kingsley's article in a piece titled 'The Appeal of the Primitive Jazz' ${ }^{29}$ Promoters of symphonic jazz in the mid-1920s similarly borrowed heavily from Kingsley. Thomas Osgood's 1926 So This Is Jazz, for instance, based its entire prehistory of jazz on Kingsley's article. ${ }^{30}$ In 1930, 'Whence Comes Jazz' provided the basis for debates on jazz in British popular music magazines, and in 1932, Kingsley's theory appeared in Robert Goffin's Aux frontières du jazz, one of the first books that was exclusively devoted to the history of jazz. ${ }^{31}$ André Cœuroy and André Schaeffner's ethnological study Jazz is one of the few exceptions that did not go back to Kingsley's article. ${ }^{32}$ It wasn't until the late-1930s that Kingsley's text was finally discarded by early jazz historians.

According to Kingsley, he had considered the views of two experts for his article: Lafcadio Hearn (1850-1904) and William Morrison Patterson. As Kingsley claimed, 'Lafcadio Hearn reported that the word "jaz," meaning to speed things up, to make excitement, was common among the blacks of the South and had been adopted by the creoles as a term to be applied to music of a rudimentary, syncopated type'. ${ }^{33}$ It is important to note that, if Hearn's alleged observation could ever be authenticated, this would in fact revolutionize the historiography of jazz even today. Since Hearn had left Louisiana in the early 1890 s and had resettled permanently to Japan, where he died in 1904, Kingsley's citation of Hearn's ostensible observation suggests that the beginnings of jazz music date back to the nineteenth century. A large number of jazz scholars have therefore combed through Hearn's writings in search for this passage, but so far to no avail. ${ }^{34}$ As Lawrence Gushee has suggested, it is possible that Kingsley received this information from Krehbiel whom he probably knew. ${ }^{35} \mathrm{He}$ also might have simply used Hearn's well-known name to give credibility to his personal speculations. In any case, even if Kingsley had thought this up, the use of Hearn illustrates that similar to Krehbiel's study of the African origins of African American popular music, the narrative of jazz's African origins could be plausibly embedded in a tradition of American writers of the nineteenth century who had exoticized ethnic minorities in the United States.

\footnotetext{
29 'The Appeal of the Primitive Jazz', The Literary Digest, 25 August 1917, 28.

${ }^{30}$ Thomas Osgood, So This Is Jazz (New York: Little, Brown and Company, 1926), 11-34.

${ }^{31}$ Robert Goffin, Aux frontières du jazz, $44 \mathrm{f}$.

${ }^{32}$ André Coeuroy and André Schaeffner, Le jazz (Paris: Claude Aveline, 1926).

${ }^{33}$ Kingsley, 'Whence Comes Jazz,' 3.

${ }^{34}$ See Lawrence Gushee, 'The Nineteenth-Century Origins of Jazz', in Black Music Research Journal 14/1 (1994): 159.

${ }^{35}$ Ibid.
} 
Kingsley's reference to the 'Gold Coast' similarly refers back to nineteenth century colonial images of West Africa. In the colonial imagination of the nineteenth century, the so-called Gold Coast signified both the abundant material promises of the African continent and blacks' ostensible ethical inferiority, thus legitimizing the exploitation of African resources by colonial powers. In an article entitled 'Chin-Music' from 1871, the author for instance associated the music of the Gold Coast with drum sounds that were produced when black pugilists stroke each others' bodies. According to the author, this 'chin music', was part of 'the rites and ceremonies of wild barbarians on the Gold Coast'. ${ }^{36}$ The racialist idea that African Americans, through their ostensible biological essence, were trans-historical carriers of African music allowed Kingsley to project these colonial images on jazz music. Since it was associated with blacks, early jazz also elicited European Americans' colonial imagination of Africa.

Kingsley's second 'expert', William Patterson, was an instructor of English who had recently finished his dissertation on The Rhythm of Prose. Patterson points to another strand of thinking that was elementary for the development of the Africanroots theory: cultural anthropology. At Columbia University, Patterson had been a student of Franz Boas's (1858-1942) who at that time was transforming anthropology from an ethnocentric discipline that reaffirmed the superiority of white races into a more relativist field of research that explored an interdependent nexus of biological, cultural, and linguistic similarities and differences between various groups of people, teaching 'a greater tolerance of forms of civilization different from our own' ${ }^{37}$ Boas, who in the early 1890s had recorded the drumming of the Kwakwaka'wakw Natives, gave Patterson valuable suggestions on the 'lost art of rhythm' of Native Americans ${ }^{\text {'38 }}$ Based on Boas's studies, Patterson conducted his own research on the drumming of the Apaches. His investigations led him to question essentialist perceptions of rhythm as a uniform element, arguing for what he called the individual difference in the sense of rhythm'. According to Patterson, 'Rhythmic experience is so complex, and individuals differ so largely in the enjoyment of it, that a new phrasing of its meaning would be necessary for each person, in order to avoid errors of inaccurate generalization' ${ }^{39}$ Patterson's book short-circuited the alleged superiority of civilized societies, arguing that what he called 'modern sophistication' in fact inhibited the development of rhythmic control. ${ }^{40}$ Kingsley applied Patterson's theory to jazz,

\footnotetext{
36 'Chin-Music,' Frank Leslie's Illustrated Newspaper 32, 5 August 1871, 347. See also Radano, Lying Up a Nation, 275.

${ }^{37}$ Franz Boas, The Mind of Primitive Man (New York: McMillan, 1911), 278.

${ }^{38}$ William Morrison Patterson, The Rhythm of Prose: An Experimental Investigation of Individual Difference in the Sense of Rhythm (New York: Columbia University Press, 1916), xix.

${ }^{39}$ Patterson, The Rhythm of Prose, 88.

${ }^{40}$ Patterson, The Rhythm of Prose, xix.
} 
thereby legitimating jazz as a complex art. At the same time, Patterson's book helped Kingsley to connect jazz to 'the marvelous syncopation of the African jungle'. ${ }^{41}$

Interestingly, Kingsley did not yet claim jazz as an exclusively national music. The national appropriation of jazz was a phenomenon that began with the historiography of Paul Whiteman (1890-1967) and his supporters, including Henry O. Osgood (1879-1927). According to Kingsley, jazz was inherently transnational. Rooted in Africa, 'it had flourished for hundreds of years in Cuba and Hayti [sic], and, of course, New Orleans derived it from there'. ${ }^{42}$ As regards jazz music, the discourse of nationalism only became commonplace when such musicians as Art Hickman and Paul Whiteman sought to legitimate jazz as art music. Starting in 1923/4, Whiteman claimed that he had developed the rudiments of early jazz into a new type of national art music that was however 'millions of miles apart' from early jazz. ${ }^{43}$ Whiteman may or may not have truly believed that jazz was essentially American, but the discourse of nationalism he employed was a way for him to legitimate his own symphonic jazz in the U.S. If the emergence of hot jazz criticism in the late 1920s challenged the paradigm of symphonic jazz, it did not replace the concept of jazz's national character. Efforts to legitimate jazz in the U.S. have relied on the discourse of nationalism ever since, so that even today major textbooks on jazz tend to reduce the music to its national character. ${ }^{44}$

The African-roots theory was subsequently elaborated by the French ethnologist André Schaeffner (1895-1980), whose study of the prehistory of jazz, Le jazz, appeared in $1926 .{ }^{45}$ If Kingsley's emphasis on jazz's supposedly African nature was the result of a limited understanding of American cultural anthropology, Schaeffner's approach to African American music was embedded in the French ethnological circles of the mid-1920s. James Clifford (*1945) has detailed how ethnology, jazz, and surrealism were interwoven in 1920s Paris. ${ }^{46}$ When jazz arrived in Paris, it lent itself to an appropriation as an art nègre and became a popular subject of ethnological research. To many ethnologists, jazz seemed to be an import of an authentically Afri-

\footnotetext{
${ }^{41}$ Kingsley, 'Whence Comes Jazz', 3.

${ }^{42}$ Ibid., 3.

${ }^{43}$ Paul Whiteman and Mary Margaret McBride, Jazz (New York: Sears \& Co., 1926), 99.

${ }^{44}$ See for instance Gary Giddins and Scott DeVeaux's otherwise excellent standard textbook Jazz (New York: W. W. Norton, 2009).

${ }^{45}$ Although André Cœuroy was officially the book's main author, he had only contributed three minor chapters to the book. Cœuroy's name has therefore been omitted in later discussions of Le jazz. See Lucien Malson, 'Un premier livre sur le jazz et ses racines africaines', Revue de Musicologie 1/2 (1982): 345-52; and Denis Martin and Olivier Roueff, La France du jazz: Musique, modernité et identité dans la première moitié du vingtième siècle (Marseille: Éditions Paranthèses, 2002), $246 f$.

${ }^{46}$ James Clifford, The Predicament of Culture: Twentieth Century Ethnography, Literature, and Art (Cambridge: Harvard University Press, 1988), $121 \mathrm{ff}$.
} 
can music. Not only did jazz seem to provide these young pioneers of field research with opportunities to practice their methodologies in their immediate environment, but it was also a way for the fledgling discipline of ethnology to generate public interest, to demonstrate its relevance, and to eventually attract funding opportunities. ${ }^{47}$

A combination of Schaeffner's training as a musicologist and ethnologist with particular interest in organology, Le jazz provided a four-century evolutionary history of jazz as an African-based type of music. In a critique of Schaeffner's book, the Belgian musicologist Arthur Hoérée (1897-1986) suggested the title Étude des éléments nègres dans la musique de jazz for Schaeffner's study since the book seemed to deny European music any relevance in the history of jazz. Providing evidence from travel reports, Schaeffner cast the African-based history of jazz as a counter-history to European evolutionary models of jazz history. He thus implicitly challenged the propaganda of French imperialism which justified the exploitation of African resources by pointing to colonialism's ameliorative impact on African culture - or rather the lack thereof. In 1921, the French colonial minister Albert Sarraut had announced the 'Mise en Valeur' project for French colonial possessions, which was based on the idea that a higher profitability of French colonies, made possible through increased industrialization, would turn out culturally and ethically beneficent for the colonized. ${ }^{48}$ Sarraut's imperialist vision was ethically legitimated by both the perceived greatness of French culture and the imagined lack of culture among the colonized. Detailing the long African-based prehistory of modern popular music, Schaeffner's history of jazz was a counter-argument to such assumptions. Not only did he demonstrate that the assumption that Africa lacked culture was unsustainable, but he also illustrated that 1920s Paris, and the rest of the Western world, was permeated with African-based music.

The investigation of late-nineteenth- and early-twentieth-century discourses on black music goes some way towards explaining the ways in which early conceptualizations of jazz emerged. These, in turn, were revised and reconfigured as jazz historiography progressed. However, they have not been discarded completely. The idea that the origins of jazz are essentially black and essentially American, for instance, has proven to be remarkably persistent. ${ }^{49}$ Instead of asking whether jazz was 'truly' American or 'really' black, it might be more useful to first consider how exactly we came to think of the emergence of jazz as a primarily racial and national phenomenon. Part of the answer to this lies in the longevity of socially grounded concepts that have conditioned the various appropriations of African American music.

\footnotetext{
${ }^{47}$ Patterson, The Rhythm of Prose, 56 and 127.

${ }^{48}$ Brent-Hayes Edwards, The Practice of Diaspora: Literature, Translation, and the Rise of Black Internationalism (Cambridge: Harvard University Press, 2009), 73.

${ }^{49}$ The most prominent example of this type of contemporary historiography is Ken Burns's highly successful documentary series Jazz (2001; Arlington: PBS, 2001), DVD.
} 


\section{Literature}

Allen, William F. 'General Characteristics of Slave Music'. In Readings in Black American Music, edited by Eileen Southern, 149-173. New York: W. W. Norton, 1983.

- Charles Pickard Ware, and Lucy McKim Garrison, eds. Slave Songs of the United States. New York: A. Simpson, 1867.

Ballanta's, Nicholas G. J. 'Jazz Music and Its Relation to African Music'. Musical Courier (June 1922). Reproduced in Jazz in Print, edited by Karl Koenig, 188-90.

Boas, Franz. The Mind of Primitive Man. New York: McMillan, 1911.

Burnim Mellonee, Victoria, and Portia K. Maultsby, eds. African American Music: An Introduction. London: Routledge, 2006.

Burns, Ken. Jazz: A Film by Ken Burns. Directed by Ken Burns. 2001. Arlington: PBS, 2001. DVD.

'Chin-Music', Frank Leslie's Illustrated Newspaper. 5 August 1871.

Clifford, James. The Predicament of Culture: Twentieth Century Ethnography, Literature, and Art. Cambridge: Harvard University Press, 1988.

Coeuroy, André, and André Schaeffner. Le jazz. Paris: Claude Aveline, 1926.

'Delving into the Genealogy of Jazz'. Current Opinion (August 1919). Reproduced in Jazz in Print, edited by Karl Koenig, 134-36. Hillsdale: Pendragon Press, 2002.

Douglass, Frederick. Narrative of the Life of Frederick Douglass, An American Slave, Written by Himself. Boston: Published at the Anti-Slavery Office, 1845.

Dunkel, Mario. 'W. C. Handy, Abbe Niles, and (Auto)biographical Positioning in the Whiteman Era'. Popular Music and Society 38/2 (2015): 122-39.

Edelstein, Tilden G. Strange Enthusiasm: A Life of Thomas Wentworth Higginson. New Haven: Yale University Press, 1968.

Edwards, Brent-Hayes. The Practice of Diaspora: Literature, Translation, and the Rise of Black Internationalism. Cambridge: Harvard University Press, 2009.

Engel, Carl. 'Jazz: A Musical Discussion'. The Atlantic Monthly 130/2 (August 1922): 182-89. 
Farmer, Harcourt. 'The Marche Funebre of "Jazz"'. Musical America (1920). Reproduced in Jazz in Print (1859-1929), edited by Karl Koenig, 144-46. Hillsdale: Pendragon Press, 2002.

Giddins, Gary, and Scott DeVeaux. Jazz. New York: W. W. Norton, 2009.

Goffin, Robert. Aux frontières du jazz. Paris: Éditions du sagittaire, 1932.

Higginson, Thomas Wentworth. 'Negro Spirituals'. The Atlantic Monthly 19/116 (1867): 685-94.

Hoérée, Arthur. 'Le Jazz'. La Revue Musicale 12 (October 1927): 213-41.

Koenig, Karl, ed. Jazz in Print (1859-1929). Hillsdale: Pendragon Press, 2002.

Krehbiel, Henry Edward. Afro-American Folk Songs: A Study in Racial and National Music. New York: Frederick Ungar Publishing, 1962.

— 'Lafcadio Hearn and Congo Music'. The Musician (1906). Reproduced in Jazz in Print (1859-1929), edited by Karl Koenig, 78-9. Hillsdale: Pendragon Press, 2002.

Malson, Lucien. 'Un premier livre sur le jazz et ses raciness africaines'. Revue de Musicologie 1/2 (1982): 345-52.

Martin, Denis, and Olivier Roueff. La France du jazz: Musique, modernité et identité dans la première moitié du vingtième siècle. Marseille: Éditions Paranthèses, 2002.

Osgood, Thomas. So This Is Jazz. New York: Little, Brown and Company, 1926.

Panassié, Hugues. Le jazz hot. Paris: Éditions R.-A. Corrêa, 1934.

Patterson, William Morrison. The Rhythm of Prose: An Experimental Investigation of Individual Difference in the Sense of Rhythm. New York: Columbia University Press, 1916.

Radano, Ronald. 'Denoting Difference: The Writing of the Slave Spirituals'. Critical Inquiry 22/3 (1996): 506-44.

Radano, Ronald. Lying Up a Nation: Race and Black Music. Chicago: University of Chicago Press, 2003.

Southern, Eileen. The Music of Black Americans: A History. New York: W. W. Norton, 1997.

— 'The Appeal of the Primitive Jazz'. The Literary Digest. 25 August 1917, 28.

Todorov, Tzvetan. On Human Diversity: Nationalism, Racism, and Exoticism in French Thought. Cambridge: Harvard University Press, 1993. 
Whiteman, Paul, and Mary Margaret McBride. Jazz. New York: Sears \& Co., 1926. 



\title{
Achim Freyers Mr. Rabbit and the Dragon King: Eine Interpretation des koreanischen P'ansori Sugungga
}

\author{
Dorothea Suh (Halle/Saale)
}

Im Folgenden sollen das P'ansori Sugungga, welches als „Der Unterwasserpalast“ übersetzt werden kann, und seine Interpretation durch Achim Freyer (1934-) in seiner Produktion Mr. Rabbit and the Dragon King näher betrachtet werden: Der Entstehungskontext des Originals und die Adaption werden im ersten Teil prüfend gegenübergestellt und durch einen ausführlichen Inszenierungsbericht ergänzt. Es folgt die Analyse der Intentionen von Freyer und der Publikums- und Pressereaktionen aus dem In- und Ausland. Abschließend gewährt die kritische Auswertung aller Befunde einen Einblick in die kontemporäre Entwicklung der P'ansori-Szene Südkoreas.

\section{Musikhistorischer Hintergrund: P'ansori}

P'ansori ist ein Genre der traditionellen koreanischen Musik (Gugak), das von einem Sänger oder einer Sängerin in einer „,combination of singing, stylized speech, and ge-

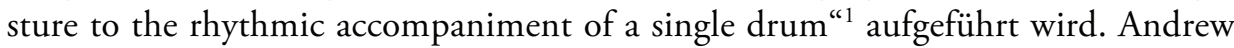
Killick charaktererisiert P'ansori als eine Form des Geschichtenerzählens, die dadurch an Theatralität gewinne, dass der Sänger (oder die Sängerin) in die Rollen verschiedener Figuren schlüpfe und auch den Trommler als Rollenfigur adressieren

\footnotetext{
${ }^{1}$ Andrew Killick, „P'ansori“, in Encyclopedia of Asian Theatre, Bd. 2, hg. von Samuel L. Leiter (Westport: Greenwood Press, 2007), 495f.; 495.
} 
könne. Ein Großteil des Textes wird gesungen und dient vor allem der Beschreibung von Gefühlen und raschen Handlungsverläufen; die gesprochenen Passagen (aniri) bringen die erzählte Geschichte voran und ermöglichen dem solistisch agierenden Sänger eine Stimmauffrischung. P'ansori, so führt Killick weiter aus, sei ein Vorläufer zweier weiterer Theatergenres, nämlich des ch'angguk, in dem Akteure beider Geschlechter gemeinsam auftreten, und des ausschließlich von Frauen ausgeführten yošŏg kukkuk: In beiden Formen sind es also mehrere Schauspieler, die die verschiedenen Figuren spielen und dabei im Stil des P'ansori singen. ${ }^{2}$ Im 18. Jahrhundert entwickelte sich P'ansori von der Unterhaltung der arbeitenden Klasse (sömin) zu einer hoch geschätzten und geförderten Darbietung, welche von der intellektuellen Elite (yangban) bei offiziellen Festlichkeiten oder privaten Hauskonzerten genossen wurde:

First documented in 1754, P'ansori originated as an oral tradition among commoners in southwestern Cholla Province. It probably developed from shamans' narrative songs, gradually elaborated by professional itinerant performers (kwangdae). Durin the nineteenth century, it won widespread favor in all social strata, including the court. To make it more acceptable to elite patrons, an aficionado, Shin Chaehyo (1812-1884) prepared written texts incorporating overt Confucian morality nd legenat phrases from Chinese poetry and ameliorating the obscenity of many passages. These modifications, however, coexist with surviving undercurrents of satire and subversion, earthly regional dialect, and Rabelaisian humor. ${ }^{3}$

Die seit Generationen ausschließlich mündlich vom Meister an der Schüler weitergegebene Kunst wurde 1964 als Nationales Immatrielles Kulturerbe Koreas klassifiziert, eine weitere bedeutende Ehrung erhielt P'ansori im Jahr 2003, als die UNESCO es als Immatrielles Kulturerbe anerkannte. Fünf P'ansori-Lieder sind vollständig erhalten geblieben: Ch'unhyangga, Shimch'ongga, Hüngbuga, Sugungga und Chokpyokka. Jedes dieser P'ansori beinhaltet eigene, scharfsinnige und erzieherische Botschaften, welche sich den Zuhörern durchaus direkt, aber oftmals nur durch Metaphern erschließen. In Ch'unhyangga stehen die Gewissenhaftigkeit und die Treue zum Geliebten im Vordergrund (jeol-gae), in Shimch'ongga werden eindrucksvoll die Kindespflicht und der Respekt gegenüber den Eltern (byo-do) eingefordert, in Hüngbuga richtet sich der Fokus auf die Kraft der Vergebung und das Einhalten der Ordnung konfuzianischer Familienregeln (bo-un), in der einzigen Tierfabel Sugungga sind die Loyalität und der bedingungslose Gehorsam an den König der Schwerpunkt (dodeokkjeok gyo-hun), während das P'ansori Chokpyokka die Soldatenehre in Zeiten des Krieges behandelt. Das traditionelle Repertoire wird laufend durch neue

\footnotetext{
${ }^{2}$ Vgl. Killick, „P'ansori“, $495 f$.

${ }^{3}$ Ebd., 496.
} 
Kompositionen erweitert, die sich - häufig in zeitgenössischem Koreanisch - mit den sozialen, religiösen und politischen Themen ihrer Gegenwart befassen. ${ }^{4}$

\section{Die Vorlage: Sugungga}

Die Geschichte von Sugungga wird in Südkorea wegen der humorvollen Erzählweise von Zuhörern aller Altersgruppen gerne gehört: Der Drachenkönig des Meeres erkrankt schwer und kann, laut dem Rat eines Weisen, nur durch das Konsumieren einer Hasenleber geheilt werden. Die loyale Wasserschildkröte Pyolchubu wird wegen ihrer Fähigkeit, an Wasser und an Land zu überleben, auserkoren, einen Hasen in den Unterwasserpalast zu holen. Pyolchubu erreicht nach einer langen Reise die Wasseroberfläche und schafft es, einen Hasen $\mathrm{zu}$ finden. Trickreich verspricht Pyolchubu dem Hasen unermessliche Reichtümer und eine Position am Hofe des Drachenkönigs und kann ihn damit zu einer Reise in den Unterwasserpalast bewegen. Im Unterwasserpalast angekommen, endeckt der Hase die Wahrheit und täuscht dem Drachenkönig vor, seine Leber an Land vergessen zu haben. Der Hase kommt mit dem Leben davon, und Pyolchubu erhält wegen seiner Bemühungen und seiner Königstreue von einem mystischen Weisen ein Heilmittel für seinen König.

Die Ursprünge der koreanischen Volksgeschichte Sugungga lassen sich bis zu den 547 Jataka-Geschichten Indiens zurückverfolgen. ${ }^{5}$ Diese Geschichten sind die wichtigsten Werke buddhistischer Literatur und erzählen von den Wiedergeburten Buddhas. Weitere Märchen mit derselben Thematik wie Sugungga sind in China, Tibet und Japan verbreitet ${ }^{6}$. Dies legt die Vermutung nahe, dass die Verbreitung der indischen Jataka-Geschichten durch Händler, Pilger und Wandermönche über die Handelswege der Seidenstraße erfolgte. Als weiterer möglicher Übertragungsweg von

\footnotetext{
${ }^{4}$ Vgl. Killick, „P'ansori“, 496. Weitere englischsprachige Forschungsliteratur zu Geschichte und Ästhetik von P'ansori stammt etwa von Yeonok Jang, Korean P'ansori Singing Tradition: Development, Authenticity, and Performance History (Lanham: Scarecrow Press, 2014); Andrew Killick, Traditional Music and the Contemporary Composer in the Republic of Korea (Farnham: Ashgate, 2013); Ders., In Search of Korean Traditional Opera: Discourses of ch 'anggŭk (Honolulu: University of Hawai i Press, 2010); Chan E. Park, Voices from the Straw Mat: Toward and Ethnography of P'ansori Singing (Honolulu: University of Hawai'i Press, 2003); Marshall R. Pihl, The Korean Singer of Tales (Cambridge: Harvard University Press, 1994).

${ }^{5}$ Dorothea Suh, „Key Papers on Korea: Essays Celebrating 25 Years of the Centre of Korean Studies“, in SOAS, University of London, hg. von Andrew David Jackson (Leiden: Brill, Global Oriental, 2014), $227-41$.

${ }^{6}$ James Huntley Grayson, „Rabbit Visits the Dragon Palace: A Korea-Adapted, Buddhist Tale from India“, Fabula 45 (2004): 1-2; 69-90.
} 
Sugungga kommt der direkte Seeweg von Indien nach Korea in Betracht; bereits im Samguk Yusa ${ }^{7}$ wird nämlich von der indischen Prinzessin Hŏ Hwangok berichtet, welche sich nach einem Traum mit dem Schiff von der indischen Stadt Ayodhya nach Korea aufmachte, um König Suro vom Königreich Kŭmgwan Kaya ${ }^{8}$ zu heiraten.

In Korea verschmolzen die buddhistischen Jataka-Geschichten mit lokalen Legenden und nahmen Einflüsse aus dem Schamanismus und dem Konfuzianismus auf - dies zeigt die Diversität und das reiche Potenzial von Sugungga für Musiker sowie Wissenschaftler. Von Sugungga existieren in Korea multiple Abwandlungen, die bekanntesten Versionen sind Tokki taryong (Die Geschichte des Hasen) und Pyolchubu jeon (Die Geschichte von Pyolchubu). Tokki taryong favorisiert die Sichtweise des Hasen und unterstreicht dessen Klugheit und den Triumph über den Drachenkönig, während Pyolchubu jeon die unbeirrbare Loyalität nach dem konfuzianistischen Ideal der Pflicht und Treue von Pyolchubu zu seinem König betont.

In Sugungga sind die Geschichten von Tokki taryong und Pyolchubu jeon komplex miteinander verwoben. Als Tierfabel spricht Sugungga durch kunstvolle Metaphern und gibt den Weg für sozialkritische, historische und politische Auslegungen frei. Dabei ist es in Sugungga dem Sänger überlassen, welche Nuancen und Schwerpunkte gesetzt werden sollen. Die bedeutendsten Interpretationen werden badi genannt; ihre Kreation obliegt ausschließlich den Meistersängern (myeongchang).

\section{Mr. Rabbit and the Dragon King in Wuppertal (2011): Ein Inszenierungs- und Aufführungsbericht}

Die Produktion Mr. Rabbit and the Dragon King von Achim Freyer wurde im September 2011 als Prestige-Projekt des Nationaltheaters von Korea (Kungnip Kukch'ang) durch die Nationale Ch'angguk-Kompanie (Kungnip Ch'angguktan) in Seoul inszeniert. Im Dezember 2011 gastierte das Nationaltheater von Korea an den Wuppertaler Bühnen in Deutschland, das einzige Gastspiel in Europa. Die Kollaboration zwischen Freyer und dem Nationaltheater Korea sollte eine modernisierte Geschichte von Sugungga erschaffen und koreanische Traditionen mit europäischer Ästhetik kombinieren, um die bessere Verständlichkeit für das deutsche Publikum zu gewährleisten. Die musikalische Einstudierung wurde durch Meistersängerin Ahn Suk-Sun $\left({ }^{*} 1948\right)$ durchgeführt und der Komponist Lee Yong-Tak erschuf nach den Wünschen von Freyer ein vollkommen neues Notenmaterial. Die ausverkauften

\footnotetext{
${ }^{7}$ Die Legenden der drei Königreiche.

${ }^{8}$ Das kleine Königreich Kaya bestand zwischen 42 v. Chr.-562 n. Chr. während der Blütezeit der drei Königreiche Silla, Goguryeo und Baekje.
} 
Vorstellungen in Wuppertal wurden laut Medienberichten mitgereister koreanischer Journalisten frenetisch gefeiert, ${ }^{9}$ und nicht zuletzt machten die Besuche hochrangiger Persönlichkeiten wie dem Kulturminister von Nordrhein-Westfalen, dem Konsul des Koreanischen Konsulats Deutschland und dem Direktor der Koreanischen Gemeinde Deutschlands den hohen Stellenwert der Inszenierung deutlich. ${ }^{10}$

Die Bühne wurde von einer Konstruktion im Hintergrund dominiert, worauf die Erzählerin, 'Madame P'ansori' (Ahn Suk-Sun in der Premiere in Korea) über der Bühne schwebte, gekleidet in ein dunkelblaues Kleid mit einer meterlangen Schleppe. Diese Stoffdrapierung diente gleichzeitig als Vorhang, aus dem die anderen Künstler hervortraten, als kämen sie aus dem Inneren von Madame P'ansori. Diese glich dem personifizierten Symbol von P'ansori selbst, sie gebar die Charaktere und schaute zu, wie sich die Geschichte unter ihr und aus ihr entfaltete. Sie erschuf förmlich die Welt von Mr. Rabbit and the Dragon King, indem sie die an ihr Kleid angebrachten Ornamente von Sonne, Mond und Sternen abzupfte und auf die Bühne herunter warf.

Das Arrangement ihres Kleides und die königliche Haltung schufen Assoziationen zum Charakter der Königin der Nacht aus Wolfgang Amadeus Mozarts Die Zauberflöte - ein aus dem Grund berechtigter Vergleich, dass Freyer als renommierter Opernregisseur bereits seit $1982^{11}$ Die Zauberflöte regelmäßig auf die Bühne gebracht hatte. Das weiße, geisterhaft bemalte Gesicht der Madame P'ansori und die zu Beginn der Aufführung bewusst langsam und erhaben gehaltenen Bewegungen glichen denen eines japanischen Kabuki-Tänzers. Wie in einer herkömmlichen P'ansori-Aufführung benutzte Madame P'ansori Rezitation (aniri) und Gesang (sori), unterbrochen durch Phasen, wo es den Anschein hatte, als ob sie einzelne Wörter in den Raum ausspeien würde - durch den poetischen und metaphorischen Inhalt ähnelten diese Momente dem Vortrag eines sijo ${ }^{12}$. Die Omnipräsenz von Madame P'ansori sollte sich durch die gesamte Aufführung hindurch ziehen.

Die Illusion einer Welt unter Wasser wurde durch ein ausgeklügeltes Beleuchtungssystem und Farbenspiel gegeben, die Farben Blau, Weiß und Schwarz dominierten hierbei. So entstand ein starker Kontrast zur gewöhnlichen Form des inszenierten P'ansori, dem traditionellen ch'angguk, wo farbenprächtige Kostüme und üppige Bühnenbilder gängig sind. Der Großteil der Charaktere aus Mr. Rabbit and the Dragon King trug Kostüme in den Farben Schwarz und Weiß, lediglich besondere Charaktere trugen bunte Farben, wie der König, welcher die Farbe Gelb trug. Wäh-

\footnotetext{
9 „Korean pansori opera makes waves in Germany“, Korea.net, http://www.korea.net/NewsFocus/ Culture/view?articleId=90736. 28.04.2014.

10 „Korean pansori opera makes waves in Germany“, a.a.O.

${ }^{11}$ „Musiktheater: Achim Freyer inszeniert Mozarts ,Zauberflöte‘ in Hamburg: Das Märchen - ein Traum“, Die Zeit 22/1982: 1-2, http://www.zeit.de/1982/22/das-maerchen-ein-traum. 28.04.2014.

${ }^{12}$ Gedichtform der Literaten, es besteht aus drei Zeilen mit 14 bis 16 Silben.
} 
rend in Asien die Farbe Gelb von königlicher Bedeutung ist, da nur der Herrscher diese Farbe tragen durfte, weckt die Farbe Gelb in der europäischen Kultur verschiedenste Assoziationen; neben dem positiv konnotierten Gold kann es auch Neid und Gier symbolisieren. Die Figur des Henkers, wenngleich in einer eher passiven Rolle, trug die Reizfarbe Rot, die in Asien und Europa mit sehr unterschiedlicher Symbolik behaftet ist: in der westlichen Kultur steht die Farbe für das Leben (Blut) und Leidenschaft, aber auch für Zorn; dagegen wird die Farbe in Asien weitgehend Glück und Freude assoziiert. Es ist paradox, dass der Henker, welcher den Bauch des Hasen aufschlitzen sollte, gerade diese Verbindung aufweist. Die Kostüme, ebenfalls von Freyer gestaltet, glichen durch die vergrößerten Proportionen und die kontrastierenden Farben Schwarz und Weiß wie ein Hybrid aus westlichem Comic und koreanischer Kalligrafie. Ähnliches ließ sich bei den Bühnenbildern beobachten, denn Freyer nahm seine Inspiration aus dem „Rhythmus der Berglinien (...), Felsschluchten Täler und Berge und Höhen “13 und wollte „diese bewegliche Zeichenwelt über die Kostüme"14 weiterentwickeln.

Freyer wendet diese Art von Überzeichnung der Figuren des Öfteren an. Bereits 1982 wurde Freyers Inszenierung von Mozarts Zauberflöte als eine Art „Comicstrip “15 bezeichnet, die die Geschichte vom Prinzen Pamino als „moderne[s] Märchen von Superman oder den lemurenhaften extraterrestrischen Lebewesen erzählt" ${ }^{\text {"16. }}$. Und auch in Mr. Rabbit and the Dragon King sind die Charaktere durch das Bühnenbild, die Kostümierung und Masken überzeichnet und gleichen lebendig gewordenen Comic-Figuren oder ausgeschnittenen Figuren aus dem chinesischen Schattentheater píylngxì oder dem koreanischen Puppentheater kkoktu kaksi noreum. Eine der tiefgreifendsten Veränderungen, die Freyer vornahm, war die vollständige Verhüllung der Künstler durch überdimensional große Gesichtsmasken. Dies führte zu einem restriktiven Bewegungsablauf und beeinflusste im hohen Maße die Tonproduktion, da die Maske sich wie eine Mauer vor dem Mund der Sänger verhielt.

Die Mimik und die Bewegungen (ballim) spielen in der P'ansori-Aufführung, sowie im ch'angguk eine wichtige Rolle. Im Kwangdae ka (Das Lied des Kwangdae), welches als die wichtigste Ressource für die P'ansori-Tradition gilt ${ }^{17}$, werden unter anderem Aussehen (inmul) und Schauspielkunst, darunter auch die Mimik (norumsae), als essentielle Ausdrucksmöglichkeiten eines jeden P'ansori-Meisters angegeben. Durch die Maskierung wurden nicht nur Mimik und Aussehen (inmul) des Interpreten verdeckt, sondern es wurden auch die Bewegungen (ballim und no-

\footnotetext{
${ }^{13}$ Achim Freyer, Programmheft Wuppertaler Bühnen, Mr. Rabbit and the Dragon King (Wuppertal: Ley \& Wiegandt, 2011), 8.

${ }^{14}$ Achim Freyer, Programmheft Wuppertaler Bühnen, 8.

15 „Musiktheater: Achim Freyer inszeniert Mozarts ,Zauberflöte‘ in Hamburg“, 1.

${ }^{16}$ Ebd.

${ }^{17}$ Bang-Song Song, Source Readings In Korean Music (Seoul: K.N.C. for UNESCO, 1980), 101.
} 
rumsae) stark eingeschränkt - in der Aufführung vom 23. Dezember 2011 fielen Masken mehrfach durch unabsichtliche Bewegungen zu Boden. Freyer verweist hier auf den Verfremdungseffekt seines früheren Lehrers Bertolt Brecht (1898-1956), dem Publikum durch Gleichnisse zeitgemäße Themen nahe zu bringen. Im Falle der Tierfabel Sugungga und seiner eigenen Adaption Mr. Rabbit and the Dragon King benötigten die Tiere, welche metaphorisch für die Menschen stehen, „ein Zeichen auf der Bühne, um auf dieser [als solche?] wahrgenommen zu werden "18 - die Masken. Im P'ansori und etwas abgeschwächt im ch'angguk sind jedoch impulsive Bewegungen und eine lebhafte Mimik die Norm. Die Schwierigkeit in der traditionellen koreanischen Aufführung liegt nicht darin, wie von Freyer hervorgehoben, „daß von Tieren erzählt wird“"19, sondern darin, wie die Musiker die Charaktere darstellen. Insbesondere im P'ansori wird vom Sänger erwartet, die verschiedensten Charaktere und Gefühlsregungen durch starke Affekte darzustellen. Da Freyer mit koreanischen Sängern arbeitete, wären diese durchaus in der Lage gewesen, die geforderten Zeichen auf der Bühne zu setzen - ohne die Masken.

Als Hauptgrund für den Einsatz von Masken führt Freyer die Abgrenzung zu dem einzigen menschlichen Charakter, der Madame P'ansori, $\mathrm{an}^{20}$. Die weiteren Sänger sollten durch die Maskierung entpersonifiziert werden und in ihrer Rolle aufgehen, um eine stärkere Trennung zwischen Madame P'ansori und den TierCharakteren zu schaffen. Das Fehlen der Mimik und die limitierten Bewegungsmöglichkeiten machten den Zuhörer in einem großen Maße abhängig von den deutschen Untertiteln, die während der Aufführung bereitgestellt wurden. Die direkte Kommunikation zwischen den Musikern und dem Publikum und die eigentlich üblichen ermunternden Zwischenrufe (ch'uimsae) fand in der Aufführung vom 23. Dezember 2011 nicht statt, obwohl ch'uimsae integral für die ideale Rezeption von P'ansori und ch'angguk ist - für die Ausführenden und auch die Zuhörer. Denn ch'uimsae gilt als Indikator für den Erfolg einer Vorstellung, in anderen Konzerten koreanischer P'ansori-Sänger in Deutschland war es auch dem deutschen Publikum möglich, sich nach einer kurzen Unterweisung am ch'uimsae zu beteiligen ${ }^{21}$. Die unpersönlich erscheinenden „Kunstfiguren“"22 aus Mr. Rabbit and the Dragon King waren augenscheinlich bar jeder Eigeninterpretation der Musiker und gaben damit die Möglichkeit für individuelle Auslegungen der Geschichte durch die Zuschauer. Dies war eine bewusste Entscheidung Freyers, denn „wichtig ist ja immer das Ahnbare, nicht das

\footnotetext{
${ }^{18}$ Freyer, Programmheft Wuppertaler Bühnen, 9.

${ }^{19}$ Ebd., 8.

${ }^{20}$ Ebd.

${ }^{21}$ Konzert von Soo Jang You, Museum für Völkerkunde Hamburg, 12. Oktober 2013.

${ }^{22}$ Freyer, Programmheft Wuppertaler Bühnen, 8.
} 
Ausgeführte, das verstopft die Phantasie, dann wird man zum Voyeur [...] daß wir alles 'todsicher' erklärt kriegen “23.

Konträr zu seiner Aussage verhält sich aber die Tatsache, dass er in seiner Inszenierung auf drastische Erklärungen anstatt auf subtile Andeutungen zurückgreift, um seine Schwerpunkte zu verdeutlichen, und so den Zuschauer bewusst als 'Voyeur' in die von ihm gewünschte Richtung lenkt. Beispielsweise ist die Krankheit des Drachenkönigs hier die Folge der Umweltverschmutzung der Meere, verdeutlicht durch Stränge von leeren PET-Wasserflaschen und Fischernetzen, welche auf der Bühne befestigt waren. Und als Pyolchubu nach seiner Reise vom Unterwasserpalast an Land ankommt, herrscht dort zwischen den Tieren Krieg. Die originale Szene aus Sugungga, in der die Tiere an Land einen König wählen wollen, überträgt Freyer auf die Moderne, auf die, wie er sagt, „,heutigen Katastrophen “24, indem er die Tiere mit tödlichen Waffen, überdimensionalen Schwertern, Maschinengewehren und Panzern kämpfen lässt. Zwei zentrale Themen der Gegenwart, die Verschmutzung der Umwelt und der Militarismus, wurden so in die Geschichte von Sugungga integriert.

Es ist durchaus in der Tradition von P'ansori, dass die Geschichten sich nach dem Geschmack des Publikums ändern können und sozialkritische und politisierende Themen des Alltags aufgegriffen werden. Doch eine zu starke Verfremdung und Verzerrung der originalen Geschichte von Sugunnga birgt auch eine Problematik, auf die später noch eingegangen werden soll. Das Ende von Sugungga wurde ebenfalls verändert, die treue Wasserschildkröte Pyolchubu bringt dem Drachenkönig, motiviert durch seine eigene bevorstehende Beförderung beim Gelingen seiner Mission, statt der Medizin einfach die Exkremente des Hasen. Versionen von Sugungga mögen diese Darstellung ebenfalls beschreiben, jedoch hat sich Fundamentales bei $M r$. Rabbit and the Dragon King verschoben: Der Schwerpunkt von Sugungga waren die Loyalität und der bedingungslose Gehorsam gegenüber dem König (dodeokkjeok gyohun); dies wurde vollständig aus Mr. Rabbit and the Dragon King entfernt. Wie bereits der Titel impliziert, sind die Hauptprotagonisten der Hase und der Drachenkönig - Sugungga, der Unterwasserpalast, ist dagegen ein neutralerer Titel, welcher den Schauplatz beschreibt. Der Hase entkam in Freyers Interpretation auf dem Land nicht in die Freiheit, sondern stieg auf einer Leiter in den Mond hinauf. Ein chinesisches Volksmärchen erzählt davon, dass der Hase der Mondgöttin dabei assistiert, das Elixier des Lebens umzufüllen, während koreanische Legenden den Hasen auf dem Mond köstlichen Reiskuchen stampfen lassen. Auf dem Mond angekommen, lamentierte der Hase über sein Leben, das das Wertvollste sei, was er besitze, und Madame P'ansori schloss die Aufführung mit dem Satz „Schnell, geh wieder zurück!“

\footnotetext{
${ }^{23}$ Freyer, Programmheft Wuppertaler Bühnen, 9.

${ }^{24}$ Ebd., 8.
} 


\section{Intentionen und Motivationen Freyers}

Freyer hatte nach eigener Aussage „kaum Gelegenheit, etwas über P'ansori zu lernen, zu lesen, mich mit der Kultur Koreas zu beschäftigen “25. Dies ist eine recht eigentümliche Proposition, da der Intendant es Nationaltheaters von Korea, Youn-Chol Lim, sich wünschte, dass durch diese Aufführung sowohl koreanischen als auch europäischen Zuhörern der Wert Pansoris verdeutlicht würde ${ }^{26}$ und er davon überzeugt war, dass Freyer die „weltumspannende Universalität von P'ansori enthüllen und die ursprüngliche Gestaltung von Pansori“ “27 bewahren werde. Aber können transkulturelle Projekte wie Mr. Rabbit and the Dragon King einem solchen Anspruch überhaupt gerecht werden? Lässt sich so etwas wie eine kulturelle Identität in diesem Fall die koreanische - in einer Aufführung vor (wohl überwiegend unkundigem) deutschem Publikum plausibel und verständlich darstellen und aufrechterhalten oder gar bestätigen ${ }^{28}$

Möglicherweise wollte Freyer mit seinem Inszenierungkonzept das Moment des Unerforschten und Provokativen befeuern, sagt er doch selbst, dass P'ansori für ihn ist, „als würde ich einen ganz neuen Komponisten mit seiner Äußerung über unsere Zeit hören“. ${ }^{29}$ Die opulente Produktion von Mr. Rabbit and the Dragon King, das Bühnenbild und die Kostüme, welches Freyer als Maler selbst erschuf, und das Einstudieren des neuen Werkes mit gestandenen Sängern wäre ohne minimales Wissen um P'ansori und ch'angguk nicht möglich gewesen. Jedoch ist Freyer der Koreanischen Sprache nicht mächtig - ein großer Nachteil, will man die oftmals zweideutigen und subtilen Texte der Rezitationen und Lieder verstehen, welche im Koreanischen um einiges derber im Wortschatz sind und sich nicht vollständig übersetzen lassen. Im Hinblick darauf ist Freyers Aussage, er hätte sich vorab nicht mit P'ansori befasst, nicht als Verweigerung zu verstehen. Die Sprachbarriere ließ es nicht zu, sich tiefgründiger mit P'ansori auseinander zu setzen. Das mag der Grund dafür sein, dass Freyer zwar das Gerüst von Sugungga genommen hat, aber darüber seine eigene Geschichte, die von Mr. Rabbit and the Dragon King, aufgebaut hat.

Andrew Killick schreibt in seinem Buch In Search of Korean Traditional Opera: „When Western audiences watch Asian drama - especially with traditional music -

\footnotetext{
${ }^{25}$ Freyer, Programmheft Wuppertaler Bühnen, 8.

${ }^{26}$ Youn-Chol Lim, Programmheft Wuppertaler Bühnen, 4.

${ }^{27}$ Ebd..

${ }^{28}$ Siehe hierzu etwa Max Peter Baumann, Jonathan Stock, Daniel Avirgbedor (Hg.), Cross-Cultural Aesthetics (Berlin: VWB, 2003) (= the world of music 45/3), darin die Aufsätze von Lawrence Kramer, „Music, Cultural Mixture, and the Aesthetic“ (11-22); Judith Lynne Hanna, „Aesthetics - Whose Notions of Appropriateness and Competency, What Are They and What Do We Know?" (29-54); Chan E. Park, „Poetics and Politics of Korean Oral Tradition in a Cross-cultural Context“ (89-102).

${ }^{29}$ Freyer, Programmheft Wuppertaler Bühnen, 8.
} 
they expect it to be different from Western drama, and its difference is part of its appeal. “30 Wie verarbeitet Freyer das Original Sugungga in seiner Produktion und welche Bedeutung hat der Begriff „Original“? Das Programm des Nationalen Immatriellen Kulturerbes in Korea setzt voraus, dass die Kunst exakt übermittelt wird und die Techniken vom Schüler detailgetreu kopiert werden. Das Kulturerbe soll dadurch erhalten werden, es wird aber dadurch zugleich an der Weiterentwicklung gehindert. Die strengen Regeln der Weitergabe und der überaus starke Wunsch nach der Bewahrung des Kulturerbes entstammen in Teilen der jüngeren koreanischen Geschichte, nämlich aus der Zeit der Kolonialisierung durch Japan zwischen 1910 und 1946. Koreanische Traditionen, Sprache und Musik wurden zunächst reglementiert und später gänzlich verboten, auch scheinbar alltägliche, intime Dinge wie der persönliche Haarschnitt wurden von den japanischen Invasoren reguliert ${ }^{31}$. Dabei wurde insbesondere das traditionelle gemeinsame Musizieren, darunter auch P'ansori, als gesetzeswidrig geahndet, da diese Zusammenkünfte als ein Hort für mögliche Rebellen angesehen wurden. Das Beharren auf einer unversehrten Weitergabe der Kultur ist damit auch ein Festhalten an der verloren geglaubten und unterdrückten Identität und die Anerkennung des Wertes der Kultur - welche kurz vor der Auslöschung stand. Denn verschwindet die Tradition, verschwindet die kulturelle Identität des Landes.

Die Überlieferung des Originals im System des Nationalen Immatriellen Kulturerbes ist somit eng mit der Wahrnehmung der koreanischen Identität verknüpft. Jedoch wird eine innovative Weiterentwicklung von den selbstauferlegten Zwängen, die Kunst so unverfälscht wie möglich zu übertragen, in einen statischen Zustand versetzt. Innerhalb des traditionellen P'ansori ist ein Ausbrechen nicht möglich, weswegen die jüngere Generation von P'ansori-Sängern, wie beispielsweise Lee Jaram, unkonventionelle Wege geht, um ihrer Kreativität Ausdruck zu verleihen. ${ }^{32}$ Sie erschaffen neue Geschichten in der alten P'ansori-Tradition und lassen Grenzen zwischen Tradition und Moderne verschwimmen. Ist nicht jedes aufgeführte Werk ein Original? Das Original der Gegenwart? P'ansori vollzog im 18. Jahrhundert selbst einen Entwicklungsprozess von der niederen Unterhaltungsmusik zur geförderten und angesehenen Kunstform.

Das Einbeziehen von aktuellen gesellschaftlichen Ereignissen und augenzwinkernden Hinweisen auf die Fehlbarkeit der regierenden Adeligen als Improvisation in Gesang und Rezitation war im P'ansori seit Anbeginn ein wichtiger Faktor, und

\footnotetext{
${ }^{30}$ Andrew Killick, In Search of Korean Traditional Opera - Discourses of Ch'angguk (Honolulu: University of Hawai'i Press, 2010), 218.

${ }^{31}$ Interview mit YS, Hamburg, Deutschland, 29.11.2013.

32 „Watch ,TEDxSeoul - Jaram Lee - 11/28/09“ Video at TEDxTalks“, Tedxtalks.ted.com, http://tedxtalks.ted.com/video/TEDxSeoul-Jaram-Lee-112809;search\%3Atag\%3A\%22TEDxSeoul $\% 22,30.04 .2014$.
} 
die Veränderungen, die Sugungga seit den Jataka durchlaufen hat, zeigen, dass P'ansori keine starre Kunst gewesen sein kann. Freyer hat jedoch bei seiner Interpretation und dem musikalischen Arrangement laut eigener Aussage das Bestreben gehabt, ein bislang weder in Asien noch im Westen gesehenes Werk zu erschaffen ${ }^{33}$. Die Musikwissenschaftler Haekyung Um und Hyunjoo Lee beschrieben dies als eine Kombination aus koreanischem Musiktheater und avantgardistischem Theater à la Bertolt Brecht und hielten fest, dass künstlerische Traditionen bei Grenzüberschreitungen etwas völlig neues erschaffen können. ${ }^{34}$ In Mr. Rabbit and the Dragon King wird die Geschichte von Sugungga zweitranging. Zwar sind die Grundzüge - der erkrankte König und die Suche nach der Hasenleber - dieselben, aber ihre Gewichtung ist unterschiedlich. In Freyers Bühnenstück wurden Modifikationen vorgenommen, um einem modernen, internationalen Publikum zugänglich zu sein: Ein Publikum wie das in Wuppertal, das das Original Sugungga ebenso wenig kennt wie seinen Kontext - das konfuzianische Regierungssystem -, hätte die Signifikanz von Pyolchubu's sturer Loyalität (dodeokkjeok gyo-hun) entweder schlicht übersehen oder nicht (bzw. miss-) verstanden.

Neben der Loyalität der Wasserschildkröte Pyolchubu und der Belohnung ihrer Untertanentreue in Sugungga ist bedeutsam, dass der Hase die Arbeiterschicht (somin) verkörpert, während die Bewohner des unberührbaren Unterwasserpalastes ebenso wie Pyolchubu und der Drachenkönig Mitglieder der Elite sind (yangban). Die Tradition würde die Arbeiter an das Ende und den König an die Spitze setzen, doch Sugungga verdreht dies und platziert die Arbeiter an die Landoberfläche und die Adeligen unter Wasser. Der königliche Palast blieb dem gemeinen Bürger in der Realität durch zahlreiche Befestigungsmauern verborgen; so repräsentiert der Unterwasserpalast das Mysterium. Durch die Wasserbarriere wurden Elite und Arbeiter voneinander abgeschirmt, genau wie in der Wirklichkeit Etikette und Traditionen beide Ränge trennten.

Geschickt werden die Gier und das spätere Scheitern des Hasen bei dem Versuch, im Unterwasserpalast zu einem Minister ernannt zu werden, als Lehrwerk dazu benutzt, das normale Volk davor zu warnen, nach dem Unerreichbaren zu greifen. Es sei ein vorhersehbarer Misserfolg, seinen vorherbestimmten Platz in der Gesellschaft des neokonfuzianistischen Staatssystems verlassen zu wollen.

Freyer erzählt mit Mr. Rabbit and the Dragon King eine zeitgenössische Geschichte über Habgier, Umweltverschmutzung und Krieg - Allegorien auf aktuelle und globale Problematiken in der Politik und Ökonomie. Es ist keine zeitlose Thematik wie die Loyalität und Staatsphilosophie es sind, aber unbestritten komplex in

\footnotetext{
${ }^{33}$ Freyer, Programmheft Wuppertaler Bühnen, 9.

${ }^{34}$ Haekyung Um and Hyunjoo Lee, Rediscovering Traditional Korean Performing Arts, TheAPro (2012), 11, veröffentlichtes Journal des Koreanischen Ministeriums für Kultur, Sport und Tourismus.
} 
der Bildsprache. Es wäre aber wünschenswert gewesen, die Geschichte von Sugungga stärker einzubeziehen, denn der koreanische Titel lautet Mr. Rabbit and the Dragon King - Sugungga, obgleich in dem Werk die Kernbotschaft von Sugungga fehlt und die Neuinterpretation eine andere Richtung in der Aufführungsform (durch die Masken) und der Botschaft einschlägt. Die Musikerin und Musikwissenschaftlerin Chan E. Park schlägt vor:

It is not unreasonable to require its makers to 'know' P'ansori. Unless this basic requirement can be met, perhaps ch'angguk is best left in the hands of the performers who originally innovated it, rather than to modern authorship or directorship. ${ }^{35}$

Und damit kommen wir zu den korrekten Bezeichnungen von P'ansori and ch'angguk, welche zusätzlich zu deutschen Begriffen für Sugungga und Mr. Rabbit and the Dragon King verwendet wurden und welche Parks Aussage unterstreichen. Die Wuppertaler Bühnen stellten die Veranstaltung folgendermaßen vor: „Dies ist die Geschichte einer P'ansori, einer koreanischen Oper. [...] Es ist eine Art 'Erzähltheater' [...]. ${ }^{36}$ Das Fehlen von äquivalenten Begriffen und auch Unwissenheit werden hier leider deutlich, auch Freyer unterscheidet nicht zwischen P'ansori und ch'angguk. P'ansori, aufgeführt durch einen Sänger und einen Trommler, kann durch die Form von Rezitativ-Gesang weitestgehend als Epengesang beschrieben werden. Die Musik steht, im Gegensatz zu einem Erzähltheater, sehr viel stärker im Vordergrund, wie der koreanische Name für den Sänger (Sorikkun) zeigt: Sori steht für Lied. Beim Begriff P'ansori wird P'an als Platz umschrieben und mit Sori zusammengesetzt. Ch'angguk ist die inszenierte Form von P'ansori mit ausgeschriebenen und einzeln besetzten Figuren und einer größeren Instrumentalbegleitung. Es ist in der Tat eine opernähnliche Form, aber keinesfalls „Erzähltheater“, denn „guk“" mag Schauspiel heißen, ch'ang bedeutet jedoch Lied. 'Musiktheater' wäre also der passendere Begriff. Jedoch wäre es für die Musikwissenschaft wünschenswert, in der Zukunft auf eine westliche Klassifizierung für bereits bestehende Genres anderer Kulturen zu verzichten. Wegen der unterschiedlichen soziokulturellen Entwicklungsprozesse können westliche Aufführungsformen nicht direkt auf ihre asiatischen Pendants übertragen werden.

\footnotetext{
${ }^{35}$ Chan E. Park, Voices from the Straw Mat: Toward an Ethnography of Korean Story Singing (Honolulu: University of Hawai'i Press, 2003), $111 \mathrm{f}$.

${ }^{36}$ Wuppertaler Bühnen, http://www.wuppertaler-buehnen.de/index.php?id=1461, 29.04.2014.
} 


\section{Schluss}

Freyer gab an: „P'ansori talks about our life, dreams, anxieties, fears and beauty. Those are things that all artists talk about, or should talk about. P'ansori has strict

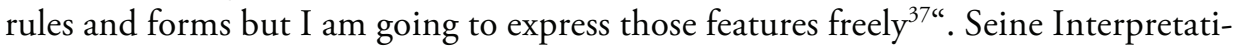
on von Sugungga in Mr. Rabbit and the Dragon King, die die koreanische Vorlage aus einem neuen Blickwinkel betrachtet, kann meiner Ansicht nach als Musiktheater mit koreanischen Einflüssen bezeichnet werden. Es ist kein P'ansori und letzlich auch kein ch'angguk. Die Quelle der Inspiration entstammt zwar dem koreanischen Sugungga. Mr. Rabbit and the Dragon King hat aber bis auf einige Äußerlichkeiten wie den Charakteren - keinen Bezug zur koreanischen Geschichte und setzt den Fokus auf eigene Schwerpunkte. Auch die Musik wurde neu in Auftrag gegeben, zwar auf koreanischen Instrumenten gespielt, aber „eine nie gehörte Musik, das ist weder die alte koreanische Musik, noch ist sie modernisiert “38. Es ist also etwas völlig neu erschaffenes, ein 'eigenes' Original, welches sich von der ursprünglichen Quelle emanzipiert hat.

Während meiner Feldforschung führte ich in Korea Interviews mit Musikern ${ }^{39}$, die ihre Sorge über die korrekte Weitergabe von P'ansori und ch'angguk zum Ausdruck brachten. Ein weiterer Punkt war der Rückgang der alten koreanischen Sprache, das Benutzen von Anglizismen und das resultierende Vergessen von traditionellen Redewendungen. Die bereits im Abschnitt ,Interpretation' zur Sprache gebrachte Verknüpfung zwischen der Kultur und Historie Koreas ist einer der Gründe, warum Mr. Rabbit and the Dragon King kontrovers aufgenommen werden kann - da es mit Sugungga in seiner Aussage fast nichts mehr gemein hat. Betrachtet man Freyers Werk aber als einen Sprössling vom koreanischen ch'angguk, als besagtes Musiktheater mit koreanischen Einflüssen, ist es dem Nationaltheater Koreas gelungen, eine für die deutsche Zuhörerschaft eingängige Inszenierung zu produzieren, denn das Ergründen von Habsucht und Arroganz, Umweltverschmutzung und Krieg sind universale Themen. Durch das eigenwillige Bühnenbild und die Kostüme und die neu komponierte Musik schaffte Freyer zudem eine Distanzierung zu traditionellen koreanischen Vorstellungen und bot dem deutschen Publikum ein von Erwartungen und Klischees befreites Erlebnis. Es wäre interessant, nachzuverfolgen, ob die Produktion von $M r$. Rabbit and the Dragon King ein Anfang ist für weitere Inszenierun-

\footnotetext{
37 Park Min-young, „Venue to bring 'pansori' to the world“, Korean Herald, 29. März 2011, http://www.koreaherald.com/entertainment/Detail.jsp?newsMLId=20110329000665. 29.03.2012.

${ }^{38}$ Freyer, Programmheft Wuppertaler Bühnen, 9.

${ }^{39}$ Interview mit Kim Sumi an der Seoul National University (11.04.2011), Interview mit Meister Song Sun-Seop während des Aufenthaltes an der Academy of Korean Studies in Seoul (22.07.2012) und mit Meister Song Sun-Seop während des DAAD-NRF Stipendiums in Seoul (15.07.2013).
} 
gen dieser Art und wie stark sich die Wirkung dieses kulturellen Experimentes innerhalb von Korea und auch dem Ausland entfaltet.

\section{Literatur}

Baumann, Max Peter, Jonathan Stock, Daniel Avirgbedor (Hg.). Cross-Cultural Aesthetics. Berlin: VWB, 2003 (= the world of music 45/3).

Gongnam Korea. „Korean pansori opera makes waves in Germany“. Ins Englische übersetzt von Kwon Jungyun. Aufgerufen am 28. April 2014. http://www. korea.net/NewsFocus/Culture/view?articleId=90736.

Grayson, James Huntley. „Rabbit Visits the Dragon Palace: A Korea-Adapted, Buddhist Tale from India“, Fabula 45 (2004): 1-2.

Herbort, Heinz Josef. „Das Märchen - ein Traum““. Die Zeit 22/1982, 1f. Aufgerufen am 28. April 2014. http://www.zeit.de/1982/22/das-maerchen-eintraum.

Jang, Yeonok. Korean P'ansori Singing Tradition: Development, Authenticity, and Performance History. Lanham: Scarecrow Press, 2014.

Killick, Andrew. In Search of Korean Traditional Opera: Discourses of Ch'angguk. Honolulu: University of Hawai’i Press, 2010.

- „P'ansori“. In Encyclopedia of Asian Theatre, Bd. 2, hg. von Samuel L. Leiter, 495f. Westport: Greenwood Press 2007.

- Traditional Music and the Contemporary Composer in the Republic of Korea. Farnham: Ashgate, 2013.

Min-young, Park. „Venue to bring 'pansori' to the world“. Aufgerufen am 29. März 2011. http://www.koreaherald.com/entertainment/Detail.jsp?newsMLI $\mathrm{d}=20110329000665$.

Park, Chan E. Voices from the Straw Mat: toward an ethnography of Korean story singing. Honolulu: University of Hawai'i Press, 2003.

Pihl, Marshall R. The Korean Singer of Tales. Cambridge: Harvard University Press, 1994.

Song, Bang-Song. Source Readings In Korean Music. Seoul: K.N.C. for UNESCO, 1980.

— Persönliches Interview. Academy Of Korean Studies. 22.07.2012.

— Persönliches Interview. Seoul. 15.07.2013. 
Suh, Dorothea. 'Key Papers on Korea: Essays Celebrating 25 Years of the Centre of Korean Studies'. In SOAS, University of London, hg. von Andrew David Jackson, 227-41. Leiden: Brill, Global Oriental, 2014.

Sumi, Kim. Persönliches Interview. Seoul National University. 11.04.2011.

TEDxTalks. „Watch ,TEDxSeoul - Jaram Lee - 11/28/09“ Video at TEDxTalks“. Aufgerufen am 30. April 2014. http://tedxtalks.ted.com/video/ TEDxSeoulJaram-Lee-112809;search\%3Atag\%3A\%22TEDxSeoul\%22.

Um, Haekyung und Hyunjoo Lee. Rediscovering Traditional Korean Performing Arts, Seoul: TheAPro für das Ministerium für Kultur, Sport ud Tourismus von Korea, 2012.

Wuppertaler Bühnen. „Mr. Rabbit and the Dragon King“. Aufgerufen am 28. September 2013. http://www.wuppertaler-buehnen.de/index.php?id=1461.

Wuppertaler Bühnen. Programmheft „Mr. Rabbit And The Dragon King“. Wuppertal: Ley \& Wiegandt, 2011.

YS. Persönliches Interview. Hamburg. 20.11.2013. 



\title{
Unity in Diversity, Antiquity in Contemporary Practice? South Indian Music Reconsidered ${ }^{1}$
}

\author{
Ludwig Pesch (Amsterdam)
}

"It is not the distinctive quality of man to be a mere repetition of his ancestors. Animals cling to the nests of their effete habits; man expresses himself age after age in new creations."

- Rabindranath Tagore, Tagore on Gandhi ${ }^{2}$

When Rabindranath Tagore (1861-1941) appealed to his contemporaries to abandon their 'effete habits' in 1931, he pursued innovation in the face of opposition from traditionalists and patriotic scholars, teachers and politicians. They revelled in their newly found pride in 'ancient traditions', while he embraced creativity as the way forward. Yet Tagore knew that innovation was prized among intellectuals and exponents of the arts and crafts even if rarely acknowledged by their patrons. $\mathrm{He}$ sought to reconcile two seemingly contradictory attitudes still prevalent all over In-

\footnotetext{
${ }^{1}$ The title of this essay refers to 'unity' of different traditions as understood by Indian practitioners and musicologists such as T. S. Parthasarathy in 'The Unity of Indian Music', The Journal of the Music Academy Madras: Golden Jubilee Special Number 1977 (1980): 192ff; published online as 'The Unifying Role of Indian Music', accessed 29 April 2014. http://carnatica.net/special/tsp-unify1.htm.

${ }^{2}$ Rabindranath Tagore, Tagore on Gandhi (New Delhi: Penguin, 2008), 31.
} 
dia: one devoted to India's 'golden past' and the conservative 'values' it stands for, the other hailing the country's cultural 'diversity'. ${ }^{3}$ As music has often been instrumentalized as an effective antidote to India's centrifugal forces since the twentieth century, the present essay explores how musicians and listeners treat their musical legacy in the modern world. This extends to 'the places of music in the South Asian diaspora' that, according to Philip Bohlman, 'form a landscape that encourages rather than stems change'. ${ }^{4}$ In view of some striking parallels between the performance practice of early European music and South Indian ('Carnatic') art music today, the question arises whether these merely reflect general attitudes and trends or point to a common ground as envisaged by Tagore. Without seeking a definite answer to a question as complex as this, taking it seriously may provide the key to an appreciation of contemporary music practice in and beyond India.

In the speech from which the above quote is taken, the 70-year-old Tagore addressed staff and students of the institutions he had established at Santiniketan ${ }^{5}$ with the words: 'Today all of us who live in the asram [sic] will joyfully celebrate Mahatma Gandhi's birthday.' Although sceptical about nationalism, he praised Gandhi for shaking the 'deepest foundation of their other-rule' as a result of 'fearless selfexpression' and asserted that '[in] the world of changing needs, the stream of continuous change flows on. ${ }^{6}$ Tagore harnessed the power of music to bind people together for a common cause. His own lyrics 'Jana Gana Mana' ('Thou art the ruler of the minds of all people" set to music in collaboration with the Irish educationist Margaret Cousins in 1919) came to be adopted posthumously as India's national anthem in

\footnotetext{
${ }^{3}$ Music held a privileged position in his life and his poetry influenced many of his European peers; for a detailed account, see Rokus de Groot, 'Rabindranath Tagore and Frederik van Eeden: Reception of a "Poet-King" in the Netherlands', in Hindustani Music: Thirteenth to Twentieth Centuries, ed. Joeb Bor, et al., (New Delhi: Codarts \& Manohar, 2010), $521 \mathrm{ff}$.

${ }^{4}$ Philip V. Bohlman, World Music: A Very Short Introduction (New York: Oxford University Press 2002), 124.

${ }^{5}$ Santiniketan (lit. shanti 'peace', niketan 'abode') was the name his father Debendranath had given to a rural estate he used as a meditation retreat. An experimental school of the same name was founded by Rabindranath in 1901, and the Viswa Bharati University with its pioneering music department (Sangeet Bhavan) in 1921. Reba Som, Rabindranath Tagore: The Singer and His Song (New Delhi: Penguin, 2009), 7. Since then, an entire town, Santiniketan (also spelt 'Shantiniketan') has grown around this university.

${ }^{6}$ Tagore, Tagore on Gandhi, 30.

${ }^{7}$ For lyrics, translation and a recording, refer to the Government of India on its 'Know India' website, accessed 29 April 2014, http://india.gov.in/india-glance/national-symbols.
} 
$1950 .{ }^{8}$ Given its scope for multiple interpretations, it lends itself well to the current topic, namely the 'unity in diversity' commonly invoked in India.

Bengali historian and musician Reba Som, herself an exponent of Tagore's music known as Rabindrasangeet, ${ }^{9}$ describes his musical encounters since the late nineteenth century and how he was attracted by the distinctive styles of regional music. Some of these he adopted for his own songs. ${ }^{10} \mathrm{His}$ interest in South Indian music was deepened during his visits to Madras in 1919 where he heard young Savitri sing Carnatic songs by Tyagaraja (1767-1847), the composer most revered today. These influences manifest themselves in songs like 'Basanti he Bhubanomohini' (1931) with Bengali lyrics in praise of spring and new life. It is grafted onto the famous kriti by Muttusvami Dikshitar (1775-1835) whose Sanskrit lyrics beginning with 'Minakshi me mudam' praise the 'vina lute playing' goddess Minaksi at Madurai whereby the tune and lyrics convey the tenfold gamaka ornamentation of Carnatic music. ${ }^{11}$

South Indian music made a great impression on Tagore in spite of his wellknown aversion to conventional music training. At a time when the practice of music was held in low esteem, he boldly introduced an integrated syllabus at two of the institutions founded by him, a rural school Santiniketan (1901) and Visva-Bharati $(1921)^{12}$. His 'world university for India' (visva bharati) emerged from a quest for a 'synthesis of the East and the West' through intellectual and cultural interaction as signatory of the 'Declaration for the Independence of the Spirit' in 1919 along with Romain Rolland and Einstein. ${ }^{13}$ Tagore accepted the premise of 'multiple origins'

\footnotetext{
${ }^{8}$ Sachidananda Mohanty, 'An 'Indo-Anglian' legacy', The Hindu, Online Edition, accessed 21 July 2013. http://www.thehindu.com/todays-paper/tp-features/tp-sundaymagazine/an-indoanglian-legacy /article4936207.ece.

${ }^{9}$ Som, Rabindranath Tagore: The Singer and His Song, xiii.

${ }^{10}$ Ibid., 146.

${ }^{11} \mathrm{~T}$. Viswanathan and Matthew Allen emphasize 'the integral role of ornamentation (gamaka, literally, graces or gracefulness) as a part of svara. The ornament in Karnatak music is not considered an addon to the basic note; gamaka is an integral structural part of svara.' Viswanathan and Allen, Music in South India: The Karnatak Concert Tradition and Beyond, 47.

${ }^{12}$ Before Visva-Bharati was declared to be a central university and an institution of national importance in 1951, Rabindranath Tagore had envisaged a less formal environment to realize his ambition: 'Visva-Bharati represents India where she has her wealth of mind which is for all. Visva-Bharati acknowledges India's obligation to offer to others the hospitality of her best culture and India's right to accept from others their best'. Visva-Bharati Homepage, accessed 4 May 2014, http://www.vis vabharati.ac.in/index.html.

${ }^{13}$ Som, Rabindranath Tagore: The Singer and His Song, 127.
} 
and reminded his fellow citizens that Indian culture cannot thrive in the absence of external contributions, today as in the remote past. ${ }^{14}$

Among the institutions he established in and around Santiniketan (since then a small town in its own right), there are the art school (Kala Bhavana), music school (Sangeet Bhavana), a centre for rural development (Sriniketan) and, as part of VisvaBharati, several university departments for the study of Asian languages (e.g. Cheena Bhavana). They soon attracted Indian and foreign scholars and artists to research and teach side by side. This policy endowed Visva-Bharati University with an enviable international reputation. ${ }^{15}$

Like Tyagaraja, the South Indian composer whose music he knew so well from early youth, he continued to create 'new' music while subjecting 'ancient' practices to innovation and reflection. David Reck describes the atmosphere of modern India as follows:

A growing and prosperous middle-class exhibits world-class competence and brilliance, particularly in the sciences, technology, and business - and in the arts. In the palimpsest that is South Asia, we find a constant interplay between the ancient and the modern. The old, the traditional, seems able to persist through all the changes of time and history. ${ }^{16}$

Where 'ancient' authorities are invoked by modern authors, it is useful to briefly consider a conventional distinction often raised, namely that between marga and desi: according to Lewis Rowell, 'if marga is compared to the Latin of Augustine and Aquinas, the desi movement corresponds to the Italian of Dante'; with the result that performers have to deal with textual information recorded by scholars who were neither practical musicians 'nor interested in attempting to recover details of musical practice other than those set down in the treatises'. ${ }^{17}$

Writing on 'The Unity of Indian Music', musicologist T. S. Parthasarathy $(1913-2006)^{18}$ suggests that mobility itself should be seen as a hallmark of Indian civilization, and this not only merely in the literal sense: 'Tamil musicologists of

\footnotetext{
14 'But a river, belonging to a country is not fed by its own waters alone. [...] Contributions have similarly found their way to India's original culture'. Ranajit Ray (publ.), Visva-Bharati and its Institutions (Santiniketan: Visva-Bharati, 1961), 32.

15 Tagore's novel ideas on the role of the arts in education guided the founders of several institutions including Kalakshetra (my own alma mater in Chennai) of which he remained Honorary Vice President for life.

${ }^{16}$ David Reck, Introduction to the Music of the World's Peoples (Belmont: Schirmer, 2002), 249.

${ }^{17}$ Lewis Rowell, Music and Musical Thought in Early India (New Delhi: Munshiram Manoharlal, 1998), 12.

${ }^{18}$ South Indian names are used here as they appear in the publications cited and/or preferred by the musician concerned.
} 
those days [i.e. the early first millennium AD] were fully conversant with Sanskrit works on music and dance written by authors who obviously lived in the Northern part of India. ${ }^{19}$ Some of the works referred to are no longer extant but mentioned by later authorities. He goes on to cast doubt on the widespread notion of a clear-cut distinction between the northern Hindustani and southern branches of Indian 'classical' music (variously anglicized as Carnatic, Karnatak or Karnataka music). ${ }^{20}$ The familiar Hindustani-Carnatic dichotomy now seems out of tune because neither regional nor linguistic differences stand in the way of mutual appreciation or collaboration. It may be compared with the changing dress code adopted by musicians and dancers on television. Mumbai-based flautist Ronu Majumdar considers the benefits and risks involved:

Hindustani, Carnatic, fusion, folk, jazz, blues, pop ... we need to bring down the walls and make music enjoyable for people. Unless you get them to listen, how can they understand the genres and their specialties? [...] An individual's experiments cannot tarnish the tradition built over centuries. ${ }^{21}$

Subrahmanya Ayyar (1885-1960), an accomplished violinist interested in subtleties such as intonation and acoustics, and a contributor to the Journal of the Music Academy Madras since the early 1930s, characterizes the misconceptions of his times as follows: 'In recent years, Karnatic music has come in for a lot of criticism by Hindustani musicians: (1) it is highly intellectual in character. (2) it is highly mechanical. (3) as a matter of mathematical computation, it tries to achieve the aesthetically impossible task of obtaining a large number of ragas. (4) it does not base its raga system on the vadi and samvadi arrangement, as understood in Hindustani music'. ${ }^{22}$

Reminiscences by Ravi Shankar (1920-2012) and others indicate that the above mentioned issues are being read quite differently today: firstly, inviting intellectual challenges is regarded as a proof of competence (again); secondly technical feats are

\footnotetext{
${ }^{19}$ T.S. Parthasarathy, 'The Unity of Indian Music', The Journal of the Music Academy Madras Golden Jubilee Special Number (1977): 192ff.

${ }^{20}$ Diacritics have been dispensed with here; a detailed 'Guide to Pronunciation and Transliteration' is found in Ludwig Pesch, The Oxford Illustrated Companion to South Indian Classical Music (New Delhi: Oxford University Press, 2009), xxif.

${ }^{21}$ Ronu Majumdar, 'Melody through the reed', The Hindu, Friday Review, Chennai 8 February 2008, accessed 4 May 2014, http://hindu.com/thehindu/fr/2008/02/08/stories/2008020850520200 .htm.

${ }^{22}$ For details on the enduring influence of Subrahmanya Ayyar's scientific experiments and publications, see Ch. 1 'Gone Native? Travels of the Violin in South India', in Amanda J. Weidman, Singing the Classical, Voicing the Modern: The Postcolonial Politics of Music in South India (Durham: Duke University Press, 2006), 122.
} 
valued by peers and audiences alike; ${ }^{23}$ thirdly 'mathematical computation' (applying four basic arithmetic operations in a performance) have since become a common feature in concerts all over India, be it in the customary context of a Carnatic drum solo or, more recently, in melodic extemporisation $;^{24}$ and fourthly, raga conventions such as Bhatkhande's vadi and samvadi arrangement, like the 'time theory' (gana kala), may be overruled by an experienced musician in accordance with practical needs and aesthetic sensibilities. ${ }^{25}$

The wide appeal of numbers in Indian music, just as the educational value ascribed to it, is rooted in a long history of 'playing' with numbers. Mathematician C. Lanczos traces our common decimal arithmetic to India and describes it as 'the most important discovery of all ages' (made around A.D. 600) on account of the 'flexibility and simplicity of the Hindu system'. ${ }^{26}$ The promise of freedom and creativity perceived by Indian 'classical' musicians in general, ${ }^{27}$ and particularly so by Carnatic musicians, is indeed rooted in a systematic approach comparable to that hailed by Lanczos. ${ }^{28}$ For centuries, aspiring drummers become conversant with these operations already at an early stage and continue to hone their reckoning skills during each

\footnotetext{
${ }^{23}$ Some of the number-based rhythmic figures 'played' by drummers are explained in Pesch, The $O x$ ford Illustrated Companion to South Indian Classical Music, 222ff; and 'Cosmic Order, Cosmic Play: An Indian Approach to Rhythmic Diversity', in Rhythm, a Dance in Time, ed. Elisabeth den Otter (Amsterdam: KIT Publishers, 2001), 83ff.

${ }^{24}$ Ravi Shankar claims to have been the first Hindustani musician to realize the possibilities of such computations when he adapted complex metric and cadential patterns (tihai) for the sitar: 'The Carnatic system's mathematical approach to rhythm and accurate application of them are also stunning. [...] As far back as 1945, I was absorbing the essence of these from the fixed calculative systems of the Carnatic system [...]'. Ravi Shankar and George Harrison (ed.), Raga Mala: The Autobiography of Ravi Shankar (New York: Welcome Rain Publishers, 1999), 294.

${ }^{25}$ In view of the difficulties posed by playing some of these ragas 'in the true Carnatic style', Ravi Shankar introduced Hindustani versions of his own; he refers to them as 'my own interpretations and embellishments [...] played by most performers nowadays'. Shankar and Harrison (ed.), Raga Mala: The Autobiography of Ravi Shankar, 294.

${ }^{26}$ C. Lanczos, Numbers Without End (Edinburgh: Oliver and Boyd, 1968), 15.

${ }^{27}$ South Indian music may be designated as 'classical' in the most general sense of the word, i.e. as 'not being popular' and 'having stood the test of time'. The distinguishing features between Indian 'art music' and other categories are discussed by Ashok Ranade in 'On Art Music', Sruti Magazine issue 336, September 2012, 33ff.

${ }^{28}$ C. Lanczos, Numbers Without End, 34; more details are found in Chapter 29 'The Origin of HinduArabic Numerals' in Georges Ifrah, From One to Zero: A Universal History of Numbers (Penguin Books, 1987), 428ff.
} 
lesson. ${ }^{29}$ Even as concert performers, they literally 'perform' all the four fundamental operations of arithmetic, 'viz. addition, subtraction, multiplication, and division' on a regular basis. Their time-proven method is based on jati syllables and serves to yield an infinite variety of number-based motifs: e.g. the 'primordial' Ta Ti Tom Nam $=4$, variants like $\mathrm{Ta} \mathrm{Ki} \mathrm{Ta}=3$, and $\mathrm{Ta} \mathrm{Di} \mathrm{Ki} \mathrm{Na}$ Tom $=5$ are then modified, for instance by precisely measured subdivisions, doubling of speed and pauses. Musicians create compositions and improvisations of great complexity by combining motifs in a logical yet (ideally) unpredictable manner. For this neither a written score nor a drum is required because spontaneity is much preferred over preconceived arrangements. Formulaic patterns within any given rhythmic cycle (tala) are typically rearranged during a drum solo interlude or special percussion recital. Cadential patterns of musical notes or drum beats are among the strategies constantly being refined by Carnatic musicians in order to demonstrate their knowledge, skill and aesthetic sense. It enables them to collaborate (and compete) with one another even without prior rehearsals. ${ }^{30}$

The intricacies of the tala system exceed the scope of this paper as musicians are free to choose from hundreds of different talas. However, two categories should be mentioned here in brief: firstly, the ancient schemes of interest to intellectual composers such as Olivier Messiaen (1908-1992); ${ }^{31}$ and secondly, the multi-layered, performance-oriented rhythmic patterns (laya) adopted by Minimal Music and percussionists drawn to the spheres of 'world', fusion and jazz music; they value the scope for competitive displays, rapid coordination and surprising conclusions of a Carnatic drum solo (tani avartanam). According to David Reck, the South Indian percussionist 'does not merely "play off the top of his head"' but is 'calculating constantly, like a master mathematician $[\ldots]$ he may compose variations, superimpose startling juxtapositions, flow from simple and easy timekeeping to mind-boggling complicated

\footnotetext{
${ }^{29}$ The formulaic patterns in South Indian drumming and their derivation from calculation are explained in an Introduction and in English summaries for each of the 77 verses that constitute Mattalaviyal (translated as 'the art of drumming'), a Tamil manuscript traced to the tenth century; it lists 108 talas (metric cycles), a highly symbolic number (i.e. regarded as auspicious in view of its scope for arithmetic variation). V. Murugan (trans.), The Art of Drumming: Mattalaviyal (Madras: Institute of Asian Studies, 1988).

${ }^{30}$ For an insider account of the analytical challenges posed by the 'wizardry' of Carnatic drummers, the underlying 'time-flow' patterns, and a critique on ethno-musicological writing devoid of 'a performer's functional understanding', see David Nelson, 'Form and Process in the Tani Avartanam: A Non-Indian Insider's Perspective', Journal of the Music Academy Madras, 82 (2011): 118ff.

${ }^{31}$ See the reference to Messiaen's 'Quatuor pour la fin du Temps' and 'Turangalila Symphony' given by Mirjana Simundza, 'Messiaen's Rhythmical Organisation and Classical Indian Theory of Rhythm (I)', International Review of the Aesthetics and Sociology of Music, 18/1 (1987): 117-44, http://www. jstor.org/stable/836909.
} 
patterns, stop for meaningful pauses, and start again'. ${ }^{32}$ Hindustani percussionists have emulated this approach for their solo drumming ever since jugalbandi instrumental ensembles became popular in the 1980s.

Carnatic musicians also use number-based strategies for the purpose of organizing scale patterns, thereby enlarging melodic diversity in a deliberate manner. The most intriguing one concerns the classification and retrieval of ragas by means of a seventeenth-century innovation. ${ }^{33}$ Its author Venkatamakhi postulates 72 'scale types' ${ }^{34}$ Its scope was intended to be so universal as to accommodate any conceivable scale based on twelve (approximate) semitones distributed within an octave. Each of these may be associated with numerous 'parental' and 'derived' ragas. Its lasting usefulness for musicians was achieved by means of an equally ingenious alpha-numerical scheme in the eighteenth century. For any given raga, this mnemonic aid visualizes the distribution of the 'seven notes' (sapta svara) among twelve semitones. ${ }^{35}$ Sixteen positions are available in a scheme that recognizes four enharmonic variants. ${ }^{36}$ Although the melakarta 'scale type scheme' was pioneered by South Indian theorists centuries ago, it also began to appeal to those among their northern peers who were keen on expanding their repertoires; ${ }^{37}$ performers who - in Ravi Shankar's words -

${ }^{32}$ Reck, Introduction to the Music of the World's Peoples, 265ff. His beautifully worded description is a welcome reminder to express my indebtedness to one such master mathematician-cum-drummer: without the insights provided by T. R. Sundaresan over several years of study and collaboration, it would be quite unthinkable for me to write on this subject with any confidence; for details, see Ludwig Pesch, 'Cosmic Order, Cosmic Play: An Indian Approach to Rhythmic Diversity', 83ff and Pesch, The Oxford Illustrated Companion to South Indian Classical Music, $204 \mathrm{ff}$.

${ }^{33} \mathrm{~S}$. Seetha emphasizes the novelty, all-inclusiveness and practical use of the invention introduced by Venkatamakhi around 1660; for details, see S. Seetha, Tanjore as a Seat of Music (Madras: University of Madras, 1989), 434.

${ }^{34}$ Harold Powers defines it as an 'arbitrarily systematic and symmetrical scheme of $2 \mathrm{x}(6 \times 6)=72$ melakartas (scale types, literally [pitch class] collection producers)'. Harold Powers, 'Sargam Notations and Rag-Ragini Theory', in Hindustani Music: Thirteenth to Twentieth Centuries, ed. Joeb Bor, et al (New Delhi: Codarts \& Manohar, 2010), 591.

35 This significant improvement is ascribed to one Govindacari; for details, see Table 11 (Katapayadi sutra) and further explanations in Pesch, The Oxford Illustrated Companion to South Indian Classical Music, $176 \mathrm{ff}$.

${ }^{36}$ The melakarta scheme is based on the assumption that neither the tonic nor the fifth will be subjected to any change; here the application of 'enharmonic notes' differs from that of a western composer introducing foreign notes to a given (minor or major) key as to contradict the actual note names by the new intervals formed in the modulation; see 'Modulation', in The Oxford Companion to Music, ed. Alison Latham (New York: Oxford University Press, 2002), $789 \mathrm{ff}$.

${ }^{37}$ Its relevance for Hindustani music theory through the pioneering efforts of Vishnu Narayan Bhathkande (1860-1936) is discussed by Dard Neuman, 'Pedagogy, Practice and Embodied Creativi- 
'think it is more reasonable and scientific to follow the old melakarta system of the South, because it can sustain almost any raga, no matter how unusual its ascending and descending structures ${ }^{38}$ Conversely, Carnatic musicians have adopted many popular northern ragas on account of their emotional appeal.

In his biography Unfinished Journey, Yehudi Menuhin (1916-1999) hails the fact that 'Indian musicians are sensitive to the smallest microtonal deviations, subdivisions of tones which the violin can find but which are outside the crude simplifications of the piano (or harmonium) ${ }^{39}$ His interest in Indian violin music motivated Menuhin to invite Lalgudi Jayaraman (1930-2013) to tour the UK and participate in the 1965 Edinburgh music festival. ${ }^{40}$ As if to return (or rather anticipate) this compliment, P. Sambamoorthy hails the emergence of the violin some two centuries ago, both on account of its 'utility as a first class accompaniment', and for its rich tone. ${ }^{41}$

In India, musical ideas were never the exclusive domain of specialists but also discussed by learned amateurs (rasikas). ${ }^{42} \mathrm{As}$ in the distant past, when royal patrons and statesmen were involved in the performing arts on a regular basis, intellectuals of the twentieth century took an active interest in music. Subrahmanya C. Ayyar (18851960) stands out for writing his Grammar of South Indian (Karnatic) Music as 'Accountant-General and Member of the Board of Studies, Indian Music, University of Madras'. ${ }^{43} \mathrm{He}$ and his contemporaries (notably musicologist-educationist Sambamoorthy) studied all the available sources (e.g. Helmholtz's 'Sensations of Tones') and compared Western acoustic research with their own findings. This gave rise to doubts whether 'the human voice in current melodies ever directly reaches the notes of these complex fractions like 256/243. ${ }^{34}$

ty in Hindustani Music', Ethnomusicology 56/3 (2012): 427ff; and also by Joep Bor and Allyn Miner, 'The Early-Twentieth Century', in Hindustani Music: Thirteenth to Twentieth Centuries, ed. Joeb Bor, et al (New Delhi: Codarts \& Manohar, 2010), 207ff.

${ }^{38}$ Ravi Shankar, My Music, My Life (New Delhi: Vikas Publishing House, 1992), 21.

${ }^{39}$ Yehudi Menuhin, Unfinished Journey (London: Futura Publications, 1978), 341.

${ }^{40}$ Gowri Ramnarayan, 'The Lalgudi Legacy', Sruti Magazine, Issue 314, November 2010, 47.

${ }^{41}$ P. Sambamoorthy, History of Indian Music (2nd ed. Madras: The Indian Music Publishing House, 1982), 247.

${ }^{42}$ With reference to the Natyasastra, the earliest treatise on Indian performing arts (c. 200 B.C.-A.D. 200), Ashok Ranade discusses the 'high status enjoyed by the audience' then and now. Ashok D. Ranade, 'Transmission in Nonclassical Traditions', in The Garland Encyclopedia of World Music, vol. 5 (New York: Garland Publishing, 1999), 470.

${ }^{43}$ Designations printed on the title page. Subrahmanya C. Ayyar, The Grammar of South Indian (Karnatic) Music (Chennai: Vidya Shankar, 1976).

${ }^{44}$ Ibid., 33. 
The spirit of his age is brought out by Suvarnalata Rao (1954-) and Wim van der Meer (1949-). Under the heading 'Deconstruction of Shruti', they give an account of the oscillographic recordings made by violinist Subrahmanya C. Ayyar in London. Unlike Sambamoorthy, he called for more, not less differentiation, something the convention of dividing an octave into 22 'pitch positions' (shrutis) would not provide for. ${ }^{45}$ Yet belonging to a family that produced two Nobel Awardees in physics his own son, Subramaniam Chandrasekar, and his brother Chandrasekhara Venkata Raman (equally known for their interest in music) - Subrahmanya Ayyar did not hesitate to debunk any exaggerated claim as 'effusion of pseudo-scientific research'; for instance the theories of Abraham Pandithar (1859-1919) who had advocated a system of 48 intervals to the octave in his voluminous work Karunamruthasagaram (published in 1946). ${ }^{46}$

In 'Science and Music vis-a-vis Science in Music', Hema Ramanathan and N. Ramanathan go one step further by voicing their conviction that 'music is totally an art, that has no association with science in its practice' ${ }^{47}$ As for the distribution of the 22 sruti among the seven notes (saptasvara), commonly ascribed to early and medieval authorities, they assert that 'there was no "scientific treatment" of the subject in the modern sense of the term'.

South Indian composers who lived before the late nineteenth century used manuscripts in a manner reminiscent of Europe's Minnesang period as described by James McMahon. This entails that exponents of both 'traditions', irrespective of differences such as geographic location, musical forms or themes underlying their lyrics, now share the same dilemma, namely that 'all the melodies we have today for these songs were handed down in an oral tradition and not written until much later. And when they were finally written down, the manuscripts were not intended to be used by performers' ${ }^{48}$ If notation can be used as a means of constraining the artistic freedom of musicians, it has tested its limits in the West more than in India. For Albert Seay, the reasons for this are obvious: in the absence of 'a multitude of individual lines sounding at the same time', other civilizations rely upon the 'improvisatory skills of the performer to produce this variety, not the guiding hand of the inventor ${ }^{2}{ }^{49}$ A simple scheme is supposed to guide performers in their individual elabora-

\footnotetext{
${ }^{45}$ Suvarnalata Rao and Wim van der Meer, 'The Construction, Reconstruction and Deconstruction of Shruti', Hindustani Music: Thirteenth to Twentieth Centuries, ed. Joeb Bor et al (New Delhi: Codarts \& Manohar, 2010), 687.

${ }^{46}$ Ayyar, The Grammar of South Indian (Karnatic) Music, 170.

${ }^{47}$ Hema Ramanathan and N. Ramanathan 'Science and Music vis-a-vis Science in Music', accessed 31 March 2008. http://www.musicresearch.in.

${ }^{48}$ James V. McMahon, The Music of Early Minnesang (Columbia, South Carolina: Camden House, 1990), 12.

${ }^{49}$ Albert Seay, Music in the Medieval World (Englewood Cliffs: Prentice-Hall, 1965), $76 \mathrm{ff}$.
} 
tions without pre-existing complications, thereby even preventing (rather than encouraging) 'the repetition of the same work in the same form and shape as in the original creation'. ${ }^{50}$

Yet the performance of South Indian music has always entailed some 'preexisting complications', namely in the form of distinct forms or genres that include elaborate compositions (e.g. études, art and dance music with lyrics); and also in the form of strategies for specific types of extemporisation (e.g. the elaborate 'ragamtanam-pallavi suite'). The use of non-lexical syllables (solfège) for both the transmission and performance of melody can be traced back to the first millennium A.D. ${ }^{51} \mathrm{At}$ the same time, Seay's characterisation calls for some qualification in view of the capacity of Carnatic musicians to faithfully reproduce every detail of their repertoire if they wish. This accomplishment is routinely demonstrated during unisono renditions of elaborate compositions by any vocal or instrumental ensemble (e.g. the ' $\mathrm{Hy}$ derabad Brothers', the violin duo of 'Lalgudi' G.J.R. Krishnan and his sister J. Vijayalakshmi, and the flute duo known as 'Sikkil Sisters'). Many South Indian performers of 'art music' may have turned to studio and stage technology as a matter of choice rather than compulsion - yet there is no sign of 'the ever-increasing domination of the creator over the reproducer' deplored by Albert Seay; nor of anyone assuming 'absolute control of the interpretation and performance of his musical creations, without intervening interpreters' ${ }^{52}$ While this may be a welcome option for contemporary composers in the West, such control remains conspicuous by its absence in Indian art music for obvious reasons; its usefulness in sophisticated film music (often involving 'traditional' Carnatic performers) is an altogether different matter. On the other hand, the technical advances demonstrated by the film and television industry have also rekindled interest in the traditional aspects of Carnatic music and a lively discussion on 'authenticity' in any conceivable context. ${ }^{53}$

In an era of institution building all over India, musicians and theorists seek to make teaching more effective. Most of them are now prepared to offer a modern variant of apprenticeship by means of communication technology - from mobile phones to online video sessions - thereby creating a highly personalized context for distance

\footnotetext{
${ }^{50}$ Seay, Music in the Medieval World, 76.

${ }^{51}$ Richard Widdess discusses the use of syllables for the development of the melodic material in early music history based on the Kudumiyamalai rock inscriptions; see Richard Widdess, 'The Kudumiyamalai inscription: A Source of Early Indian Music in Notation.' Musica Asiatica 2 (1979). A summary is given in Pesch, The Oxford Illustrated Companion to South Indian Classical Music, $9 \mathrm{ff}$.

${ }^{52}$ Seay, Music in the Medieval World, 77.

${ }^{53}$ Online discussions continue a long-standing debate on this topic in the print and online editions of periodicals such as the review section of The Hindu (daily) and Sruti Magazine (monthly); scholarly papers are presented and published during an international music conference held annually during the Chennai music festival.
} 
learning. Apprenticeship was traditionally known as gurukulavasam (lit. being absorbed in one's teacher's household) or guru shishya parampara (lit. 'teacher-pupillineage') which implies reciprocity rather than paid lessons. Although rarely viable today, it continues to be eulogized..$^{54}$ As a pragmatic compromise, most teachers follow a standard syllabus in order to prepare their pupils for auditions and degrees, while reaffirming the 'classical values' of their ancestors (sampradaya). ${ }^{55}$

Although standardized notation of any type may be seen as a challenge by selfrespecting tutors - particularly the senior authoritative teacher referred to as one's guru - printed textbooks are now widely used as an aid to memory. This saves time during a brief weekly lesson, especially in the absence of opportunities for 'total immersion' of the kind past learners had as members of a guru's household. In the absence of a tradition for 'prescriptive music in written notation', musicians continue to rely on 'oral notation', referred to as sargam solfa-notation ( $\mathrm{Sa} \mathrm{Ri}$ Ga Ma Pa Dha $\mathrm{Ni}$ for the seven primary notes or scale degrees) ${ }^{56}$ Howard Boatwright (Associate Professor of the Theory of Music, Yale University, and Fulbright Lecturer 1959-60) compares the dilemma faced by Indian musicians with that of their counterparts in eighteenth-century Europe whom composers supplied with a mere 'skeleton': ${ }^{57}$ the use of solfa-notation presupposes familiarity with the reading or style (pathantara) associated with one's own musical or hereditary 'tradition' (referred to as sampradaya and bani respectively). ${ }^{58}$ This need for familiarity (in a musical as well as personal sense) motivates a few high-level exponents to maintain the one-to-one teacher-

\footnotetext{
${ }^{54}$ The guru shishya parampara of North Indian (Hindustani) music is contextualized in a video documentary by Ronald Kurt, 'Be a Medium. Teaching and Learning Indian Classical Music' accompanying Indien und Europa: ein kultur-und musiksoziologischer Verstehensversuch (Bielefeld: Transcript 2009).

${ }^{55}$ For a discussion of the South Indian 'gurukula system' (gurukulavasam) and its perception as being 'pre-modern' (hence incompatible with modernity, the busy life in the city and technology), see 'Gurukulam Is Dead' in Amanda J. Weidman, Singing the Classical, Voicing the Modern: The Postcolonial Politics of Music in South India, 275ff.

${ }^{56}$ A historical overview can be found in Harold Powers, 'Sargam Notations and Rag-Ragini Theory', in Hindustani Music: Thirteenth to Twentieth Centuries, ed. Joeb Bor, et al (New Delhi: Codarts \& Manohar, 2010), 579ff.

${ }^{57}$ Howard Boatwright, A Handbook on Staff Notation for Indian (Bombay: Bharatiya Vidya Bhavan, 1960), 60 .

${ }^{58}$ South Indian music publications based on western staff notation (including one by the author herself) are described in Emmie te Nijenhuis, 'Notation of South Indian Music', Oideion; Performing arts online 4 (2004), accessed 4 May 2014. http://www.iias.nl/oideion/journal/issue04/nijenhuis/ indexa.html.
} 
disciple tradition in the face of modernization. ${ }^{59}$ On the basis of personal experience, David Reck reiterates the ethos of any oral tradition that 'lives primarily in the hands, voices, memory, and creative imagination of individual human beings ${ }^{6}{ }^{60}$ It does not lend itself to being written down with the result that the music 'lives uniquely in each performance $[\ldots]$ in the ephemeral spontaneity and creativity of improvisation' ${ }^{61}$

Mutual understanding, appreciation and a commitment to innovation have become commonplace among 'classical' performers. But which are the features that prepare a student to participate in South Indian music today? Several features have contributed to the continuity of Carnatic music for centuries and can be summarized as follows: firstly, its scope for integrated education (i.e. arts, crafts and sciences contextualized by India's pioneering institutions and their alumni); ${ }^{62}$ secondly, effective transmission in time (i.e. over generations) and space (i.e. reaching out beyond the 'cradle' of any art form); thirdly, affinity with 'universal' values ${ }^{63}$ akin to those advocated by Rabindranath Tagore (i.e. reform movements transcending religious doctrines and sectarian practices); ${ }^{64}$ this has long fostered critical thinking and introspection rather than conservatism (e.g. the unorthodox song lyrics widely sung today,

${ }^{59}$ Joep Bor and Allyn Miner, 'Hindustani Music: A Historical Overview of the Modern Period', in Hindustani Music: Thirteenth to Twentieth Centuries, ed. Joeb Bor, et al (New Delhi: Codarts \& Manohar, 2010), 209.

${ }^{60}$ This has been confirmed by my own experience, as former music student in South India (trained as flautist), and as researcher on modes of transmission used by Indian performers of traditional music, dance and theatre; see Sam, Reflection, Gathering Together!. A music education research project initiated at the Bern University for the Arts (HKB, Switzerland) in collaboration with Natanakairali, an institution for the performing arts in Irinjalakuda (Kerala, India). Accessed 4 May 2014. http://sam.mimemo.net/Projekt_description.html.

${ }^{61}$ David B. Reck, 'India/South India' in Worlds of Music: An Introduction to the Music of the World's Peoples (Belmont: Schirmer, 2002), 256.

${ }^{62}$ Tagore's Visva-Bharati inspired several modern institutions including Kalakshetra Foundation another 'institution of national importance' as declared by the Government of India (1994): it was established by Rukmini Devi 'with the sole purpose of resuscitating in modern India recognition of the priceless artistic traditions of our country'; this includes a college for dance, music and visual arts as well as a craft centre. Kalakshetra website, accessed 3 May 2014. http://www.kalakshetra.in.

${ }^{63}$ Arnold Bake describes the degree to which Tagore's songs are indebted to 'a folk-life with a deep and living mysticism'; particularly to the philosophy of the Bengali Baul ('mad') mendicant movement which has a 'Great Self (rather than any particular divinity) as its focus. Arnold Bake, 'Indian Music and Rabindranath Tagore', in Rabindranath Tagore: Centenary Number, ed. Pulinbihari Sen and Khitis Ray (New Delhi: Sangeet Natak Akademi, 1961), 22ff.

${ }^{64}$ See Ch. 8, 'Questions about the 'Rememberers': Smarta Brahmanas as Renewers of Tradition', in William Jackson, Tyagaraja and the Renewal of Tradition: Translations and Reflections (Delhi: Motilal Banarsidass, 1994), 207ff. 
some on social issues); fourthly, the most important trait of any living 'art music' is bound to be the scope it affords for creativity: its capacity to accommodate new genres, instruments and theories ${ }^{65}$ just as the degree to which it lends itself to experimentation with unconventional teaching methods. ${ }^{66}$ Lewis Rowell describes how musicians adapted themselves to changing conditions, and - to give a specific example of interest to an international public - made 'virtuoso attempts to construct a theoretical framework that will accommodate the hundreds of existing ragas' (as well as new ones) at their disposal. ${ }^{67}$ Their preference for an 'evolutionary' approach to innovation has yielded a large body of compositions. This ensures that Carnatic music remains relevant and also finds patronage in a democratic, rapidly modernizing society. Among the compositions preferred today, it is the tripartite 'art song' (kriti) perfected by Tyagaraja - a contemporary of the Vienna school of classical music - that provides the model for scholarly musicians and forms the nucleus of virtually every Carnatic concert. In view of the fact that a spiritual or religious 'message' is generally associated with this repertoire, William Jackson argues - in keeping with Tyagaraja's artistic accomplishment - that 'a song is more than a verbal text set to notes' given the rapport it establishes with its listener; quoting Labyrinths by Jorge Luis Borges, he emphasizes that this rapport leaves 'changing and durable images' on a listener's memory. ${ }^{68}$

Whenever musicians succeed in establishing this rapport, their music comes alive, even becomes timeless irrespective of its historical connotations. A striking precursor to the concert conventions of 'modern' Carnatic music is found in the description of a typical performance in Tristan by Minnesinger Gottfried (approx. AD 1200). The following juxtaposition of specific characteristics is a case in point: it reflects the sequence of the original text as translated and explained by James McMahon: ${ }^{69}$

\footnotetext{
${ }^{65}$ Post-fourtheenth-century theorists brought about several major changes corroborated by the fact that 'the mela-janya [reference/derived scale] system of raga classification emerged when the gramamurcchana-jati [concept regulating the redistribution of intervals within any scale] fell into disuse. Along with the harp vinas [since then replaced by the present zither type of vina, a long-necked lute with mela-frets] fell also the grama system' [outlined in the most ancient source, the much quoted Natya Sastra, about one millennium earlier]. S. Seetha: in Tanjore as a Seat of Music, 403.

${ }^{66}$ P. Sambamurthy, Aids to the Teaching of Music (Chennai: The Indian Music Publishing House, 1984).

${ }^{67}$ Rowell, Music and Musical Thought in Early India, $178 \mathrm{f}$.

${ }^{68}$ William Jackson. Tyagaraja and the Renewal of Tradition: Translations and Reflections (Delhi: Motilal Banarsidass, 1994), 253.

${ }^{69}$ McMahon. The Music of Early Minnesang, $71 \mathrm{ff}$.
} 
Raga alapana (a raga sketched by melismatic phrases or non-lexical syllables) First the performer had to 'warm up' [...] He played some preliminary snatches of melody, not only to get his fingers used to the instrument, but also to check the tuning. [...]

Paddhati (adhering to an established performance convention)

Then he played a few more preliminary pieces and only then did he play the song he intended to perform. [...]

Tanam (a raga evolves further through pulsating groups of notes or syllables)

His fingers were very nimble as he played [plucking the strings with] fingers moving quickly and lightly, looking as if they were more numerous than they are (lit. "walgende in den seiten”), i.e. 'rolling, rotating, moving around' and also 'swarming, teeming.' [...]

Pallavi (the main theme of a composition or ragam-tanam-pallavi suite)

At the appropriate place the minstrel began to sing. [...]

Prayoga (touching the proper starting and landing notes for any given raga)

Beginnings and endings of musical phrases were particularly important and had to be managed well $[\ldots]$

Raga jnanam ('raga knowledge' on intonation and ornamentation; experience) And in general, a good musician produces the notes correctly

Bhava (appropriate rendition; aesthetic sense)

and is able to understand the song and interpret it with fingers and voice. ${ }^{70}$

\section{Conclusion}

Are South Indian performers justified in claiming 'unity in diversity, antiquity in contemporary practice'? To some degree, such a claim may be justified when considering the larger context of India's living traditions: 'the coexistence of oral and written traditions' whereby 'reference to the written [material] is not forbidden but placed in a carefully constructed procedural chain'. ${ }^{71}$ In this sense, such a claim

\footnotetext{
${ }^{70}$ It is this text-based juxtaposition that provided the framework for a lecture recital by Carnatic singer Manickam Yogeswaran and Ludwig Pesch; we presented it on 7 September 2012 on the occasion of the 15th International Conference of the Gesellschaft für Musikforschung 'Music| Musics. Structures and Processes' in Göttingen.

${ }^{71}$ See 'The Coexistence of Oral and Written Traditions' by Ashok D. Ranade, 'Transmission in Nonclassical Traditions', in The Garland Encyclopedia of World Music, vol. 5, 470.
} 
would reflect the real needs of performers whose prestige largely depends on their memory and extemporization skills. ${ }^{72}$

This reading of Indian music history from a performer's point of view brings us back to Tagore's maxim as artist, educationalist and social reformer, namely that 'is not the distinctive quality of man to be a mere repetition of his ancestors' even while rediscovering one's cultural roots. ${ }^{73}$ According to Arnold A. Bake (1899-1963), a Dutch indologist, musician and musicologist who became a close associate of Rabindranath Tagore, continuity is indeed the most outstanding feature of Indian music. He regards India's intercultural relations as self-evident not just as regards music theory but also in view of shared linguistic features and similarities between ancient Indian and Greek mythology. ${ }^{74}$ As for the relations between India and Europe throughout the Hellenistic period, Bake points to marked differences that reflect the lives of the people involved. ${ }^{75}$

It does not surprise that musicians and listeners explore more than one musical idiom while taking pride in tracing their roots. Many of their practices, theories and lyrics may even precede extant written records. ${ }^{76}$ What matters here, however, is the fact that Carnatic music continues to inspire modern listeners in and outside India. The resilience of this idiom is there for all to see and hear, thanks to the internet; and there are no signs of its weakening in the wake of modernization. In short, being partial to an oral tradition is not a sign of ignorance or backwardness; nor would it endanger the continuity of a 'living tradition' such as this.

${ }^{72}$ During music lessons in Chennai from 1977 onwards, my teacher Ramachandra Shastry (19061992) insisted that transcribing anything in excess of the lyrics and a mere outline of a song's melodic and metrical structure would discourage learners from developing their hearing and 'memory power'. The same conviction prevailed among other respondents during interviews.

${ }^{73}$ Rabindranath Tagore explained his vision as follows: 'I selected a beautiful place, far away from the contamination of town life' [where] 'the mind could have its fearless freedom to create its own dreams and the seasons could come with all their colours and movements and beauty into the very heart of the human dwelling.' Visva-Bharati Homepage. Accessed 4 May 2014. http://www.visvab harati.ac.in/Santiniketan.html.

${ }^{74}$ In a lecture delivered at the India Society London in 1930 Bake proclaims: 'The similarity between Indian and old European music has struck every investigator, and can be traced theoretically as wellan interesting field for research, and one hardly explored yet.' Arnold Bake, 'Indian Music and Rabindranath Tagore'. In Rabindranath Tagore: Centenary Number edited by Pulinbihari Sen and Khitis Ray, 25.

${ }^{75}$ Arnold A. Bake, 'Indische Musik' in Musik in Geschichte und Gegenwart, Bd. 6 (Kassel: Bärenreiter, 1989), 1150ff. References to Bake's research are also found throughout Joep Bor et al, Hindustani Music: Thirteenth to Twentieth Centuries.

${ }^{76}$ For references to archeological evidence, see Pesch, The Oxford Illustrated Companion to South Indian Classical Music, $14 \mathrm{ff}$. 


\section{Literature}

Ayyar, Subrahmanya C. The Grammar of South Indian (Karnatic) Music. 3rd rev. ed. Chennai: Vidya Shankar, 1976.

Bake, Arnold A. 'Indische Musik'. In Die Musik in Geschichte und Gegenwart. Allgemeine Enzyklopädie der Musik, 2nd rev. ed., edited by Ludwig Finscher, Sachteil vol. 6, 1150-85. Kassel: Bärenreiter, 1989.

- 'Indian Music and Rabindranath Tagore'. In Rabindranath Tagore: Centenary Number edited by Pulinbihari Sen and Khitis Ray. 21-33. New Delhi: Sangeet Natak Akademi, 1961.

Bakhle, Janaki. Two Men and Music: Nationalism in the Making of an Indian Classical Tradition. New Delhi: Permanent Black, 2005.

Boatwright, Howard. A Handbook on Staff Notation for Indian Music. Bombay: Bharatiya Vidya Bhavan, 1960.

Bohlman, Philip V. World Music: A Very Short Introduction. New York: Oxford University Press, 2002.

Bor, Joep and Allyn Miner, 'Hindustani Music: A Historical Overview of the Modern Period'. In Hindustani Music: Thirteenth to Twentieth Centuries, edited by Joeb Bor, et al, 197-220. New Delhi: Codarts \& Manohar, 2010.

Ifrah, Georges. From One to Zero: A Universal History of Numbers. Penguin Books, 1987.

Jackson, William. Tyagaraja and the Renewal of Tradition: Translations and Reflections. Delhi: Motilal Banarsidass, 1994.

Kurt, Ronald. Indien und Europa: ein kultur- und musiksoziologischer Verstehensversuch. Bielefeld: Transcript, 2009.

Lanczos, C. Numbers Without End. Edinburgh: Oliver and Boyd, 1968.

Majumdar, Ronu. 'Melody through the reed'. The Hindu, Friday Review, Chennai 8 February 2008. Accessed 28 April 2014. http://hindu.com/thehindu/fr/ 2008/02/08/stories/2008020850520200.htm.

McMahon, James V. The Music of Early Minnesang. Columbia, South Carolina: Camden House, 1990.

Menuhin, Yehudi. Unfinished Journey. London: Futura Publications, 1978.

Mohanty, Sachidananda. 'An “Indo-Anglian” legacy'. The Hindu, 21 July 2013. Accessed 25 April 2014. http://www.thehindu.com/todays-paper/tp-features/ tp-sundaymagazine/an-indoanglian-legacy/article4936207.ece. 
Mudaliyar, A.M.C. Oriental music in European notation: a monthly periodical. Madras: A.M. Chinnaswami Mudaliyar, 1892-1893. New Delhi: Cosmo Publications, 1982.

Murugan, V. (trans.). The Art of Drumming: Mattalaviyal. Commentary by V.P.K. Sundaram. Madras: Institute of Asian Studies, 1988.

Nelson, David. 'Form and Process in the Tani Avartanam: A Non-Indian Insider's Perspective'. Journal of the Music Academy Madras, 82 (2011): 118-32.

Neuman, Dard. 'Pedagogy, Practice and Embodied Creativity in Hindustani Music'. Ethnomusicology 56/3 (2012): 426-49.

Nijenhuis, Emmie te. 'Notation of South Indian Music'. Oideion; Performing arts online 4 (2004). Accessed 4 May 2014. http://www.iias.nl/oideion/journal/iss ue04/nijenhuis/index-a.html.

- Varnam: Selected Concert Studies for the South Indian Lute (accompanied by two audio-CDs). Naarden: Sarasvati Bhavan, 2002.

The Oxford Companion to Music edited by Alison Latham. New York: Oxford University Press, 2002.

Parthasarathy, T.S. 'The Unity of Indian Music'. The Journal of the Music Academy Madras: Golden Jubilee Special Number 1977. Madras (1980): 192-202.

Pesch, Ludwig. The Oxford Illustrated Companion to South Indian Classical Music. 2nd rev. ed. New Delhi: Oxford University Press, 2009.

- 'Cosmic Order, Cosmic Play: An Indian Approach to Rhythmic Diversity'. In Rhythm, a Dance in Time edited by Elisabeth den Otter, 83-99. Amsterdam: KIT Publishers, 2001.

Powers, Harold. 'Sargam Notations and Rag-Ragini Theory'. In Hindustani Music: Thirteenth to Twentieth Centuries edited by Joep Bor et al., 579-671. New Delhi: Codarts \& Manohar, 2010.

Ramakrishna, Lalitha. Varnam: A Special Form in Karnatic Music. New Delhi: Harman Publishing House, 1991.

Ramanathan, Hema and N. Ramanathan. 'Science and Music vis-a-vis Science in Music'. Accessed 31 March 2008. http://www.musicresearch.in.

Ramnarayan, Gowri. 'The Lalgudi Legacy'. Sruti Magazine. Issue 314 (November 2010):39-49. 
Ranade, Ashok D. 'Transmission in Nonclassical Traditions'. The Garland Encyclopedia of World Music. Volume 5. South Asia: The Indian Subcontinent, 468477. New York: Garland Publishing, 1999.

— 'On Art Music', Sruti Magazine. Issue 336 (September 2012): 33-34.

Rao, Suvarnalata and Wim van der Meer. 'The Construction, Reconstruction and Deconstruction of Shruti'. In Hindustani Music: Thirteenth to Twentieth Centuries edited by Joep Bor et al, 673-96. New Delhi: Codarts \& Manohar, 2010.

Ray, Ranajit (publ.). Visva-Bharati and its Institutions. Santiniketan: Visva-Bharati, 1961.

Reck, David B. 'India/South India'. In Worlds of Music: An Introduction to the Music of the World's Peoples. 4th ed. Belmont: Schirmer, 2002.

Rowell, Lewis. Music and Musical Thought in Early India. New Delhi: Munshiram Manoharlal, 1998.

Sambamoorthy [Sambamurthy], P. Aids to the Teaching of Music. Chennai: The Indian Music Publishing House, 1984.

- History of Indian Music. 2nd ed. Madras: The Indian Music Publishing House, 1982.

Seay, Albert. Music in the Medieval World. Englewood Cliffs: Prentice-Hall, 1965.

Seetha, S. Tanjore as a Seat of Music. Madras: University of Madras, 1989.

Shankar, Ravi. My Music, My Life. Introduction by Yehudi Menuhin. New Delhi: Vikas Publishing House, 1992.

Shankar, Ravi and George Harrison (ed.). Raga Mala: The Autobiography of Ravi Shankar. New York: Welcome Rain Publishers, 1999.

Simundza, Mirjana. 'Messiaen's Rhythmical Organisation and Classical Indian Theory of Rhythm (I)'. International Review of the Aesthetics and Sociology of Music, 18/1 (1987): 117-44.

Som, Reba: Rabindranath Tagore: The Singer and His Song. New Delhi: Penguin 2009.

Tagore, Rabindranath. Tagore on Gandhi. New Delhi: Rupa \& Col, 2008.

- Visva-Bharati. Rev. ed. Santiniketan: Visva-Bharati, 1961.

Viswanathan, T. and Matthew Allen. Music in South India: The Karnatak Concert Tradition and Beyond. Oxford University Press, 2004. 
Weidman, Amanda J. Singing the Classical, Voicing the Modern: The Postcolonial Politics of Music in South India. Durham: Duke University Press, 2006.

Widdess, Richard. The Ragas of Early Indian Music: Modes, melodies and musical notations from the Gupta period to c. 1250. Oxford: Clarendon Press, 1995.

- 'The Kudumiyamalai inscription: A Source of Early Indian Music in Notation'. Musica Asiatica 2 (1979). Accessed 1 May 2014. http://www.musicresearch.in 
$\mathrm{M}$ usik ist immer auch Spiegel und Kristallisationspunkt gesellschaftlicher Paradigmen und politisch-nationaler Identitätsdiskurse. Der vorliegende Sammelband vereint Beiträge zu historischen und gegenwärtigen Fragestellungen, die um das Verhältnis von Politik und musikalischem Schaffen kreisen. Im ersten Teil sind Beiträge zusammengefasst, die sich mit „Musikalischer Identität und politischer Realität" befassen und dabei ideologische Zuschreibungsprozesse im Musikdiskurs thematisieren. Der zweite Teil des Bandes umfasst Betrachtungen über „(Musikalische) Konstruktionen von eigener und fremder Identität" aus verschiedensten nationalen Zusammenhängen.

Music always mirrors and acts as a focal point for social paradigms and discourses surrounding political and national identity. The essays in this volume combine contributions on historical and present-day questions about the relationship between politics and musical creativity. The first part concentrates on musical identity and political reality, discussing ideological values in musical discourses. The second part deals with (musical) constructions, drawing on diverse national connections within our own and foreign identity.

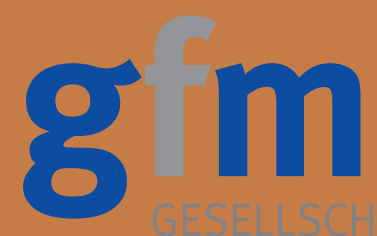

ISBN: 978-3-86395-258-7 